\title{
ANÁLISIS, DESARROLLO Y EVALUACIÓN DE UN PLAN DE ENTRENAMIENTO SOBRE BICICLETAS ESTÁTICAS "E.S.B.E."
}

\author{
MARCO ANTONIO RÍOS ZORRILLA
}

Tesis para optar por el grado de Magíster en Educación Corporal Director Profesor Ricardo Crisorio - UNLP

Codirector Profesor Adrián Casas - UNLP

La Plata, 22 de agosto de 2013 
Como persona de título universitario de "Profesional del deporte", y ahora como estudiante de la Maestría en "Educación Corporal" de la Universidad Nacional de La Plata, pretendo con este trabajo escrito dar variantes a lo conocido mundialmente como ciclismo de salón o como "spinning".

Desde 1992, y durante nueve años, representé a Colombia en el área del ciclismo de pista. En 2001 entré a trabajar en gimnasios de Medellín (Colombia), haciendo énfasis en el trabajo sobre la bicicleta estática, hasta que viajé a la ciudad de La Plata (Argentina) donde continué el trabajo en la misma dirección.

Me considero preparado para abordar el reto de este trabajo, que espero sea de utilidad para los colegas e instituciones formadoras de profesionales del área del deporte, la educación física y la salud. 
Tabla de Contenido

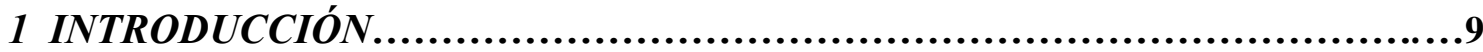

2 PLANTEAMIENTO Y DELIMITACIÓN DEL PROBLEMA.........................10

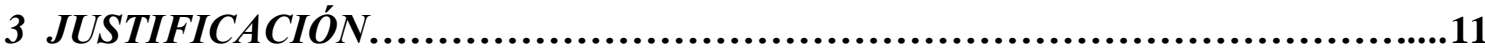

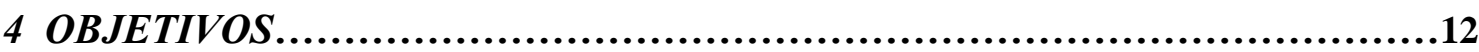

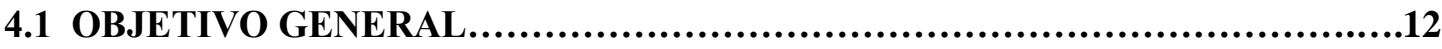

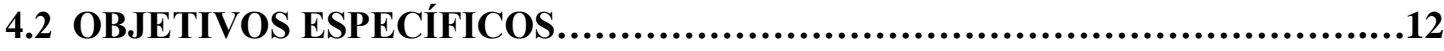

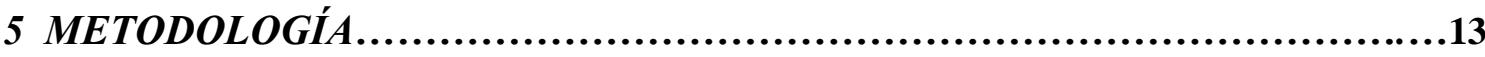

6 PLANTEAMIENTO TEÓRICO....................................................14

6.1 CONCEPTO DE LA ACTIVIDAD FÍSICA DENOMINADA MUNDIALMENTE COMO "SPINNING"................................................................................14

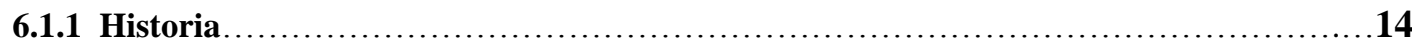

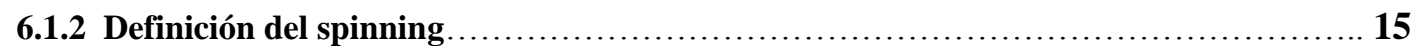

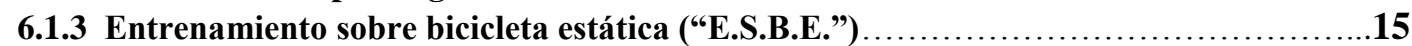

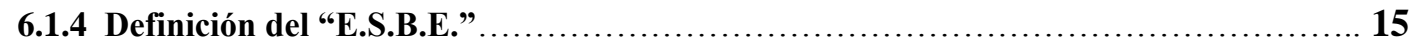

6.2 DESCRIPCIÓN DE LA BICICLETA ESTÁTICA.....................................16

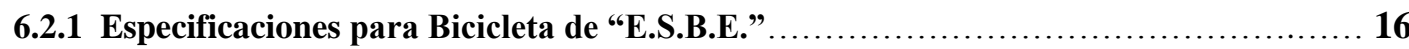

6.2.2 Descripción general de una bicicleta para ciclismo estático ...........................................19

6.3 ADECUACIÓN DE LA BICICLETA AL USUARIO - PRACTICANTE...............20

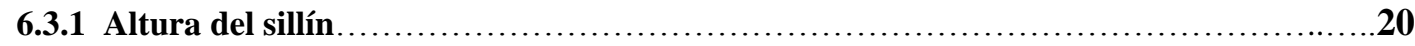

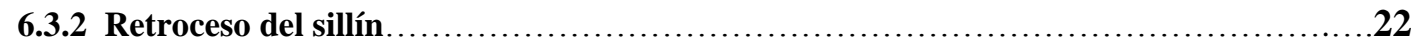

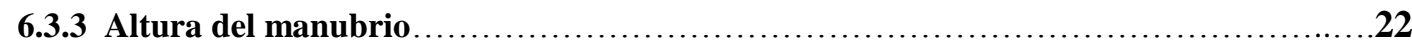

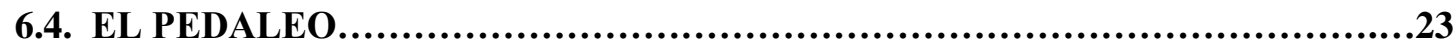

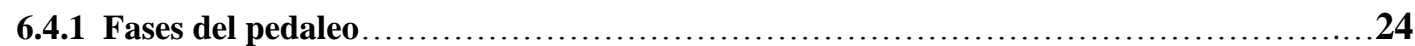

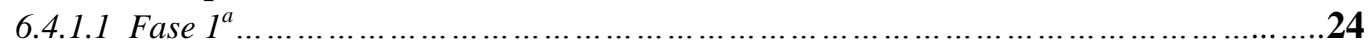

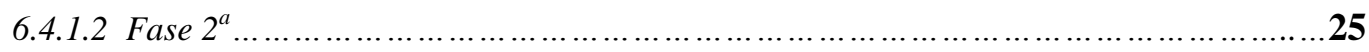

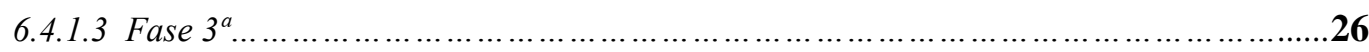

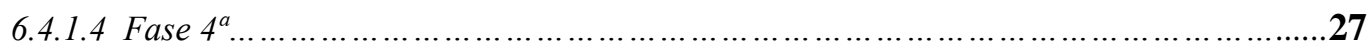

6.4.2 Resumen de trabajos musculares en el pedalear....................................27

6.5 TRABAJO DEL TRONCO EN EL CICLISMO.................................28

6.6 EL TRABAJO DEL CUELLO..............................................................28

6.7 EL TRABAJO DE LAS EXTREMIDADES SUPERIORES............................29

6.8 TÉCNICA CORRECTA EN EL “E.S.B.E.”...............................................

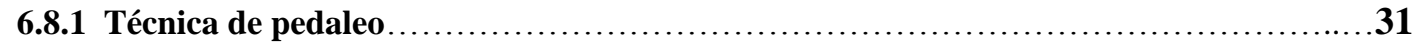

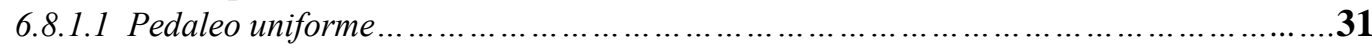

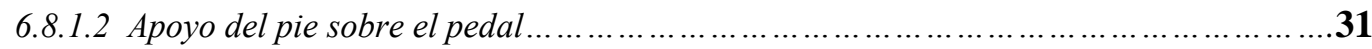

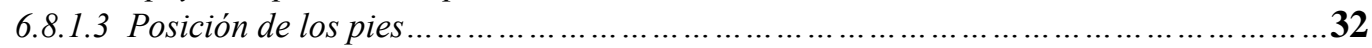

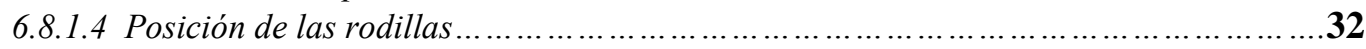

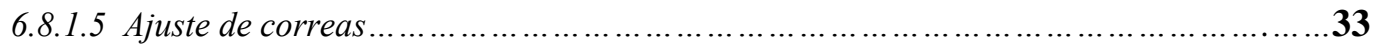

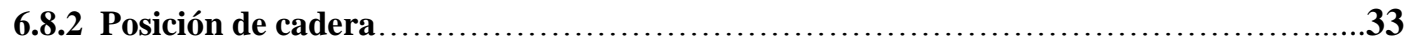

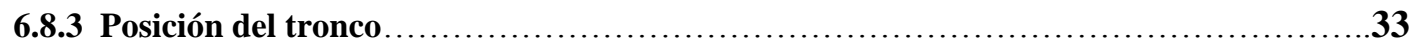




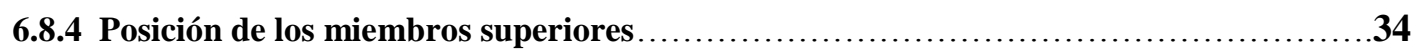

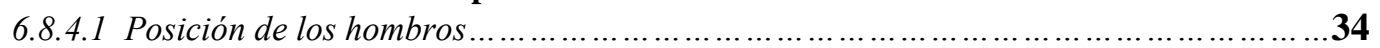

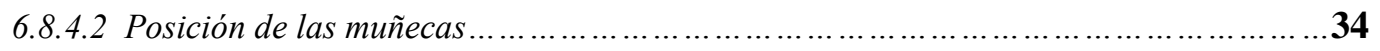

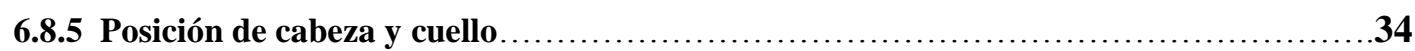

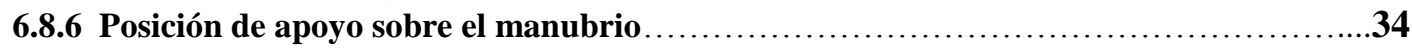

6.9 INDUMENTARIA PARA LA PRÁCTICA...................................35

6.10 TRABAJOS DEL TREN SUPERIOR SOBRE LA BICICLETA...................36

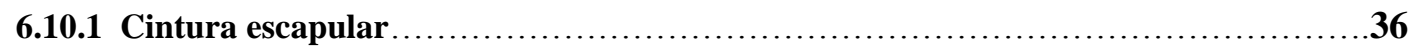

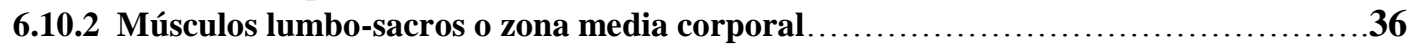

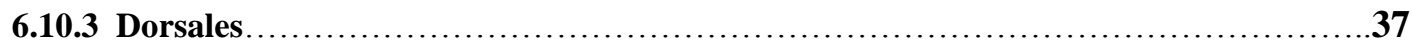

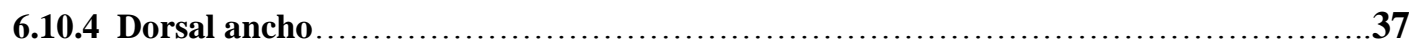

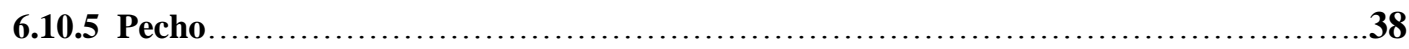

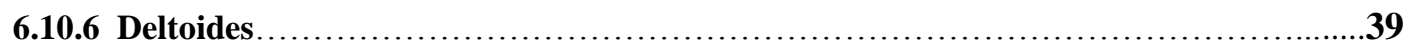

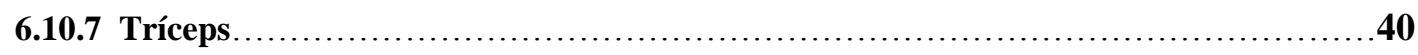

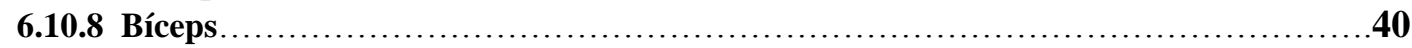

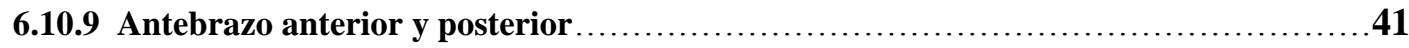

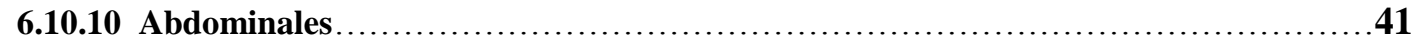

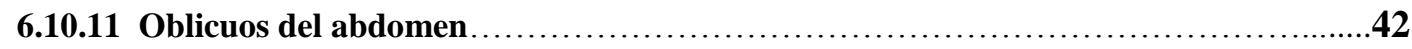

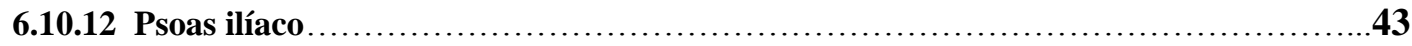

6.11 CADENCIAS..................................................................4

6.12 RESISTENCIAS DE TRABAJO EN “E.S.B.E.”..............................44

6.13 MÚSICA.........................................................................45

6.14 RECOMENDACIONES PARA UN INSTRUCTOR EN UNA CLASE DEL

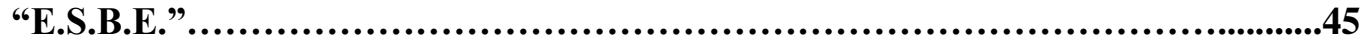

6.15 TRABAJOS CÍCLICOS BASE SOBRE LA BICICLETA ESTÁTICA............47

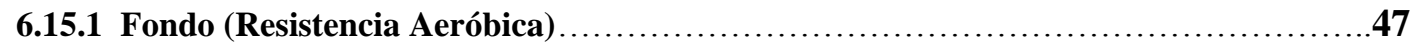

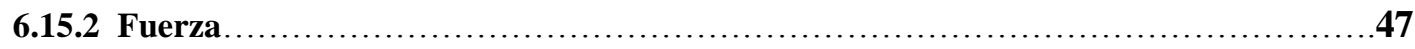

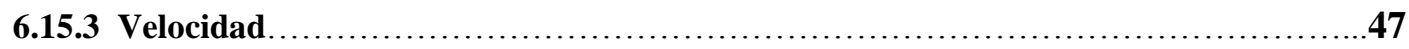

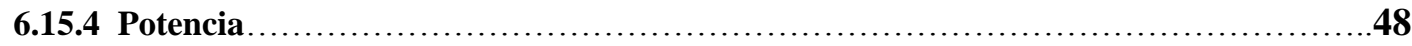

7 MICROCICLO DE TRABAJO EN EL “E.S.B.E.” (EJEMPLO DE UN

CICLO DE TRABAJO PARA EL “E.S.B.E.”, BASADO EN CUATRO

MICROCICLOS)............................................................50

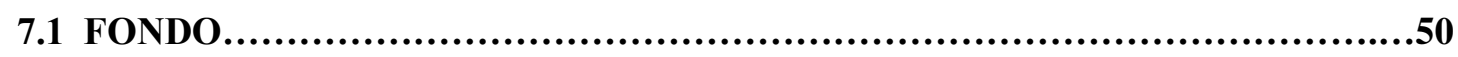

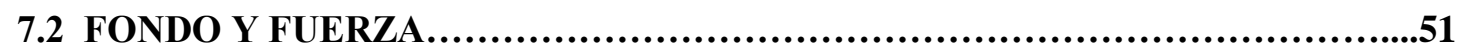

7.3 VELOCIDAD Y POTENCIA.............................................52

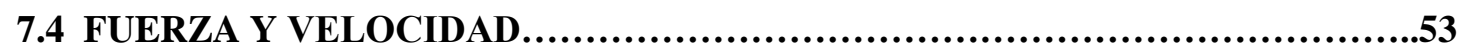

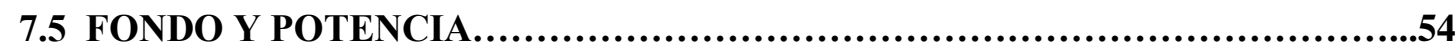

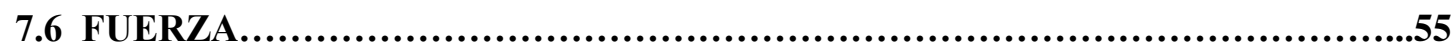

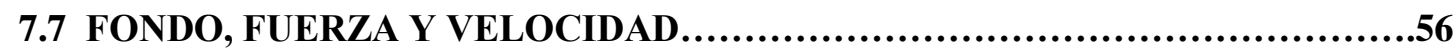

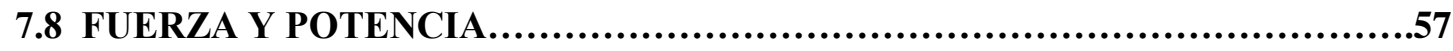

7.9 FONDO Y VELOCIDAD.........................................................58

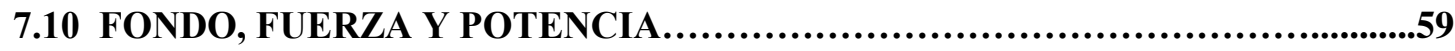


7.11 FUERZA, VELOCIDAD Y POTENCIA.........................................60

7.12 FONDO, VELOCIDAD Y POTENCIA..........................................61

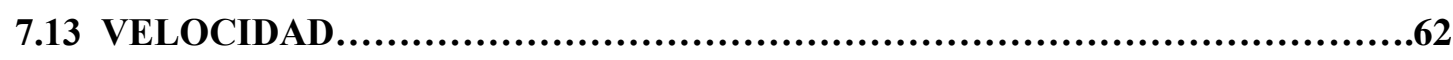

7.14 FONDO, FUERZA, VELOCIDAD Y POTENCIA.............................63

8 ENCUESTAS A USUARIOS............................................66

9 EVALUACIONES.......................................................75

9.1 EVALUACIONES ANTROPOMÉTRICAS REALIZADAS A TRES

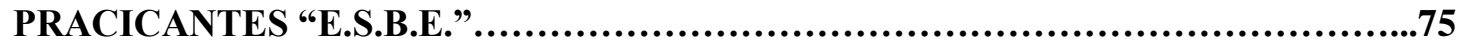

9.1.1 Descripción de evaluación de perímetro corporal ..........................75

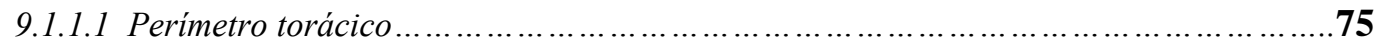

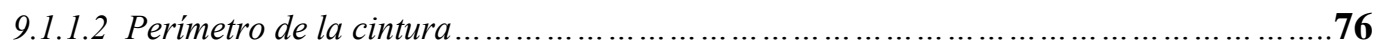

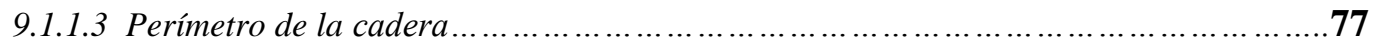

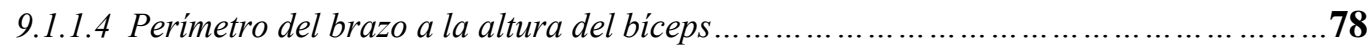

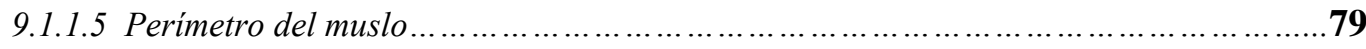

9.1.1.6 Perímetro de la pierna a la altura del gastrocnemio .......................................82

9.1.2 Descripción de la toma de pliegues cutáneos a las tres personas

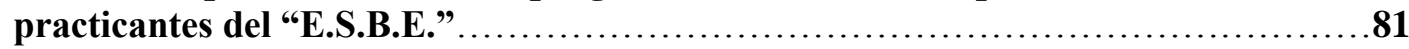

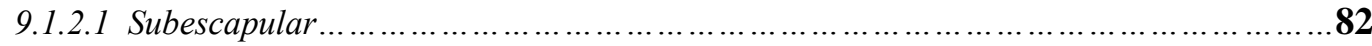

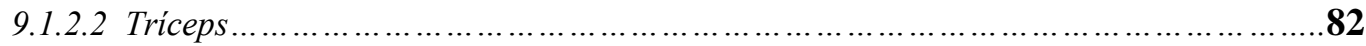

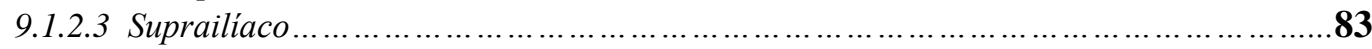

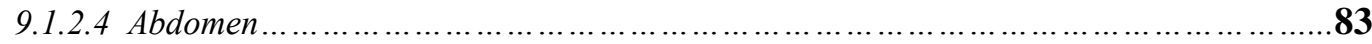

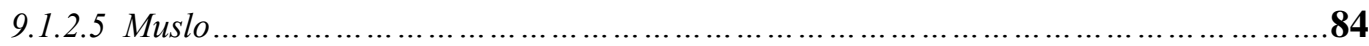

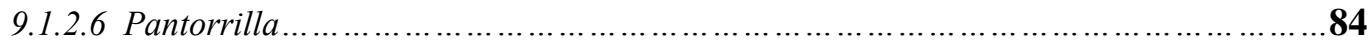

9.2 PRUEBA DE RESISTENCIA MUSCULAR DINÁMICA.........................85

9.2.1 Descripción de evaluación de la fuerza en aparatos multifuncionales..........86

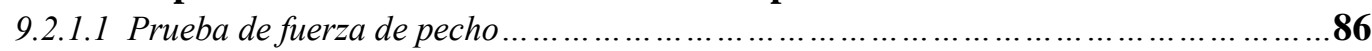

9.2.1.2 Prueba de fuerza para extensión de pierna .................................................86

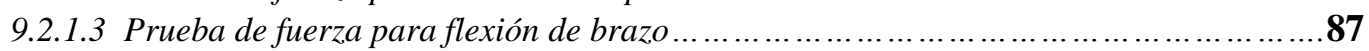

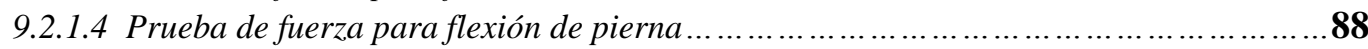

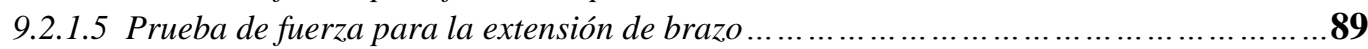

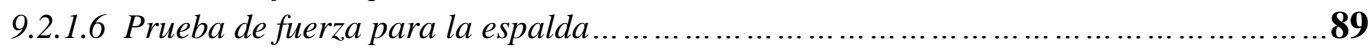

9.2.1.7 Prueba de fuerza para extensión de cadera .................................................90

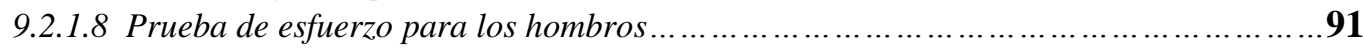

9.3 PRUEBA PROGRESIVA DE ESFUERZO MÁXIMO SOBRE BICICLETA ESTÁTICA ANALIZANDO EL COMPORTAMIENTO

CARDIOVASCULAR..........................................................91

9.3.1 Descripción de la prueba de esfuerzo sobre bicicleta estática.................91

10 RESULTADOS DE LAS EVALUACIONES ANTROPOMÉTRICAS.............93

10.1 RESULTADOS DE LAS EVALUACIONES DE PERÍMETROS

CORPORALES................................................................93

10.1.1 Evaluaciones antropométricas de primera voluntaria.........................93

10.1.2 Evaluaciones antropométricas de segunda voluntaria..........................95

10.1.3 Evaluaciones antropométricas de tercera voluntaria.........................97

10.2 RESULTADOS DE LAS EVALUACIONES DE PLIEGUES CUTÁNEOS.........98

10.2.1 Evaluaciones de pliegues cutáneos a primera voluntaria.......................99 
10.2.2 Evaluaciones de pliegues cutáneos a segunda voluntaria.....................100

10.2.3 Evaluaciones de pliegues cutáneos a tercera voluntaria......................102

10.3 RESULTADOS DE LAS EVALUACIONES DE FUERZA.......................103

10.3.1 Evaluación de fuerza a la primera voluntaria............................104

10.3.1.1 Evaluación de pectorales a la primera voluntaria ...................................104

10.3.1.2 Evaluación de extensión de pierna a la primera voluntaria .............................104

10.3.1.3 Evaluación de flexión de brazo a la primera voluntaria .................................105

10.3.1.4 Evaluación de flexión de pierna a la primera voluntaria ...........................106

10.3.1.5 Evaluación de extensión de brazo a la primera voluntaria ................................106

10.3.1.6 Evaluación de espalda a la primera voluntaria .........................................107

10.3.1.7 Evaluación de extensión de cadera para pierna derecha a la primera voluntaria.....108

10.3.1.8 Evaluación de extensión de cadera para pierna izquierda a la primera voluntaria ...108

10.3.1.9 Evaluación de extensión de hombros a la primera voluntaria ...........................109

10.3.2 Evaluación de fuerza a la segunda voluntaria............................110

10.3.2.1 Evaluación de pectorales a la segunda voluntaria ..................................110

10.3.2.2 Evaluación de extensión de pierna a la segunda voluntaria .............................110

10.3.2.3 Evaluación de flexión de brazo a la segunda voluntaria ...................................111

10.3.2.4 Evaluación de flexión de pierna a la segunda voluntaria ................................112

10.3.2.5 Evaluación de extensión de brazo a la segunda voluntaria ..............................113

10.3.2.6 Evaluación de espalda a la segunda voluntaria ..........................................113

10.3.2.7 Evaluación de extensión de cadera para pierna derecha a la segunda voluntaria .....114

10.3.2.8 Evaluación de extensión de cadera para pierna izquierda a la segunda voluntaria ...115

10.3.2.9 Evaluación de extensión de hombros a la segunda voluntaria .........................115

10.3.3 Evaluación de fuerza a la tercera voluntaria................................116

10.3.3.1 Evaluación de pectorales a la tercera voluntaria ....................................116

10.3.3.2 Evaluación de extensión de pierna a la tercera voluntaria ...............................117

10.3.3.3 Evaluación de flexión de brazo a la tercera voluntaria ...................................117

10.3.3.4 Evaluación de flexión de pierna a la tercera voluntaria ................................118

10.3.3.5 Evaluación de extensión de brazo a la tercera voluntaria ................................118

10.3.3.6 Evaluación de espalda a la tercera voluntaria........................................119

10.3.3.7 Evaluación de extensión de cadera para pierna derecha a la tercera voluntaria ......120

10.3.3.8 Evaluación de extensión de cadera para pierna izquierda a la tercera voluntaria .....121

10.3.3.9 Evaluación de extensión de hombros a la tercera voluntaria .............................121

11 RESULTADOS DE LAS PRUEBAS DE ESFUERZO ...........................123

11.1 TABLA RESUMEN DE LOS RESULTADOS DE LA PRIMERA

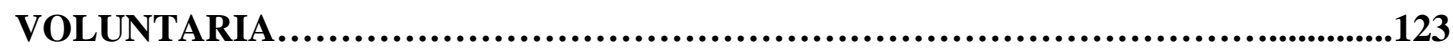

11.1.1 Evaluaciones de peso corporal de la primera voluntaria......................123

11.1.2 Evaluaciones de índice de masa corporal de la primera voluntaria...........124

11.1.3 Relación entre las pulsaciones máximas reales y las teóricas de la primera

voluntaria...........................................................................125

11.1.4 Pulso basal de la primera voluntaria.........................................126

11.1.5 Rango de trabajo cardiovascular de la primera voluntaria...................127

11.1.6 Frecuencia cardíaca luego de recuperarse un minuto de la primera voluntaria.

11.1.7 Porcentaje de recuperación al minuto del esfuerzo de la primera

voluntaria.

11.2 TABLA RESUMEN DE LOS RESULTADOS DE LA SEGUNDA

VOLUNTARIA 
11.2.1 Evaluaciones de peso corporal de la segunda voluntaria......................130

11.2.2 Evaluaciones de índice de masa corporal de la segunda voluntaria............130

11.2.3 Relación entre las pulsaciones máximas reales y las teóricas de la segunda

voluntaria.........................................................................131

11.2.4 Pulso basal de la segunda voluntaria.......................................132

11.2.5 Rango de trabajo cardiovascular de la segunda voluntaria....................132

11.2.6 Frecuencia cardíaca luego de recuperarse un minuto de la segunda

voluntaria...

11.2.7 Porcentaje de recuperación al minuto del esfuerzo de la segunda

voluntaria.

\subsection{TABLA RESUMEN DE LOS RESULTADOS DE LA TERCERA}

VOLUNTARIA.....................................................................135

11.3.1 Evaluaciones de peso corporal de la tercera voluntaria.......................136

11.3.2 Evaluaciones de índice de masa corporal de la tercera voluntaria..............136

11.3.3 Relación entre las pulsaciones máximas reales y las teóricas de la tercera voluntaria.........................................................................137

11.3.4 Pulso basal de la tercera voluntaria.........................................138

11.3.5 Rango de trabajo cardiovascular de la tercera voluntaria.....................138

11.3.6 Frecuencia cardíaca luego de recuperarse un minuto de la tercera voluntaria........................................................................139

11.3.7 Porcentaje de recuperación al minuto del esfuerzo de la tercera voluntaria..140

12 CONCLUSIONES ...........................................................141

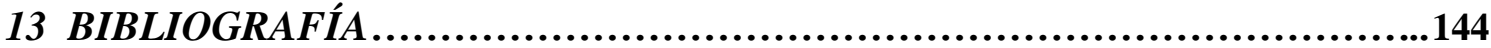

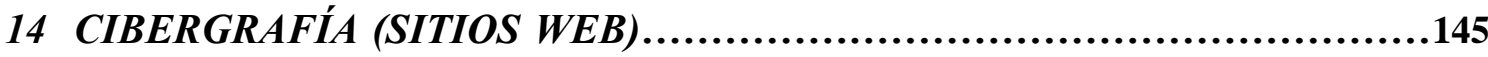




\section{Agradecimientos}

Quiero demostrar mi gratitud a todos los usuarios que participaron en esta experiencia y que colaboraron con las encuestas, especialmente a las tres practicantes que participaron con las exhaustivas evaluaciones.

También quiero agradecer a la Profesora Gabriela García, propietaria del Gimnasio "La Horqueta", que me facilitó el espacio para todas las evaluaciones. Además al señor Adrián Casas, como codirector de esta tesis, y al señor Ricardo Crisorio como director, por la ayuda brindada durante todo el tiempo de realización de pruebas de campo y de escritura. Finalmente, no quiero olvidar a la secretaria encargada de la maestría, la señora María Eugenia Villa, quien fue una persona bien importante durante todo el proceso. 


\section{INTRODUCCIÓN}

Este trabajo de tesis propone desarrollar y evaluar un plan de entrenamiento realizado en bicicletas estáticas. El hecho de haber estado inmerso en esta actividad durante 11 años me permite aportar conocimientos prácticos al tema. Trabajé en esto desde el 2002 al 2004 en los gimnasios Laureles, Match, Santillana y Ser Activo en Medellín, Colombia. En la ciudad de La Plata trabajé durante el 2005 en los gimnasios La Horqueta y Palestra, y a partir del 2006 únicamente en el gimnasio La Horqueta hasta que regrese a Colombia en el año 2008. En este último gimnasio es donde se llevó a cabo el desarrollo del programa de entrenamiento, las pruebas y también las encuestas. Luego del regreso a Colombia se retomo el trabajo con bicicletas estáticas hasta noviembre del 2012

Hasta el momento, y a pesar de la gran aceptación que tiene el ciclismo de salón en el mundo, no existe ninguna investigación donde se analice el impacto de este tipo de actividad. Para este trabajo se hizo una adaptación de los planes de entrenamiento para el ciclismo profesional de alto rendimiento a las posibilidades del entrenamiento de personas que llevan una vida cotidiana, especialmente mujeres no deportistas que concurren a un gimnasio.

El propósito de este trabajo es investigar el impacto y la repercusión funcional de este tipo de entrenamiento, así como la percepción en la calidad de vida de los practicantes.

Para este trabajo se revisaron una serie de libros y documentos, principalmente de ciclismo, debido al limitado número de publicaciones científicas en el campo específico del entrenamiento con bicicletas estáticas.

Las conclusiones de este estudio son muy importantes, aunque debe tenerse en cuenta que se utilizó un número limitado de participantes y, sin duda, harán falta investigaciones posteriores para profundizar las conclusiones de la presente tesis.

Se contó con la colaboración de usuarios practicantes para responder las encuestas, y para las evaluaciones se optó por trabajar con personas que pasaban de la inactividad total a ejercitarse 2 y 3 veces por semana. 


\section{PLANTEAMIENTO Y DELIMITACIÓN DEL PROBLEMA}

Como instructor de gimnasios de la ciudad de Medellín (Colombia) y, hasta el 2008, de la ciudad de La Plata (Argentina), he visto con preocupación cómo una actividad física como la que mundialmente se conoce con el nombre de "spinning" ha sido señalada tanto por médicos y usuarios como una actividad que inevitablemente genera lesiones.

La práctica del ciclismo estático en gimnasios de Colombia y Argentina ha originado diferentes puntos de vista, algunos buenos, otros no tanto, que tienen que ver con sus resultados, con cómo se debe hacer el trabajo, con técnicas y posturas, etc.

Existe un claro problema y es la diversidad de conceptos utilizados por parte de los instructores en la práctica del entrenamiento sobre bicicletas estáticas, por lo cual es necesaria la unificación de conceptos para encontrar la forma adecuada de trabajo, para dar así seguridad al usuario cuando decida realizar esta actividad física.

Por lo anterior se hace un estudio diagnóstico, para lo cual se consiguió la opinión de casi 60 usuarios con el fin de identificar algunos problemas y recomendar los correctivos para una práctica adecuada. 


\section{JUSTIFICACIÓN}

Una de las características de la sociedad moderna es la búsqueda de la efectividad, rapidez y seguridad en el logro de sus inversiones. Se considera que este es el motivo de la popularidad del ciclismo estático, denominado por algunos como "spinning", "indoor-cycling", "r.p.m.", "spinning store", "top ride", etc., que de hecho nace de estas exigencias. Por esto se busca con la siguiente tesis encontrar el valor de este tipo de práctica como ejercicio, definiendo su correcta técnica y metodología de trabajo.

Dado que la práctica de actividad física sobre bicicletas estáticas se convirtió en una de las actividades más importantes de la población que acude a los gimnasios, se considera de gran utilidad realizar un diagnóstico sobre la práctica en general, determinando qué necesitan los usuarios para su seguridad y comodidad, y sobre la repercusión y la incidencia que la calidad y el diseño de los equipos tiene en la práctica.

Como deportista de alto rendimiento durante 9 años en la Selección de Colombia de ciclismo de pista, aprendí y experimenté las diferentes posiciones y técnicas en la bicicleta de piñón fijo, lo cual me permite guiar mejor las formas prácticas de esta actividad y desarrollar correctamente el uso y trabajo en la bicicleta estática para la práctica del "E.S.B.E." (entrenamiento sobre bicicleta estática).

La experiencia de más de 7 años como instructor de esta actividad sobre bicicletas estáticas, en varios gimnasios en Colombia y Argentina, me ha permitido conocer a fondo las dificultades y beneficios de esta práctica. Por ello considero que este trabajo escrito aportará a la mejoría sobre la bicicleta estática. 


\section{OBJETIVOS}

\subsection{OBJETIVO GENERAL}

Caracterizar el "E.S.B.E." como actividad saludable y estudiar las diferentes repercusiones sobre los participantes, con énfasis en el plano orgánico-funcional.

\subsection{OBJETIVOS ESPECÍFICOS}

- Caracterizar los procesos de instrucción idóneos para la práctica del "E.S.B.E."

- Exponer los trabajos que pueden ser incorporados sobre la bicicleta estática.

- Reportar los campos fisiológicos de las personas evaluadas, registrando el tiempo de trabajo.

- Usar la herramienta encuesta con practicantes del "E.S.B.E." y conocer el aspecto motivante a su práctica.

- Desarrollar pautas para la práctica del "E.S.B.E." y sus diferentes posturas sobre la bicicleta estática.

- Conocer la razón por la cual se practica el "E.S.B.E." 


\section{METODOLOGÍA}

Se realizó una búsqueda bibliográfica en sitios Web sobre textos y artículos específicos referidos al ciclismo.

El diagnóstico sobre la práctica se realizó en un gimnasio de la ciudad de La Plata (Argentina).

Se realizaron encuestas a usuarios en general, y evaluaciones más completas a tres practicantes voluntarias, las cuales llevaron una muy buena uniformidad en su asistencia; estas personas demostraron desde la misma exposición del escrito un importante compromiso para la investigación y un muy buen ánimo para las evaluaciones que serían tomadas en cuenta para la tesis.

Se realizaron evaluaciones antropométricas (pliegues y perímetros), pruebas de fuerza muscular dinámica (sobre las máquinas multifuncionales), pruebas de esfuerzo (sobre la misma bicicleta estática), y las personas evaluadas participaron también de las encuestas. Se organizaron cuatro diferentes campos a lo largo de 5 meses que fueron tomados como tiempo de trabajo, distribuyendo uniformemente la recepción de datos de cada una de las evaluadas. Las evaluaciones sobre la bicicleta estática, además del trabajo mismo durante el tiempo de preparación, fueron hechas sobre una bicicleta Indoor EMBREEX - ARG340

* Indoor Bike Profesional.

* Sistema de transmisión por cadena.

* Rueda de inercia cromada de $22 \mathrm{~kg}$ de resistencia.

* Carga Máxima: 160 kg.

* Peso del producto: 48,5 kg.

* Sistema de freno de emergencia.

* Manubrio antideslizante.

* Regulación del asiento horizontal y vertical.

* Patas para nivelación de pisos irregulares.

Los aparatos multifuncionales para las evaluaciones de fuerza fueron construidos por "Pacific Fitness".

Las encuestas fueron tabuladas mediante un manual de codificación generado para este tipo de trabajo y luego se graficaron los resultados para su análisis. 


\section{PLANTEAMIENTO TEÓRICO}

\subsection{CONCEPTO DE LA ACTIVIDAD FÍSICA DENOMINADA MUNDIALMENTE COMO "SPINNING"}

\subsubsection{Historia}

El spinning fue desarrollado a finales de la década de los ochenta por el ciclista norteamericano Johnny Goldberg (Johnny "G"), y la bicicleta utilizada ha sido denominada por su creador como "SPINNER". (El hilador).

Cuando Johnny G. desarrolló el programa de spinning, tenía como meta crear algo nuevo que fuese mucho más que una clase de ejercicios aeróbicos al ritmo desenfrenado de la música. Entonces puso en práctica los conocimientos que había adquirido a través de sus años como ciclista profesional y cinturón negro de karate, junto con sus estudios de la filosofía "Zen", para crear un ejercicio de "bajo impacto" pero altamente efectivo. Su inventor no era un aficionado, ya que en 1989 había ganado la "Race Across America", una carrera que cubre 6.500 kilómetros.

En el spinning dirigió su atención no sólo al plano físico, sino también al mental, ya que los diferentes tipos de rutina que se realizan en una clase proponen reducir el nivel del estrés.

Johnny G. empezó a enseñar su programa de spinning en el garaje de su casa, hasta que sus clases se hicieron tan populares que llegaron a los oídos de los directores de los principales gimnasios de Los Ángeles en California, U.S.A.

La premisa básica de este ejercicio era la de llevar los elementos de las élites atléticas a personas "no deportistas" que eran apáticas ante el uso las bicicletas estáticas, que ya existían. Para lograr su propósito, Johnny G. decidió combinar un poco de yoga, otro tanto del "Tour de Francia" y una bicicleta estática que diseñó especialmente para el caso y que bautizó como la "Johnny G. Spinner". A todo esto se le debe añadir un "detallado grupo de movimientos cíclicos combinados con un entrenamiento de la frecuencia cardíaca, para alcanzar el desarrollo personal deseado".

Quizá lo que más haya atraído al público hacia este ejercicio sea la posibilidad de bajar de peso en un tiempo relativamente corto, ya que los participantes de una sesión de spinning (con un instructor que dirija el ejercicio) pueden llegar a utilizar un promedio de 500 calorías en 45 minutos, combinando la diversión y la motivación de una clase de ejercicios; además, es un programa de entrenamiento ideado para evitar las lesiones de quienes se ejercitan.

Muchos ciclistas ("ruteros", "pisteros", "ciclo montañistas" y "triatletas") incorporan el spinning en sus programas de entrenamiento para mejorar su capacidad cardiovascular y pulmonar. ${ }^{1}$

\footnotetext{
${ }^{1}$ Tomado de: http://magiseducacionfisica.blogspot.com/2007/12/historia-del-spinning.html
} 


\subsubsection{Definición del Spinning}

El "Spinning" es un ejercicio inspirado en el ciclismo de ruta, que se realiza sobre una bicicleta estática diseñada especialmente para tal fin. La clase se desarrolla en forma grupal, con la dirección y compañía de un instructor, simulando trabajos de competencia con un trasfondo musical.

\subsubsection{Entrenamiento sobre bicicleta estática (“E.S.B.E.”)}

Esta forma de entrenamiento nace en Colombia bajo mi dirección y propuesta. En esta forma de entrenamiento, propongo sistematizar un orden diferente dentro de las clases e introducir ejercicios para el entrenamiento del tren superior sobre la bicicleta estática. En mi propuesta se incrementan los ejercicios y la exigencia de trabajo antero-posterior y lateral del tronco.

En cierto modo se realiza una adaptación del entrenamiento del ciclismo de alto rendimiento al trabajo sobre bicicleta estática, teniendo en cuenta posturas, técnicas, duración de intervalos de trabajo, además de los trabajos base de todo ejercicio físico como la resistencia, la fuerza, la velocidad y la potencia.

La propuesta está organizada en microciclos que constan de 14 diferentes orientaciones de clase realizadas en cadena, aumentando exigencia y duración de intervalos con el pasar del tiempo.

Esta actividad no solo tiene como objetivo la mejora físico - muscular; también busca la colateralidad, velocidad de reacción, percepción, propiocepción, recreo, la socialización y la autoestima, buscando reducir los niveles de estrés.

\subsubsection{Definición del "E.S.B.E."}

El "E.S.B.E." es un trabajo sobre bicicleta estática que se apoya estrictamente en el ritmo musical para marcar la cadencia de pedaleo, trabajando sobre 5 diferentes cargas de trabajo que van desde la carga mínima hasta la alta, manejando además trabajos de tensión muscular isométrica, excéntrica y concéntrica para el tren superior, con exigencias progresivas y ajustes constantes de la actividad. 


\subsection{DESCRIPCIÓN DE LA BICICLETA ESTÁTICA}

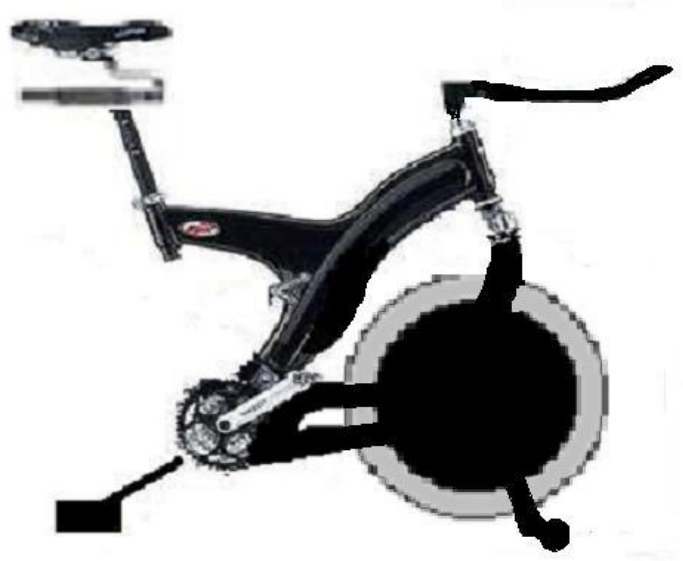

llustración 1

\subsubsection{Especificaciones para Bicicleta de "E.S.B.E."}

Manubrio: Es el apoyo de las extremidades del tren superior (brazos). El ancho debe ser entre 40 y $50 \mathrm{~cm}$. -ya que éste es el ancho promedio de la caja torácica en los adultos-, y está conformado en general por tubos de $2,5 \mathrm{~cm}$. de diámetro.

Ancho del eje centro de biela: La estructura de la bicicleta estática posee un eje centro al cual van unidas las palancas (bielas), que trasmiten el movimiento desde las extremidades inferiores (piernas) hacia la volante por medio de una cadena mecánicametálica. El ancho del eje debe estar entre 24 y $30 \mathrm{~cm}$. para evitar lesiones en la región interna de la rodilla y para que la transmisión de la fuerza sea lo más vertical posible.

Altura caja centro: Se recomienda que esta altura esté entre 24 y $30 \mathrm{~cm}$. por sobre la horizontal (suelo), por efectos de estabilidad para la bicicleta.

Esta altura es la real en bicicletas de ciclismo profesional y está avalada por la U.C.I. (Unión Ciclística Internacional).

Tamaño de las bielas: Se recomienda entre 168 y $175 \mathrm{~mm}$. Este tamaño de biela está diseñado para que las personas de una altura entre los 1,60 y 1,90 m. puedan pedalear evitando al máximo lesiones e incomodidades en la actividad, sobre todo cuando se realizan trabajos de velocidad. 
Tamaño del sillín: Los más comunes en el mercado están entre los 24 y los $27,5 \mathrm{~cm}$. de largo. Se recomienda que no sean demasiado anchos porque puede hacer que se abran las piernas inconscientemente al momento de pedalear, impidiendo la correcta técnica (y generando incomodidad), partiendo de aquí las posibles lesiones para las piernas.

Ángulo barra caja centro-silla (respecto a la horizontal): Hay un ángulo importantísimo a tener en cuenta en la elaboración de esta bicicleta, que es el motivo de muchas lesiones.

La línea que va desde el eje centro y la espiga de la silla debe estar entre los 74 y 76 grados con respecto a la horizontal; si este ángulo es menor, el trabajo de pierna y cadera deja de ser equilibrado para desviarse más a un trabajo de pierna, dando lugar a sobrecargas en la articulación de la rodilla. Con un ángulo correcto este trabajo debe ser un trabajo armónico-dinámico, continuo y equilibrado.

\section{Observaciones adicionales:}

- Se recomienda tener doble "porta termos", ubicados uno a cada lado de las barras que van al lado de la volante.

- El manubrio debe tener desplazamiento horizontal y dar mayores posibilidades de posición (ampliar o disminuir distancia silla - manubrio).

- No es recomendable el uso de las punteras de un solo y único tamaño, por las siguientes razones:

A. Las personas tienen puntos de apoyo y articulación metatarso-falángica de diferente medida respecto a la punta de los pies.

B. El ajuste extremo de las correas puede ocasionar dificultad de irrigación sanguínea para los pies.

C. Al entrar todo el pie en la puntera no se logra el punto de apoyo en el lugar indicado, ocasionando problemas neuro-musculares, (sensación de adormecimiento muscular, calambres). Las personas que tengan pies pequeños ubicarán su calzado hasta el final de la puntera, haciendo que esta articulación no quede sobre el eje-centro del pedal. 


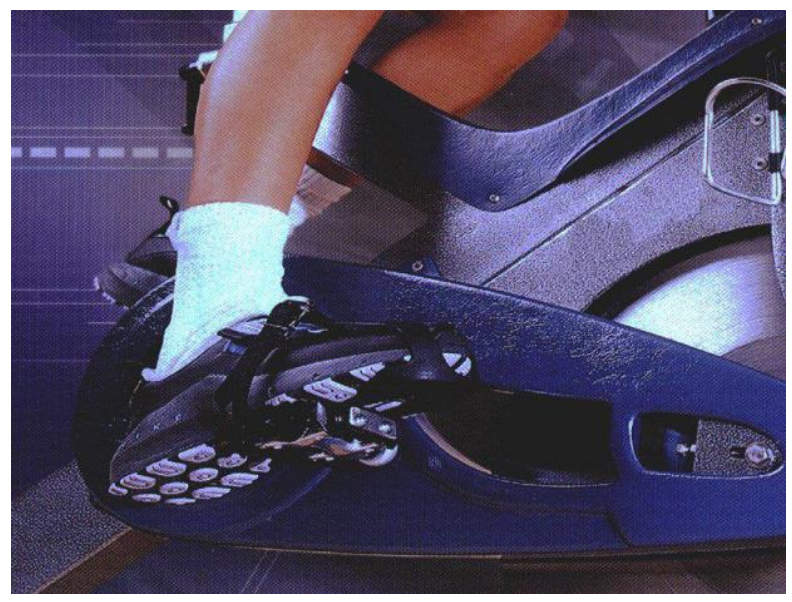

Ilustración 2: Ubicación errónea del pie dentro de la puntera

Se puede observar en la llustración 2 cómo el pie de la modelo se encuentra ubicado hasta el final de la puntera, con lo cual el punto de apoyo, es decir el eje del pedal, queda más atrás de la articulación metatarso-falángica. Además la correa está floja, lo que va en contra de la seguridad del usuario. ${ }^{2}$

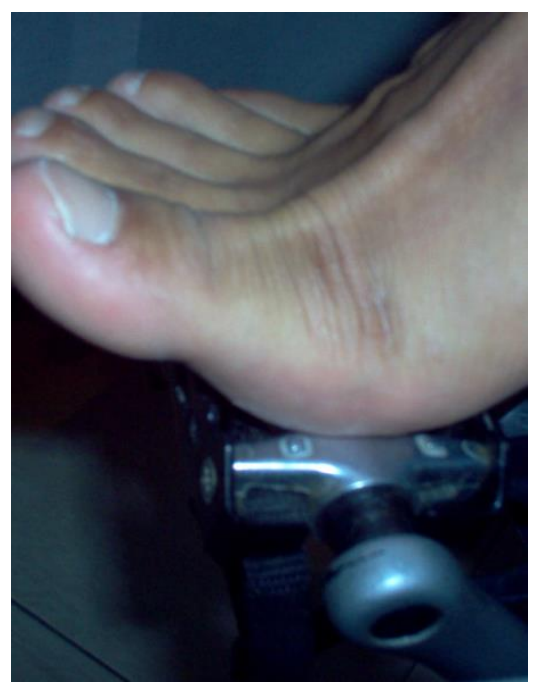

Ilustración 3: Ubicación correcta del pie en el pedal

El pie esta correctamente ubicado sobre el pedal cuando es apoyado como se muestra en la llustración 3.

\footnotetext{
${ }^{2}$ Tomado de la publicidad de una marca llamada "Forma", líder en construcción de bicicletas para spinning y equipos para gimnasio en el país de Colombia.
} 


\section{CUADRO DE RESUMEN}

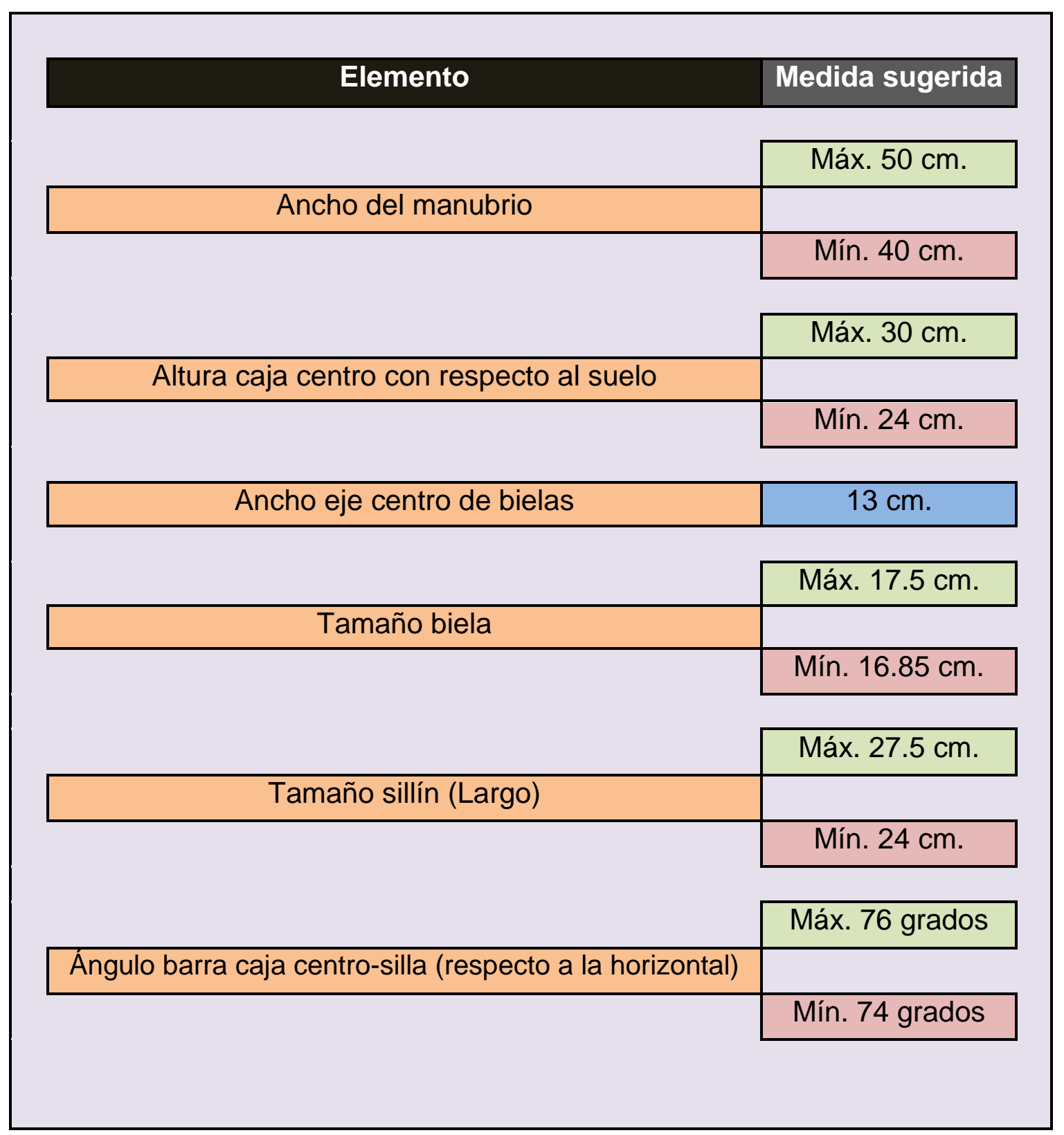

\subsubsection{Descripción general de una bicicleta para ciclismo estático}

- ESTRUCTURA: De alto tráfico, fabricada por lo general en tubería 90X50 mm. de acero, rígida, de mayor estabilidad.

- PINTURA, pensada para intemperie, ambiente ácido y salino, por lo general poliéster "TGIC" aplicado por sistema electrostática en polvo 60-80 micras de espesor.

- Caja centro con rodamientos industriales rígidos y sellados de alta duración. 
- Accesorios como bielas y pedales en aluminio para alto tráfico, cadena exterior independiente, removible.

- Volante aerodinámica balanceada en acero cromado, soportada sobre rodamientos de bolas rígidos y balanceados, libres de mantenimiento

- Comando de intensidad del ejercicio de freno radial o axial

- Manubrio de 1", soporte de asiento y guías de deslizamiento fabricadas en acero inoxidable al igual que la tortillería y accesorios.

- Perillas y manijas de sujeción en aluminio, con recubrimiento en plástico.

- Cubiertas plásticas sobre estructura principal para proteger de la transpiración, como las guardas de protección en cadenillas y bielas que, además, realzan la apariencia estética de la bicicleta.

- Sillín ergonómico y confortable, guías y soportes de asiento y manubrio graduables en acero inoxidable, soporte para termos.

\subsection{ADECUACIÓN DE LA BICICLETA AL USUARIO - PRACTICANTE}

La bicicleta para "E.S.B.E." y sus componentes se han desarrollado hasta su forma actual para adaptarse a los requisitos ergonómicos esenciales del tipo de esfuerzo.

La bicicleta debe permitir:

- Poner el sillín a tal altura sobre los pedales y con tal retroceso que permita pedalear suave y eficazmente en posición sentada.

- Una posición sobre el manubrio en la cual la parte superior del cuerpo quede adaptada a la flexibilidad y anatomía de cada usuario, permitiendo un pedaleo efectivo cuando se carga todo el peso sobre los pedales y una posición para conducción relajada con el tronco moderadamente inclinado.

- El diseño de los diversos componentes debe proporcionar suficiente flexibilidad para adaptarse a una variada gama de características físicas de hombres y mujeres.

\subsubsection{Altura del sillín}

Altura del sillín dada por una completa extensión de la pierna estando el sujeto sentado de forma correcta y cómoda sobre el sillín de la bicicleta y apoyando el talón con la pierna en extensión sobre el eje centro del pedal; la cadera estará formando entre sus crestas ilíacas una línea paralela al piso.

Para la persona que tiene bicicleta de "E.S.B.E." de uso personal, o que puede dedicar mayor tiempo a la adecuación de la altura del sillín, se recomienda un método más exacto: 


\section{Método de Wilfried Hugui (suizo)}

Este es el método más reconocido en el ciclismo y fácilmente aplicable.

- Medir la entrepierna: Con los talones, glúteos y espalda apoyados contra una pared y el sujeto descalzo, se mide la altura del pubis (el punto mas alto entre las piernas, sínfisis pubis o entrepierna) usando una escuadra o un libro, herramienta que marque 90 grados.

- Entre los pies se deja una distancia de $10 \mathrm{~cm}$.

- El resultado en centímetros se multiplica con la constante de Hugui $(0,885)$ y se obtiene la altura del sillín en $\mathrm{cm}$.

Entrepierna $(\mathrm{cm}$.$) x 0,885 = Altura del Sillín (\mathrm{cm}$.

\section{Método (ADS)}

La altura del sillín es la distancia entre la mitad del eje pedal (cuando se encuentra en el punto muerto inferior) y la superficie del sillín.

El método proviene de los tempranos años 80 , en los que se utilizaban pedales de punteras, zapatillas convencionales y bielas en la mayoría de $170 \mathrm{~mm}$.

Para los pedales del sistema de nuestra época, el método de "Hugui" mantiene validez aun para los pedales de ajuste con correas; solo se tiene que considerar que, en los sistemas de trabas "look" o "time", similares al anterior, hay que adicionar aproximadamente $1 \mathrm{~cm}$. por el grosor de la traba y suela (dispositivo de ajuste de las zapatillas a los pedales).

Generalmente no se puede ajustar al milímetro exacto, pues no se sabe el grosor de la suela de la zapatilla y el sillín también es elástico.

La altura del sillín es de suma importancia, ya que si se ubica demasiado bajo en la bicicleta las piernas estarán encogidas y no podrán aprovechar su plena fuerza muscular. Por añadidura se someterán las piernas a un esfuerzo extra innecesariamente y se fatigará mucho antes de lo esperado. Además el esfuerzo de los músculos actuará como una fuente de tensión para todos sus tejidos conjuntivos: ligamentos, cartílagos y tendones.

Por otra parte, si está demasiado alto, la persona tendrá que extenderse demasiado y no podrá alcanzar la potencia plena en el punto muerto inferior del pedaleo, además de que extenderá demasiado e incesantemente los músculos y tejidos conjuntivos de las piernas, una circunstancia propicia para tirones y desgarros musculares y lesiones de los tejidos conjuntivos. ${ }^{3}$

\footnotetext{
${ }^{3}$ Greg Lemond. Ciclismo Completo. Pág. 115
} 


\subsubsection{Retroceso del sillín}

El retroceso está dado por una línea vertical imaginaria entre la punta del sillín y el ejecentro de las bielas. Definimos este retroceso cuando la persona ejercitando se encuentra sentado correctamente sobre la bicicleta, habiendo marcado antes la altura de la silla, y, cuando sus pies son puestos a la misma altura del suelo, se lanza otra línea imaginaria perpendicular al piso entre la rótula (de la pierna que se encuentra adelantada) y el eje centro del pedal que apoya el pie adelantado.

Esa línea pasa (imaginariamente) por la rótula y la articulación metatarso-falángica del pie adelantado y el eje pedal. Este retroceso varía según el tamaño de la extremidad inferior del practicante, por lo general entre los 2 y $6 \mathrm{~cm}$.

\subsubsection{Altura del manubrio}

La altura del manubrio debe ser como máximo la misma del sillín, para favorecer el trabajo del tren superior y el fortalecimiento de los músculos cervicales, dorsales y lumbares, además de los brazos en general. Si el usuario no se adapta a esta posición, será él mismo quién marque la altura de acuerdo a su flexibilidad, su fuerza y anatomía.

Para las personas que tienen problemas en la columna vertebral o dolores en la espalda, se recomienda una altura mayor del manubrio (sin exagerar), con el fin de evitar el trabajo de los músculos comprometidos. Una altura exagerada en el manubrio hará que se pierda el correcto apoyo y dirección del peso corporal sobre la bicicleta, recargando el peso en las piernas y dando paso a las lesiones. 


\subsection{EL PEDALEO}

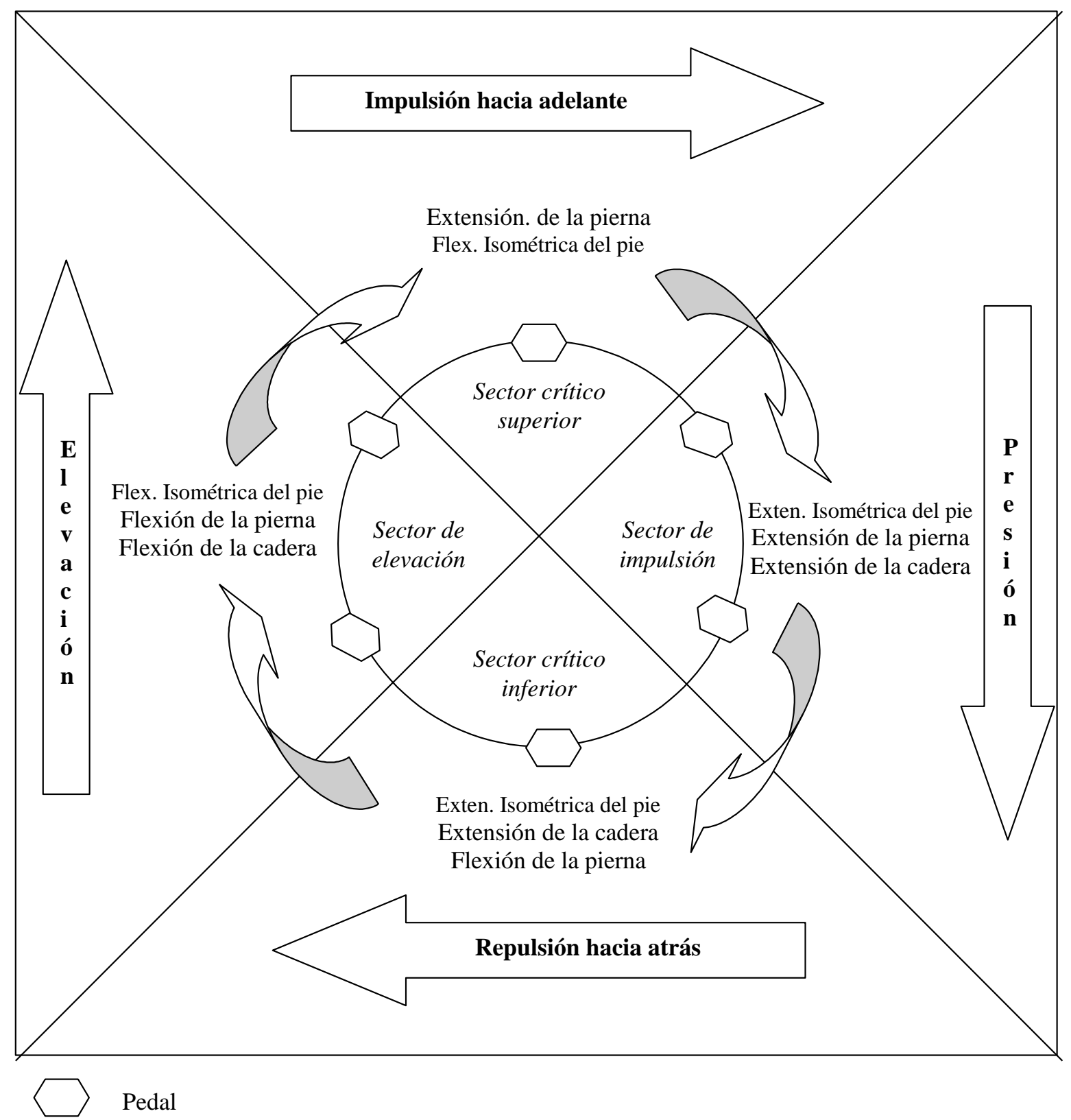

Ilustración 4: Diagrama explicativo del pedaleo 
La acción técnica más sobresaliente en el ciclismo en general es el pedaleo. Consiste en efectuar una rotación de $360^{\circ}$ en torno al eje de las bielas, transmitiendo fuerza a través de unos pedales. Esta rotación determina el avance de la rueda trasera de la bicicleta por medio de un engranaje dentado (plato-piñón) con el que está relacionado por una cadena metálica acondicionada para tal fin. En la bicicleta estática hay un sistema que funciona de forma muy similar, dando movimiento a una "volante" que nunca está en contacto con el suelo y que reemplazaría a la rueda antes mencionada.

\subsubsection{Fases del pedaleo}

El análisis de la mecánica del pedaleo, además de la posición de los miembros inferiores y el pie, debe referirse a la acción motora para obtener la máxima fuerza propulsora, la acción que se hace sobre el pedal que, acondicionado a las bielas, mueve el disco dentado que lleva la fuerza a través de la cadena para hacer girar la volante.

Dividiremos el pedalear en 4 puntos (referencia). Así, si tenemos 360 grados divididos en 4 puntos, el punto 1 será a los 0 grados de iniciado el giro del pedalear, el punto 2 a los 90 grados, el punto 3 a los 180 grados y el punto 4 a los 270 grados.

Estos puntos se irán cubriendo de forma progresiva en cuanto a las acciones musculares generadas por los distintos grupos que intervienen en esta acción propulsora. Estando sobre la bicicleta, el rostro estará en la dirección del accionar del pedaleo.

\subsubsection{Fase 1므}

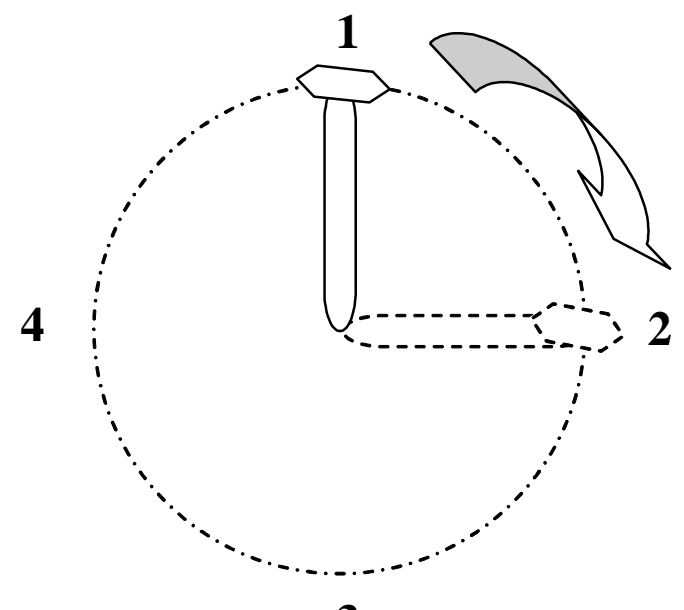

3

Biela

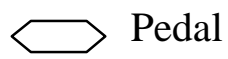

Ilustración 5: Primera fase del pedaleo 
Estando el pedal en el punto muerto superior ( 0 grados) y desplazándose a los 90 grados de recorrido (del punto 1 al 2), hay fuerza aplicada hacia el frente y abajo al pedal, y están en acción los siguientes grupos musculares (ver llustración 5):

- Los flexores del primer dedo del pie y del arco plantar, los cuales son los que dan una mayor adherencia del pie al calzado y así al pedal.

- Los extensores del pie mantienen una contracción isométrica, aumentando su exigencia a medida que se pasa del punto 1 al 2. La pierna, por acción de sus extensores (cuádriceps), proporciona la más fuerte acción propulsora de todo el ciclo del pedaleo (también por ayuda de la gravedad). Los extensores del pie son los que regulan la posición del pie respecto a la horizontal, así como la transmisión de la fuerza de la pierna-glúteo hacia el pie, y por consiguiente al pedal.

- Los extensores de la pierna (cuádriceps), vasto interno, vasto externo, recto femoral y tensor de la fascia lata son los que hacen que la pierna se extienda, haciendo la fuerza para adelante.

- Se hace además una fuerza para abajo, trabajo de los grupos musculares como el glúteo mayor, medio y menor.

\subsubsection{Fase $2^{a}$}

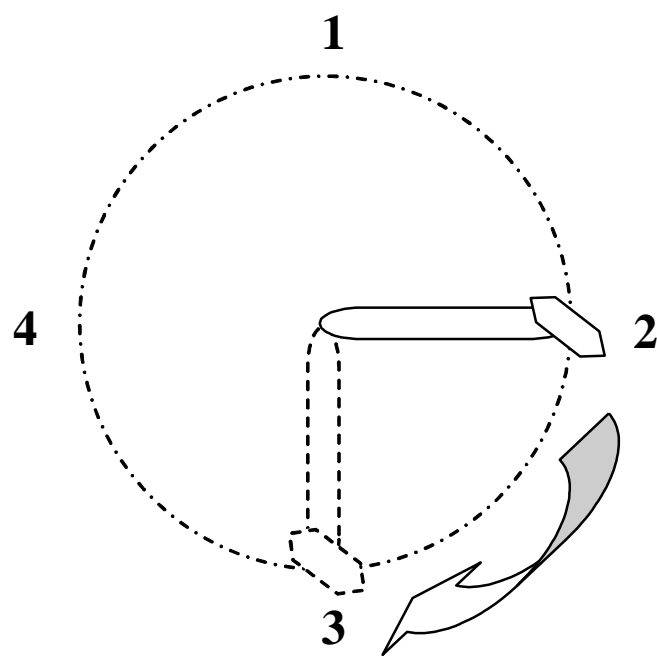

Ilustración 6: Segunda fase del pedaleo

Desplazándose del punto 2 al punto 3 (ilustración 6-6), se ve que hay fuerza para abajo y atrás. Sigue actuando el mismo grupo de músculos que trabajan en la extensión de la cadera (músculos de glúteo mayor, medio y menor), empezando su trabajo el grupo muscular de flexión de pierna al llegar al punto 3 (semitendinoso y bíceps femoral) 
Los trabajos musculares de la rodilla al tobillo siguen siendo los mismos que se presentaban en el desplazamiento del punto 1 al 2.

\subsubsection{Fase $3^{\underline{a}}$}

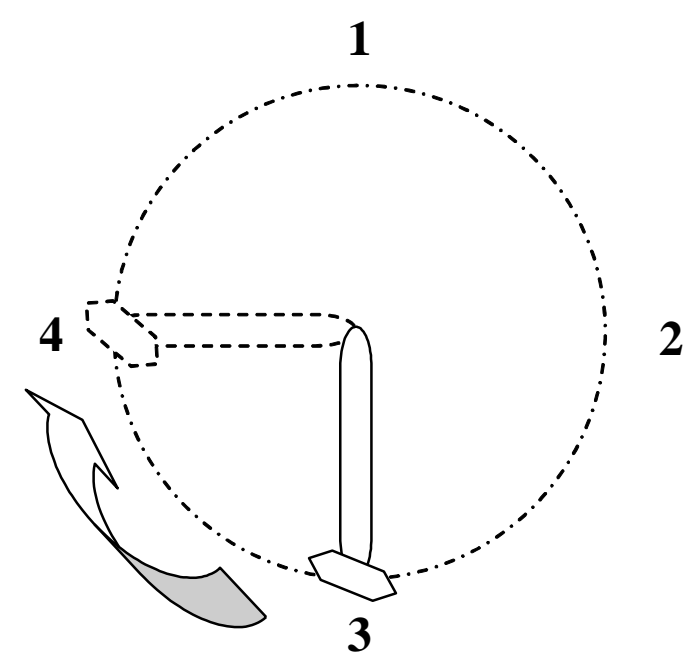

Ilustración 7: Tercera fase del pedaleo

Luego de llegar al punto 3 (desplazándose del punto 3 al 4):

- los trabajos de glúteos terminan temporalmente, continuando el trabajo de tracción de la pierna por parte de los músculos semitendinoso y del bíceps femoral, e iniciando el trabajo de los psoas mayor e ilíaco, llevando ahora la pierna hacia arriba.

- La postura del pie respecto al suelo, es decir la horizontal, sigue siendo la misma: ahora el pie, al igual que toda la pierna, va en contra de la gravedad, y son ahora el tibial anterior y el peroneo mayor los encargados de hacer que el pie no cambie su postura anatómica. 


\subsubsection{4 $\underline{\text { Fase } 4^{a}}$}

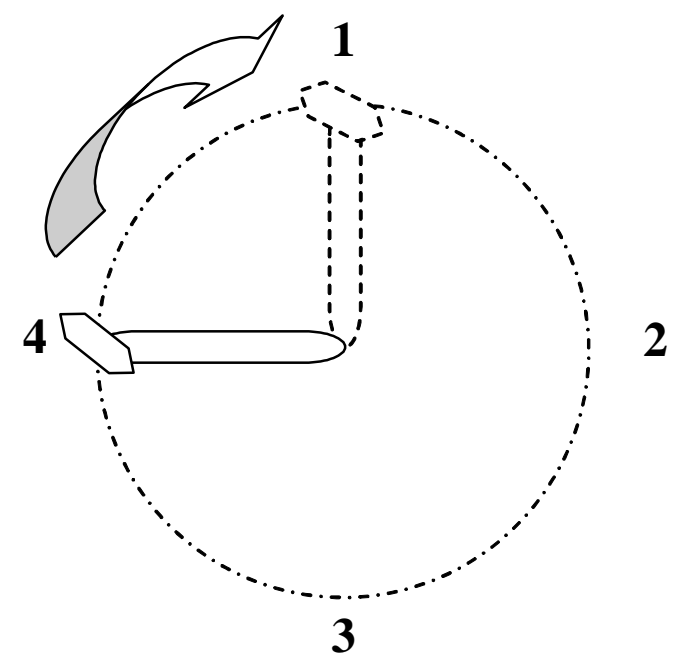

Ilustración 8: Cuarta fase del pedaleo

La acción de la $\quad$ llustración 8 (desplazamiento del punto 4 al 1):

- Retorna el trabajo de los músculos de la pierna anterior, cuádriceps, vasto interno, vasto externo, recto femoral y tensor de la fascia lata, trabajando de nuevo en la extensión de la pierna y no dejando de flexionar la cadera por acción de los músculos psoas mayor y psoas ilíaco.

- El trabajo de los músculos tibial anterior y peronéo mayor sigue siendo el mismo, manteniendo la postura del pie y garantizando la buena transmisión de la fuerza de toda la pierna al pedal.

\subsubsection{Resumen de trabajos musculares en el pedalear}

A. Del punto 1 al 2 se hace fuerza para adelante y para abajo.

Trabajan el cuádriceps, el vasto interno y externo, el recto femoral y el tensor de la fascia lata para adelante, y para abajo los músculos glúteo mayor, medio y menor con el cuadrado crural. De la rodilla para abajo se puede hacer mención directa al músculo gastrocnemio

B. Del 2 al 3 se hace fuerza para atrás y para abajo.

Trabajan el semitendinoso y el bíceps femoral para atrás, y para abajo los músculos glúteo mayor, medio y menor con el cuadrado crural. De la rodilla para abajo se involucra mucho el músculo gastrocnemio.

C. Del 3 al 4 se hace fuerza para atrás y para arriba.

Trabajan el semitendinoso y el bíceps femoral para atrás, y para arriba trabajan el psoas mayor e ilíaco. De la rodilla para abajo, el tibial anterior y el peroneo mayor. 
D. Del 4 al 1 , se hace fuerza hacia arriba y adelante.

Trabajan el psoas mayor e ilíaco para arriba y el cuádriceps, vasto interno, externo, recto femoral y tensor de la fascia lata para adelante. De la rodilla para abajo, el tibial anterior y el peroneo mayor.

La tensión de abductores es la misma durante todo el pedalear, tensión mínima para que las piernas trabajen haciendo fuerza en línea recta (vista frontalmente).

\subsection{TRABAJO DEL TRONCO EN EL CICLISMO}

El tronco, conformado por el tórax, el abdomen y la cadera, es el punto de anclaje de las articulaciones inferiores y está sometido a notables y constantes fuerzas desestabilizadoras. Su estabilidad es esencial para un buen rendimiento muscular y para evitar alteraciones de la columna vertebral, especialmente a nivel lumbosacro. El movimiento alternado de las piernas al pedalear tiende a desviar la columna y crestas ilíacas, además de la pelvis, sobre todo en la primera parte del pedaleo, al apoyar y empujar.

Los músculos para-vertebrales evitan el balanceo de la pelvis, con la colaboración de los oblicuos: su acción tiende a enderezar el tronco, que es mantenido en flexión gracias no solo a la gravedad sino también a las extremidades superiores que le dan apoyo y anclaje; también evita el desplazamiento de la pelvis de su apoyo cuando se manejan cargas altas.

Los músculos abdominales son bien importantes en la dinámica respiratoria, principalmente durante ejercicios intensos. La acción del glúteo mayor tiende también a mover lateralmente la pelvis. El músculo cuadrado lumbar se opone a este movimiento ayudado por el dorsal ancho. El balanceo anormal de la pelvis es una de las causas principales de las lumbalgias por sobre-esfuerzo, y es evidente el trabajo de los músculos dorsales, en particular el dorsal ancho y el cuadrado lumbar, los cuales son fundamentales para obtener una buena postura y evitar los síntomas dolorosos sobre la bicicleta.

Otros factores posturales y anatómicos, como las asimetrías en las extremidades inferiores, influyen en el movimiento tipo "péndulo" de la pelvis. También influyen la longitud de la biela, la altura y retroceso del sillín (posición del sillín): una altura excesiva o un retraso exagerado aumentan el desequilibrio lateral de la pelvis.

\subsection{EL TRABAJO DEL CUELLO}

En el hombre en posición orto-estática (de pie), los músculos extensores del cuello están siempre en contracción (tal como lo demuestra la posición correcta de la ilustración 6-9), puesto que el centro de gravedad de la cabeza está situado un poco adelantado. Respecto a la articulación entre el hueso occipital (nuca) y la columna cervical, este desequilibrio gravitacional está más acentuado en la posición del ciclista (las posiciones correcta e incorrecta de la ilustración 6-9 pueden facilitar la apreciación de lo aquí expuesto). 
Hasta ahora se consideraba que esta zona, incluyendo las extremidades superiores, estaba privada de movimientos bruscos, salvo en las fases de pedaleo de pie sobre los pedales y los movimientos direccionales del manubrio. El análisis biomecánico dinámico ha puesto en evidencia complejos movimientos de la cintura escapular y de la columna cervical, con diversos componentes:

- $\quad$ Flexo-extensión de la columna durante las cuatro fases del pedaleo, mucho más notoria en las sobrecargas y fatiga.

- Movimientos oscilantes respecto al plano longitudinal del cuerpo.

- Movimientos de balanceo involuntario de cabeza que producen tensión muscular isométrica.

- La parte dorso-cefálica de la cabeza del practicante tiende siempre, por acción de la gravedad, a ir hacia delante, como lo muestra la ilustración incorrecta 6-9.

A

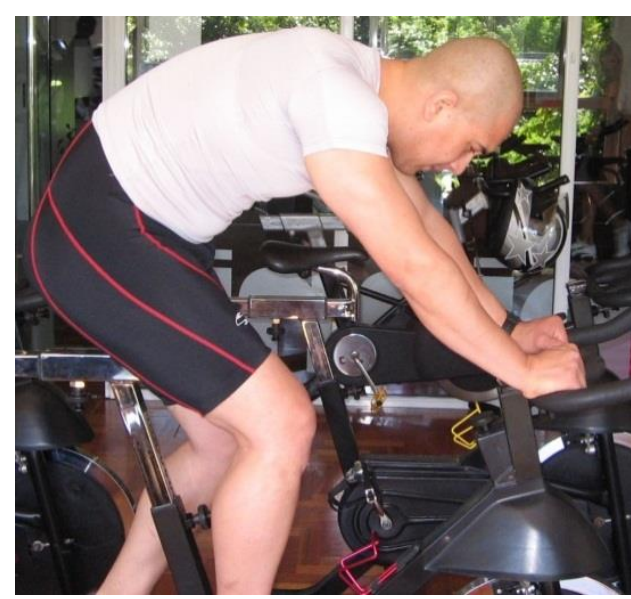

llustración 9: A) Posición incorrecta y
B

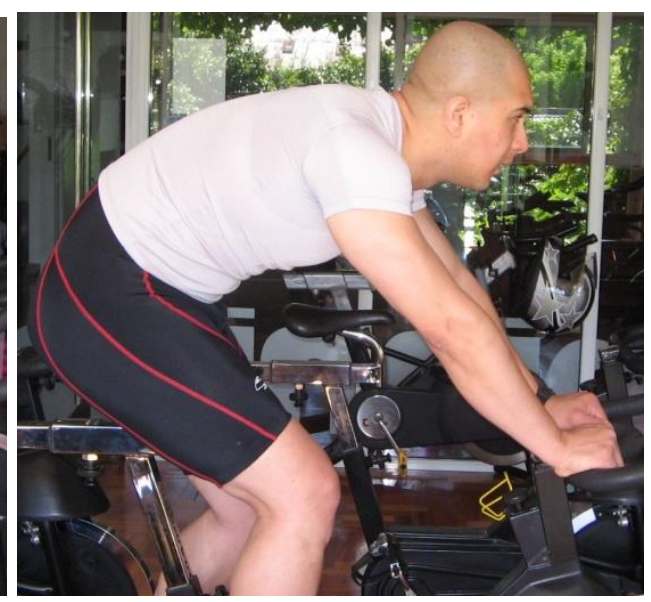

B) Posición correcta

\subsection{EL TRABAJO DE LAS EXTREMIDADES SUPERIORES}

El brazo y el antebrazo realizan diversas acciones, como se ha señalado anteriormente:

- Evitan la flexión del tronco, dando colaboración al trabajo de la zona lumbar y facilitando la técnica de pedaleo.

- Colaboran con la estabilidad, principalmente cuando se trabaja de pie sobre los pedales. 
Una vez las manos apoyadas sobre el manubrio, se aprecia un movimiento de tracción y empuje alternado y sincronizado con las fases de la pedalada, especialmente en trabajos de fuerza (sentado y de pie). Se trata de una acción de empuje del tren inferior. Los músculos del tren superior implicados fundamentalmente en este movimiento son el deltoides, el tríceps e indirectamente el bíceps, que flexionan y extienden los brazos (articulación del codo); además el braquial anterior, pronador redondo y braco radial dan ajuste a estas extremidades y al cerrado seguro y firme de las manos. El abdomen con su trabajo de contracción isométrica da aún más estabilidad al empuje cuando se está de pie sobre los pedales.

A

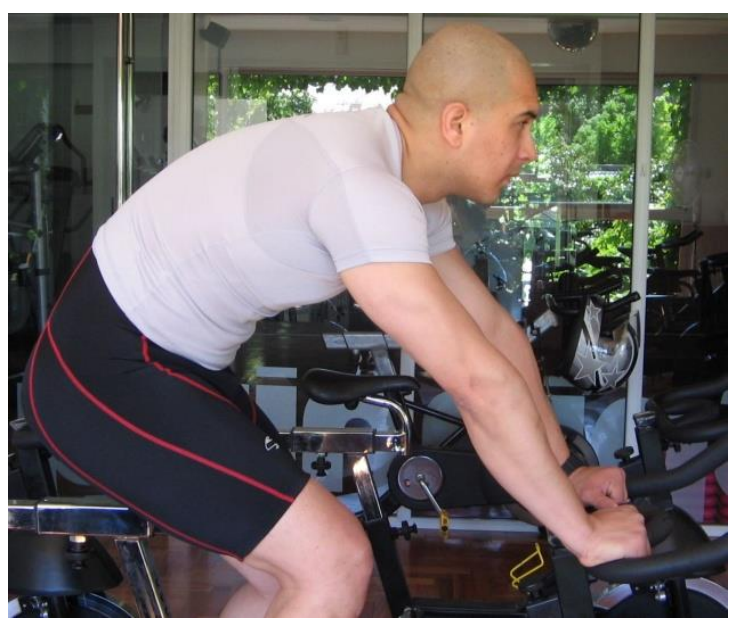

B

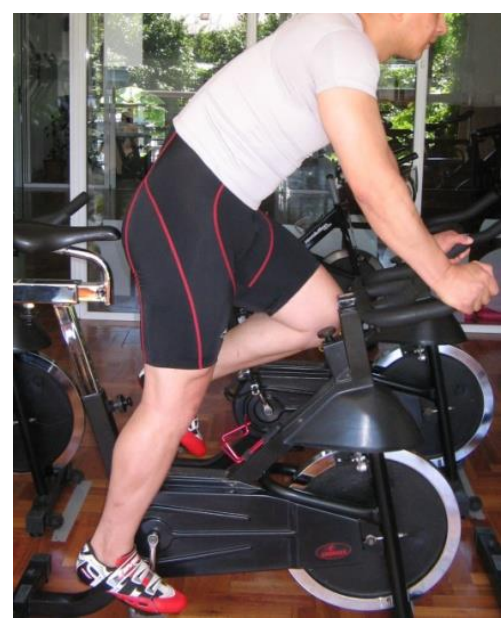

Ilustración 10: A) Trabajo sentado y B) Trabajo de pie.

\subsection{TÉCNICA CORRECTA EN EL “E.S.B.E."}

El practicante está sentado sobre un sillín y los miembros inferiores trabajan en descarga relativa. No tienen que soportar todo el peso de la parte superior del cuerpo, excepto cuando el instructor anuncia el comienzo de un trabajo sobre los pedales simulando una pendiente o simplemente un cambio de posición. En este caso se debe adoptar una posición casi erguida (parado sobre los pedales); solo se transmite a los pedales la fuerza muscular desarrollada esencialmente por el tren inferior, luego de la seguridad que da el tren superior a través de los brazos. Durante el movimiento de pedaleo las articulaciones de los miembros inferiores (cadera, rodilla, tobillo) trabajan en su eje fisiológico natural, así como en unas amplitudes medias, normales dentro del pedaleo. 


\subsubsection{Técnica de pedaleo}

\subsubsection{Pedaleo Uniforme}

Aquí todos los grupos musculares trabajan en perfecta coordinación.

Con esto podría casi asegurarse que no existe ningún "punto muerto" o "sector crítico" en toda la circunferencia seguida por el pedal, trabajando en coordinación perfecta los grupos musculares mencionados en la sección 6.4 (Fases del Pedaleo).

Si se diese un trabajo no uniforme, empezarían las sobrecargas para una de 4 etapas del pedaleo aquí descritas, propiciando de esta forma las lesiones.

Ejemplo de esto es pedalear solo con el trabajo de extensión de la pierna, es decir, dar énfasis al trabajo (citando una vez mas el punto 6.4.1) entre los puntos 4 y 2, donde trabajan de forma directa el cuádriceps, recto femoral y la fascia lata, dando el $100 \%$ de trabajo de pedaleo a este grupo muscular.

No podemos olvidar que el ciclo de pedaleo es un trabajo de extensión y flexión de pierna y también cadera.

\subsubsection{Apoyo del pie sobre el pedal}

El pie deberá apoyarse sobre el pedal siempre en la articulación metatarso - falángica. Este es el punto de transmisión de la fuerza desde la pierna al pie y desde éste hacia el sistema pedal-biela que, a su vez, transmite el movimiento a la volante.

Además, este apoyo permite mantener la posición anatómica (leve extensión) del pie y la articulación del tobillo durante todo el movimiento de pedaleo.

No apoyar el pie de esta forma trae consecuencias no deseadas: por ejemplo, cuando la suela del calzado es un poco blanda, se puede observar la fascitis plantar debido a un apoyo incorrecto del pie. 


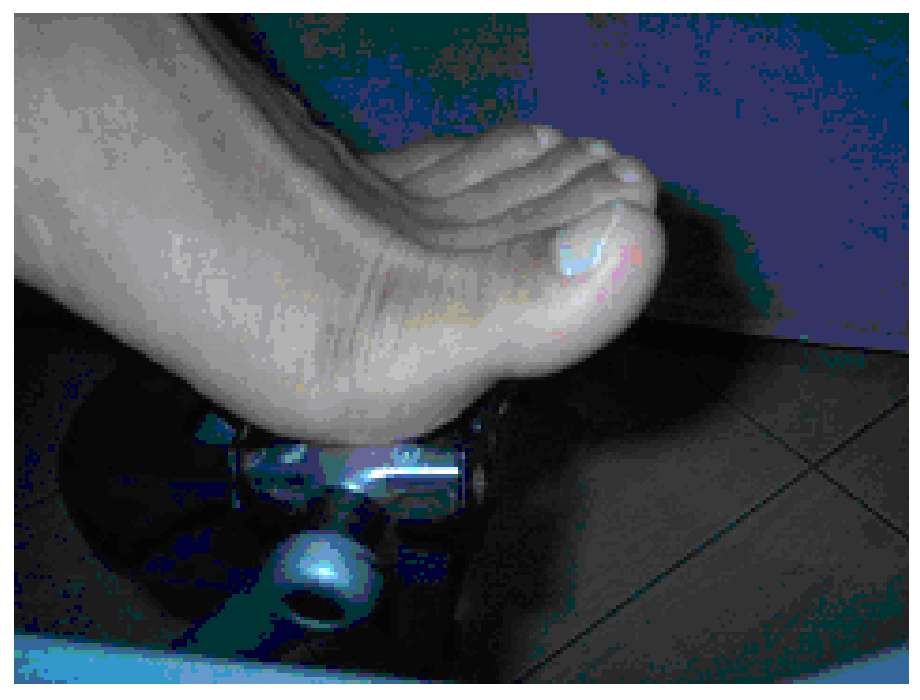

llustración 11

\subsubsection{Posición de los pies}

Se debe trazar una línea longitudinal imaginaria que divida el pie en dos secciones similares. Durante el pedaleo las líneas imaginarias de los dos pies deben permanecer paralelas entre sí.

$\mathrm{Si}$ el usuario tiene alteraciones anatómicas desde las rodillas, como genu valgo, genu varo o recurvatum, cambiará la forma de pedaleo para adaptarse a estas características.

La posición incorrecta puede traer problemas en los ligamentos cruzados de la rodilla.

\subsubsection{Posición de las rodillas}

Las rodillas deben ir proyectadas sólo al frente. Se deben mantener sobre el plano formado por los hombros, las rodillas, los tobillos y la punta del calzado. No olvidar que la articulación de la rodilla solo maneja extensión y flexión y no rotación, como ejemplifica la siguiente ilustración. 


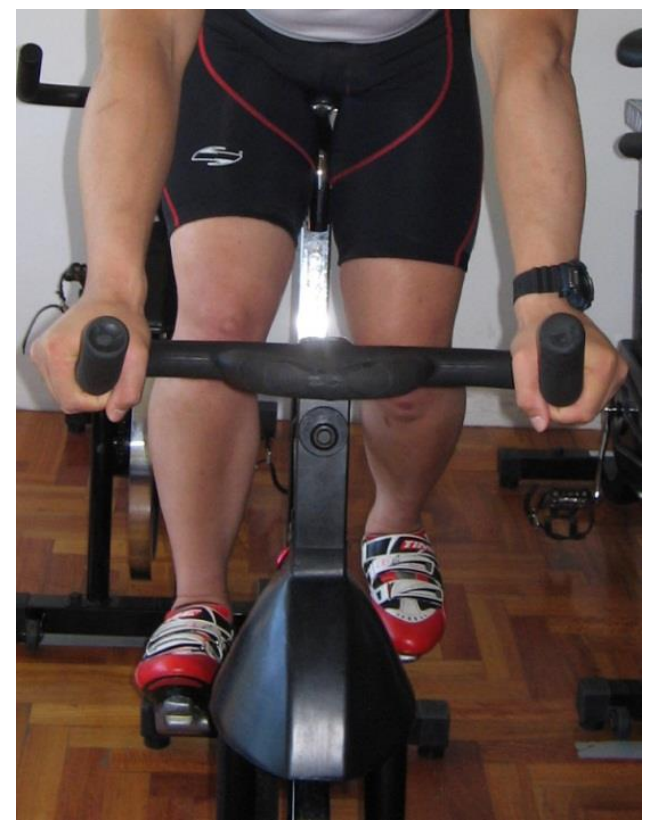

Ilustración 12

\subsubsection{Ajuste de correas}

Dado que el piñón es fijo, cuando la volante alcanza una velocidad crea una inercia que no es fácil de romper; por lo tanto, por seguridad del practicante, las correas deben mantenerse ajustadas. Además, la adecuada sujeción del pie al pedal facilita la técnica adecuada de pedaleo, evitando que el calzado cambie su posición sobre el pedal.

\subsubsection{Posición de cadera}

Trazando una línea imaginaria entre las crestas ilíacas, la cadera debe mantenerse paralela al piso (casi siempre). Si tuviera inclinación hacia alguno de los lados, se sobrecargaría una de las piernas, y además daría problemas intervertebrales y a nivel óseo a lo largo de toda la columna, y tensión innecesaria e irregular en los músculos oblicuos y transversos del tronco.

El balanceo de cadera puede deberse a una altura del sillín superior a la adecuada para la persona 0 , por qué no, a una asimetría en la longitud de las extremidades inferiores, que es muy corriente.

\subsubsection{Posición del tronco}

El tronco debe estar alineado con el eje longitudinal de la bicicleta, en posición siempre semi-erguida, sin forzar las curvaturas cervical, lumbar y dorsal. Su inclinación respecto a la horizontal está siempre marcada por la posición respecto al manubrio y por si se está de pie o sentado sobre la silla. 


\subsubsection{Posición de los miembros superiores}

\subsubsection{Posición de los hombros}

Mantener los hombros paralelos entre sí (a la misma altura respecto a la horizontal), en una posición anatómica, no forzada, un poco en ante versión.

\subsubsection{2 $\underline{\text { Posición de las muñecas }}$}

Respecto a la articulación de las muñecas, su posición estará dada por la postura que tengamos sobre la bicicleta, además del trabajo del tren superior que se esté haciendo; debe tratarse siempre de mantener las muñecas en el eje longitudinal del antebrazo, de su forma anatómica.

\subsubsection{Posición de cabeza y cuello}

La cabeza debe estar siempre con vista al frente, para facilitar la observación del instructor, el mantenimiento del equilibrio, la correcta respiración y las curvaturas naturales de la columna. El cuello debe permanecer lo mas relajado posible.

\subsubsection{Posición de apoyo sobre el manubrio}

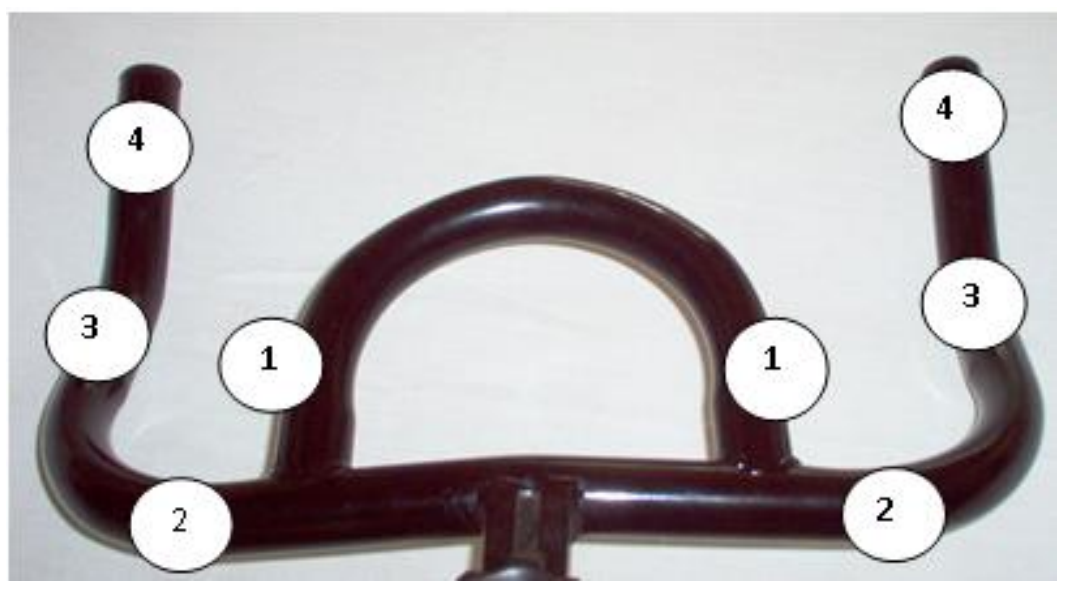


Las posiciones 1,2, 3 y 4 se pueden usar mientras se está sentado sobre la silla de la bicicleta.

Cuando se esta de pie sobre los pedales se usan los apoyos 3 y 4.

Nota: Si se pedalea parado en los pedales usando los apoyos 1 y 2 (donde la posición de las muñecas es paralela al tronco), no hay un control del peso a nivel axial (radial si lo hay) y se provoca una sobrecarga en la articulación del hombro y fundamentalmente en la articulación de las rodillas, que no tienen cómo hacer trabajo axial; diferente es cuando, en las posiciones 3 y 4 (donde la posición de las muñecas es perpendicular al tronco), se favorece la estabilidad axial.

\subsection{INDUMENTARIA PARA LA PRÁCTICA}

Aparte de la excelente condición de la bicicleta y de la adecuada postura, además del acondicionamiento de la bicicleta al usuario, es muy importante que éste cuente con una indumentaria que permita el adecuado desarrollo de la actividad física.

Para la práctica del "E.S.B.E." se recomienda:

- Calzado de suelas no muy blandas, para facilitar los movimientos y evitar tensiones en el arco plantar. Las suelas blandas y delgadas en extremo hacen los movimientos más difíciles; además, en posición de parados sobre los pedales la suela puede doblarse y producir aislamiento a nivel nervioso en los pies. Lo ideal sería el uso de zapatillas de ciclismo.

- Pantalones cortos, apropiados para la actividad física, ceñidos al cuerpo y preferentemente con protector "badana" para la silla. Se debe evitar el uso de pantalones anchos que pueden causar problemas y enredarse en los sistemas no móviles de la bicicleta, lo que puede generar accidentes.

- Remeras cómodas, no muy anchas, preferentemente en tela no muy gruesa para q no retengan mucha transpiración.

- Toallas de uso personal: por lo general, el "E.S.B.E." se realiza en lugares en donde no hay tanta evaporación del sudor, por lo que se debe mantener una toalla de uso personal para el secado permanente de la transpiración del usuario.

- Guantes: para algunas personas el uso de guantes puede favorecer la comodidad durante la práctica, al evitar la presión fuerte sobre la palma de la mano y ayudar a la sujeción del manubrio.

- Termo hidratante: como en todo tipo de actividad física, la hidratación debe ser periódica, permanente y adecuada. 


\subsection{TRABAJOS DEL TREN SUPERIOR SOBRE LA BICICLETA}

La mayoría de los instructores insisten en que sobre las bicicletas estáticas sólo se debe trabajar el tren inferior; otros, sin embargo, comparten el hecho y la posibilidad de trabajar el tren superior.

Con respecto al tren superior se pueden realizar trabajos que impliquen la musculatura de la cintura escapular, de la zona media y de los miembros superiores

\subsubsection{Cintura escapular}

En los cambios de posición y estabilidad corporal sobre la bicicleta estática, podemos dar campo al trabajo de músculos del empate de las extremidades del tren superior con el tronco.

Cuando se está parado en pedales, la calidad y efectividad del pedaleo depende de lo que los músculos de este sector puedan ofrecer.

Los trabajos isométricos a realizar dependen casi en su totalidad del tren superior, que les da eficiencia y velocidad de acción.

Por lo anterior, podemos mencionar el trabajo muscular de la cintura escapular como espacio de acción física.

\subsubsection{Músculo lumbosacro o zona media corporal}

Este músculo se trabaja de forma continua por tensión isométrica, y más cuando se usa el manubrio un poco más bajo que el sillín. Este trabajo mejora el tono muscular, pero no aumenta el volumen.

Durante el ejercicio, cuando no se cambia de posición de las manos sobre el manubrio, los músculos lumbares permanecen en continua y controlada tensión isométrica; al momento de cambiar de posición y al pararse en pedales aumenta su trabajo. Cuando se cambia a una posición en donde se da la flexión del tronco, se da un trabajo excéntrico de estos músculos; cuando la angulación de los brazos respecto a la columna es mermada, cambiando el apoyo manual sobre el manubrio, es decir pasando del apoyo cuatro al tres, dos o uno, los músculos lumbares trabajan concéntricamente

Si estos cambios de posición se hacen con las manos a la vez y lo más lento posible, los lumbares aumentan su exigencia. 


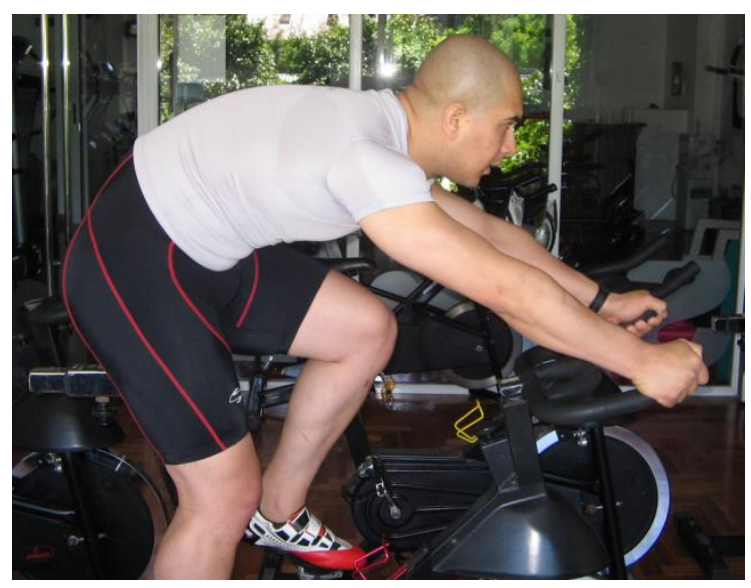

Ilustración 14

\subsubsection{Dorsales}

De igual forma que los lumbares, los dorsales trabajan de forma continua por tensión isométrica, y también su intensidad depende del contraste de altura entre sillín y manubrio; al momento de cambiar de posición y pararse en pedales la intensidad del trabajo aumentará o disminuirá.

Estos músculos también están comprometidos cuando se realiza el trabajo de espalda como los de dorsal ancho y deltoides, dando postura y correcta técnica a los trabajos recién mencionados.

Estos músculos, dorsales y lumbares, cuando se regresa de la posición 4 a la 1, dan estabilidad corporal; igual ocurre al pararse en pedales, notándose más al hacer trabajos de fuerza y/o potencia.

\subsubsection{Dorsal Ancho}

Los músculos dorsales anchos trabajan de forma agonista a los músculos dorsales. El continuo cambio de posición, al pararse y sentarse de forma continua, hace que se aumente el trabajo para los hemisferios derecho e izquierdo.

Trabajamos de forma directa esta zona manejando una extensión del húmero, en un movimiento que puede realizarse en cualquiera de las posiciones (tratando que no sea la posición dos) sobre el manubrio, intentando por lo general que se forme un ángulo entre el húmero y las costillas de 90 grados desde su posición anatómica.

Además, como se muestra en la ilustración, puede hacerse con los brazos rectos, tratando de dar más apertura a los brazos sin dejar de sujetar el manubrio. 


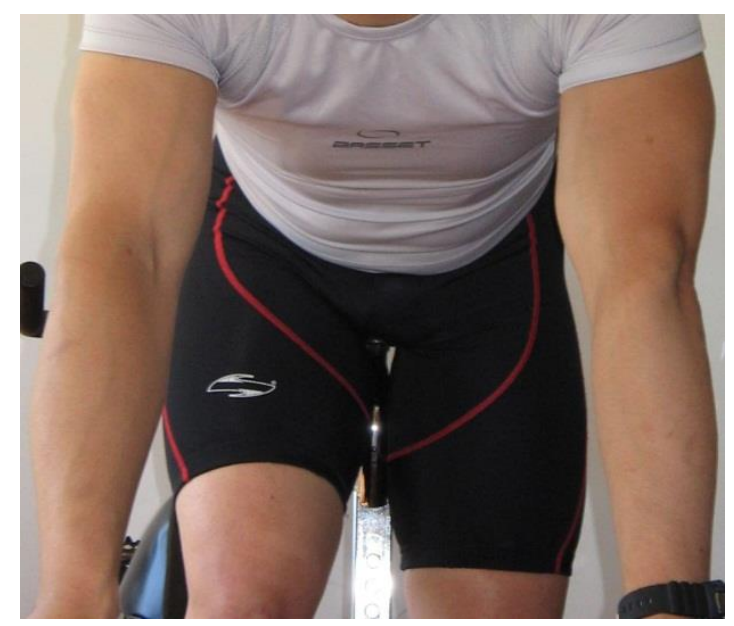

Ilustración 15: Trabajo del dorsal ancho

\subsubsection{Pecho}

Se realiza el trabajo cuando los brazos toman una postura similar a la del trabajo del dorsal ancho.

Al igual que en el caso anteriormente mencionado, se trata de una tensión isométrica, siendo un trabajo netamente concéntrico, dado por la flexión del húmero con respecto al tronco. Entre mayor sea la inclinación del tronco el trabajo del bíceps será menor, así que debe buscarse que la flexión de los brazos sea mínima, no olvidando tener como prioridad el trabajo de los músculos pectorales. 


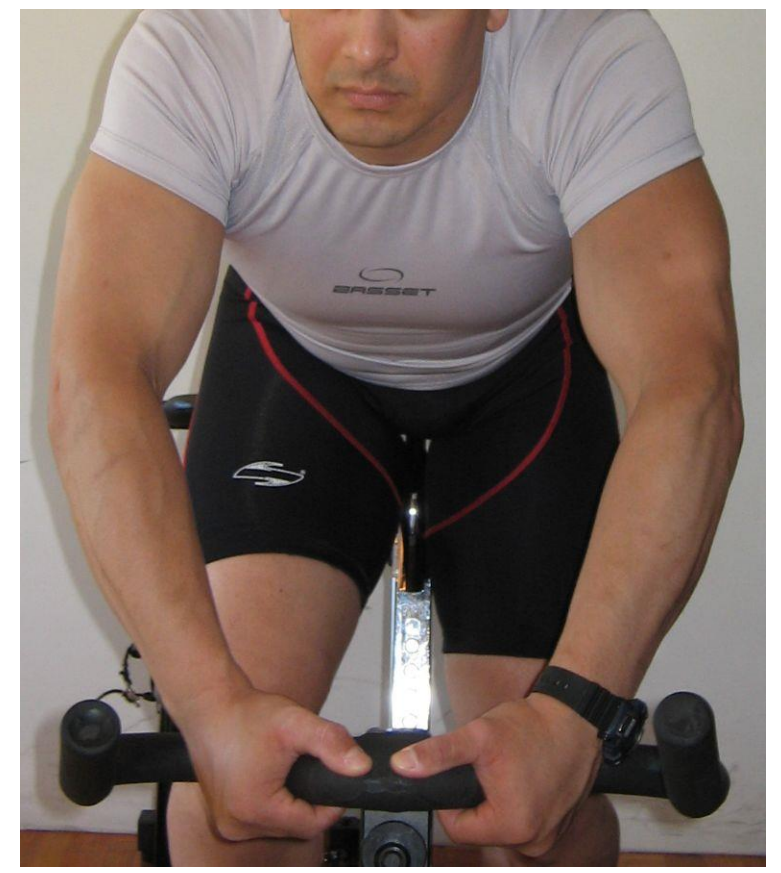

Ilustración 16: Trabajo de pecho

\subsubsection{Deltoides}

El trabajo de este músculo está dado por la abducción de brazos. Se puede hacer en cualquiera de las posiciones y posturas sobre el manubrio. Los brazos, preferiblemente, estarán rectos con el trabajo del tríceps, sin flexionar.

Trabajo también tomado como isométrico para este músculo.

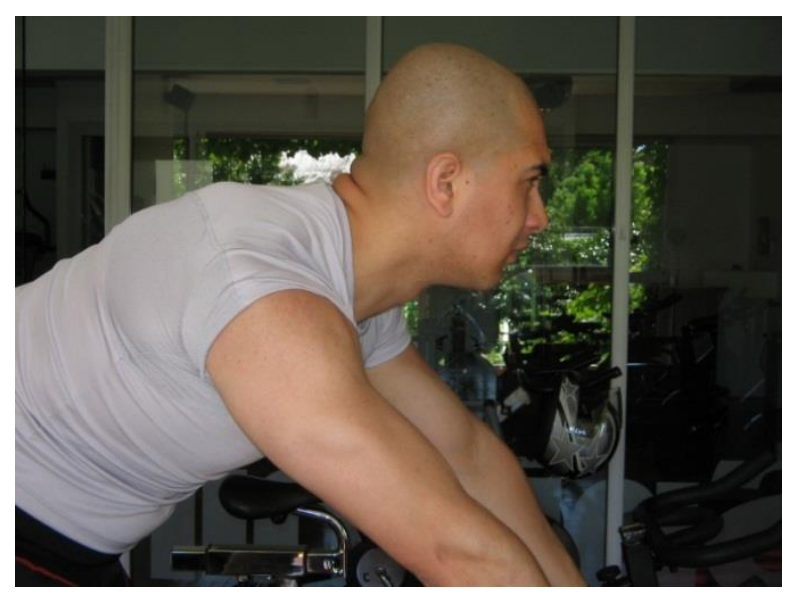

Ilustración 17: Trabajo del deltoides 


\subsubsection{Tríceps}

Este trabajo es dado por la extensión de los brazos y la tensión isométrica de los mismos cuando estos ya han sido flexionados (por acción de la gravedad); también se trabajan cuando buscamos tener los brazos rectos en el trabajo del deltoides.

Se realiza estando sentado o de pie sobre los pedales; puede también realizarse en cualquiera de las posiciones. También se trabaja, aunque en menor proporción, cuando se da la orden de mantener los brazos totalmente rectos y rígidos estando sobre la bicicleta. Cuando se esta de pie debe existir un adelanto de los hombros respecto del punto de apoyo (manos); si esto no se cumple, el trabajo será lumbar.

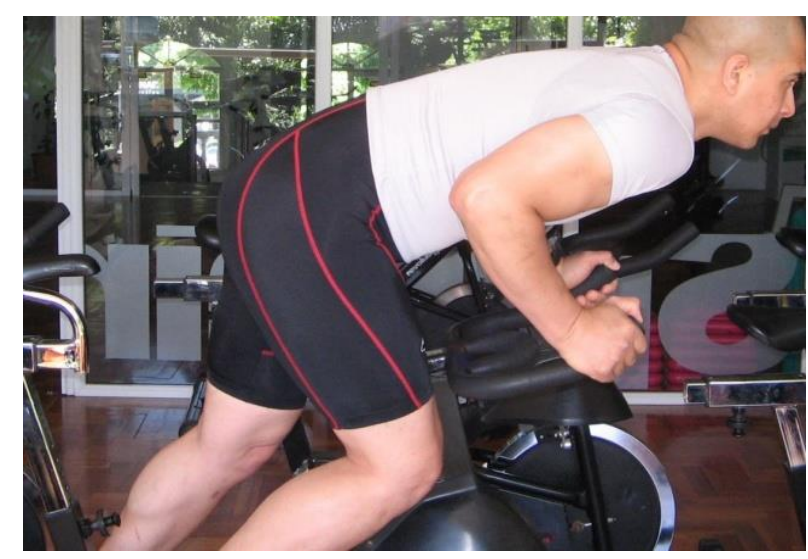

llustración 18: Trabajo del tríceps

\subsubsection{Bíceps}

Este músculo, como sabemos, trabaja en la flexión del brazo, o, retomando el concepto de la isometría, si se mantiene flexionado; además, está involucrado en el trabajo de los pectorales, haciendo que se mantengan los brazos en semi extensión y dándole así un trabajo de tensión isométrica al bíceps. También se trabaja, en menor proporción, de forma similar al tríceps cuando se da la orden de mantener los brazos totalmente rectos y rígidos estando sobre la bicicleta.

En la siguiente imagen los bíceps trabajan no permitiendo la extensión del tronco y realizando un tipo de enfrentamiento entre la zona lumbar y el bíceps. 


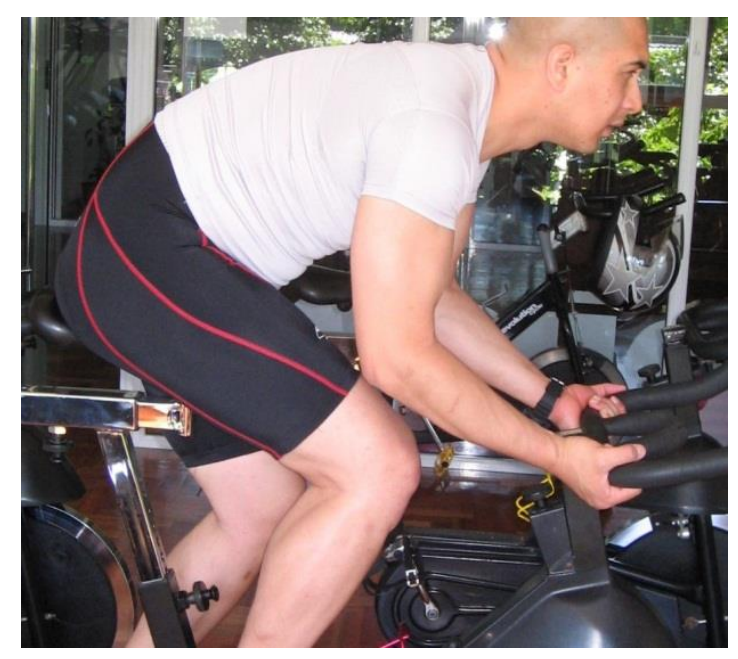

llustración 19: Trabajo de bíceps

\subsubsection{Antebrazo anterior y posterior}

Zona muscular involucrada en la flexión y extensión de mano y dedos.

El trabajo se acrecienta cuando aumentamos la presión que los dedos hacen alrededor del manubrio (cerrando más fuerte la mano). También se trabaja, de forma similar (indirecta) el tríceps y el bíceps cuando se da la orden de mantener los brazos totalmente rectos y rígidos estando sobre la bicicleta, teniendo más trabajo la zona braquial anterior que el bíceps y el tríceps.

Esto puede hacerse sentado sobre la silla de las bicicletas estáticas y también parado en pedales; en esta última situación el trabajo es aún mayor.

Mientras más alta sea la carga con la que estén trabajando las piernas, la exigencia para los brazos en este tipo de ejercicio será mayor.

\subsubsection{Abdominales}

Este trabajo, como la mayoría de los trabajos que se hacen sobre la bicicleta del tren superior, puede ser tomado como isométrico y además como concéntrico.

Es un trabajo de retroversión de cadera que se hace estando sentado y apoyado sobre la silla de la bicicleta estática. Normalmente tiene, antes de la contracción abdominal, una anteversión de cadera, y así da cabida a un mayor trabajo abdominal de forma concéntrica. Si no se da el desplazamiento de cadera sobre el punto de apoyo, también puede hacerse una contracción isométrica, tanto sentado como de pie. Un punto a tener en cuenta es que, si la tensión abdominal es permanente o muy extensa, seguramente dará lugar a la negación a la expansión interna de pulmones por acciones de la respiración dentro de la caja torácica. 


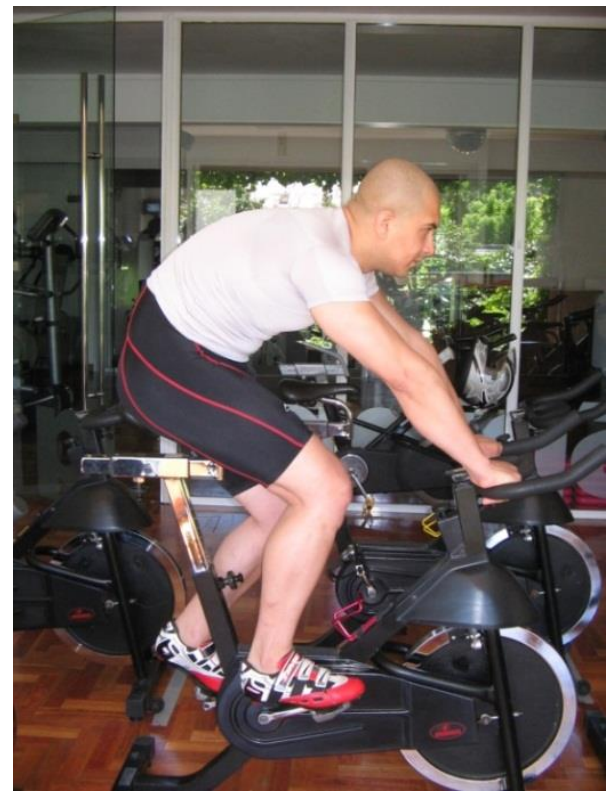

Ilustración 20: Trabajo de abdomen

\subsubsection{Oblicuos del abdomen}

Los oblicuos se trabajan más cuando estamos pedaleando de pie sobre los pedales, aumentando la exigencia cuando estamos realizando el trabajo de potencia y fuerza manteniendo los brazos en tensión.

Si bien el esfuerzo de estos músculos no es realmente significativo en estos casos, no está de más mencionar estos trabajos isométricos que aumentan cuando la orden del ejercicio es aumentar el balanceo del cuerpo lo que más se pueda, con los brazos flexionados o rectos.

Estas tensiones son graduadas siempre por el practicante.

Este accionar también puede hacerse sentado, buscando una flexión lateral del tronco; su exigencia aumenta cuando los brazos no lo permiten, estando estos últimos en tensión isométrica.

Como opción de trabajo se puede trabajar una zona oblicua a la vez y el soporte solo de uno de los brazos. 


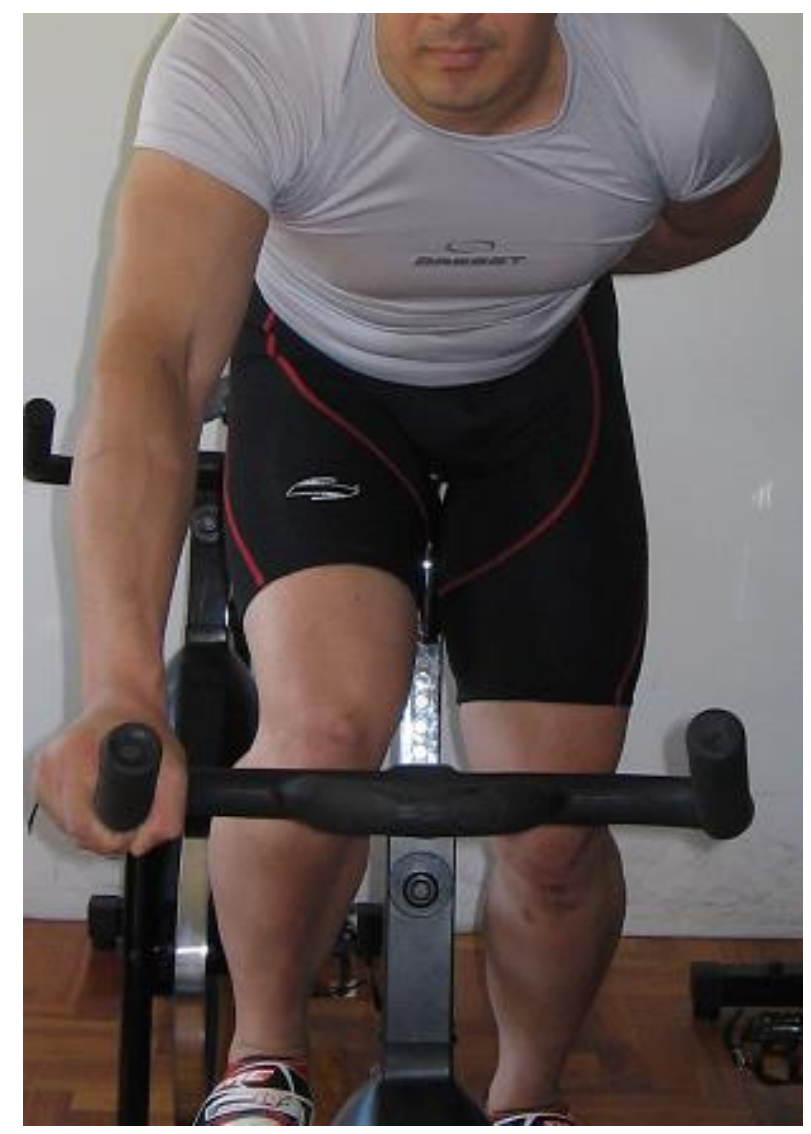

Ilustración 21: Trabajo de los oblicuos

\subsubsection{Psoas ilíaco}

El trabajo para estos músculos normalmente no es tan pesado como cuando trabajamos de la siguiente forma:

Se trabajará sin tomar el manubrio, manteniendo el tronco perpendicularmente respecto a la horizontal (suelo), y permaneciendo sentado.

Se dará una especie de complemento antagónico para mantenerse sobre la silla, más cuando se realicen trabajos de potencia y fuerza, haciendo que el trabajo del psoas aumente y nos mantenga en la correcta posición; si esto no ocurre, la técnica del pedaleo se pierde, haciendo que el practicante de la acción sobre la bicicleta estática se mueva horizontalmente de un lado para otro a manera de péndulo. Para evitar esto, mientras una pierna demuestra extensión de cadera la otra deberá hacer el ejercicio contrario simultáneamente, es decir, flexionar cadera. La calidad de esta acción hará que el movimiento de la cadera mientras se está sentado sea mínimo sobre la silla. Como opción de trabajo podría aplicarse el cambio de dirección del pedaleo, buscando ser invertida, y cambiar el acto de empujar de las piernas de forma alterna por el de elevar. 


\subsection{CADENCIAS}

Las cadencias de pedaleo pueden ser clasificadas de innumerables formas, partiendo, claro, de la cantidad de las revoluciones por minuto (R.P.M.).

Así, podríamos clasificar las cadencias de pedaleo de 7 diferentes formas, 7 ritmos o cadencias de pedaleo, sin apartarnos nunca y tampoco olvidando que la cadencia de pedaleo debe estar dada siempre por la música.
- Muy Lento
30 a $40 \mathrm{rpm}$
- Lento
40 a $50 \mathrm{rpm}$
- Medio - bajo
50 a $70 \mathrm{rpm}$
- Medio
60 a $80 \mathrm{rpm}$
- Medio - Rápido
80 a $100 \mathrm{rpm}$
- Rápido
100 a $120 \mathrm{rpm}$
- Muy Rápido
120 a $150 \mathrm{rpm}$

Para comodidad del instructor, del practicante y del trabajo mismo sobre la bicicleta estática, descartamos la primera y última de estas clasificaciones, "muy lento" y "muy rápido", quedando al final con 5 velocidades de trabajo: la razón es que para velocidad de "muy rápido" se debe ya tener muy buena experiencia y condición física, y para la de "muy lento" deben manejarse cargas altísimas de exigencia, que, si bien se deben llegar a trabajar, requieren, al igual que la velocidad anterior, de una muy buena condición física.

\subsection{RESISTENCIAS DE TRABAJO EN “E.S.B.E.”}

Se propone trabajar a 5 diferentes resistencias que se incrementan de uno en uno, siendo la 1 la más liviana y la 5 la más pesada.

Las resistencias deben ser sugeridas por el instructor, pero son realmente impuestas por el mismo practicante-usuario, quien conoce su fuerza partiendo de una percepción de esfuerzo básica.

La resistencia cero solo debe ser usada para trabajos de velocidad o alta velocidad, además de recuperación (siempre sentados).

Para tener una idea de qué resistencias y a qué velocidad se puede trabajar, se describe a continuación que carga usar cuando se lleva cierta cadencia de pedaleo.

La carga de entrenamiento es el producto de la resistencia a vencer por la cadencia de pedaleo. Además debe ser considerado el tiempo de aplicación de esa carga para considerar su impacto metabólico. 


$\begin{array}{cll}\text { Carga } & \text { Resistencia } & \text { Cadencia } \\ 0 & \text { Sin carga } & \text { Para cadencias de pedaleo de más de } 120 \mathrm{rpm} \\ 1 & \text { Mínima } & \text { Para cadencias de pedaleo entre } 100 \text { y } 120 \mathrm{rpm} \\ 2 & \text { Media baja } & \text { Para cadencias de pedaleo entre } 80 \text { y } 100 \mathrm{rpm} \\ 3 & \text { Media } & \text { Para cadencias de pedaleo entre } 60 \text { y } 80 \\ 4 & \text { Media alta } & \text { Para cadencias de pedaleo entre } 50 \text { y } 70 \mathrm{rpm} \\ 5 & \text { Alta } & \text { Para cadencias de pedaleo entre } 40 \text { y } 50 \mathrm{rpm}\end{array}$

La tabla anterior es para facilitar su comprensión, pero también se darán casos en donde, por ejemplo, se pedalee entre 60 y $80 \mathrm{rpm}$ y la carga sea alta, como cuando se trabaja potencia.

Los intervalos de potencia desarman un poco la tabla anterior, ya que, para hacer potencia, mientras se pedalea a 100 y $120 \mathrm{rpm}$ la carga puede ser media baja por algunos segundos (no más de 5).

Cuando se trabaja de 80 a $100 \mathrm{rpm}$ las cargas pueden ser media alta y alta, siendo posible hacer el intervalo un poco más extenso, de 10 y hasta 15 segundos (eso se da de acuerdo a la condición física de los practicantes). Estos son solo ejemplos que se pueden llevar a la práctica.

\subsection{MÚSICA}

Algo que parece no tener mucha trascendencia es la música pero, realmente, es fundamental seleccionarla teniendo en cuenta el idioma, el ritmo, el volumen y el género (electrónica, alternativa, rock en ingles y español, new age, clásicos, merengue, salsa etc.); ésta es determinante a la hora de la actividad, constituyéndose en el mecanismo del instructor para manejar la actividad.

La música juega un papel muy importante en la clase, ya que es parte esencial en la motivación que se complementa con el trabajo verbal y gestual que realice el instructor durante la actividad.

La música debe ser escogida de tal manera que ayude a establecer una cadencia de pedaleo para todos los que participen en la clase; además, se deben utilizar canciones que motiven y eleven el ánimo y el deseo de trabajar físicamente.

Las canciones deben ser escogidas cuidadosamente, de acuerdo a la estructura de la clase; deben mostrar la "ruta", el ritmo o cadencia para trabajos netamente aeróbicos, trabajos de velocidad, fuerza y potencia, además debe ser agradable, debe motivar a realizar trabajos específicos que involucren mente y cuerpo.

La música de una clase debe ser continua, sin dejar nunca de sonar y sin cambios bruscos de ritmo, y debe ajustarse al trabajo y el objetivo de la clase.

\subsection{RECOMENDACIONES PARA UN INSTRUCTOR EN UNA CLASE DEL "E.S.B.E."}

La práctica de esta actividad física sobre la bicicleta estática presenta, en algunas personas que aún no la han experimentado, un tipo de creencia que no es correcta: de 
hecho, las lesiones articulares o musculares pueden presentarse en toda actividad, debido a su sobrecarga o su mala ejecución. La formación académica y práctica por parte del instructor hará que se presenten rápidos resultados que propicien la aprobación tanto para el instruido como para el instructor.

Algunas personas conocen y aceptan el hecho de la genética y aprueban su imagen corporal, los instruidos deben tener claro que la salud corporal y calidad de acción física es mucho más importante que la imagen y belleza corporal. Una actividad física dirigida debe desarrollar un trabajo sobre el practicante y cubrir la mayor cantidad de campos de acción posibles que incumben a la educación física.

Antes de dar inicio a la actividad se debe revisar la postura que tienen los usuarios (altura y retroceso del sillín, también el manubrio) y recordar la importancia de tener las correas que dan ajuste al calzado.

Posteriormente se debe exponer el tipo de trabajo que se realizará y qué objetivo tiene, y se puede dar a conocer el tipo de música que se va a usar.

Se debe realizar una "activación articular" de entre 3 y 5 minutos, que consiste en rotaciones en una dirección y otra de las articulaciones del cuello, hombros, muñecas, cadera y tobillos, en la extensión y flexión de las articulaciones de rodillas y codos, y simultáneamente dar inicio al calentamiento, con bajas restricciones, a velocidades medias, medias-altas.

Recordar la importancia de la hidratación antes, durante y después de la actividad, así como el uso de la toalla personal.

Durante la clase, el profesor observará individualmente los diferentes indicadores de esfuerzo (coloración de la piel, comportamiento de la frecuencia respiratoria, sensaciones y percepciones individuales, etc.) y las manifestaciones de cansancio, con el fin de integrarlos al desarrollo natural de la clase y a sus objetivos. El ejercicio debe ser placentero y eficaz.

Durante la clase y luego de ésta se formularán preguntas tales como:

¿Cómo se sintieron?

¿La música fue de su agrado?

¿El tipo y el volumen de la música que se usó fueron adecuados?

¿Cómo se sintieron la duración del trabajo o de los intervalos?

¿La atención del instructor es adecuada?

¿Se presentaron molestias? 


\subsection{TRABAJOS CÍCLICOS BASE SOBRE LA BICICLETA ESTÁTICA}

El entrenamiento ESBE presenta cuatro direcciones:

\subsubsection{Fondo (Resistencia Aeróbica)}

Denominamos fondo al trabajo base de todo ejercicio, y es el trabajo netamente aeróbico.

En nuestras exigencias, la resistencia se encuentra exactamente en medio de las opciones de trabajo; es tomada por los practicantes del "E.S.B.E." como "carga 3", la cual nos permite pedalear entre 60 y 80 revoluciones por minuto (R.P.M.).

Ver la tabla del punto 6.12 facilitaría la combinación del concepto aquí expuesto (página 74 del presente trabajo escrito).

Las resistencias, antes sugeridas por el instructor (en este caso la carga 3) serán impuestas siempre por el usuario-practicante, quien pondrá sus cargas partiendo sí o sí de su percepción individual.

Las resistencias podrán tener un poco de variación, siendo mínimamente más pesadas a revoluciones más bajas y más livianas a revoluciones más altas.

Con esto, se supone, se trabajará dentro del campo aeróbico, es decir, a intensidades cardíacas de entre el 60 y $80 \%$ de la capacidad máxima.

Este trabajo puede hacerse sentado o de pie sobre los pedales, no dando problema alguno al practicante. Además pueden usarse las 4 posiciones sugeridas sobre el manubrio.

\subsubsection{Fuerza}

Trabajo de resistencia medias-alta y alta, con cadencias de pedaleo menores a 60 R.P.M.

Se busca trabajar a intensidades cardiacas del 80 al $95 \%$.

Para nuestro trabajo son las cargas tomadas como "cargas 4 y 5 ", cargas siempre dadas por la percepción del practicante.

Como en el caso anterior, esto se puede hacer sentado o de pie sobre los pedales sin causar problemas a quien lo realiza, y también usando las 4 posiciones que ofrece el manubrio.

\subsubsection{Velocidad}

Acción que se realiza sin resistencia alguna, con cadencias de pedaleo que pueden ir desde las 100 R.P.M. en adelante para ser tomadas como trabajo de velocidad. 
Los practicantes podrían eventualmente pararse en pedales (nunca en la posición uno o dos) con intervalos muy cortos, dependiendo esto de la destreza y agilidad de los usuarios.

En este trabajo, ni las pulsaciones ni la percepción son tomadas como niveladores de la intensidad el trabajo. Estando sentado puede pedalearse rápido en cualquiera de las posiciones.

\subsubsection{Potencia}

Acción dada entre las cadencias de pedaleo y resistencias de todo tipo, dependiendo de la velocidad y la carga con la que se pedalea. Se da por intervalos en nuestro caso no muy extensos, y puede darse mientras se trabaja en el área del fondo o la velocidad cuando nos referimos a aumentar la carga.

Cuando se trata de realizar trabajos de potencia y no hacer cambios de carga, entonces aumentamos la cadencia de pedaleo, pasando desde la cadencia baja y carga alta a velocidades medias, medias altas y altas.

Continuando con los trabajos de potencia podemos pasar desde la carga media, a la carga media alta y alta junto a velocidades medias, medias altas y altas.

Podemos también estar dentro del trabajo de fuerza y realizar un aumento en la cadencia de pedaleo.

Este entrenamiento puede realizarse por personas que llevan no menos de 3 semanas de acondicionamiento sobre la bicicleta, antes trabajando dentro del área del fondo y la fuerza.

Los trabajos se hacen cuando se dan aumentos súbitos de carga hasta donde sea posible, impidiendo sin embargo que la cadencia marcada por la música se pierda. Para que los trabajos de potencia queden un poco más claros usamos la siguiente tabla: 


\begin{tabular}{|c|c|}
\hline Resistencia & $\underline{\text { Velocidad }}$ \\
\hline Mínima & media alta y alta \\
\hline Media Baja & media, media alta \\
\hline Media & media alta, alta \\
\hline Media Alta & media, media baja \\
\hline Alta & media baja \\
\hline
\end{tabular}




\section{MICROCICLO DE TRABAJO EN EL "E.S.B.E." (EJEMPLO DE UN CICLO DE TRABAJO PARA EL "E.S.B.E.", BASADO EN CUATRO MICROCICLOS)}

\subsection{FONDO}

Trabajo básico, es lo que un practicante en primera instancia llegaría a realizar. Cadencias de pedaleo y resistencia según se han descrito anteriormente.

La intensidad de este trabajo podrá ser variada con el trabajo del tren superior, además de los cambios de postura y el estar sentado o de pie pedaleando sobre los pedales; entre más continuos sean los cambios, la intensidad del entrenamiento aumentará.

Esta actividad siempre será la primera en los microciclos, compuestos de catorce unidades que podrán tener variaciones según la temperatura, humedad y estación climática (invierno, primavera, verano u otoño).

Son catorce, ya que de la combinación de las bases del trabajo físico (resistencia, fuerza, velocidad y potencia) resultan catorce diferentes formas de dirección a la actividad.

Se puede tomar la siguiente propuesta para 4 microciclos de trabajo, donde se muestra el porcentaje del tiempo de la clase:

\begin{tabular}{|l|c|l|l|l|}
\hline & Fondo & Fuerza & Velocidad & Potencia \\
\hline Microciclo 1 & 100 & & & \\
\hline Microciclo 2 & 100 & & & \\
\hline Microciclo 3 & 100 & & & \\
\hline Microciclo 4 & 100 & & & \\
\hline
\end{tabular}




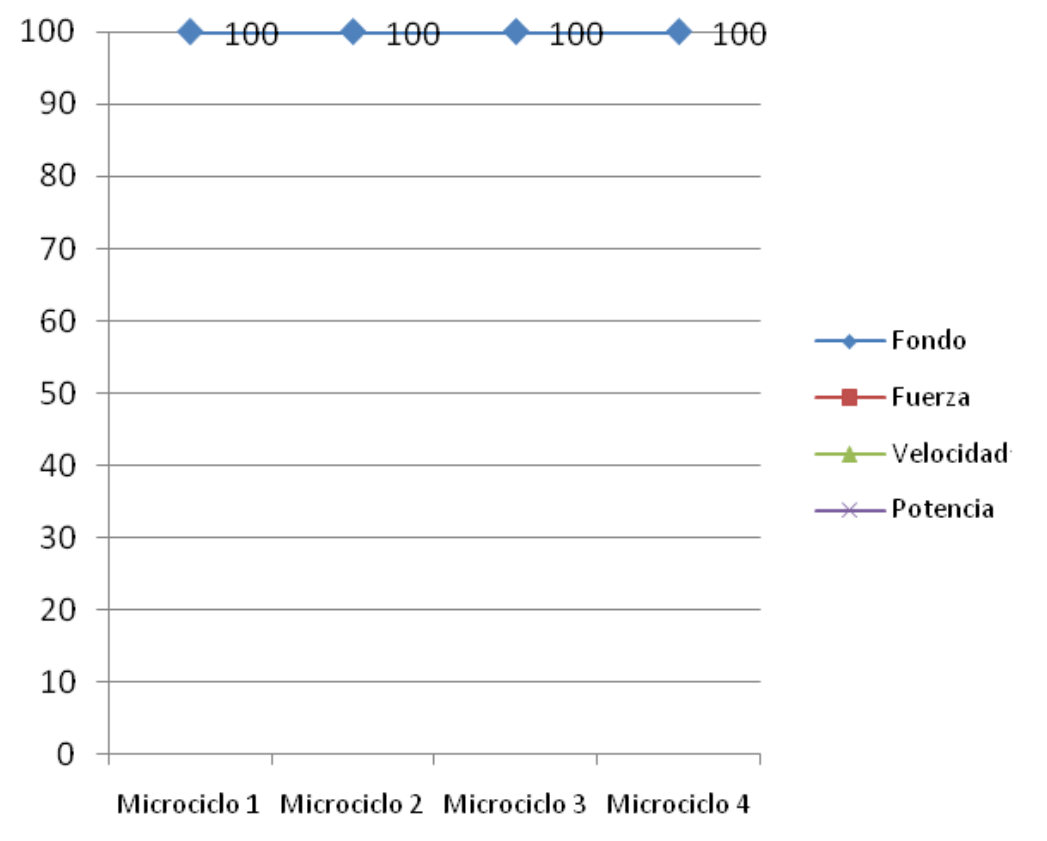

La anterior tabla muestra el trabajo en cada micro ciclo en su totalidad como trabajo de fondo

\subsection{FONDO Y FUERZA}

La relación y mezcla entre la resistencia y la Fuerza es de vital importancia en toda actividad física.

Se puede optar por empezar el trabajo con proporción de un $90-10 \%$, o un $80-20 \%$, según sea el caso, dejando en claro que el mayor porcentaje es trabajo de fondo.

Se trabajará hasta un 50-50\%, es decir, un 50\% de fondo y un 50\% de fuerza (porcentajes respecto al tiempo de la actividad).

Se puede tomar la siguiente propuesta para 4 microciclos de trabajo, donde se muestra el porcentaje del tiempo de la clase:

\begin{tabular}{|l|c|c|l|l|}
\hline & Fondo & Fuerza & Velocidad & Potencia \\
\hline Microciclo 1 & 80 & 20 & & \\
\hline Microciclo 2 & 70 & 30 & & \\
\hline Microciclo 3 & 60 & 40 & & \\
\hline Microciclo 4 & 50 & 50 & & \\
\hline
\end{tabular}




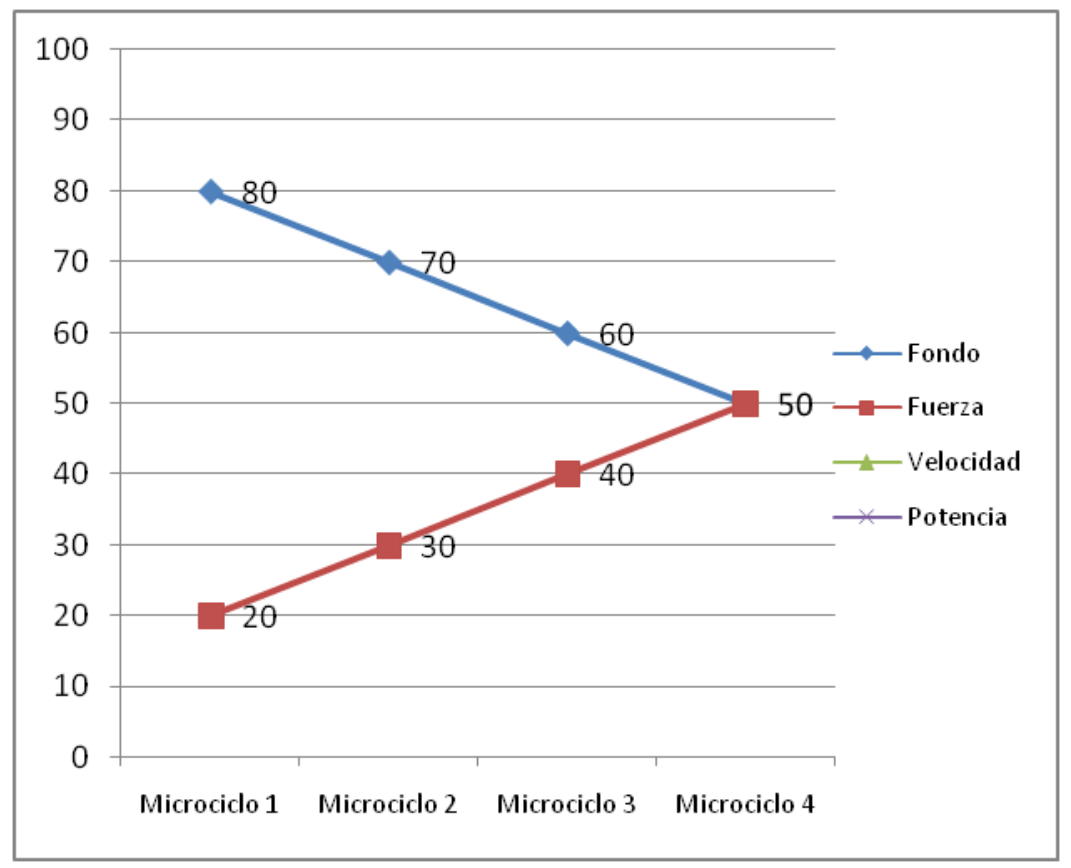

\subsection{VELOCIDAD Y POTENCIA}

Trabajo de cadencias de pedaleo siempre medias altas y altas, de más de cien revoluciones por minuto. De acuerdo a la habilidad de los usuarios se darán paradas en pedales no muy extensas, pero la mayoría del trabajo se hará siempre sentado.

Los intervalos de potencia se realizarán a las mismas revoluciones, podrán hacerse en las posiciones de sentado o parado sobre los pedales; estos intervalos van desde los 5 segundos hasta los 30 y 40 segundos en personas que tengan una muy buena condición física.

Lo realmente importante es que, al momento de poner las resistencias, éstas sean tan altas como sea posible, y que nunca caiga la velocidad con la que se pedalea.

Las personas que recién empiezan tendrán que omitir este tipo de trabajo.

La sumatoria de tiempo de estos intervalos no deberá pasar el $12 \%$ de la actividad, es decir, unos 6 minutos en total.

Se puede tomar la siguiente propuesta para 4 microciclos de trabajo, donde se muestra el porcentaje del tiempo de la clase:

\begin{tabular}{|c|c|c|c|c|}
\hline & Fondo & Fuerza & Velocidad & Potencia \\
\hline Microciclo 1 & & & 98 & 2 \\
\hline Microciclo 2 & & & 97 & 3 \\
\hline Microciclo 3 & & & 95 & 5 \\
\hline Microciclo 4 & & & 90 & 10 \\
\hline
\end{tabular}




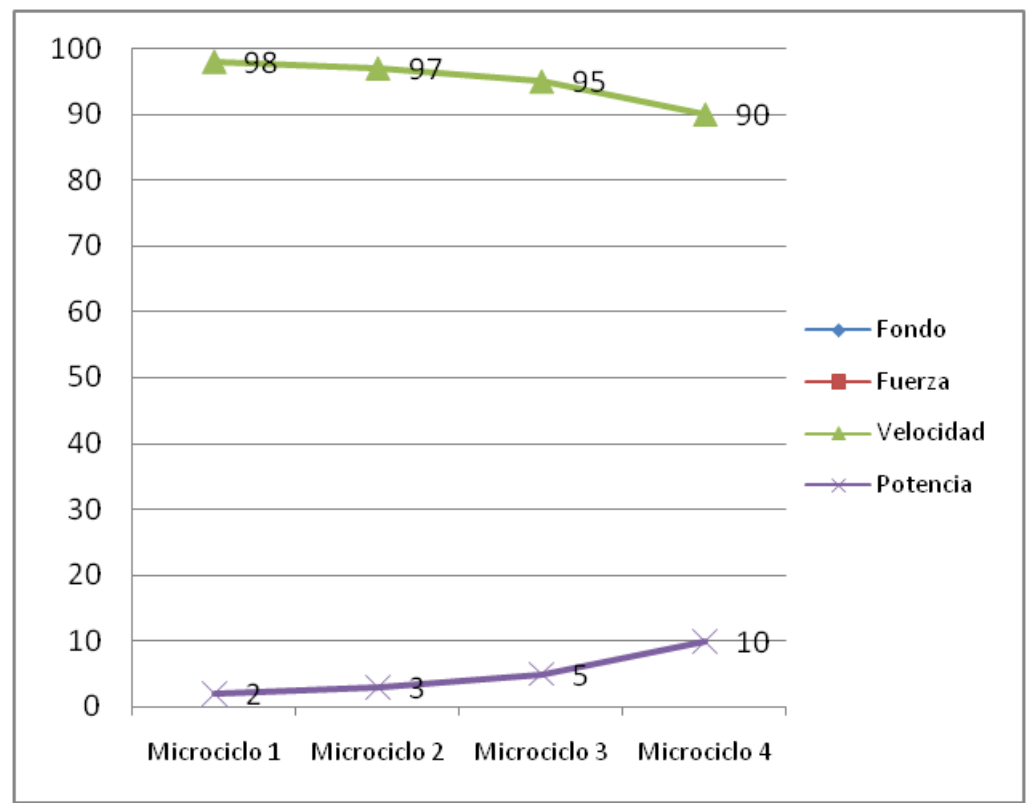

\subsection{FUERZA Y VELOCIDAD}

Relación de dos extremos totalmente diferentes, como son la fuerza y la velocidad. La fuerza trabajada a resistencias medias altas y altas (resistencia 4 y 5 ) y la velocidad trabajada con resistencias mínimas o sin resistencia (resistencia uno o sin resistencia). Las cadencias de pedaleo, tal como fueron mencionadas anteriormente.

Se recomienda trabajar hasta un $50-50 \%$; si esto es un inconveniente, sobre todo para los principiantes, se recomienda un $70-30 \%$, es decir, $70 \%$ fuerza y $30 \%$ velocidad; con la práctica y la experiencia en la actividad, el trabajo de velocidad aumentará hasta lograr el 50-50\% recomendado inicialmente (esto es solo una sugerencia)

Se puede tomar la siguiente propuesta para 4 microciclos de trabajo, donde se muestra el porcentaje del tiempo de la clase:

\begin{tabular}{|l|c|c|c|c|}
\hline & Fondo & Fuerza & Velocidad & Potencia \\
\hline Microciclo 1 & & 60 & 40 & \\
\hline Microciclo 2 & & 50 & 50 & \\
\hline Microciclo 3 & & 40 & 60 & \\
\hline Microciclo 4 & & 50 & 50 & \\
\hline
\end{tabular}




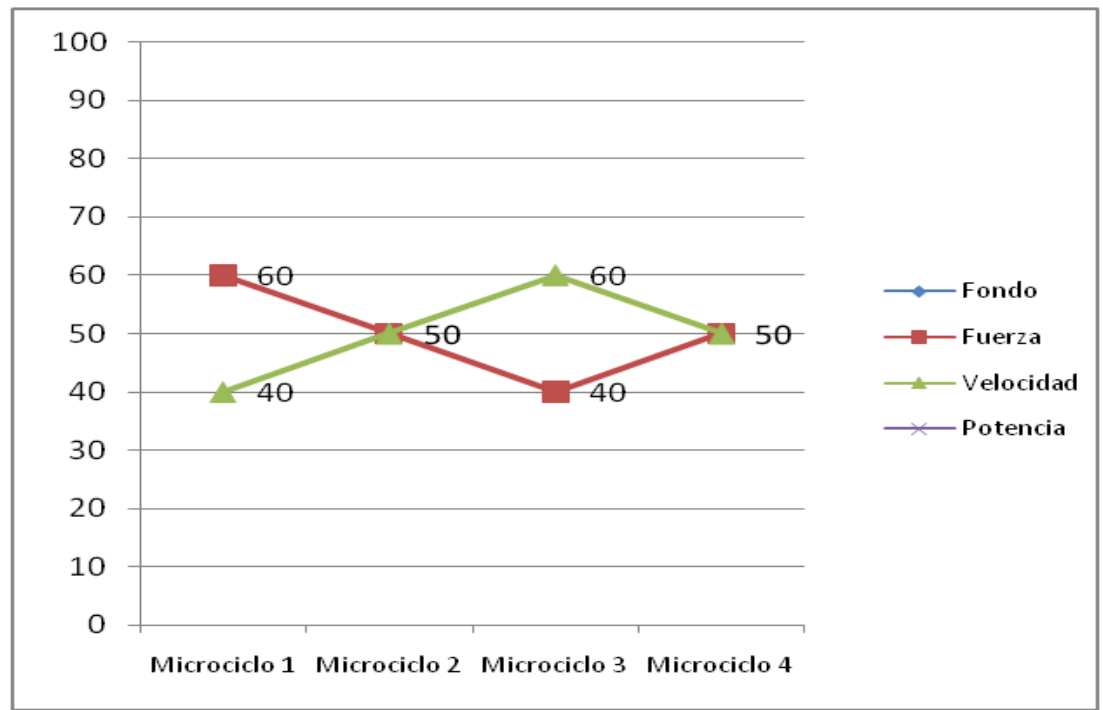

\subsection{FONDO Y POTENCIA}

Actividad desarrollada entre las 60 y 80 revoluciones por minuto.

Éste, como la mayoría de los trabajos de potencia, tendrá intervalos que no vayan más allá de los 30 o 40 segundos, no pasando nunca la sumatoria de los intervalos del 10\% del total de la actividad.

Durante este trabajo la resistencia mínima será la resistencia de percepción media; así, luego de un intervalo de potencia la resistencia bajará a la media.

En los intervalos de potencia la resistencia será aumentada tanto como sea posible sin perder nunca la cadencia de pedaleo.

Se puede tomar la siguiente propuesta para 4 microciclos de trabajo, donde se muestra el porcentaje del tiempo de la clase:

\begin{tabular}{|c|c|c|c|c|}
\hline & Fondo & Fuerza & Velocidad & Potencia \\
\hline Microciclo 1 & 96 & & & 4 \\
\hline Microciclo 2 & 93 & & & 7 \\
\hline Microciclo 3 & 90 & & & 10 \\
\hline Microciclo 4 & 85 & & & 15 \\
\hline
\end{tabular}




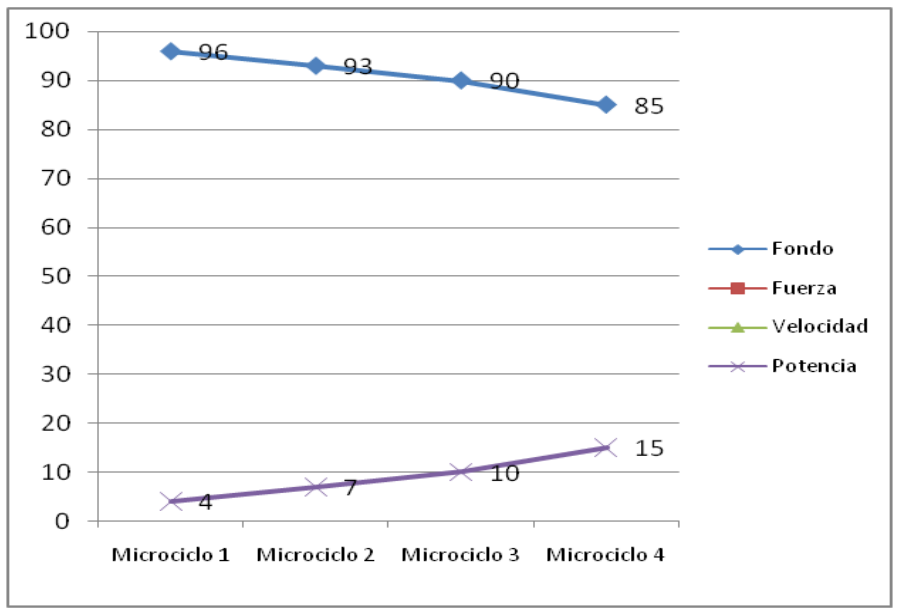

\subsection{FUERZA}

Trabajo en donde se manejan cadencias de pedaleo bajas, entre las 40 y 50 por minuto durante toda la actividad. En la mayor parte de la actividad las resistencias manejadas serán las medias altas y altas (resistencias 4 y 5), aunque eventualmente se bajará a la resistencia 3 (la resistencia media) para dar recuperación activa a quien está trabajando sobre la bicicleta.

Se puede tomar la siguiente propuesta para 4 microciclos de trabajo, donde se muestra el porcentaje del tiempo de la clase:

\begin{tabular}{|l|c|c|l|l|}
\hline & Fondo & Fuerza & Velocidad & Potencia \\
\hline Microciclo 1 & & 100 & & \\
\hline Microciclo 2 & & 100 & & \\
\hline Microciclo 3 & & 100 & & \\
\hline Microciclo 4 & & 100 & & \\
\hline
\end{tabular}

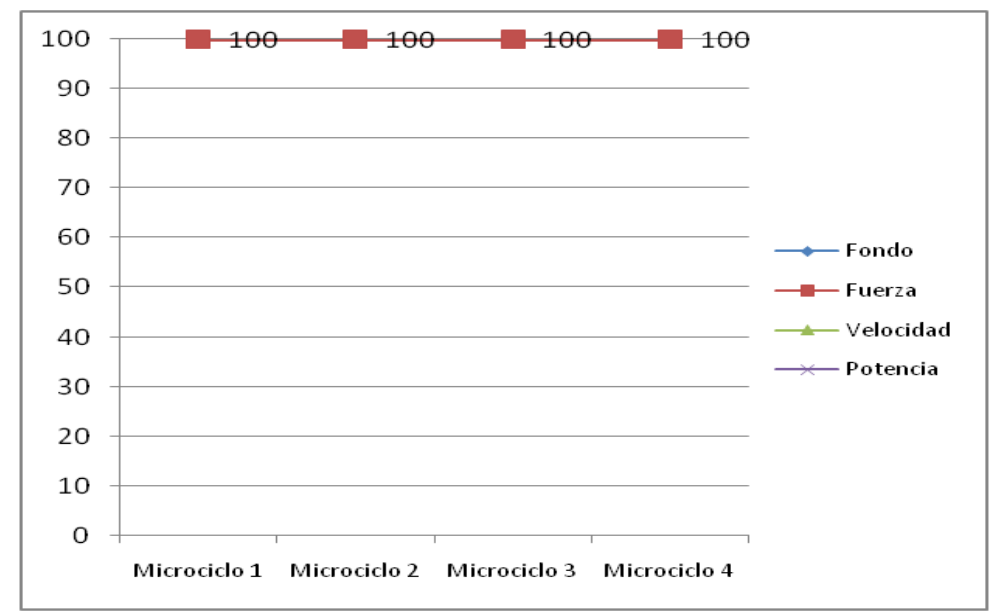

La anterior tabla muestra el trabajo en cada micro ciclo en su totalidad como trabajo de fuerza 


\subsection{FONDO, FUERZA Y VELOCIDAD}

Actividad un poco más completa con respecto a las anteriores, que requiere una mayor exigencia física.

Se trabaja con las 5 percepciones de trabajo, además de pedalear a cadencias que van desde 40 a 120 revoluciones por minuto.

Para esta acción se puede diseñar una actividad en donde se efectúen por igual (respecto al tiempo) cada uno de los campos de acción.

Se recomienda trabajar en el orden mencionado, sobre todo si se esta dentro del primer ciclo del trabajo; luego, pasado un tiempo y conociendo la forma física del practicante, se pueden dar infinitas variantes.

Este puede ser tomado como el punto medio del ciclo de trabajo, en donde es aumentada la intensidad del ejercicio.

Se puede tomar la siguiente propuesta para 4 microciclos de trabajo, donde se muestra el porcentaje del tiempo de la clase:

\begin{tabular}{|l|c|c|c|c|}
\hline & Fondo & Fuerza & Velocidad & Potencia \\
\hline Microciclo 1 & 35 & 30 & 35 & \\
\hline Microciclo 2 & 30 & 35 & 35 & \\
\hline Microciclo 3 & 35 & 35 & 30 & \\
\hline Microciclo 4 & 30 & 40 & 30 & \\
\hline
\end{tabular}




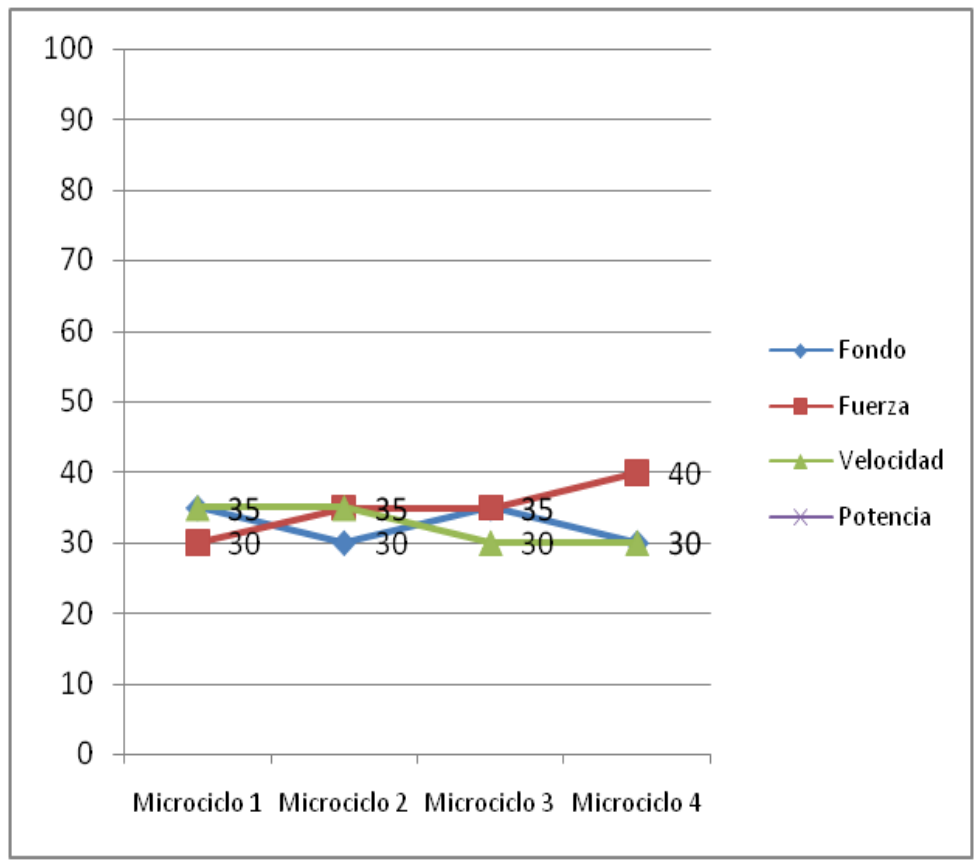

\subsection{FUERZA Y POTENCIA}

A nuestro modo de ver, y de acuerdo con la experiencia obtenida, esta actividad puede ser tomada como la más pesada y dura para realizar de las catorce propuestas.

El trabajo es en su mayoría un trabajo de fuerza, el cual maneja resistencias medias altas y altas ( 4 y 5), aunque eventualmente se bajen hasta la media (3) a manera de recuperación, dando como máximo 3 minutos de recuperación activa, o bien cortos tramos de hasta un minuto.

Junto a lo anteriormente descrito, trabajamos la potencia, manejando resistencias también medias altas y altas y aumentando la intensidad de las mismas cuando la cadencia de pedaleo es aumentada, pasando de fuerza a potencia. Un ejemplo es trabajar con resistencias altas, pedaleando a 40 revoluciones por minuto y, sin bajar la resistencia, aumentar la cadencia de pedaleo a 70 revoluciones por minuto; al final del intervalo de potencia, sin bajar la resistencia, volver a las 40 revoluciones por minuto. Los intervalos de potencia no deberán nunca superar los 40, 50 segundos como máximo.

Estos trabajos manejan por lo general altísimas frecuencias cardíacas, de no menos del $75 \%$ u $80 \%$.

Se puede tomar la siguiente propuesta para 4 microciclos de trabajo, donde se muestra el porcentaje del tiempo de la clase: 


\begin{tabular}{|c|c|c|c|c|}
\hline & Fondo & Fuerza & Velocidad & Potencia \\
\hline Microciclo 1 & & 97 & & 3 \\
\hline Microciclo 2 & & 95 & & 5 \\
\hline Microciclo 3 & & 93 & & 7 \\
\hline Microciclo 4 & & 90 & & 10 \\
\hline
\end{tabular}

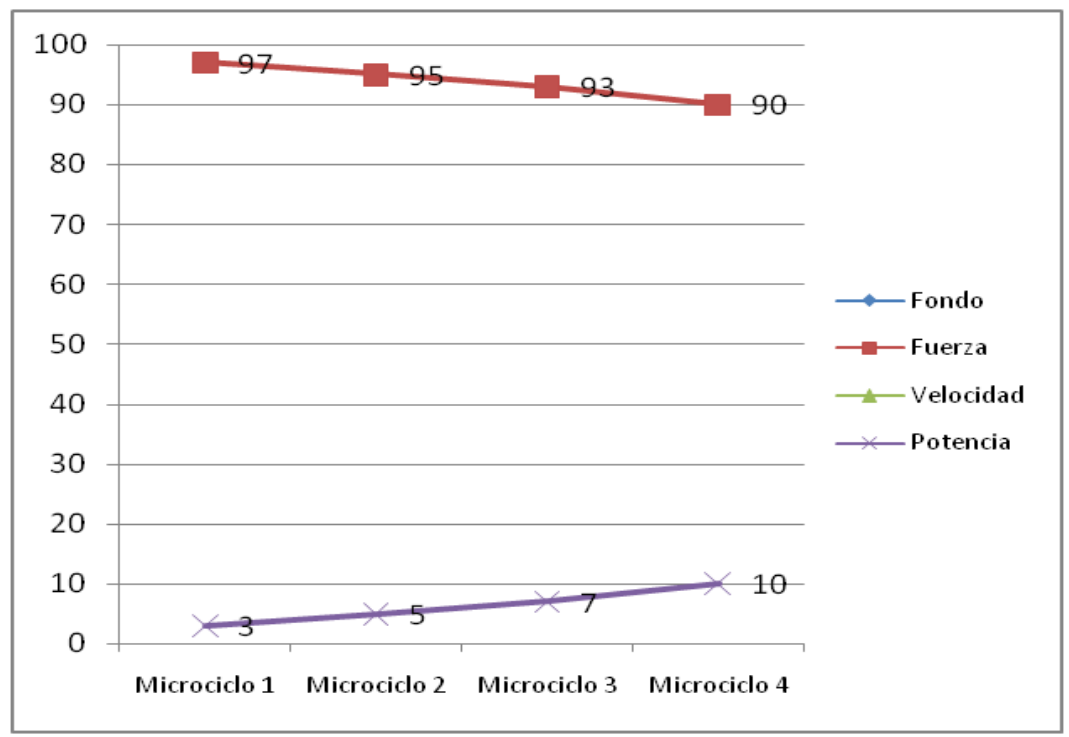

\subsection{FONDO Y VELOCIDAD}

Trabajo físico a intensidades medias (resistencia 3), excepto la parte de velocidad que se realiza sin resistencia.

Las velocidades del trabajo de fondo pueden ser consideradas entre las 60 y 80 revoluciones por minuto.

Los trabajos de velocidad se harán a más de cien revoluciones por minuto.

Como en las anteriores, se piensa en un 50-50\% de trabajo. Al inicio del trabajo, cuando recién se empieza, cuando se hace parte del primer circuito, la proporción será mayor para el trabajo de fondo; luego, gradualmente se irá aumentando el porcentaje de trabajo de velocidad hasta llegar a las proporciones inicialmente sugeridas.

Se puede tomar la siguiente propuesta para 4 microciclos de trabajo, donde se muestra el porcentaje del tiempo de la clase: 


\begin{tabular}{|l|c|c|c|c|}
\hline & Fondo & Fuerza & Velocidad & Potencia \\
\hline Microciclo 1 & 70 & & 30 & \\
\hline Microciclo 2 & 60 & & 40 & \\
\hline Microciclo 3 & 50 & & 50 & \\
\hline Microciclo 4 & 40 & & 60 & \\
\hline
\end{tabular}

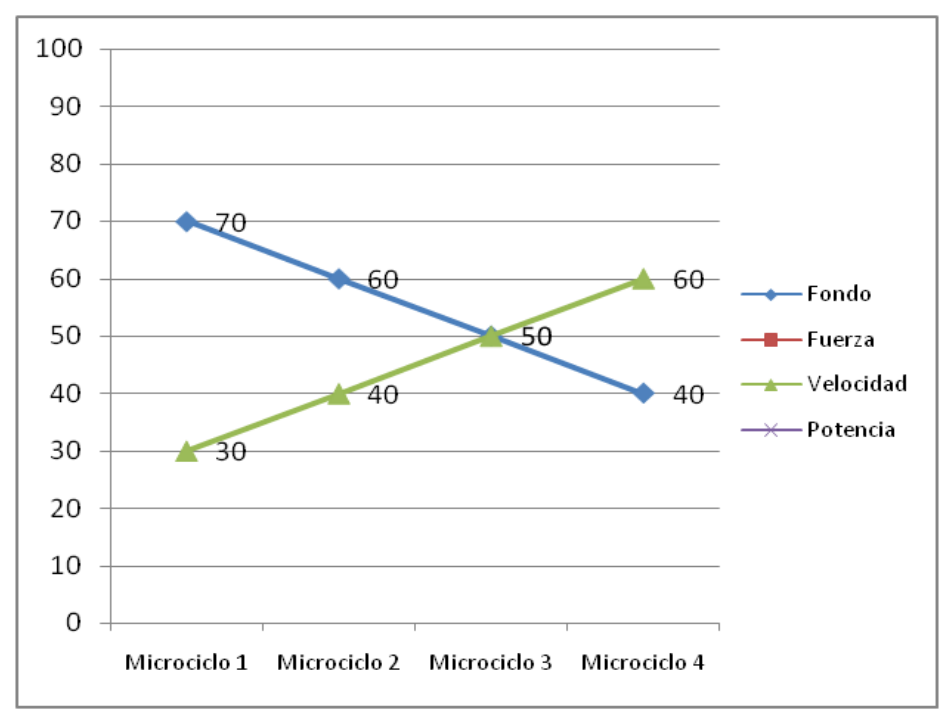

\subsection{FONDO, FUERZA Y POTENCIA}

Actividad de cadencias de pedaleo entre las 40 y 80 revoluciones por minuto; las resistencias de trabajo estarán entre las medias, medias altas y altas (3, 4 y 5).

La fuerza se trabajará, como ya lo hemos descrito, con resistencias altas y cadencias de pedaleo bajas, el trabajo de fondo se hará a resistencias y velocidades medias, y los trabajos de potencia serán realizados mientras se está sobre el trabajo de fondo, haciendo aumentos en la resistencia y pasando de las resistencias medias a las altas, sin perder nunca la cadencia de pedaleo.

Los intervalos de potencia, por su intensidad no deberán durar más de 30 segundos, ni la sumatoria de las anteriores el $10 \%$ de la actividad; el resto de la acción se repartirá entre los ejercicios tomados como fondo y fuerza, que serán distribuidos según el tiempo de la experiencia cardiovascular del practicante.

Se puede tomar la siguiente propuesta para 4 microciclos de trabajo, donde se muestra el porcentaje del tiempo de la clase:

\begin{tabular}{|l|c|c|l|c|}
\hline & Fondo & Fuerza & Velocidad & Potencia \\
\hline Microciclo 1 & 50 & 48 & & 2 \\
\hline Microciclo 2 & 45 & 50 & & 5 \\
\hline Microciclo 3 & 45 & 48 & & 7 \\
\hline Microciclo 4 & 50 & 40 & & 10 \\
\hline
\end{tabular}




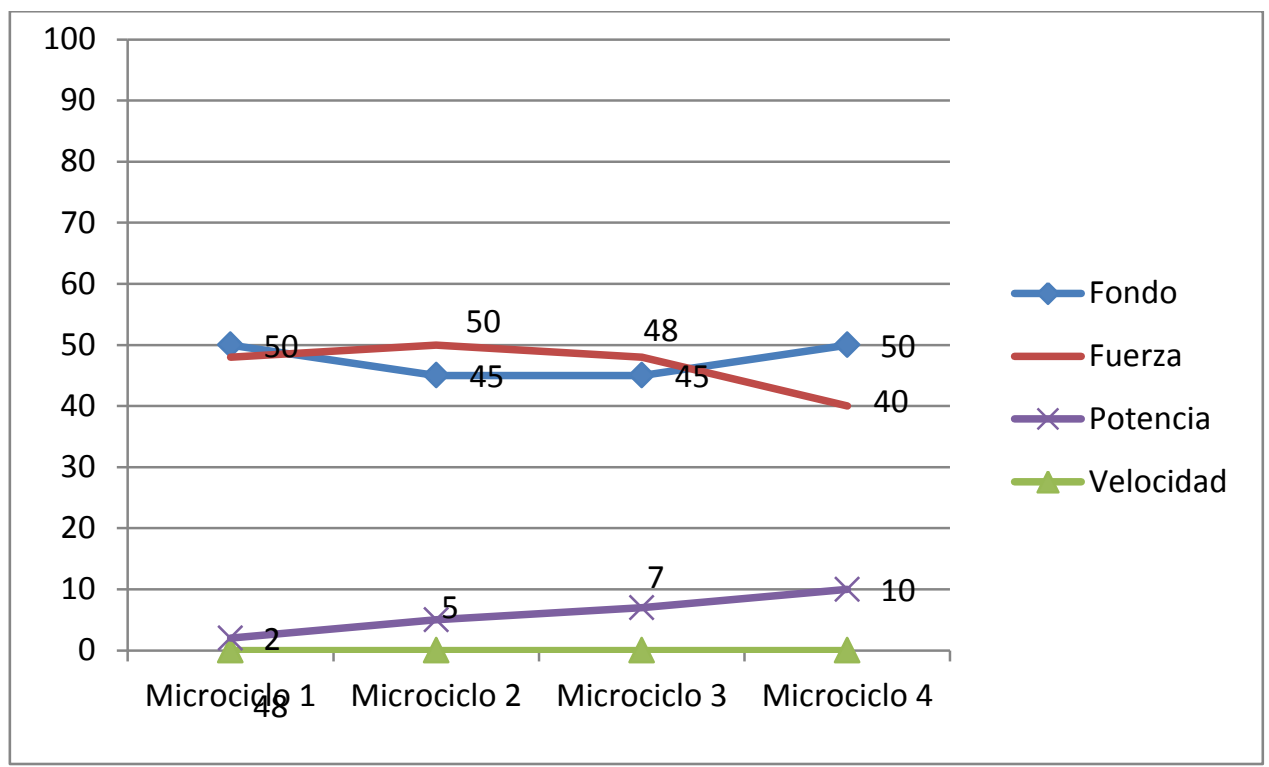

\subsection{FUERZA, VELOCIDAD Y POTENCIA}

Trabajo que maneja dos extremos totalmente opuestos: la velocidad y la fuerza.

La fuerza puede ser manejada con resistencias medias altas y altas, es decir, como lo hemos dicho antes, resistencias 4 y 5 ; los trabajos de velocidad serán hechos en su mayoría a no menos de cien revoluciones por minuto y estando sentado, claro, sobre la silla de la respectiva bicicleta.

Durante el trabajo de velocidad es posible hacer cortas paradas en pedales, cambio de posición que harán preferiblemente los practicantes con mayor experiencia.

Los trabajos de potencia serán hechos en medio del trabajo de velocidad, aumentando la carga sin perder la cadencia de pedaleo, también serán hechos cuando se hagan los trabajos de fuerza aumentando las revoluciones del pedaleo. Serán manejadas resistencias tan altas como se pueda, manteniendo siempre la cadencia de pedaleo marcada por la música; así, se pasará de trabajar sin resistencia a los trabajos de potencia, y los trabajos de fuerza se volverán de potencia al aumentar la cadencia.

Se puede tomar la siguiente propuesta para 4 microciclos de trabajo, donde se muestra el porcentaje del tiempo de la clase:

\begin{tabular}{|c|c|c|c|c|}
\hline & Fondo & Fuerza & Velocidad & Potencia \\
\hline Microciclo 1 & & 50 & 45 & 5 \\
\hline Microciclo 2 & & 50 & 40 & 10 \\
\hline Microciclo 3 & & 40 & 50 & 10 \\
\hline Microciclo 4 & & 40 & 45 & 15 \\
\hline
\end{tabular}




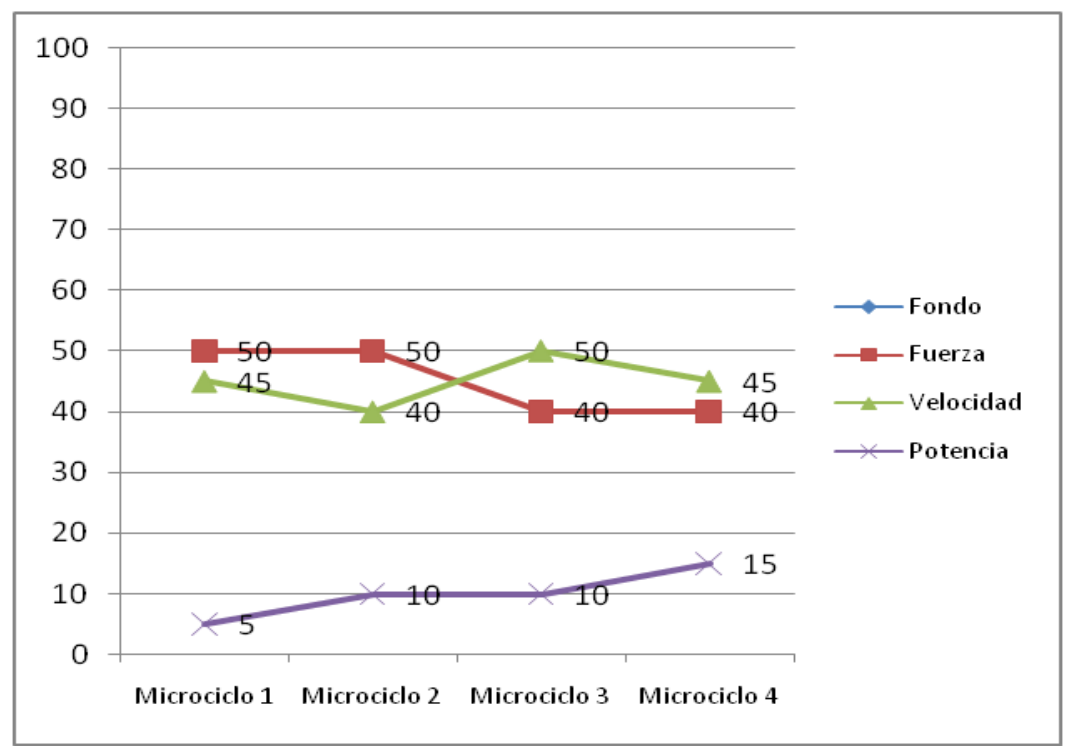

\subsection{FONDO, VELOCIDAD Y POTENCIA}

Trabajo físico en el cual se puede trabajar potencia mientras se está sobre el trabajo de fondo o sobre el de velocidad.

Los intervalos de potencia podrían llegar hasta los 40 segundos mientras se está en una cadencia de pedaleo de entre 60 y 80 revoluciones por minuto; mientras se está con la velocidad, podríamos hablar de intervalos de hasta veinte segundos.

El trabajo de fondo, tal como se ha descrito, estará entre las resistencias 2 y 3 , entre 60 y 80 revoluciones por minuto.

La velocidad se trabajará sin resistencia, a no menos de cien revoluciones por minuto.

Se pensará siempre en una distribución del $50 \%$ y $50 \%$ respecto a la velocidad y el trabajo de fondo, medido por el tiempo.

Los intervalos de potencia estarán entre estos dos trabajos, aumentando la intensidad del trabajo con resistencias más altas para el trabajo de fuerza y velocidades más altas para el de velocidad, además del hacer los intervalos de potencia más extensos.

Se puede tomar la siguiente propuesta para 4 microciclos de trabajo donde, se muestra el porcentaje del tiempo de la clase:

\begin{tabular}{|c|c|c|c|c|}
\hline & Fondo & Fuerza & Velocidad & Potencia \\
\hline Microciclo 1 & 60 & & 37 & 3 \\
\hline Microciclo 2 & 50 & & 45 & 5 \\
\hline Microciclo 3 & 50 & & 42 & 8 \\
\hline Microciclo 4 & 40 & & 50 & 10 \\
\hline
\end{tabular}




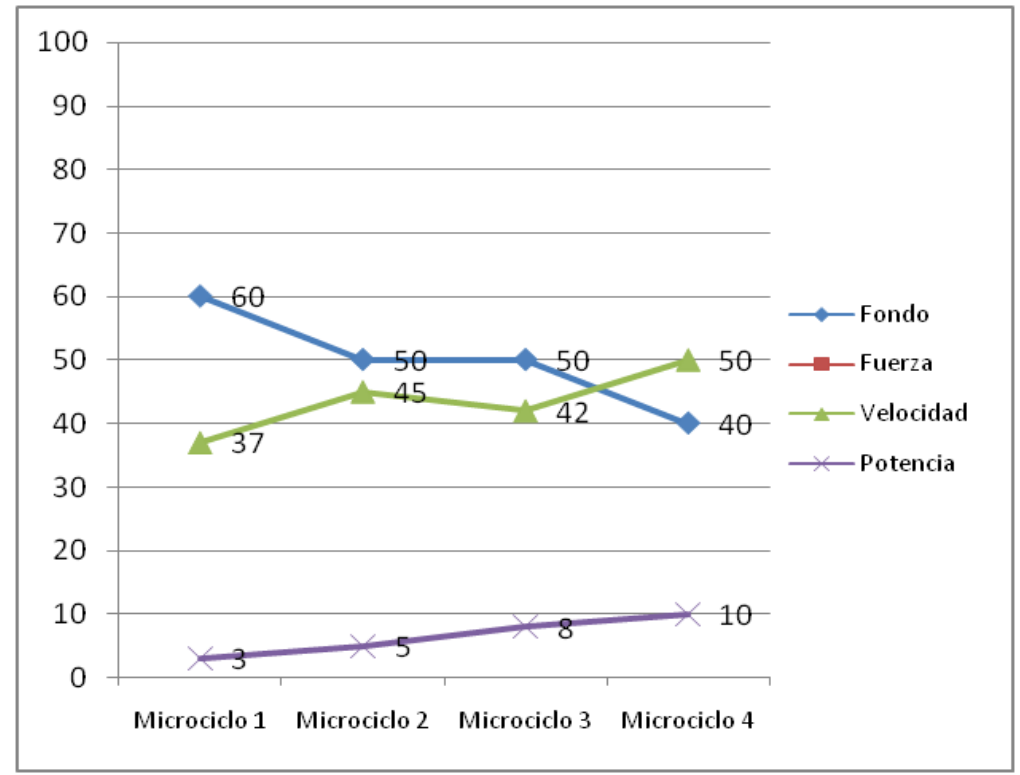

\subsection{VELOCIDAD}

Durante esta actividad se estará mucho tiempo sentado, las resistencias serán nulas, y la velocidad no podrá estar por debajo de las cien revoluciones por minuto.

Podría pensarse en trabajos de una misma velocidad durante toda la actividad y también en actividades con cambios de cadencia de pedaleo, pero estas nunca deberán bajar a menos de las cien revoluciones por minuto.

Se podrá pensar en estar de pie por un tiempo no mayor a los 30 segundos, dejando, claro, que solo los más experimentados sean quienes lo hagan.

Se puede tomar la siguiente propuesta para 4 microciclos de trabajo, donde se muestra el porcentaje del tiempo de la clase:

\begin{tabular}{|l|l|l|c|l|}
\hline & Fondo & Fuerza & Velocidad & Potencia \\
\hline Microciclo 1 & & & 100 & \\
\hline Microciclo 2 & & & 100 & \\
\hline Microciclo 3 & & & 100 & \\
\hline Microciclo 4 & & & 100 & \\
\hline
\end{tabular}




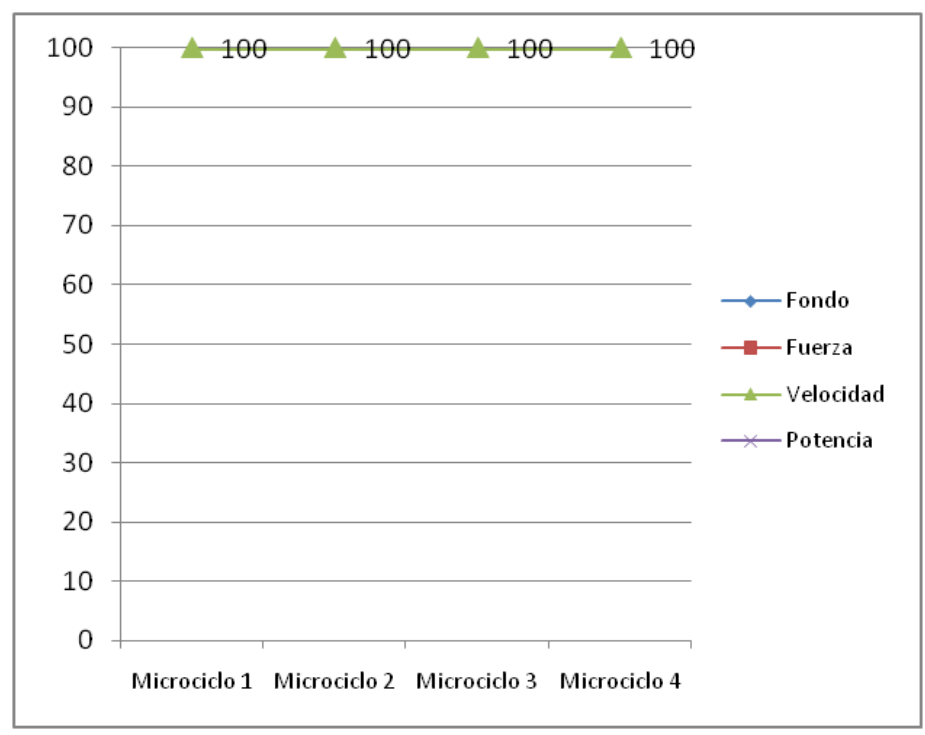

La anterior tabla muestra el trabajo en cada micro ciclo en su totalidad como trabajo de velocidad

\subsection{FONDO, FUERZA, VELOCIDAD Y POTENCIA}

Esta es la última y más completa de las catorce actividades aquí propuestas, que contiene las 4 bases del trabajo físico generalizado.

Podría proponerse un trabajo repartido final de porcentajes con respecto al tiempo: $30 \%$ para el trabajo de fondo, otro $30 \%$ para el trabajo de fuerza y un $30 \%$ para la velocidad, finalizando con un $10 \%$ para el trabajo de potencia.

Esta proporción, como en todos los casos anteriores, será dada por la misma práctica y el tiempo que lleve quien hace el trabajo; esto quiere decir que quien recién inicia puede intentar un trabajo bajando el porcentaje del trabajo de potencia y fuerza, y aumentando un poco el trabajo de fondo y velocidad.

La intensidad de todos los trabajos anteriores (punto 7) puede ser aumentada con el trabajo del tren superior antes descrito en el punto 6.10.

La duración y el tiempo de recuperación entre estos trabajos harán que se dé una opción más para que el trabajo sobre la bicicleta estática tenga más variabilidad.

\begin{tabular}{|l|c|c|c|c|}
\hline & Fondo & Fuerza & Velocidad & Potencia \\
\hline Microciclo 1 & 30 & 35 & 30 & 5 \\
\hline Microciclo 2 & 40 & 25 & 30 & 5 \\
\hline Microciclo 3 & 30 & 30 & 33 & 7 \\
\hline Microciclo 4 & 25 & 25 & 40 & 10 \\
\hline
\end{tabular}




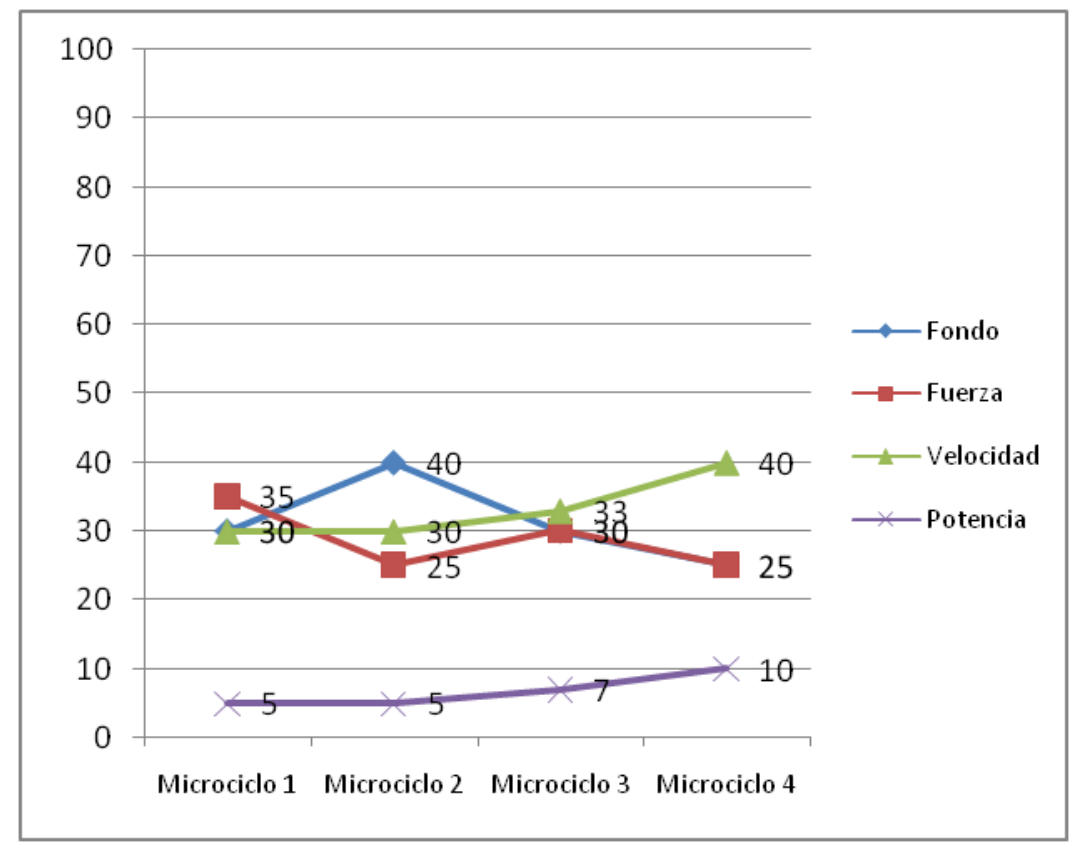

Luego de conocer la descripción del trabajo podría manejarse un programa de 4 microciclos (por ejemplo), dando paso así a un meso ciclo de casi 5 meses de trabajo.

Retomando los puntos del 7.1 al 7.14 se puede tomar la siguiente propuesta para 4 microciclos de trabajo donde se muestra el porcentaje del tiempo de la clase. 


\begin{tabular}{|c|c|c|c|c|c|c|c|c|c|c|c|}
\hline \multirow[t]{2}{*}{ Clase } & \multirow[t]{2}{*}{ Microciclo } & \multicolumn{4}{|c|}{ \% en tiempo de clase del tipo de trabajo } & \multirow[t]{2}{*}{ Clase } & \multirow[t]{2}{*}{ Microciclo } & \multicolumn{4}{|c|}{ \% en tiempo de clase del tipo de trabajo } \\
\hline & & Fondo & Fuerza & Velocidad & Potencia & & & Fondo & Fuerza & Velocidad & Potencia \\
\hline \multirow[t]{4}{*}{1} & 1 & 100 & & & & 8 & 1 & & 97 & & 3 \\
\hline & 2 & 100 & & & & & 2 & & 95 & & 5 \\
\hline & 3 & 100 & & & & & 3 & & 93 & & 7 \\
\hline & 4 & 100 & & & & & 4 & & 90 & & 10 \\
\hline \multirow[t]{4}{*}{2} & $\overline{1}$ & 80 & 20 & & & 9 & 1 & 70 & & 30 & \\
\hline & 2 & 70 & 30 & & & & 2 & 60 & & 40 & \\
\hline & 3 & 60 & 40 & & & & 3 & 50 & & 50 & \\
\hline & 4 & 50 & 50 & & & & 4 & 40 & & 60 & \\
\hline \multirow[t]{4}{*}{3} & 1 & & & 98 & 2 & $\overline{10}$ & $\overline{1}$ & 50 & 48 & $\overline{2}$ & \\
\hline & 2 & & & 97 & 3 & & 2 & 45 & 50 & 5 & \\
\hline & 3 & & & 95 & 5 & & 3 & 45 & 48 & 7 & \\
\hline & 4 & & & 90 & 10 & & 4 & 50 & 40 & 10 & \\
\hline \multirow[t]{4}{*}{4} & 1 & & 60 & 40 & & 11 & 1 & & 50 & 45 & 5 \\
\hline & 2 & & 50 & 50 & & & 2 & & 50 & 40 & 10 \\
\hline & 3 & & 40 & 60 & & & 3 & & 40 & 50 & 10 \\
\hline & 4 & & 50 & 50 & & & 4 & & 40 & 45 & 15 \\
\hline \multirow[t]{4}{*}{5} & 1 & 96 & & & 4 & 12 & 1 & 60 & & 37 & 3 \\
\hline & 2 & 93 & & & 7 & & 2 & 50 & & 45 & 5 \\
\hline & 3 & 90 & & & 10 & & 3 & 50 & & 42 & 8 \\
\hline & 4 & 85 & & & 15 & & 4 & 40 & & 50 & 10 \\
\hline \multirow[t]{4}{*}{6} & 1 & & 100 & & & 13 & 1 & & & 100 & \\
\hline & 2 & & 100 & & & & 2 & & & 100 & \\
\hline & 3 & & 100 & & & & 3 & & & 100 & \\
\hline & 4 & & 100 & & & & 4 & & & 100 & \\
\hline \multirow[t]{4}{*}{7} & 1 & 35 & 30 & 35 & & 14 & $\overline{1}$ & 30 & 35 & 30 & 5 \\
\hline & 2 & 30 & 35 & 35 & & & 2 & 40 & 25 & 30 & 5 \\
\hline & 3 & 35 & 35 & 30 & & & 3 & 30 & 30 & 33 & 7 \\
\hline & 4 & 30 & 40 & 30 & & & 4 & 25 & 25 & 40 & 10 \\
\hline
\end{tabular}




\section{ENCUESTAS A USUARIOS}

Estas encuestas fueron hechas a personas a las cuales se les propuso cambiar el llamado "spinning" por esta nueva actividad llamada aquí "E.S.B.E.", Entrenamiento Sobre Bicicleta Estática.

Las preguntas fueron hechas a personas que asisten a un prestigioso gimnasio que tiene poco más de 10 años de actividad en la ciudad de La Plata.

Dentro del mismo gimnasio existe un adecuado salón con 12 bicicletas estáticas, lugar en el cual se trabajó y probó lo aquí mencionado.

Los grupos de trabajo están divididos en diferentes horas y días. Uno de ellos trabaja los días lunes, miércoles y viernes a las 15:00 horas, y otros 3 diferentes grupos trabajan a las 18:30, 19:30 y 20:30 horas.

Los días martes y jueves también hay grupos a las 18:30, 19:30 y 20:30 horas, todos manejados por la misma persona, con un criterio muy parecido.

Fueron hechas en total 60 evaluaciones, de las cuales 2 fueron eliminadas ya que no contaban con buena parte de sus respuestas y se notaba que no habían sido contestadas con el debido compromiso.

No todas las personas se prestaron a este trabajo, y muchas que lo hicieron nunca regresaron las encuestas; a otras hubo que darles el formato de la encuesta por segunda vez, pues lo perdían demostrando muy poco interés en la colaboración del trabajo. Esto es una lastima, ya que se mantenía contacto con casi 90 personas.

Luego de que las encuestas fueron recolectadas y enumeradas, se inició el trabajo de su codificación.

Muchas de las preguntas eran abiertas haciendo que las respuestas fuesen múltiples.

A las personas que colaboraron con la investigación se les reconoce una vez más, guardándoles gratitud. 
La sigla C.P. se refiere a $\mathbf{C}$ antidad de $\mathbf{P}$ ersonas

\section{Edad}

\begin{tabular}{|c|c|c|}
\multicolumn{1}{c}{} & C.P. & $\%$ \\
\hline 21 a 30 & 26 & 44,8 \\
\hline 31 a 40 & 16 & 27,6 \\
\hline No responde & 7 & 12,1 \\
\hline 41 a 50 & 4 & 6,9 \\
\hline Menor de 20 & 3 & 5,2 \\
\hline 51 a 60 & 2 & 3,4 \\
\hline
\end{tabular}

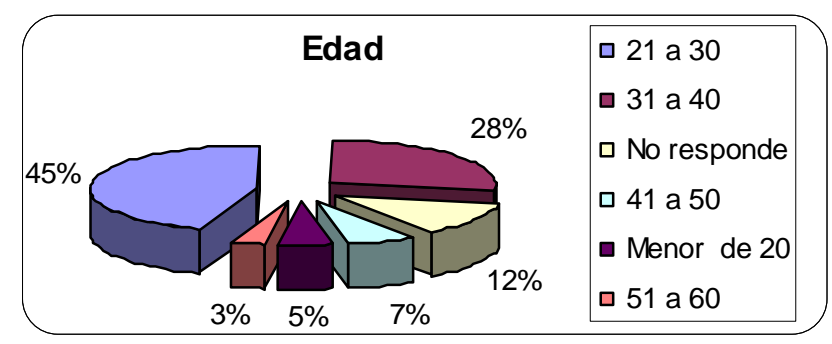

En su mayoría (el $45 \%$ ) la gente encuestada está entre los 21 y 30 años; luego sigue la gente que está entre los 31 y 40 años con un $28 \%$. Existe gente entre el grupo mayor de los 50 años, casi la misma cantidad que la gente menor de los 20 años de edad.

Sexo

\begin{tabular}{|c|c|c|}
\multicolumn{1}{c}{ C.P. } & $\%$ \\
\hline Femenino & 51 & 87,9 \\
\hline Masculino & 7 & 12,1 \\
\hline
\end{tabular}

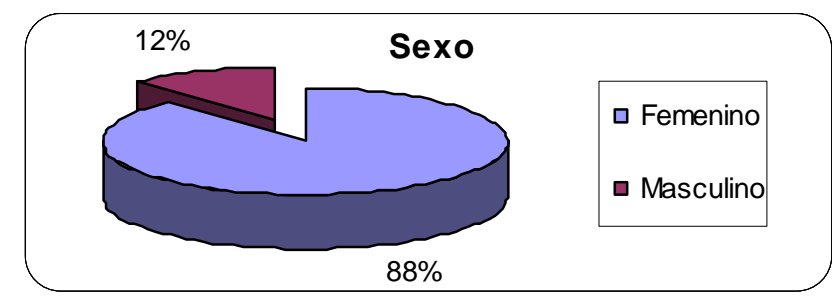

Es notoria la diferencia de practicantes femeninas, que representan casi el el 90\%.

\section{Ocupación}

\begin{tabular}{|c|c|c|}
\multicolumn{1}{c}{} & \multicolumn{1}{c}{ C.P. } & $\%$ \\
\hline Estudiante & 13 & 22,4 \\
\hline Empleado/Administrativo & 13 & 22,4 \\
\hline Salud & 6 & 10,3 \\
\hline Abogado & 5 & 8,6 \\
\hline No responde & 5 & 8,6 \\
\hline Ventas y comercio & 4 & 6,9 \\
\hline Profesor/Docente & 3 & 5,2 \\
\hline Estudia y Trabaja & 3 & 5,2 \\
\hline Estudiante de post grado & 2 & 3,4 \\
\hline Contador & 2 & 3,4 \\
\hline Diseño Artes & 1 & 1,7 \\
\hline Ciencias & 1 & 1,7 \\
\hline
\end{tabular}




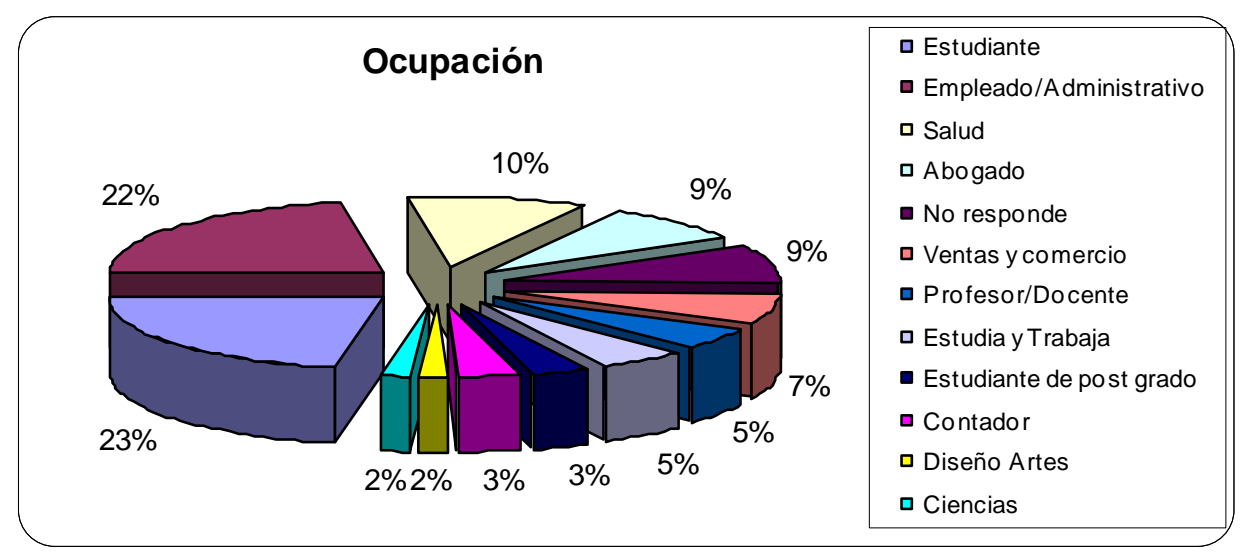

Once diferentes labores se encontraron entre la gente que practica esta actividad, en su mayoría estudiantes y empleados administrativos $(22,4 \%)$, y luego gente que trabaja en el campo de la salud (10\%).

Por otro lado, los campos de diseño de artes y ciencias tienen sólo un $2 \%$ cada uno.

Abogados, gente de ventas, docentes, estudiantes de pos grado y contadores también son parte de las ocupaciones de usuarios.

\section{¿Hace cuánto se ejercita en forma regular?}

\begin{tabular}{|c|c|c|}
\multicolumn{1}{c}{} & C.P. & $\%$ \\
\hline 0 a 6 meses & 15 & 25,9 \\
\hline 6 meses a 1 año & 13 & 22,4 \\
\hline 1 a 5 años & 12 & 20,7 \\
\hline 5 a 10 años & 9 & 15,5 \\
\hline Más de 10 años & 6 & 10,3 \\
\hline No responde & 3 & 5,2 \\
\hline
\end{tabular}




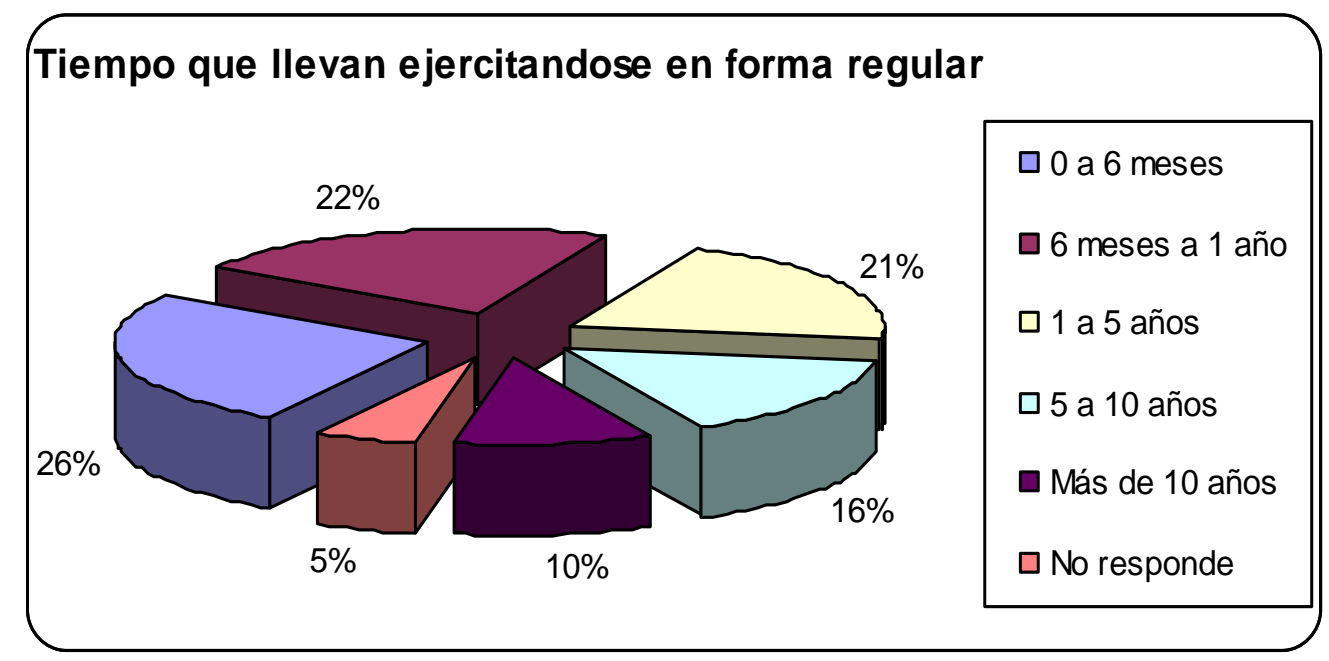

La gente que se ejercita no hace más de 6 meses representa la mayoría de los encuestados con un $26 \%$, luego se encuentran los que se ejercitan no hace más de un año, con un $22 \%$, y quienes hacen ejercicio entre uno y 5 años con un $21 \%$.

La encuesta muestra además un 16\% que tiene entre 5 y 10 años de actividad física, y un $10 \%$ que hace más de 10 años está dentro del ejercicio corporal.

Un 5\% no responde a la pregunta.

¿Hace cuánto que practica esta actividad del "Entrenamiento sobre la bicicleta estática” (“E.S.B.E.”) con Marco Ríos?

\begin{tabular}{|c|c|c|}
\multicolumn{1}{c}{} & \multicolumn{1}{c}{ C.P. } & $\%$ \\
\hline 0 a 3 meses & 17 & 29,3 \\
\hline 3 a 6 meses & 18 & 31,0 \\
\hline 6 meses a 1 año & 12 & 20,7 \\
\hline Más de un año & 10 & 17,2 \\
\hline No responde & 1 & 1,7 \\
\hline
\end{tabular}




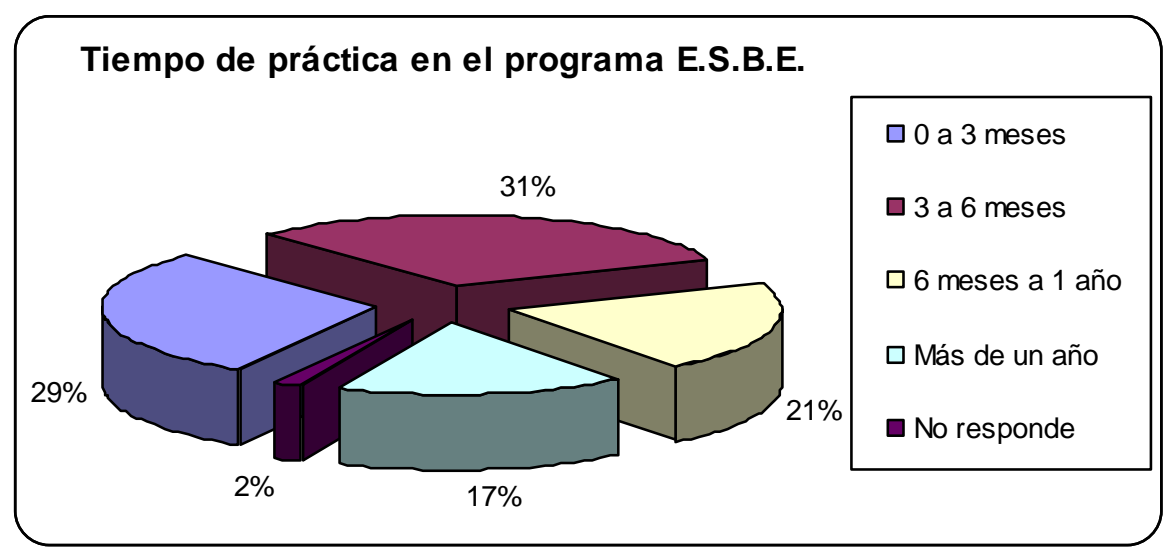

Casi la misma cantidad de gente hace esta actividad desde hace menos de 3 meses (29\%) y entre 3 y 6 meses (31\%). Un 17\% lo practica hace más de un año, y un $21 \%$ desde hace mas de 6 meses y menos de un año.

\section{¿Cuántas veces por semana?}

\begin{tabular}{|c|c|c|}
\hline \multicolumn{1}{c}{} & \multicolumn{1}{c}{ C.P. } & $\%$ \\
\hline 2 veces & 31 & 53,4 \\
\hline 3 veces & 25 & 43,1 \\
\hline 4 veces y más & 2 & 3,4 \\
\hline
\end{tabular}

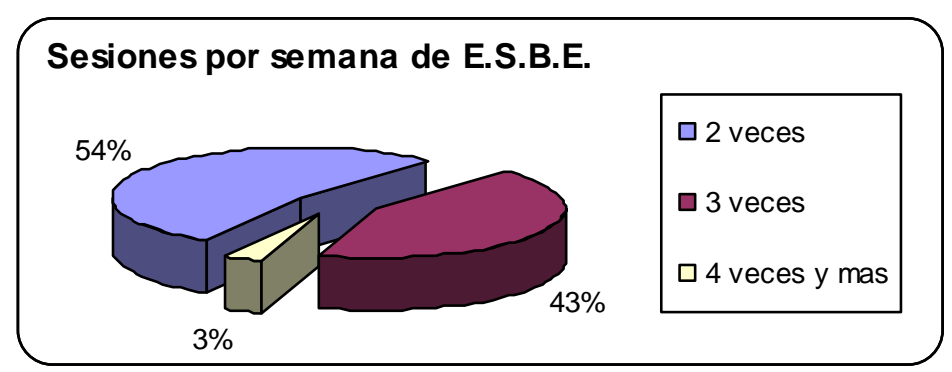

El $54 \%$ de los encuestados lo hace 2 veces por semana, el $43 \%$ lo hace 3 . Hay un $3 \%$ que va más de 3 veces por semana.

\section{¿Hizo Spinning con otro instructor?}

\begin{tabular}{|c|c|c|}
\multicolumn{1}{c}{} & \multicolumn{1}{c}{ C.P. } & \% \\
\hline No & 33 & 56,9 \\
\hline Sí & $\mathbf{2 4}$ & 41,4 \\
\hline No responde & 1 & 1,7 \\
\hline
\end{tabular}




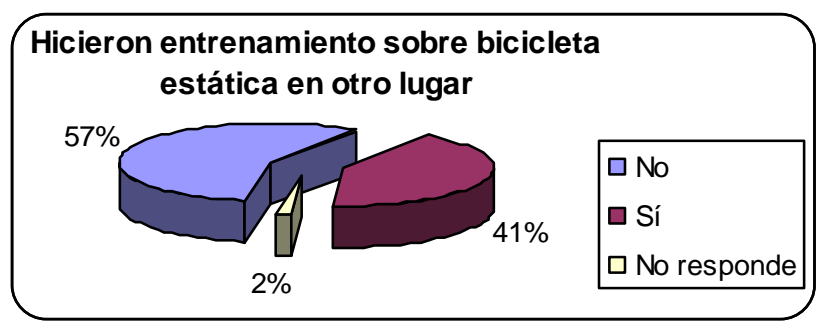

El 57\% de las personas con las que se trabajó dijo no haberlo hecho antes, dando pie a creer que los resultados físicos, son en parte por esta actividad.

El hecho de tener gente que estuvo en el trabajo sobre la bicicleta estática no más de 3 meses facilitará la credibilidad en la rapidez con que la gente nota o no cambios de la acción física.

El 41\% de este grupo sí había hecho algo similar llamado "Spinning".

\section{¿Encuentra diferencias entre éste y otros profesores?}

\begin{tabular}{|c|c|c|}
\multicolumn{1}{c}{} & \multicolumn{1}{c}{ C.P. } & \% \\
\hline Sí. & $\mathbf{2 4}$ & 100 \\
\hline No & 0 & 0,0 \\
\hline No responde & 0 & 0,0 \\
\hline
\end{tabular}

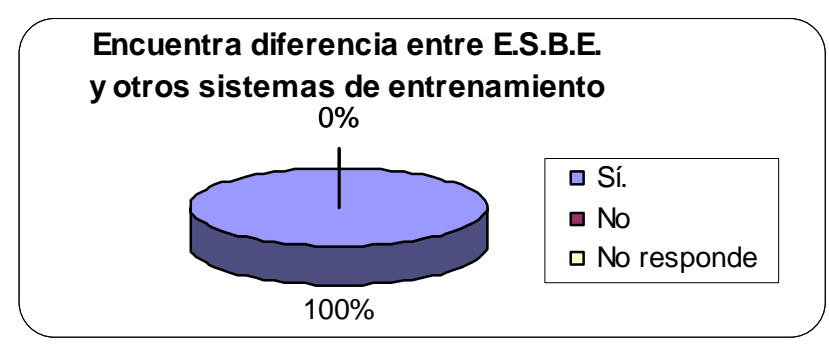

Esta pregunta sobre el actuar de los instructores en el "Spinning" y en el entrenamiento ahora propuesto fue respondida por quienes sí habían hecho antes algo similar, hablamos del $41 \%$ de los encuestados.

La intención de la pregunta es saber qué valoran los usuarios de este diferente formato de trabajo. Estas personas dicen notar diferencias entre lo aquí hecho y lo tomado como "Spinning".

\section{Realiza en la actualidad otra actividad física}

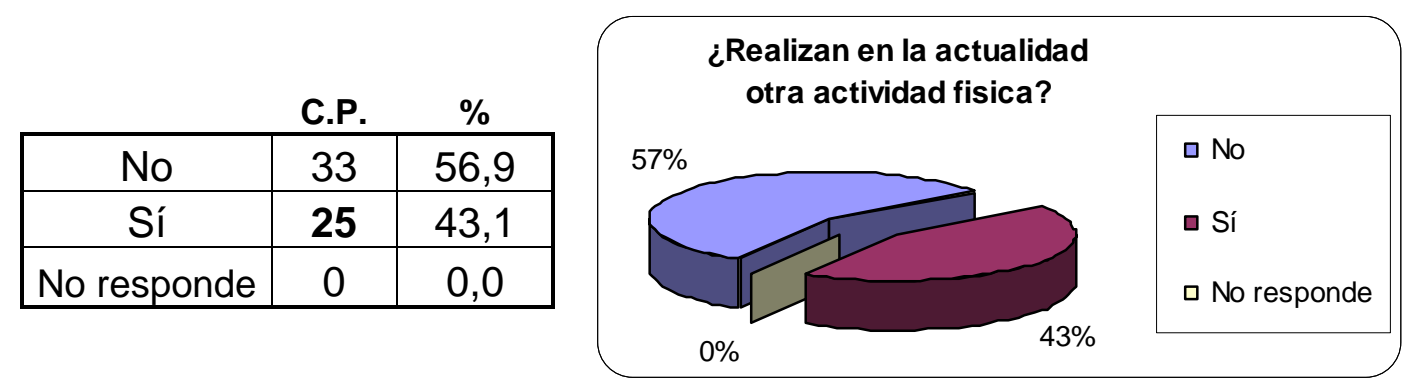




\section{¿Qué otra actividad realiza?}

\begin{tabular}{|c|c|c|}
\multicolumn{1}{c}{} & \multicolumn{1}{c}{ C.P } & $\%$ \\
\hline Pádel & 3 & 12,5 \\
\hline Pesas-Aparatos-Máquinas & 3 & 12,5 \\
\hline Pilates & 2 & 8,3 \\
\hline Caminar & 2 & 8,3 \\
\hline Bicicleta en carretera & 2 & 8,3 \\
\hline Natación & 2 & 8,3 \\
\hline Pesas-Trotar & 2 & 8,3 \\
\hline Correr & 1 & 4,2 \\
\hline Basquetbol & 1 & 4,2 \\
\hline Tenis & 1 & 4,2 \\
\hline Baile & 1 & 4,2 \\
\hline Boxeo Recreativo & 1 & 4,2 \\
\hline Fútbol-Golf-Tenis & 1 & 4,2 \\
\hline Pesas-Ciclismo en carretera & 1 & 4,2 \\
\hline No responde & 1 & 4,2 \\
\hline
\end{tabular}

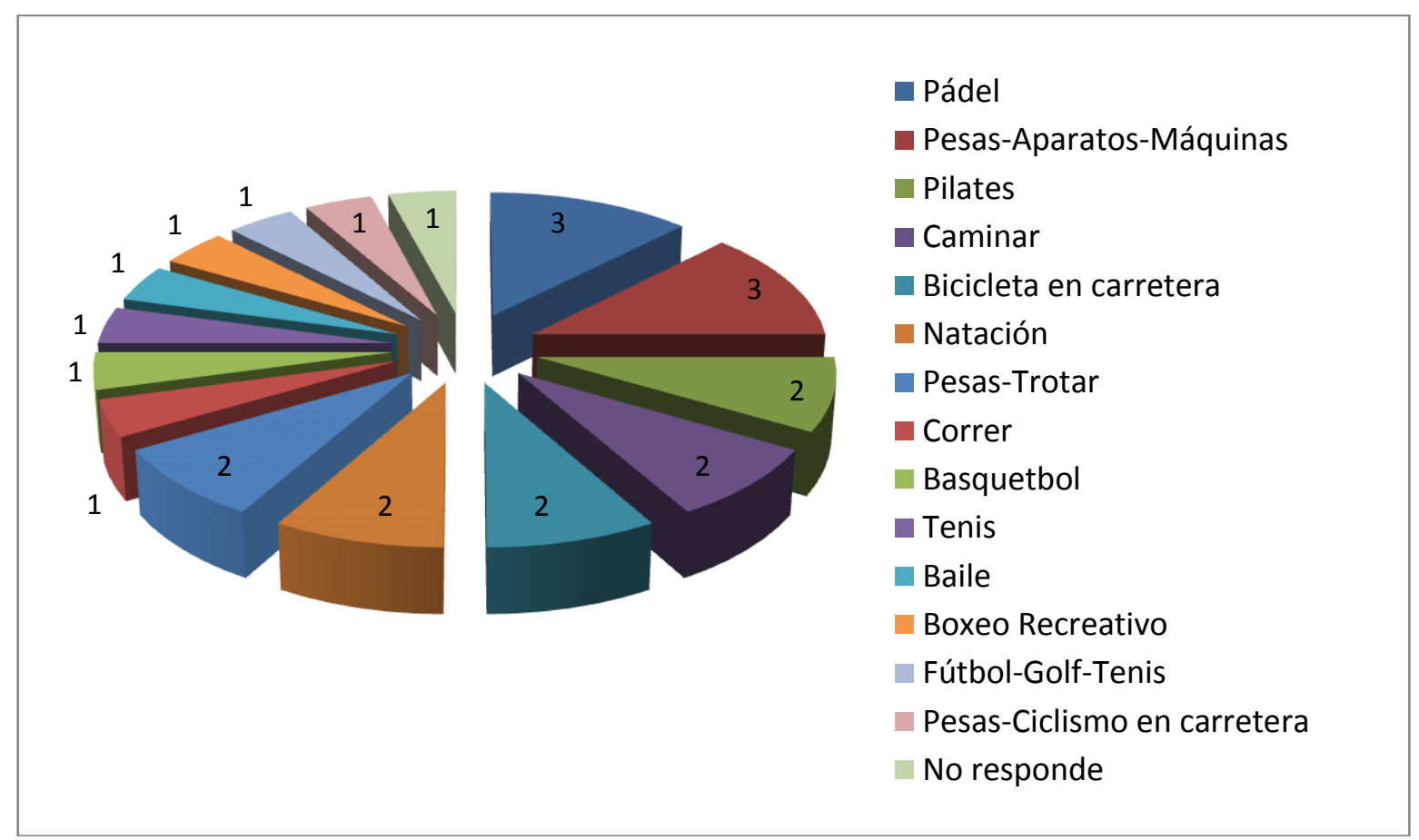


¿Conoce cuál es su colesterol total?

\begin{tabular}{|c|c|c|}
\multicolumn{1}{c}{} & \multicolumn{1}{c}{ C.P. } & $\%$ \\
\hline No & 31 & 53,4 \\
\hline Sí & $\mathbf{2 3}$ & 39,7 \\
\hline No responde & 4 & 6,9 \\
\hline
\end{tabular}

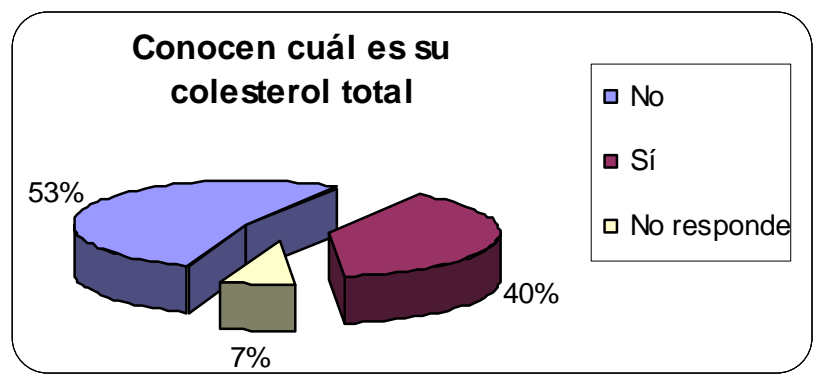

El colesterol de quienes lo conocen está en:

\begin{tabular}{|c|c|c|}
\multicolumn{1}{c}{} & \multicolumn{1}{c}{ C.P } & $\%$ \\
\hline Valores normales (menos de $200 \mathrm{mg} / \mathrm{ml}$ ) & 14 & 58,3 \\
\hline Valores altos (mayores a $200 \mathrm{mg} / \mathrm{ml}$ ) & 5 & 20,8 \\
\hline No responde & 4 & 16,7 \\
\hline
\end{tabular}

Cuadro que manifiesta el porcentaje de quienes conocen su colesterol

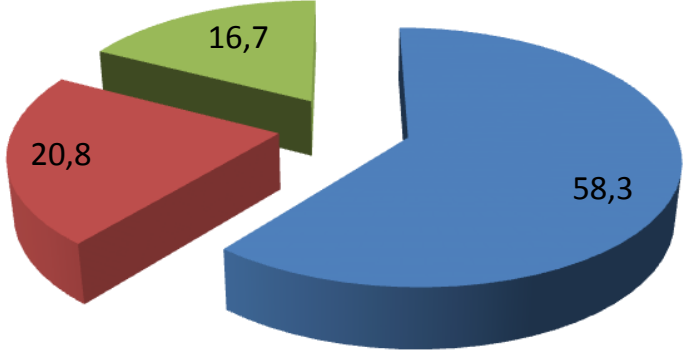

Valores normales (menos de 200 mg/ml) - Valores altos (mayores a $200 \mathrm{mg} / \mathrm{ml}$ )

No responde

¿Conoce su presión arterial?

\begin{tabular}{|c|c|c|}
\multicolumn{1}{c}{ C.P. } & $\%$ \\
\hline No & 34 & 58,6 \\
\hline Sí & 20 & 34,5 \\
\hline No responde & 4 & 6,9 \\
\hline
\end{tabular}

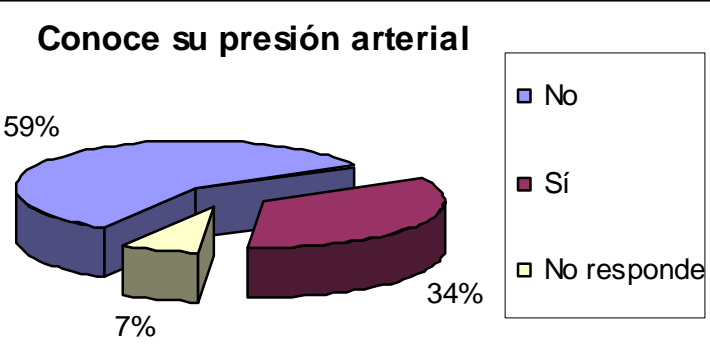

La presión sanguínea de quienes la conocen está en: 


\begin{tabular}{|c|c|c|}
\multicolumn{1}{c}{} & \multicolumn{1}{c}{ C.P } & $\%$ \\
\hline Valores Normales & 8 & 33,3 \\
\hline Valores altos & 5 & 20,8 \\
\hline Valores bajos & 5 & 20,8 \\
\hline No responde & 2 & 8,3 \\
\hline
\end{tabular}

Cuadro que manifiesta el porcentaje de quienes conocen su presión sanguínea

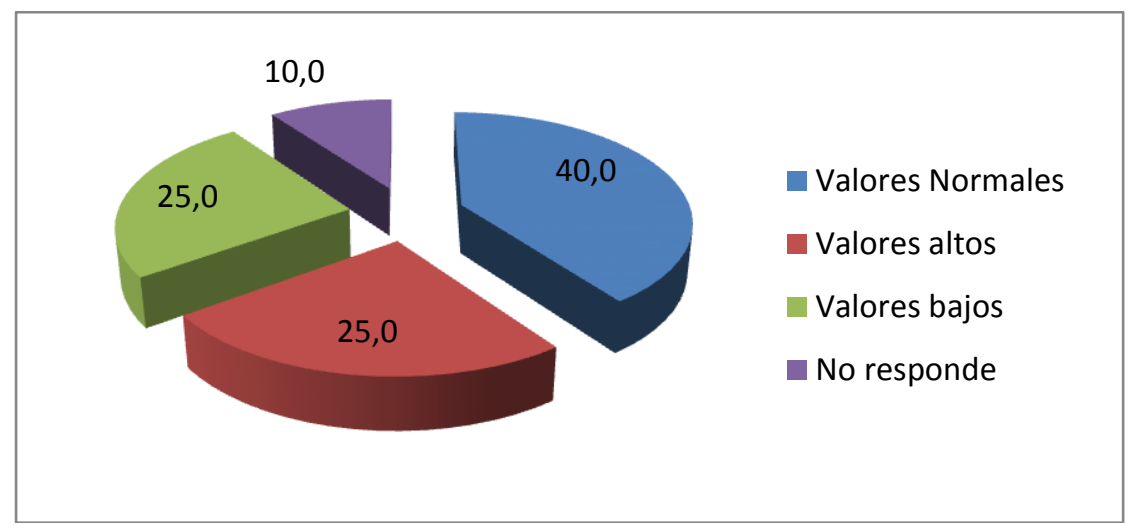

Índice de Masa Corporal I.M.C. actual

\begin{tabular}{|c|c|c|}
\multicolumn{1}{c}{} & \multicolumn{1}{c}{ C.P } & $\%$ \\
\hline Saludable & 35 & 60,3 \\
\hline Sobre peso & 9 & 15,5 \\
\hline Bajo peso & 9 & 15,5 \\
\hline No responde & 5 & 8,6 \\
\hline
\end{tabular}

Cuadro que manifiesta el porcentaje de quienes conocen su peso y altura para calcular su I.M.C. actual

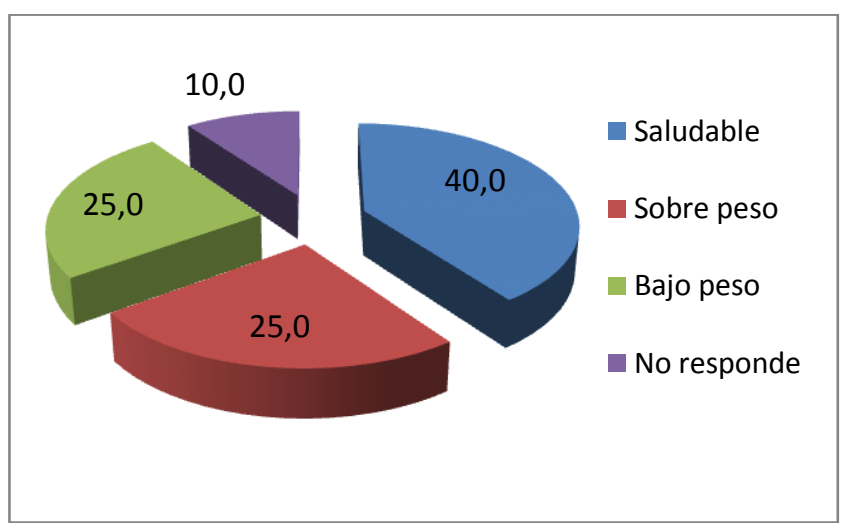




\section{EVALUACIONES}

Se realizaron Pruebas y evaluaciones a 3 practicantes femeninas del "E.S.B.E." durante 5 meses de actividad.

Las principales dimensiones antropométricas utilizadas en la antropología deportiva son: talla o estatura, longitud de segmentos (extremidades), perímetros (circunferencias), diámetros, anchuras, peso corporal y pliegues cutáneos.

Para nuestro estudio fueron tenidos en cuenta perímetros, peso y pliegues corporales.

Se les practicó además pruebas de fuerza muscular en aparatos multifuncionales.

También se tuvieron en cuenta para el seguimiento pruebas de esfuerzo físico.

Las pruebas fueron hechas buscando diferencias en la velocidad de recuperación, siempre tomada al minuto de llegar al máximo de sus pulsaciones sobre la bicicleta estática.

\subsection{EVALUACIONES ANTOPOMÉTRICAS REALIZADAS A TRES PRACTICANTES “E.S.B.E.”}

La medición antropométrica hecha en la investigación registró la respuesta corporal de las tres personas evaluadas.

Se apoyó en la toma de las circunferencias corporales más significativas -la circunferencia torácica, cadera, cintura, brazo, muslo y pierna-, y, haciendo referencia a los pliegues cutáneos, se tuvo en cuenta los del área subescapular, tríceps, supra ilíaco, abdomen, muslo y pantorrilla.

No se usó ninguna fórmula de cálculo graso corporal, pues no se hizo referencia a esta área.

Se buscó dar contraste entre las evaluaciones luego del inicio de la actividad.

\subsubsection{Descripción de evaluación de perímetro corporal}

\subsubsection{Perímetro Torácico}

Su definición depende de los puntos somato-métricos que se utilicen como referencia. Así, puede considerarse como el perímetro del tronco obtenido en el nivel del punto meso esternal.

Como todo perímetro del tronco, su dimensión varía de acuerdo con el estado de la respiración del evaluado; por ello, debe delinearse una circunferencia torácica normal, que se obtiene entre una inspiración y una espiración normal; una circunferencia torácica máxima, que se obtiene en una máxima inspiración; y una circunferencia torácica mínima que es obtenida en una espiración máxima. 


\section{Procedimiento:}

1. El evaluado debe estar en posición de atención antropométrica.

2. La cinta métrica se pasa alrededor del tronco, tomando como referencia la punta meso esternal.

3. La medida debe ser el promedio de las medidas obtenidas durante una inspiración y una espiración normales.

4. Se debe procurar que la cinta métrica permanezca en forma horizontal, en contacto con toda la superficie de la piel. Puede recurrirse a un espejo para ayudarse.

5. La presión ejercida sobre la piel debe ser leve para evitar la compresión de los tejidos.

Otros puntos de referencia para la medición de la circunferencia torácica pueden ser el apéndice xifoideo y la parte más alta del tronco, en el nivel de las axilas.
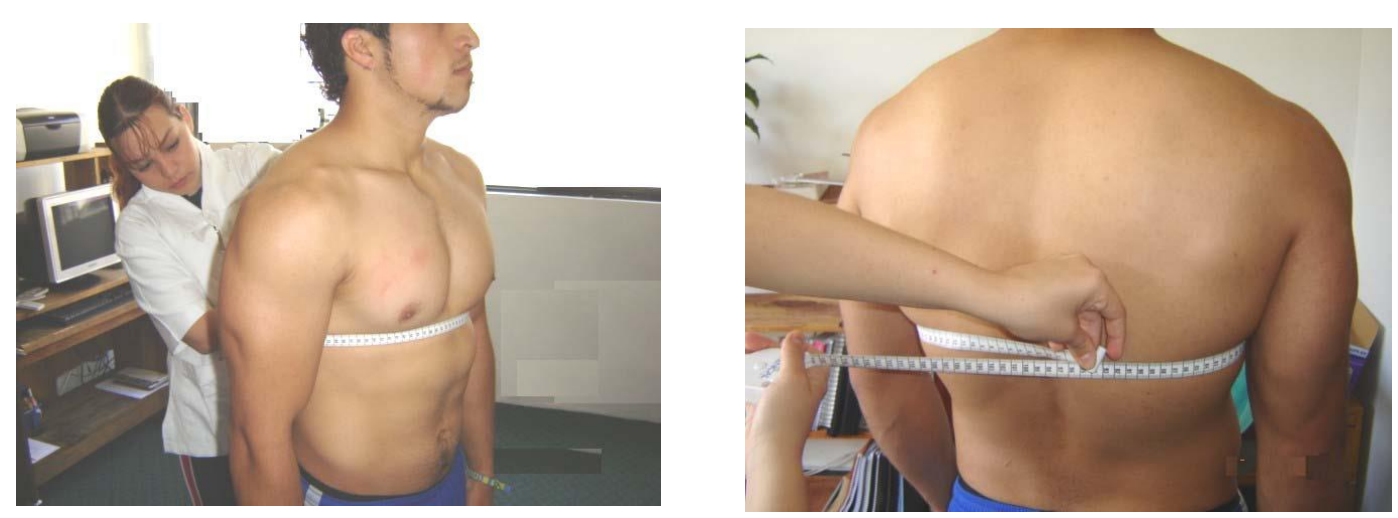

Ilustración 22: Medición de la circunferencia torácica

\subsubsection{Perímetro de la Cintura}

Puede definirse como el perímetro obtenido en el nivel del onfálico.

\section{Procedimiento:}

1. El evaluado debe estar de pie.

2. El evaluador debe estar colocado al frente o por detrás del evaluado, según sea la estatura de éste. 
3. La cinta se pasa alrededor del tronco en el nivel del onfálico, manteniendo la horizontalidad.

4. La presión ejercida debe ser leve para evitar la compresión de los tejidos. La definición de esta dimensión está en correspondencia con el punto somato-métrico que se tome como referencia.
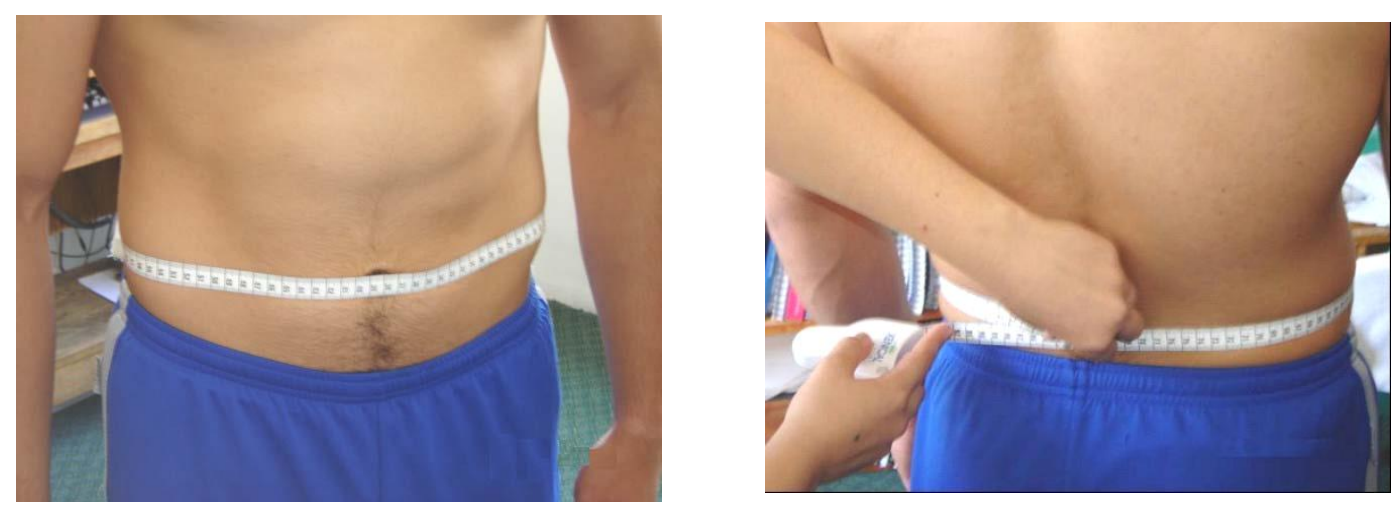

Ilustración 23: Medición de la circunferencia de cintura

\subsubsection{Perímetro de la Cadera}

Se puede definir como la máxima circunferencia entre la cintura y los muslos, de acuerdo a los puntos que se utilicen como referencia para su medición.

Es llamada a veces circunferencia de los glúteos, y se toma horizontalmente en el nivel de la máxima extensión de los glúteos.

Puede tomarse en el nivel de los trocánteres, tomando como referencia la parte prominente de los glúteos y los trocánteres; o en la zona del pubis: la parte delimitada por los dos anteriores.

\section{Procedimiento:}

1. El evaluado de estar colocado en posición de atención antropométrica.

2. El evaluado debe estar casi desnudo o con ropa ligera, que no restrinja los tejidos.

3. El evaluador observa al evaluado por un extremo y pasa la cinta alrededor de las caderas en un plano horizontal, en el nivel de la extensión máxima de los glúteos.

Nota: Se sugiere tomar la medida de esta manera porque los glúteos son un punto más fácil de visualizar, lo cual hace que se reduzca potencialmente el error de medición. 


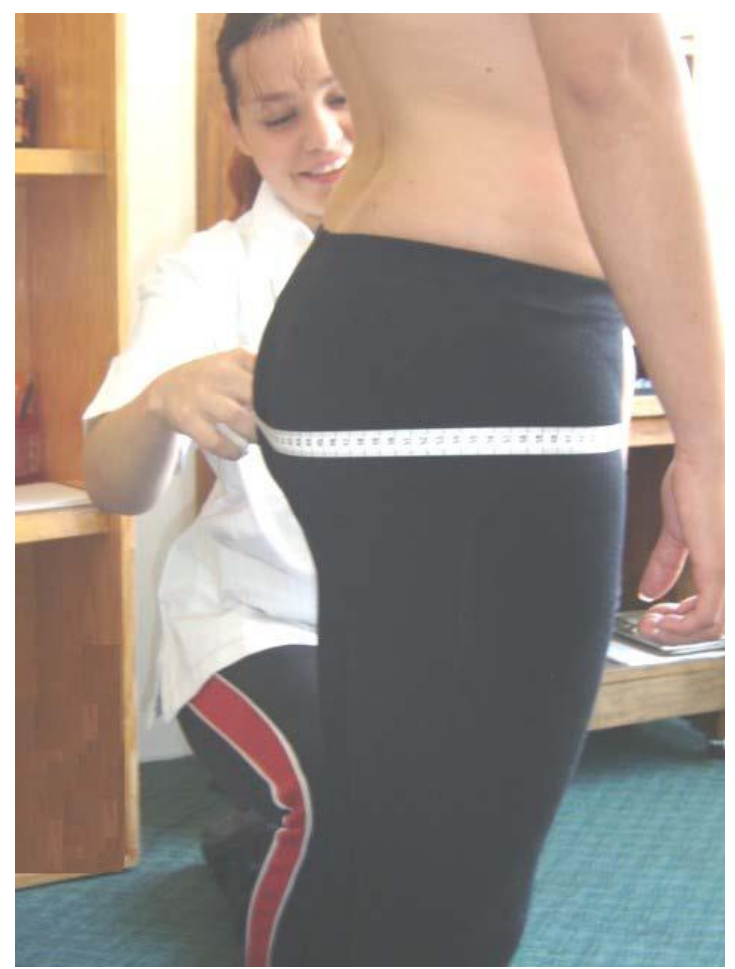

llustración 24: Medición de la circunferencia de cadera

\subsubsection{Perímetro del Brazo a la altura del Bíceps}

Puede ser tomado de dos formas: con el brazo relajado en línea con la columna (circunferencia en extensión del bíceps) y con el brazo flexionado a 90 grados y dando máxima tensión al bíceps (circunferencia en flexión del bíceps).

La circunferencia media del brazo $(\mathrm{CMB})$ en extensión se define como el perímetro obtenido en el brazo a nivel meso braquial.

\section{Procedimiento:}

1. El evaluado debe estar de pie o sentado con espalda recta.

2. Debe marcarse el punto meso braquial, con el brazo relajado. Para esto se mide el tamaño del brazo desde el acromion (protuberancia ósea en el hombro formada por la apófisis acromial del omóplato) hasta el olecranon (hueso que marca el codo); se considera el punto medio del sector humeral.

3. Se mide la circunferencia media del brazo relajado; se pasa la cinta métrica alrededor del brazo, de manera que toque la piel sin comprimir el tejido. 
4. Se mide la circunferencia máxima del brazo (perímetro obtenido estando el antebrazo a 90 grados del brazo, en su máxima tensión, y los músculos subyacentes del brazo completamente contraídos); se mide con la cinta métrica en el punto meso braquial marcado anteriormente.
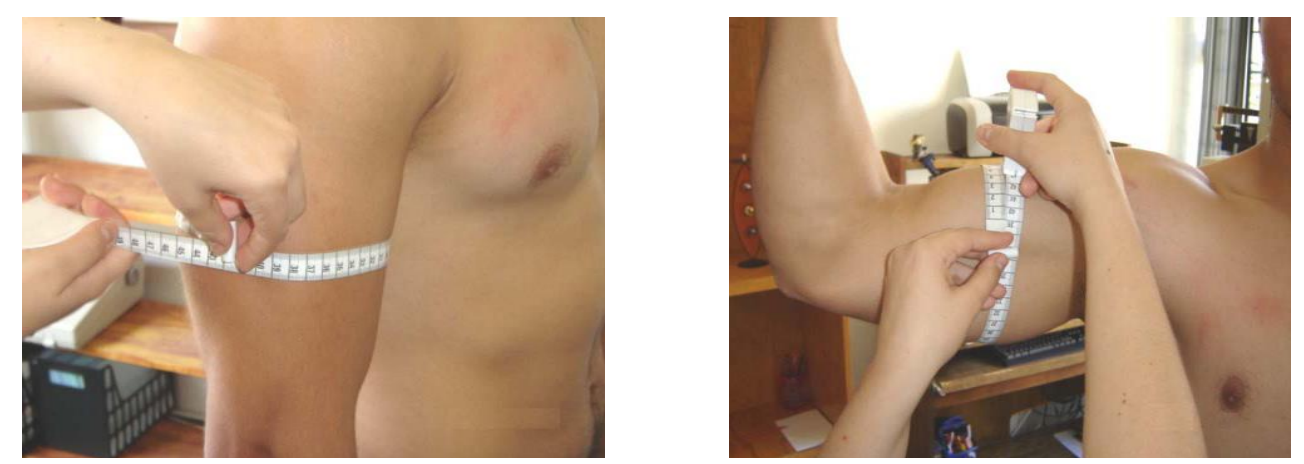

Ilustración 25: Medición de la circunferencia del brazo

\subsubsection{Perímetro del Muslo}

Para esta dimensión existen 3 medidas:

1. Circunferencia Superior

2. Circunferencia Media

3. Circunferencia Inferior

La circunferencia media es la que normalmente debe utilizar el evaluador, ya que tiene mayor variación al desarrollar algún programa de acondicionamiento físico.

La circunferencia media del muslo puede determinarse marcando la distancia media entre el pliegue inguinal y el borde proximal de la rótula.

\section{Procedimiento:}

1. El evaluado debe estar de pie para identificar el borde proximal de la rótula, y luego sentarse o poner el pie sobre un banco para marcar el trocánter. Es una medida en la que el evaluado debe tomar dos posiciones para la misma medición.

2. Esta medida debe tomarse en la mitad del muslo, para lo cual se localiza el trocánter y el borde proximal de la rótula; para medir el largo del muslo se marca el punto medio en la parte anterior con la musculatura del muslo relajada. El evaluador debe medir el largo del muslo y marcar el punto medio.

3. Se pasa la cinta métrica por el punto marcado, sin presionar los tejidos. 


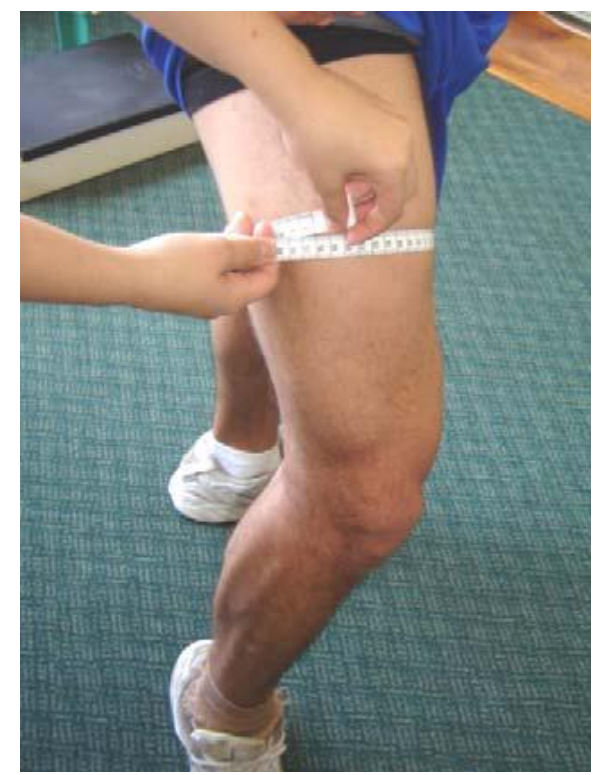

llustración 26: Medición circunferencia del muslo

\subsubsection{Perímetro de la pierna a la altura del gastrocnemio}

\section{Procedimiento:}

1. El evaluado debe estar de pie, apoyando toda la planta del pie sobre el piso y sin levantar el talón, evitando realizar una contracción muscular en el gastrocnemio.

2. El evaluador pasa la cinta de forma que rodee la zona de máximo volumen, formando un plano que es perpendicular al eje longitudinal de la pierna. 


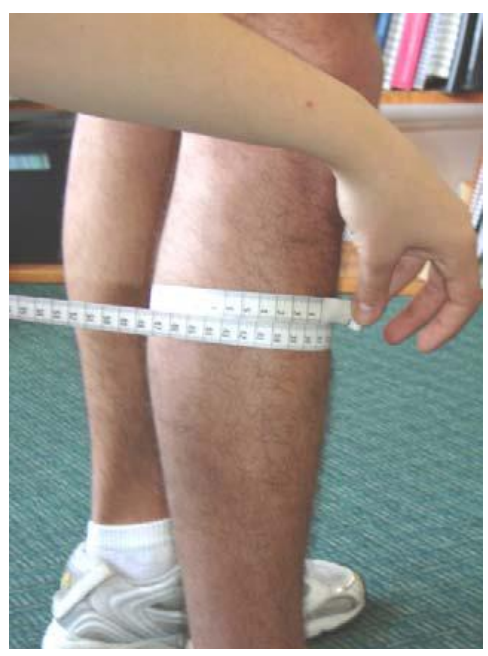

Ilustración 27: Medición circunferencia de la pierna

\subsubsection{Descripción de la toma de pliegues cutáneos a las tres personas practicantes del "E.S.B.E."}

Como responsable del programa de acondicionamiento físico, el entrenador utiliza la herramienta más adecuada para realizar esta evaluación; en este caso se usó un calibrador de los pliegues cutáneos.

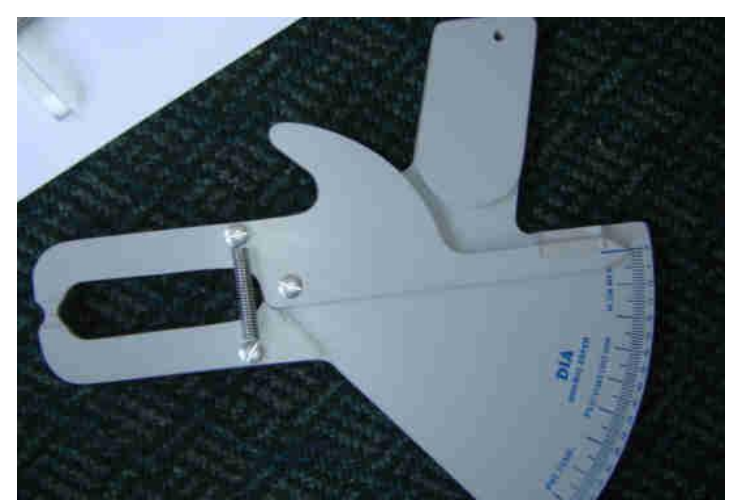

Ilustración 28: Calibrador de pliegues cutáneos

El éxito de la medición de los pliegues cutáneos depende de los detalles y técnicas a manejar durante la toma de las muestras.

Estas medidas en las zonas destinadas tienen que ser correctas para que haya exactitud entre las diferentes pruebas. 
A pesar de que soy una persona que afirma que lo más conveniente es tomar 3 mediciones consecutivas en la misma zona y escoger el resultado intermedio, una técnica más objetiva consiste en medir los diferentes puntos sucesivamente, repitiendo la serie 2 o 3 veces sin apoyarse en los valores anteriores.

Para efectos de este trabajo, con las personas evaluadas se trabajó con los pliegues subescapular, tricipital, suprailíaco, abdominal, muslo anterior y pierna. ${ }^{4}$

Estas son las localizaciones anatómicas especificadas:

\subsubsection{Subescapular}

Se toma el pliegue oblicuo medido justo debajo del ángulo inferior de la escápula.

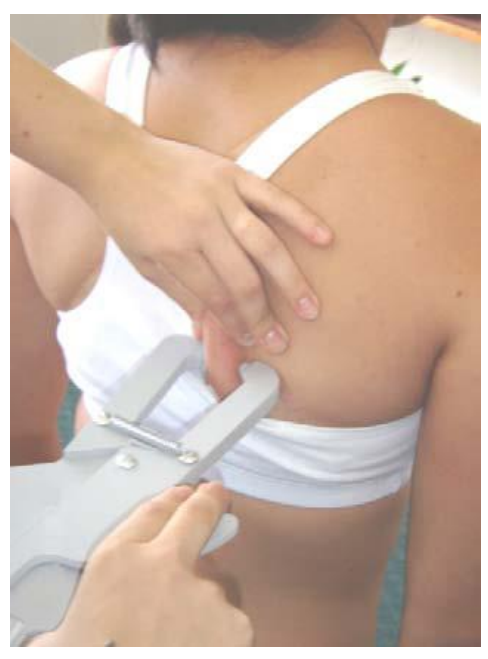

Ilustración 29: Medición del pliegue subescapular

\subsubsection{2 $\underline{\text { Tríceps }}$}

Es el pliegue paralelo al eje longitudinal del brazo, medido en el punto medio entre el olecranon y el acromion con el brazo relajado libremente a un lado del cuerpo.

\footnotetext{
${ }^{4}$ Cf. Fitness muscular - George et-al. test y pruebas físicas. Paidotribo 1996. Barcelona y V.H Heyward. Evaluacion y prescripción del ejercicio Paidotribo 2006. Barcelona.
} 


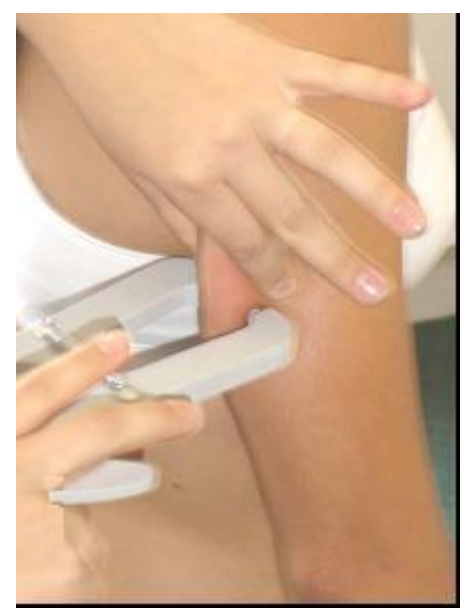

llustración 30: Medición del pliegue del tríceps

\subsubsection{Suprailíaco}

Pliegue ligeramente oblicuo levantado siguiendo el contorno natural del pliegue que está encima de la cresta ilíaca, en la línea axilar anterior.

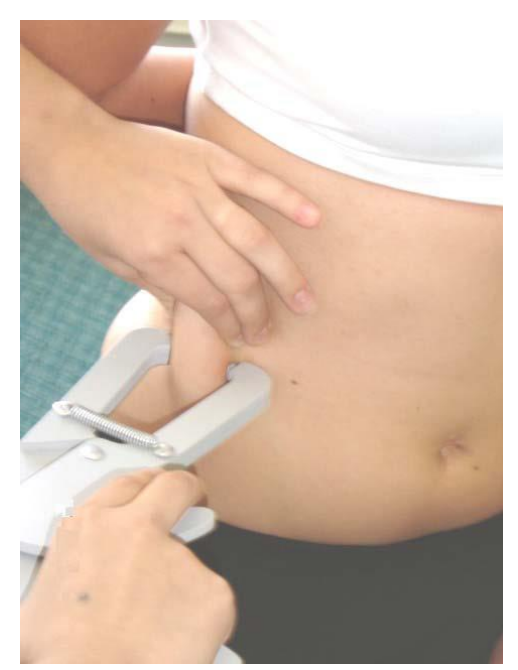

Ilustración 31: Medición del pliegue supra ilíaco

\subsubsection{Abdomen}

Pliegue vertical, tomado por lo general a la derecha del ombligo de quien esta siendo evaluado, a unos 3 centímetros del mismo 


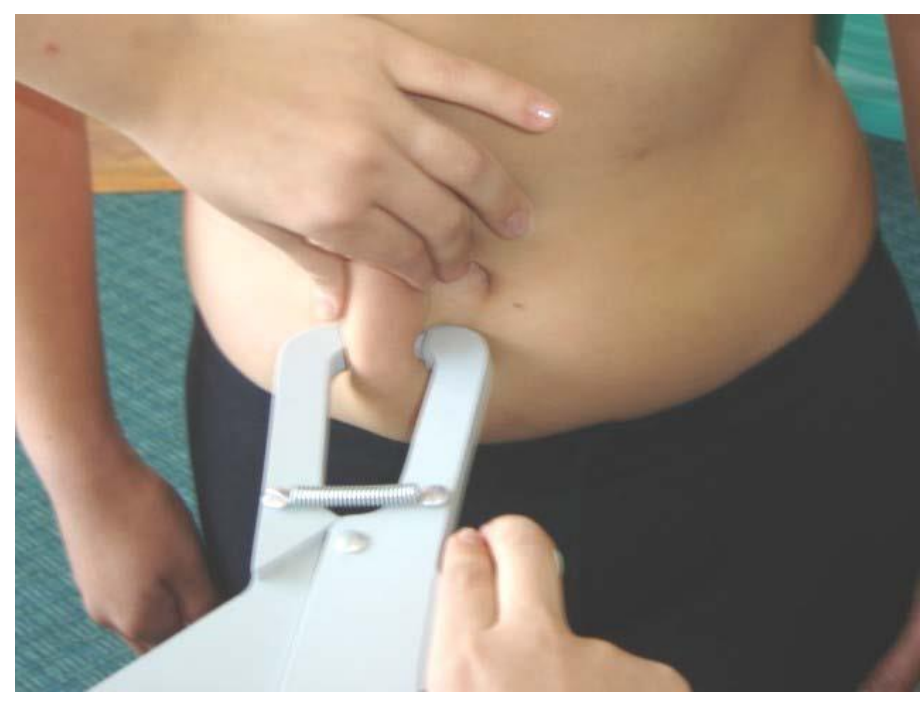

Ilustración 32: Medición del pliegue abdominal

\subsubsection{Muslo}

Se toma el pliegue vertical en la mitad de la parte anterior del muslo, tomado a la mitad de la medida tomada entre la rótula y la cadera.

Medida tomada desde el pliegue de la parte anterior de la cadera y muslo, la cual debe estar a 90 grados (preferiblemente).

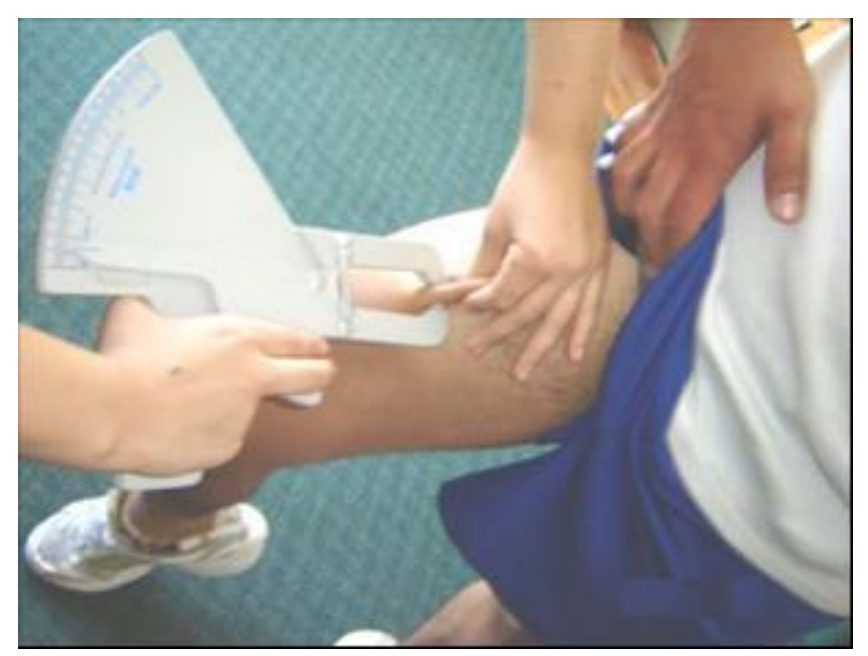

Ilustración 33: Medición del pliegue del muslo

\subsubsection{Pantorrilla}


Medida tomada en el perímetro mayor de la pantorrilla (gastrocnemio), preferiblemente en la pierna derecha. La mayoría de veces es tomada en la parte interna de la pierna.

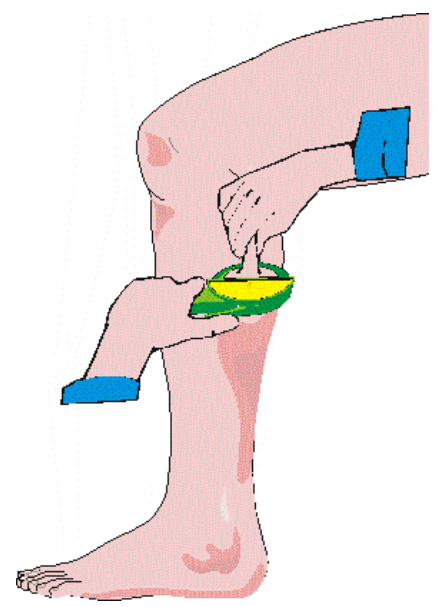

Ilustración 34: Medición del pliegue de pantorrilla

\subsection{Prueba de resistencia muscular dinámica}

La resistencia muscular dinámica puede evaluarse haciendo que el individuo ejecute tantas repeticiones como sea posible empleando un peso que represente un porcentaje determinado del peso corporal o de la fuerza máxima (1RM). Conociendo su fuerza máxima, algunos autores sugieren usar un peso que sea el $70 \%$ del valor del 1RM para cada ejercicio. ${ }^{15}$

El 1RM es la medida estándar para valorar la fuerza máxima dinámica concéntrica. No obstante, este tipo de pruebas toma mucho tiempo de práctica y puede exponer a los individuos que recién inician a un alto riesgo de lesión, cuando son evaluados.

Algunos escritores dan a entender que el uso de un procedimiento que requiere una carga dada por el evaluado para estimar el 1RM la fuerza máxima individual tiene un gran atractivo. Por consiguiente, las pruebas de $\mathrm{RM}$ son la herramienta más comúnmente usada en la población general.

En las últimas décadas han sido desarrolladas muchas estimaciones para predecir el 1RM usando tests sub-máximos. ${ }^{5}$

\begin{tabular}{|l|l|}
\hline Autor & Ecuación predicción 1-RM \\
\hline Brzycki $(1993)$ & $1-\mathrm{RM}=$ peso $/(1.0278-(0.0278 \times$ reps. $))$ \\
\hline Epley $(1985)$ & $1-\mathrm{RM}=($ peso $\times 0,0333 \times$ reps. $)+$ peso \\
\hline Lander $(1985)$ & $1-\mathrm{RM}=100 \times$ peso $/(101,3-2,67123 \times$ reps. $)$ \\
\hline Mayhew et al. $(1992)$ & $1-\mathrm{RM}=100 \times$ peso $/(52,2+41,9 \times$ exp. $(-0,055 \times$ reps. $))$ \\
\hline O'Conner et al. $(1989)$ & $1-\mathrm{RM}=$ peso $(1+0,025 \times$ reps. $)$ \\
\hline Wathan $(1994)$ & $1-\mathrm{RM}=100 \times$ peso $/(48,8+53,8 \times$ exp. $(-0,075 \times$ reps. $))$ \\
\hline
\end{tabular}

\footnotetext{
${ }^{5}$ Cf. nuevamente Fitness muscular - George et-al. test y pruebas físicas. Paidotribo 1996. Barcelona y V.H Heyward. Evaluacion y prescripción del ejercicio Paidotribo 2006. Barcelona.
} 
*reps.: repeticiones// exp.: exponente// peso: peso usado en la evaluación

Para este trabajo se optó por usar la formula de Body Epley Workout, por estar entre las más usadas y conocidas.

Epley (1985): (Peso levantado x 0,0333 x Repeticiones hasta el fallo) + Peso levantado

En la primera de las pruebas se buscaba tener un peso de referencia para las siguientes evaluaciones.

Las fechas de evaluación de fuerza estuvieron lo más cercanas posible a las evaluaciones antropométricas.

\subsubsection{Descripción de evaluación de la fuerza en aparatos multifuncionales}

\subsubsection{Prueba de fuerza de pecho}

La evaluación de fuerza de pecho se realizó en lo que los gimnasios de Argentina llaman ejercicio de mariposa, en el que se está sentado con la espalda apoyada totalmente sobre el espaldar de una silla mínimamente inclinada.

Es un trabajo en donde los brazos parten estando a 90 grados respecto al tronco, al igual que los antebrazos respecto a los brazos.

Se da el trabajo de pecho cuando se cierran los antebrazos buscando tener la articulación media de los brazos en frente del esternón. Se buscó que la velocidad de contracción y extensión del grupo muscular en cuestión fuese la misma, controlada, por ejemplo, de 2 y 4 segundos por fase de contracción y extensión.

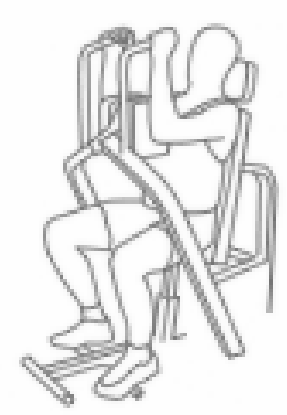

Ilustración 35: Prueba de fuerza de pecho

\subsubsection{Prueba de fuerza para extensión de pierna}

Se realizó en una máquina adecuada para tal evaluación, a dos piernas. 
La goma protectora quedó montada en la parte anterior de la pierna, ubicada entre el empeine y tibia, los cuales daban elevación a la barra que llevaba el peso a levantar.

Se buscó siempre no despegar los glúteos de la silla de apoyo, comprometiendo la buena sujeción de las manos a las barras de apoyo.

Los pies siempre deben estar paralelos entre sí.

El trabajo de cuádriceps se da al extender las piernas y levantar la carga a superar.

La extensión y flexión de las piernas debe ser, como en todos los movimientos, controlada, no dejando caer las pesas bruscamente.

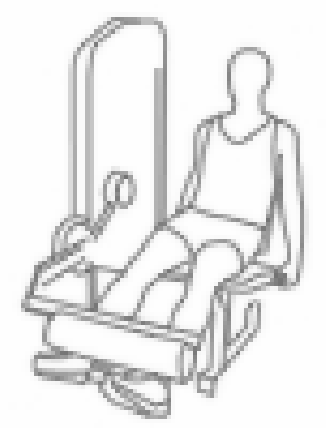

Ilustración 36: Prueba de fuerza de extensión de pierna

\subsubsection{Prueba de fuerza para flexión de brazo}

Evaluación en la que la persona está de pie, con los brazos relajados a ambos lados del tronco en posición anatómica, es decir, con la palma de las manos al frente también en ante versión, las piernas con mínima flexión y el tronco lo bastante rígido como para no ser desplazado por el peso levantado.

La articulación media del brazo debe estar tan junta al tronco como sea posible.

Las manos deben estar siempre en la misma posición, buscando estar en línea con el antebrazo, la barra es sujetada normalmente con todos los dedos de la mano, el pulgar es el único que pasa por sobre la barra.

El trabajo es flexionar el brazo sin perder la posición del tronco, llevando la barra que está atada al peso a superar. 


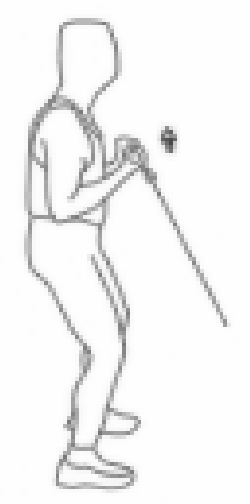

\section{Ilustración 37: Prueba de fuerza de flexión de brazos}

\subsubsection{Prueba de fuerza para flexión de pierna}

Este es un trabajo de flexión de pierna que se hace en la camilla de fortalecimiento de isquiotibiales en la posición decúbito ventral, sobre un tipo de plataforma que queda en contacto directo con la parte anterior de la pierna desde la articulación de la rodilla y cintura, inclusive el abdomen y pecho.

La cabeza normalmente trabaja en posición anatómica y los brazos, los cuales están flexionados aproximadamente a unos 90 grados, dan apoyo y ajuste del cuerpo para con la maquina.

Este movimiento es realizado por el músculo femoral, el semitendinoso y los isquiotibiales.

Se deben tener los pies paralelos entre sí para la uniformidad del accionar muscular y para que sean los músculos citados anteriormente los que trabajen directamente.

Como en los anteriores movimientos, la flexión y extensión deben ser lo más uniformes posible y manejar la misma velocidad en las dos acciones.

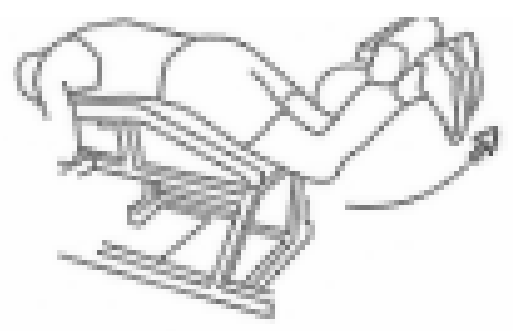

llustración 38: Prueba de fuerza flexión de la pierna 


\subsubsection{Prueba de fuerza para la extensión de brazo}

En este trabajo, la posición de tronco y piernas es la misma que se adopta cuando se trabaja con la flexión de brazo; pero con la diferencia de que aquí el músculo que está comprometido directamente es el que da extensión al brazo, el tríceps.

El ejercicio inicia estando los brazos flexionados en su totalidad y termina con la completa extensión del brazo, las manos en la parte anterior de la pierna.

Las manos, al igual que en su moviendo antagónico, deben permanecer siempre en línea con el antebrazo.

Como en todos los casos, la velocidad de extensión y flexión del brazo debe ser lo más uniforme posible, controlando entre 2 y 4 segundos por fase de contracción y extensión.

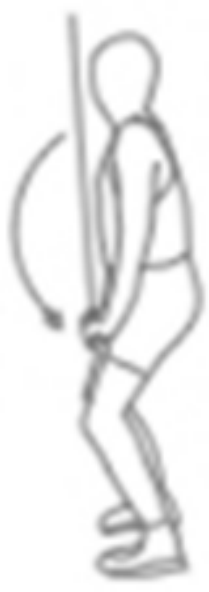

Ilustración 39: Prueba de fuerza extensión de brazos

\subsubsection{Prueba de fuerza para la espalda}

Estando sentado con espalda recta y perpendicular al piso, se hace una abducción de brazos, los cuales inician su acción estando extendidos en frente del pecho y dando el trabajo al dorsal ancho para que sean los codos quienes superen la línea media del tronco; el ejercicio es conocido en Argentina como remo en polea.

Las palmas de las manos estarán enfrentadas entre sí, sujetando la barra que está atada al peso a mover.

Es muy corriente que se deforme la técnica del trabajo haciendo que sea el lumbar quien inicie el movimiento; por el contrario, este músculo debe trabajar de forma isométrica, dando firmeza al tronco.

El apoyo y estabilidad del cuerpo lo da el apoyo de los pies contra una platina que esta a unos 45 grados respecto a la horizontal. 


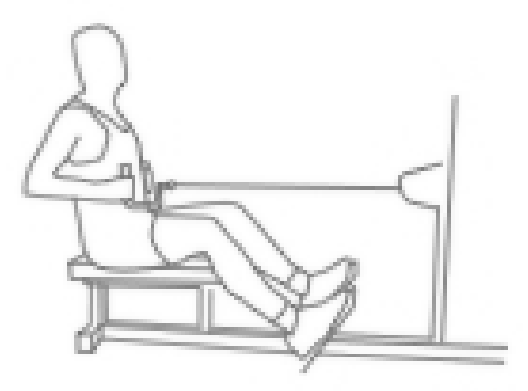

\section{llustración 40: Prueba de fuerza para dorsal ancho}

\subsubsection{Prueba de fuerza para extensión de cadera}

Este trabajo se realiza de pie, en la máquina para glúteos en multipiernas, estando el cuerpo apoyado solo en una de las piernas, que soporta el peso del cuerpo; por lo general esta pierna se encuentra en una mínima flexión.

Los pies estarán siempre paralelos entre sí, y los brazos, estando flexionados, darán estabilidad al movimiento apoyándose en una barra que forma parte del aparato.

El trabajo es realizado directamente por el glúteo medio y el mayor, que son los encargados de la extensión de cadera.

La prueba inicia teniendo la pierna del hemisferio a evaluar casi contra el abdomen, para luego dar la extensión de cadera sin que la posición de espalda sea deformada.

La cabeza estará preferiblemente siempre en extensión, mirando al frente.

Tanto la flexión como la extensión de la cadera tendrán preferiblemente la misma velocidad.

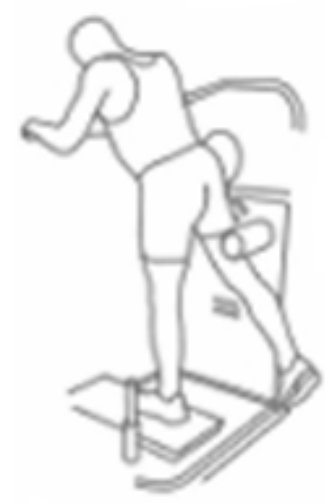

llustración 41: Prueba de fuerza para extensión de cadera 


\subsubsection{Prueba de esfuerzo para los hombros}

El músculo que trabaja de forma directa en este movimiento es el deltoides, sin por eso descartar el trabajo del trapecio, supra espinoso, infra espinoso, subescapular, ni el trabajo del redondo menor, serrato mayor, y los romboides.

Para realizar el ejercicio hay que estar sentado con un apoyo total de espalda en superficie plana, a poco menos de 90 grados respecto a la horizontal.

El trabajo, extender verticalmente los brazos en sentido contrario a la gravedad, inicia con los brazos flexionados con las manos sobre el hombro, y buscando la extensión de los mismos para llegar a tener los húmeros paralelos entre si.

La articulación de las muñecas dará preferiblemente a las manos una posición en línea con el antebrazo.

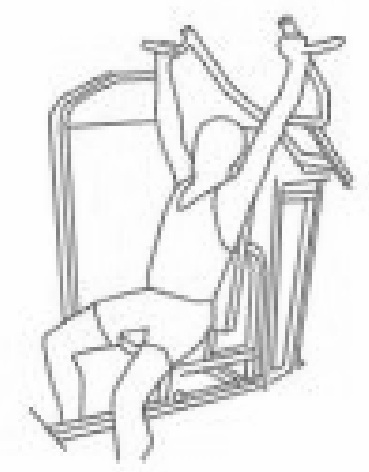

Ilustración 42: Prueba de fuerza para hombros

\subsection{PRUEBA PROGRESIVA DE ESFUERZO MÁXIMO SOBRE BICICLETA ESTÁTICA, ANALIZANDO EL COMPORTAMIENTO CARDIOVASCULAR}

\subsubsection{Descripción de la prueba de esfuerzo sobre bicicleta estática ${ }^{6}$}

La prueba de esfuerzo fue hecha de forma individual sobre la bicicleta estática, dando un cambio de carga progresiva cada 2 minutos y registrando las pulsaciones por minuto de la persona evaluada.

Se trató que el aumento de carga siempre fuese el mismo para que el comportamiento cardíaco fuese lo más progresivo posible y no aumente sus pulsaciones (registradas minuto a minuto) repentinamente.

\footnotetext{
${ }^{6}$ Cf. nuevamente Fitness muscular - George et-al. test y pruebas físicas. Paidotribo 1996. Barcelona y V.H Heyward. Evaluacion y prescripción del ejercicio Paidotribo 2006. Barcelona.
} 
En la evaluación, la cadencia de pedaleo estuvo marcada por la música que se acondicionó para tal efecto, manteniendo el ritmo lo más pronunciado posible y no dando espacios de silencio en ningún momento para no perder la misma cadencia de pedaleo durante toda la prueba.

60 giros por minuto fue la cadencia de pedaleo que se manejo para la evaluación.

Se usó siempre la misma herramienta de evaluación, la bicicleta de menos uso del gimnasio, buscando así que las bandas de frenado a la volante estuviesen lo menos solidificadas posibles.

El objetivo de esta evaluación es conducir a las personas que hicieron la prueba hasta el máximo de sus pulsaciones y tener una relación de su velocidad de recuperación, además de comparar estos datos con la apreciación teórica respecto a las máximas pulsaciones, conocer sus rangos aeróbicos y conocer si hay cambios en la pulsación basal.

Las voluntarias, las mismas que para las anteriores evaluaciones, fueron tomadas como "A", "B" y "C", siendo la primera voluntaria la persona de la evaluación " $A$ ", la segunda la "B" y tercera la "C".

Las evaluadas "A" y "C" realizaron cuatro evaluaciones, la evaluada "B" tres.

Aunque una de las fórmulas más difundidas es la de (220 - edad) en el caso de los hombres, y para las mujeres la de (225 - edad), ambas están siendo cuestionadas en la actualidad, se han difundido otro tipo de fórmulas como las siguientes:

Para hombres: F.C. máx. $=205.8-(0.685 x \text { edad en años })^{7}$

Para mujeres: F.C. máx. $=206.3-(0.771 \times \text { edad en años })^{8}$

Para hombres: F.C. máx. $=217-(0.85 \times \text { edad en años })^{9}$

Para mujeres: F.C. máx. $=208-(0.7 \times \text { edad en años })^{10}$

Y la formula de Karvonen, que será la usada en este trabajo para hallar la frecuencia máxima teórica:

Para hombres F.C. máx. $=\left(\left(210-\left(0,5^{*}\right.\right.\right.$ edad en años $\left.)\right)-1 \%$ del peso $)+4^{11}$

Para mujeres F.C. máx. $=\left(210-\left(0,5^{*}\right.\right.$ edad en años $\left.)\right)-1 \%$ del peso ${ }^{12}$

\footnotetext{
${ }^{7}$ Inbar, O.Oten, Scheinowitz, MRotstein, A, Dlin, R and Casaburi. R.Normal - Cardiopulmonary responses during incremental exercise in 20-70 yr old men. Med Sci Sport exerc 26(5): 538.546.1994.

${ }^{8}$ Londeree, $\mathrm{Br}$ and Moesberg, ML. Effect of age and other factors on maximal heart rate. Res Quarter exerc.Sport 1982; 53(4):297-304.

${ }_{9}$ Miller,WC Wllace,JP and Eggert, KE.Predicting max har and the HR-WO2 relationship for exercise prescription in obesity. Med Sci Sports Exerc 1993;25 (9):1077-1081

${ }^{10}$ Whaley,MW,Kaminsky,L.A,Dwyer,GB,Getchell,L.H and Norton, J.A Predictors of over - and underachievement of age - predicted maximal heart rate. Med Sci Sports Exerc 1992 24(10):1173-1179

${ }_{12}$ Best Fit Formula, "BFF”,Adams 2002. - Referenciada por Maestro Adrián Casas.

12 Ibid.
} 


\section{RESULTADOS DE LAS EVALUACIONES ANTROPOMÉTRICAS}

\subsection{RESULTADOS DE LAS EVALUACIONES DE PERÍMETROS CORPORALES}

Se tuvo que trabajar estableciendo un punto como fecha de inicio, las 3 personas habían iniciado poco tiempo antes.

Se trabajó con gente que nunca había llegado al ejercicio sobre la bicicleta estática.

Si se trabajó sólo con 3 personas es porque no era nada fácil disponer del tiempo de las demás; de hecho, ellas no fueron las únicas que fueron evaluadas, pero otras personas que habían comenzado las pruebas no pudieron continuarlas.

Todas las evaluaciones fueron hechas entre las 14 y 17 horas del día.

En evaluaciones como estas donde no se tiene una marcación digestiva, se nota cómo el cuerpo toma de diferente manera la actividad física, perdiendo tamaño no de manera localizada como pudiese llegarse a pensar.

La intensidad en la asistencia a la actividad no fue la misma en cada una de las evaluadas.

\subsubsection{Evaluaciones antropometricas de la primera voluntaria}

Con la primera voluntaria se hizo la primera evaluación luego de haber asistido a 18 clases de "E.S.B.E."

La segunda evaluación se hizo a las 15 clases de la primera evaluación, y por lo tanto luego de haber hecho 33 clases desde su inicio.

La tercera evaluación se hizo a las 15 clases de la segunda evaluación y luego de haber hecho 48 clases desde su inicio.

La cuarta y última evaluación se hizo a las 19 clases de la tercera evaluación y luego de haber hecho 67 clases desde su inicio.

Esta voluntaria practica la actividad 3 veces por semana. 
(Medidas tomadas en centímetros)

\begin{tabular}{|c|c|c|c|c|c|c|c|}
\hline 95 & 75,5 & 97,8 & 26 & 26,4 & 51,7 & 31,5 & Evaluación $\mathrm{A}$ \\
\hline Pecho & Cintura & Cadera & Brazo Re. & Brazo T. & Muslo & Pantorrilla & \\
\hline 92,8 & 77,8 & 96,5 & 25,8 & 27,5 & 52,1 & 31 & Evaluación B \\
\hline$-2,2$ & 2,3 & $-1,3$ & $-0,2$ & 1,1 & 0,4 & $-0,5$ & Diferencia A-B \\
\hline 93 & 78,2 & 96 & 27 & 27,4 & 51 & 32 & Evaluación C \\
\hline-2 & 2,7 & $-1,8$ & 1 & 1 & $-0,7$ & 0,5 & Diferencia A-C \\
\hline 94,2 & 77,7 & 95 & 26,5 & 27,3 & 49,5 & 32,7 & Evaluación $\mathrm{D}$ \\
\hline$-0,8$ & 2,2 & $-2,8$ & 0,5 & 0,9 & $-2,2$ & 1,2 & Diferencia A-D \\
\hline
\end{tabular}

Esta persona bajó, en el tiempo de trabajo, 2,8 cm. en el perímetro de la cadera y 2,2 $\mathrm{cm}$. en el del muslo.

Aumentó en cintura más de $2 \mathrm{~cm}$. y en pantorrilla poco más de 1 .

Si comparáramos la suma de los perímetros de la primera prueba $(403.9 \mathrm{~cm}$.) con la suma de los perímetros de la última $(402.9 \mathrm{~cm}$.), encontraríamos que sólo bajo $1 \mathrm{~cm}$. Veremos en las siguientes pruebas cómo es el comportamiento de sus pliegues y peso corporal, además de su comportamiento cardiovascular que es de lo más importante, así como su fuerza muscular en los músculos esqueléticos.
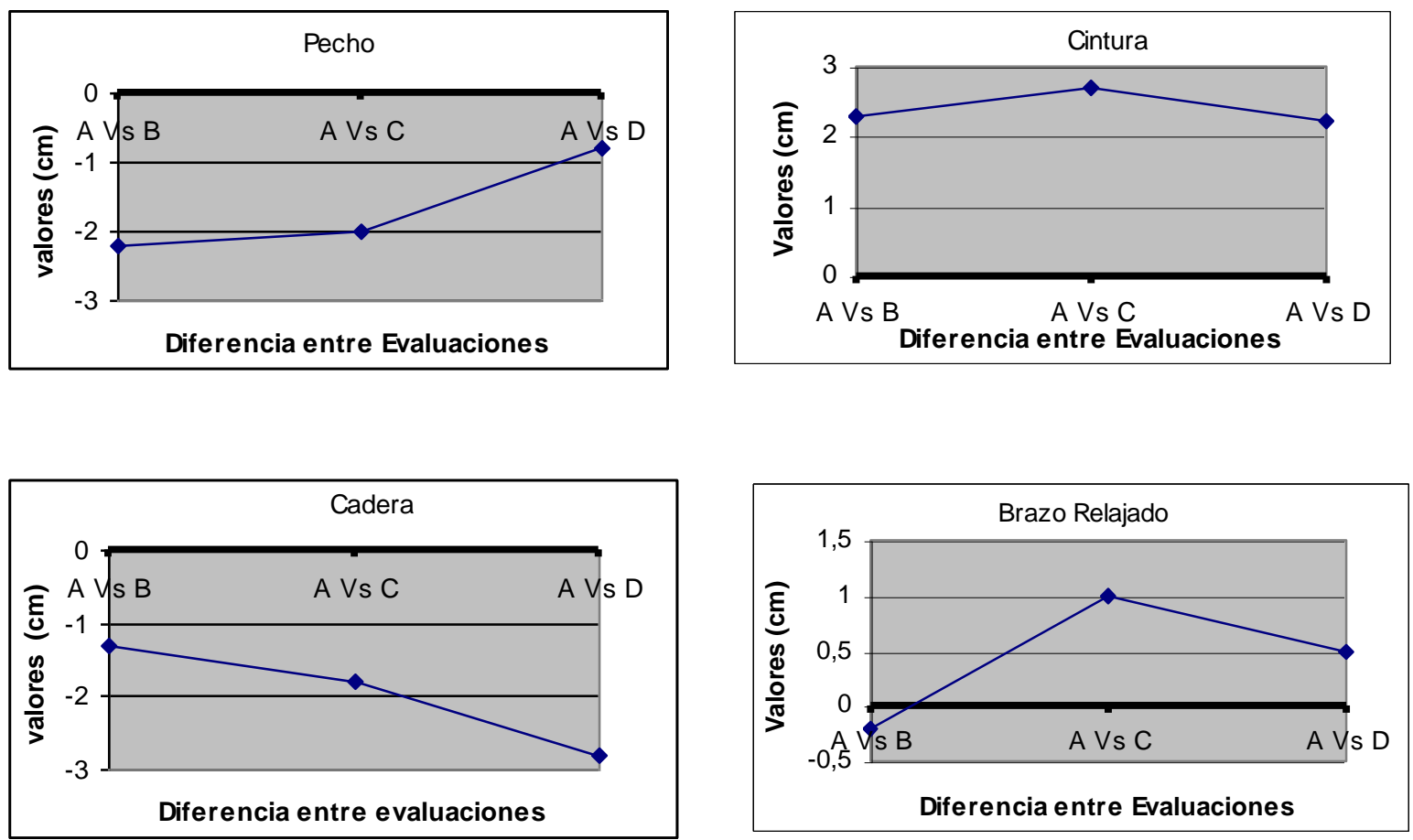

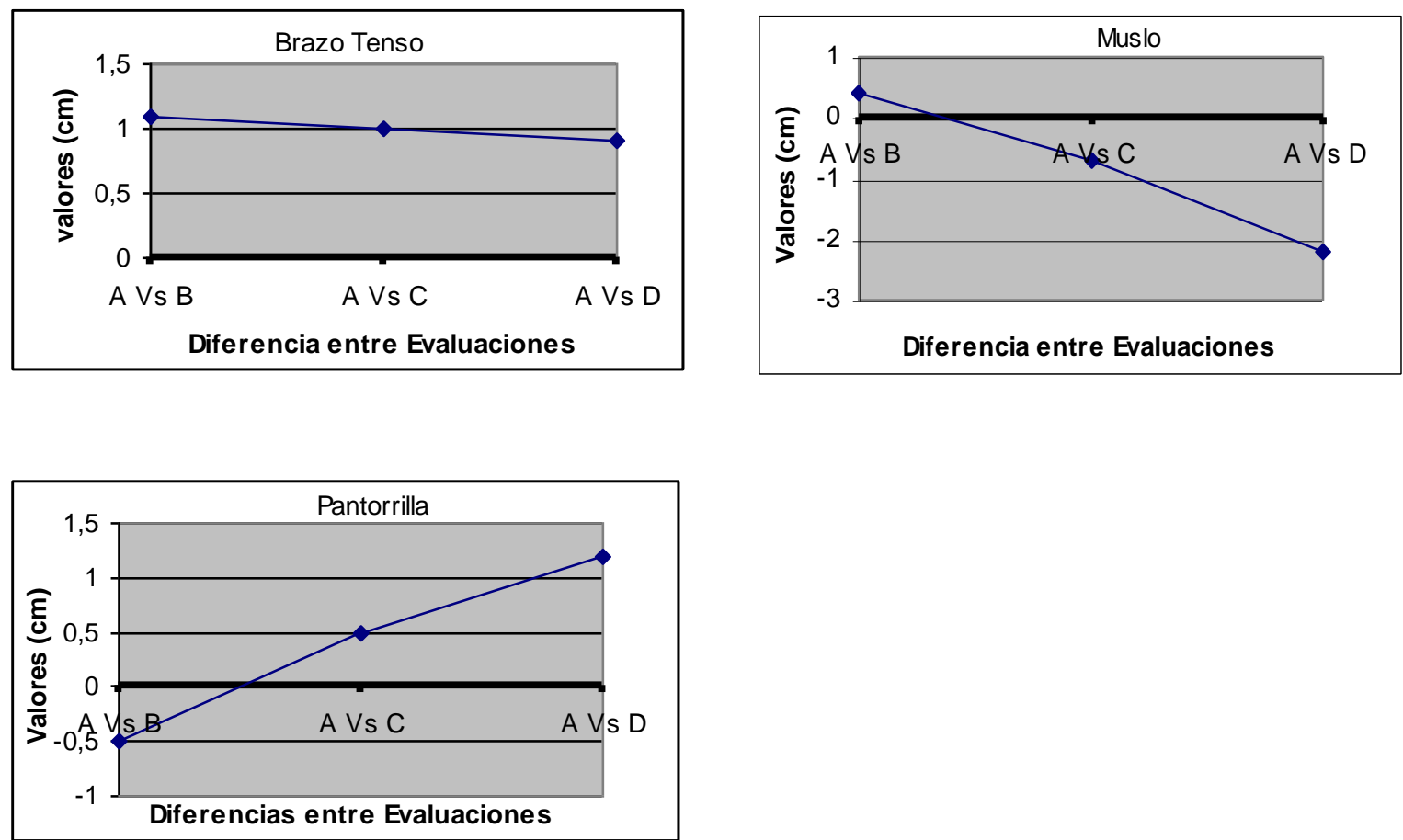

\subsubsection{Evaluaciones antropometricas de la segunda voluntaria}

Con la primera voluntaria se hizo la primera evaluación luego de haber asistido a 15 clases.

La segunda evaluación se hizo a las 11 clases de la primera evaluación, y por lo tanto luego de haber hecho 26 clases desde su inicio.

La tercera evaluación se hizo a las 12 clases de la segunda evaluación y luego de haber hecho 38 clases desde su inicio.

La cuarta y última evaluación se hizo a las 17 clases de la tercera evaluación y luego de haber hecho 55 clases desde su inicio.

Esta voluntaria practica la actividad 3 veces por semana.

(Medidas tomadas en centímetros)

\begin{tabular}{|c|c|c|c|c|c|c|}
\hline 93 & 74 & 108 & 29 & 29,5 & 61 & 37 \\
\hline Pecho & Cintura & Cadera & Brazo Re. & Brazo T. & Muslo & Pantorrilla \\
\hline 90,5 & 71,5 & 104 & 29 & 29,5 & 57,5 & 36,6 \\
\hline$-2,5$ & $-2,5$ & -4 & 0 & 0 & $-3,5$ & $-0,4$ \\
\hline 91 & 72 & 104,5 & 28,3 & 28,3 & 54,3 & 37 \\
\hline-2 & -2 & $-3,5$ & $-0,7$ & $-1,2$ & $-6,7$ & 0 \\
\hline 89,6 & 69 & 96,5 & 27,2 & 28 & 53 & 36,2 \\
\hline$-3,4$ & -5 & $-11,5$ & $-1,8$ & $-1,5$ & -8 & $-0,8$ \\
\hline
\end{tabular}

Evaluación A

Evaluación $B$ Diferencia A-B

Evaluación $\mathrm{C}$

Diferencia A-C

Evaluación D

Diferencia A-D 
Esta segunda persona asistió a la actividad 13 veces menos de lo que asistió la primera persona evaluada.

Sin embargo, bajó en todos los perímetros, y llegó a bajar más de $11 \mathrm{~cm}$. en uno de ellos.

Donde más bajó fue en la cadera: $11,5 \mathrm{~cm}$.

Donde menos bajó fue en la pantorrilla: $0.8 \mathrm{~cm}$.

Sumando todos los perímetros y comparando la primera medición $(436 \mathrm{~cm}$.) con la última $(399,5 \mathrm{~cm}$.), vemos que hay una diferencia de perímetros corporales de $-36,5$ $\mathrm{cm}$.
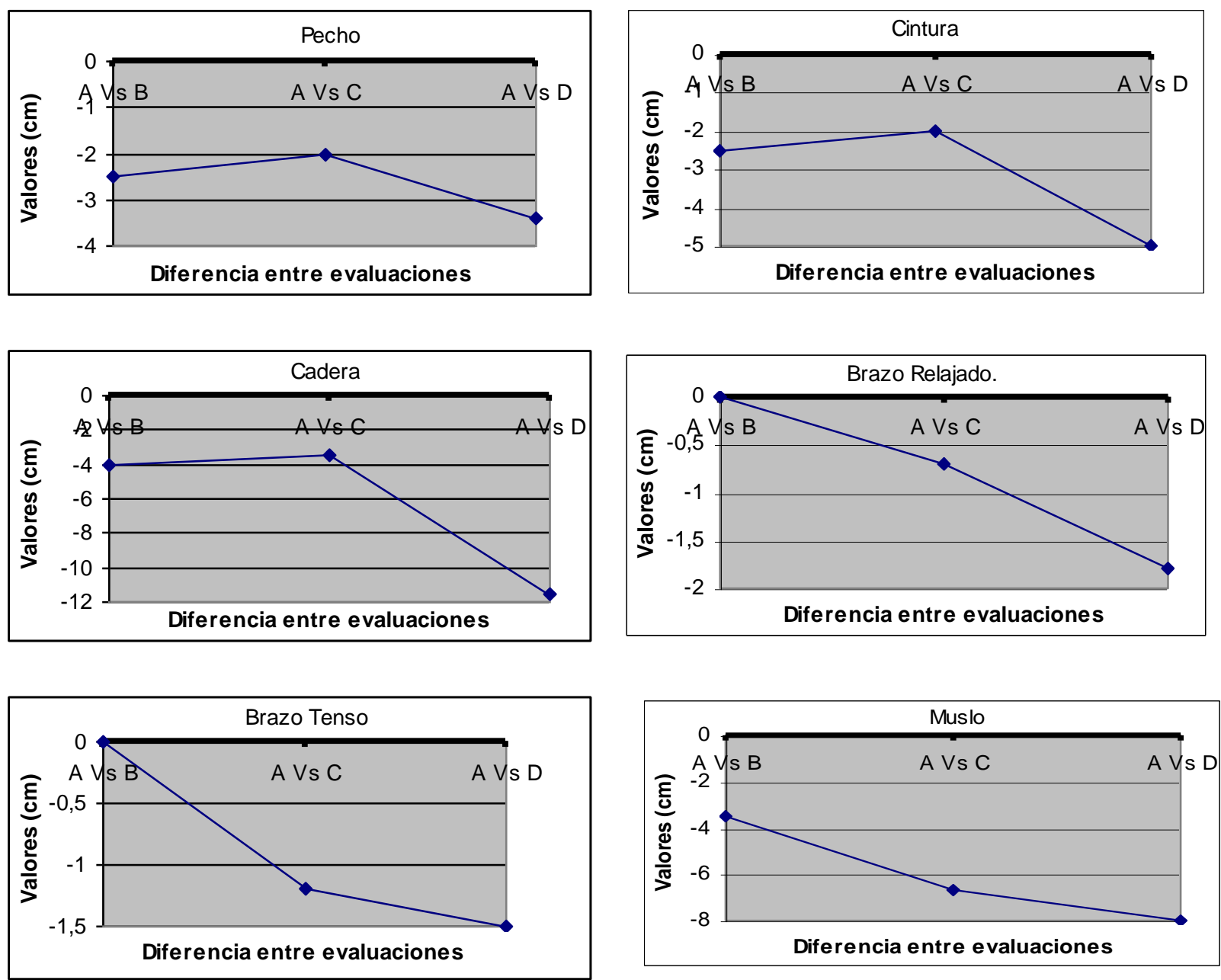


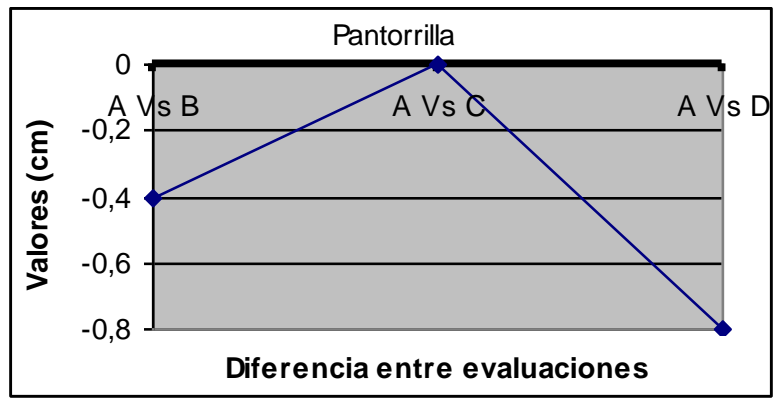

\subsubsection{Evaluaciones antropometricas de la tercera voluntaria}

Con la primera voluntaria se hizo la primera evaluación luego de haber asistido a 11 clases.

La segunda evaluación se hizo a las 7 clases de la primera evaluación, y por lo tanto luego de haber hecho 18 clases desde su inicio.

La tercera evaluación se hizo a las 9 clases de la segunda evaluación y luego de haber hecho 27 clases desde su inicio.

La cuarta y última evaluación se hizo a las 17 clases de la tercera evaluación y luego de haber hecho 44 clases desde su inicio.

Esta voluntaria practica la actividad 2 veces por semana.

(Medidas tomadas en centímetros)

\begin{tabular}{|c|c|c|c|c|c|c|c|}
\hline 80 & 64,6 & 96,9 & 28,8 & 28,8 & 56,3 & 35,8 & Evaluación A \\
\hline Pecho & Cintura & Cadera & Brazo Re. & Brazo T. & Muslo & Pantorrilla & \\
\hline 81 & 64,4 & 96,5 & 26,8 & 27,5 & 54 & 36,6 & Evaluación $B$ \\
\hline 1 & $-0,2$ & $-0,4$ & -2 & $-1,3$ & $-2,3$ & 0,8 & Diferencia A-B \\
\hline 79,5 & 65,3 & 96,2 & 26,9 & 27 & 55 & 35,8 & Evaluación C \\
\hline$-0,5$ & 0,7 & $-0,7$ & $-1,9$ & $-1,8$ & $-1,3$ & 0 & Diferencia A-C \\
\hline 80,5 & 64 & 94,7 & 26,6 & 27,2 & 55 & 35,5 & Evaluación D \\
\hline 0,5 & $-0,6$ & $-2,2$ & $-2,2$ & $-1,6$ & $-1,3$ & $-0,3$ & Diferencia A-D \\
\hline
\end{tabular}

Si bien esta persona no bajó tanto como la segunda, no hay que olvidar que asistía 2 veces por semana, mientras que la primera y la segunda lo hacían 3 veces.

El pecho aumentó su perímetro en $0,5 \mathrm{~cm}$.

La cadera y el brazo relajado fue en donde más se bajó, siendo $2,2 \mathrm{~cm}$. la diferencia con la primera medida.

Donde menos se bajó fue en la pantorrilla, con sólo $0,3 \mathrm{~cm}$. la diferencia.

Teniendo en cuenta la sumatoria de las primeras medidas $(362,4 \mathrm{~cm}$.) y la sumatoria de las medidas de la última prueba $(383,5 \mathrm{~cm}$.) hay una diferencia de $-21,1 \mathrm{~cm}$. 

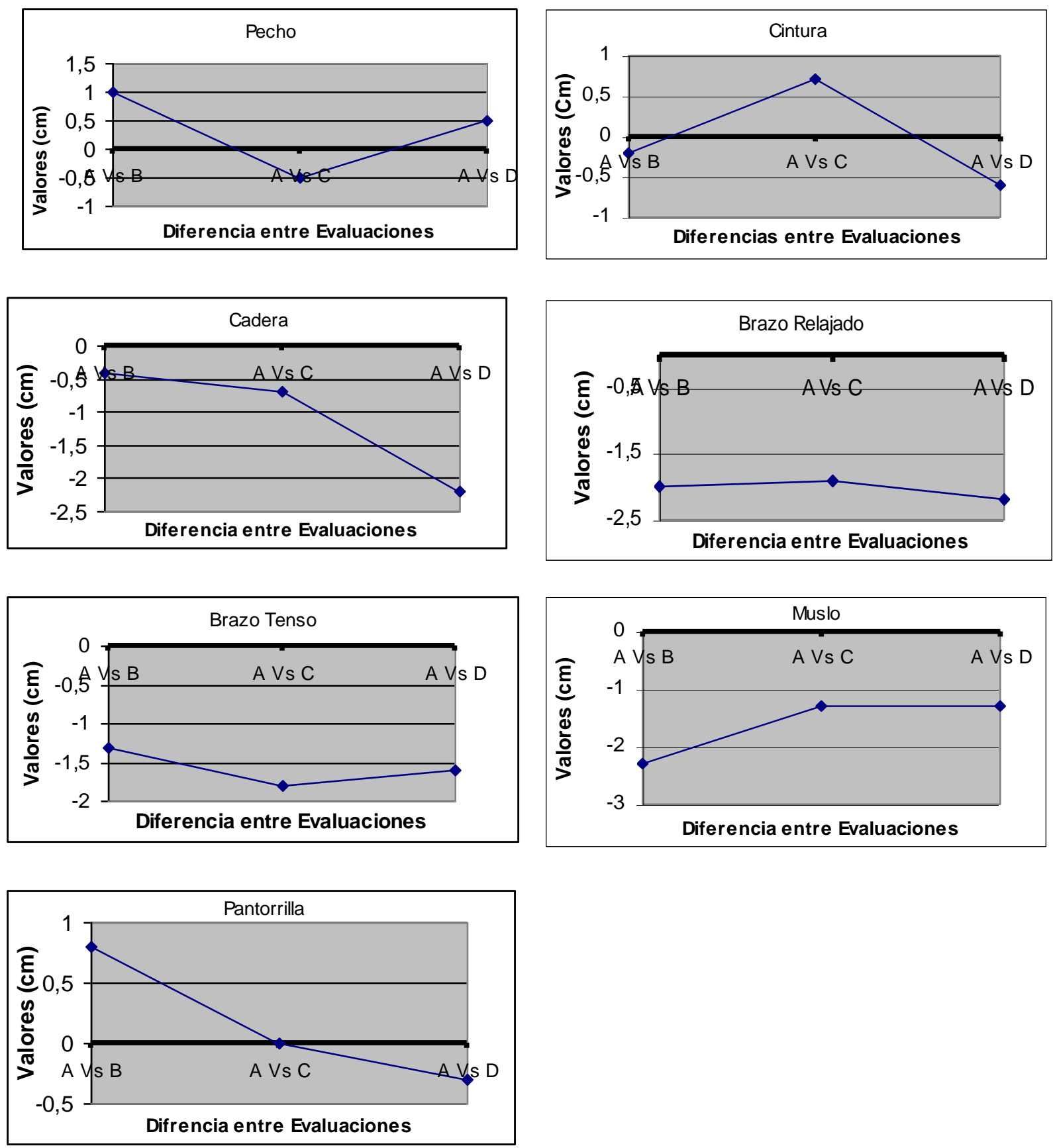

\subsection{RESULTADOS DE LAS EVALUACIONES DE PLIEGUES CUTÁNEOS}

Continuando con las evaluaciones a las 3 mujeres voluntarias, y no olvidando el tiempo de trabajo de cada una, retomamos el informe de las antropometrías, esta vez manejando los pliegues cutáneos.

No se manejó ningún tipo de fórmula para encontrar porcentajes grasos, solo se anotó directamente el valor de los pliegues y la sumatoria de los mismos. 


\subsubsection{Evaluaciones de pliegues cutáneos a la primera voluntaria}

\begin{tabular}{|c|c|c|c|c|c|}
\hline 19 & 13 & 28 & 37 & 31 & 15 \\
\hline Subescapular & Tricipital & Suprailiaco & Abdom inal & Muslo Ant & Pierna In \\
\hline 17 & 15 & 22 & 35 & 17 & 17 \\
\hline-2 & 2 & -6 & -2 & -14 & 2 \\
\hline 15 & 12,5 & 18 & 25 & 15 & 13,5 \\
\hline-4 & $-0,5$ & -10 & -12 & -16 & $-1,5$ \\
\hline 14,5 & 12 & 16 & 23 & 12,5 & 15 \\
\hline$-4,5$ & -1 & -12 & -14 & $-18,5$ & 0 \\
\hline
\end{tabular}

Evaluación A

Evaluación B

Diferencia A-B

Evaluación $\mathbf{C}$

Diferencia A-C

Evaluación D

Diferencia A-D

La anterior es la tabla de datos y la diferencia entre las tomas hechas durante el seguimiento.

La siguiente gráfica es la exposición de los datos anteriores, donde se marcan las diferencias:

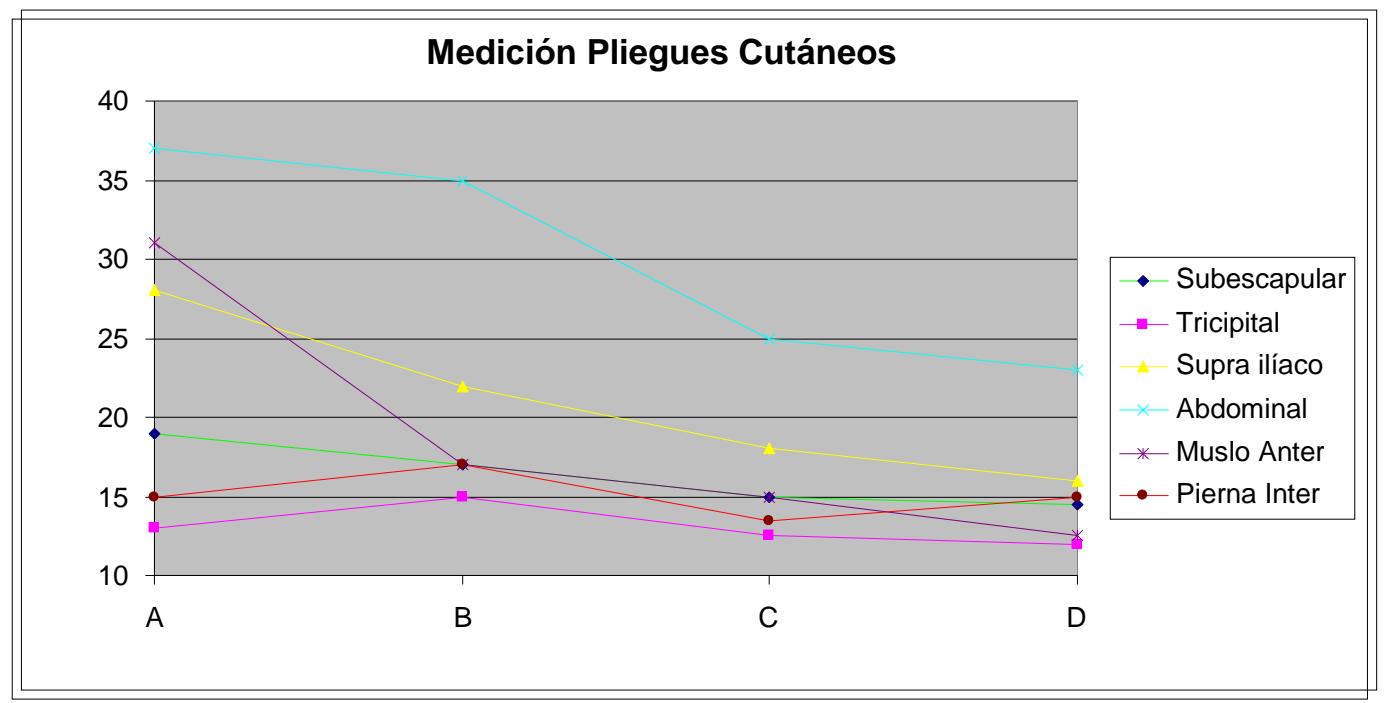

Visto de otra manera, sumando todos los pliegues cutáneos tomados en cada una de las evaluaciones encontramos lo siguiente: 


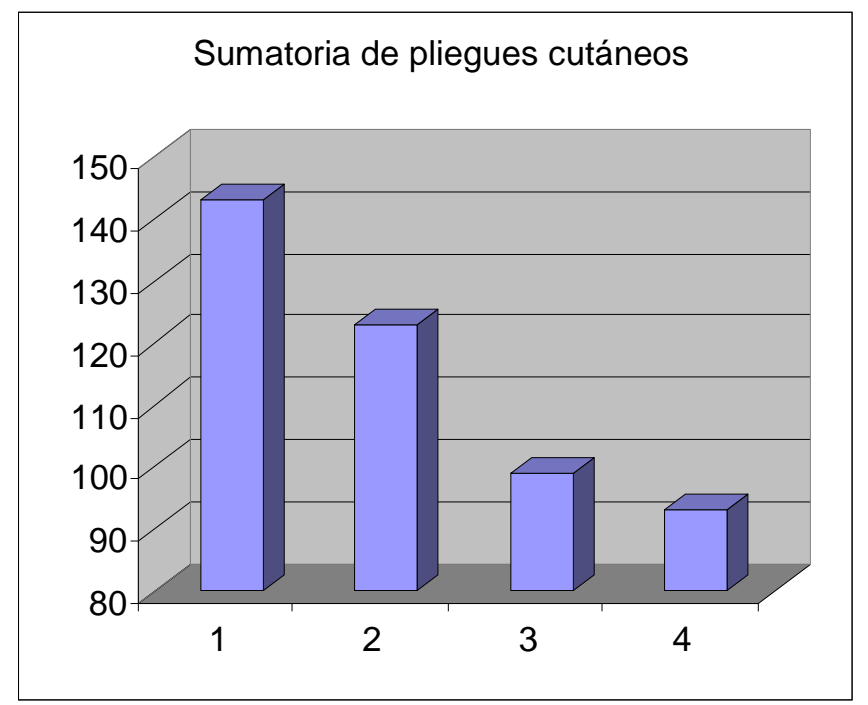

Sumando los 6 pliegues cutáneos de esta persona tenidos en cuenta, y comparando el resultado de la primera prueba y la última, se ve que pasó de $143 \mathrm{~mm}$. a $93 \mathrm{~mm}$; es decir, bajó $50 \mathrm{~mm}$. Se realizaron con ella 67 clases.

\subsubsection{Evaluaciones de pliegues cutáneos a la segunda voluntaria}

\begin{tabular}{|c|c|c|c|c|c|}
\hline 9 & 18 & 25 & 23 & 37 & 18 \\
\hline Subescapular & Tricipital & Suprailiaco & Abdom inal & Muslo Ant & Pierna In \\
\hline 9 & 15 & 13 & 19 & 30 & 19 \\
\hline 0 & -3 & -12 & -4 & -7 & 1 \\
\hline 8 & 16 & 11 & 20 & 26,5 & 15,5 \\
\hline-1 & -2 & -14 & -3 & $-10,5$ & $-2,5$ \\
\hline 7,5 & 15 & 9 & 13,5 & 22 & 13 \\
\hline$-1,5$ & -3 & -16 & $-9,5$ & -15 & -5 \\
\hline
\end{tabular}

\section{Evaluación A}

Evaluación B

Diferencia A-B

Evaluación $\mathbf{C}$

Diferencia A-C

Evaluación D

Diferencia A-D

Como con la primera persona evaluada, la anterior es la tabla de datos y la diferencia entre cada una de las pruebas.

La siguiente es la tabla de datos volcada a una gráfica: 


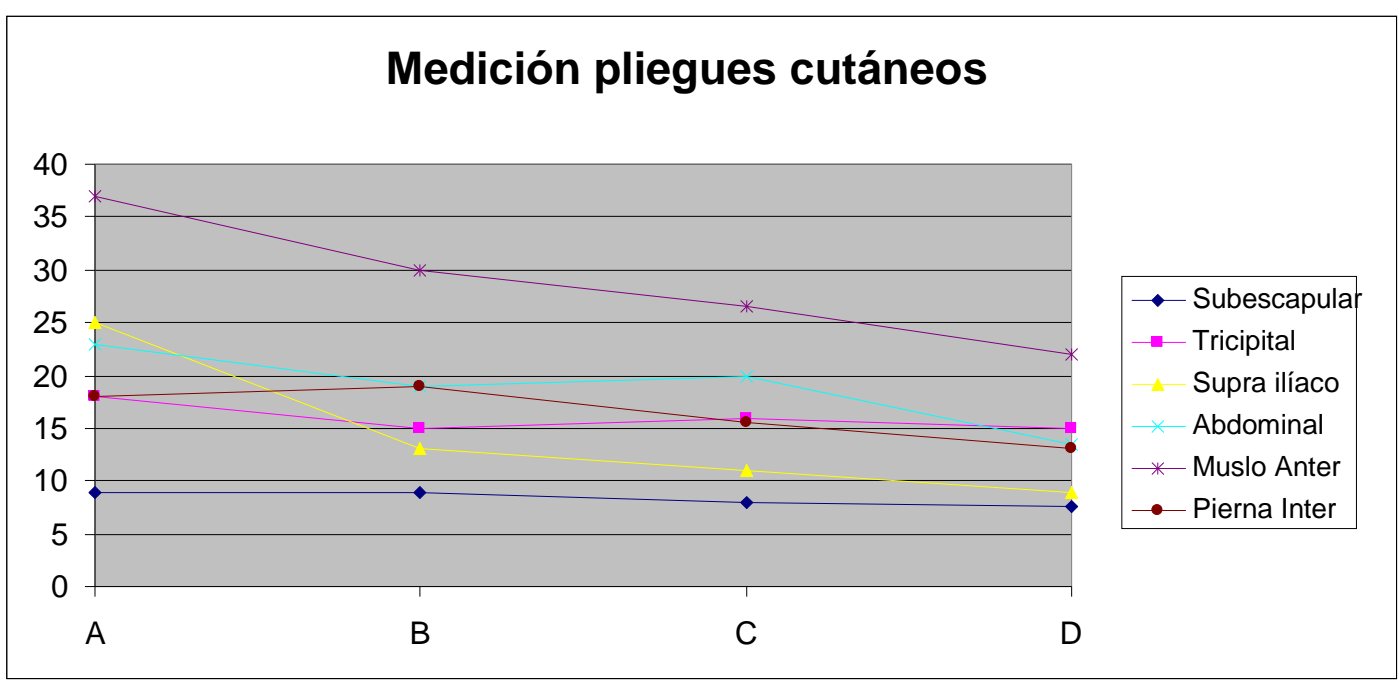

Sumando los pliegues cutáneos, las evaluaciones se ven de esta manera:

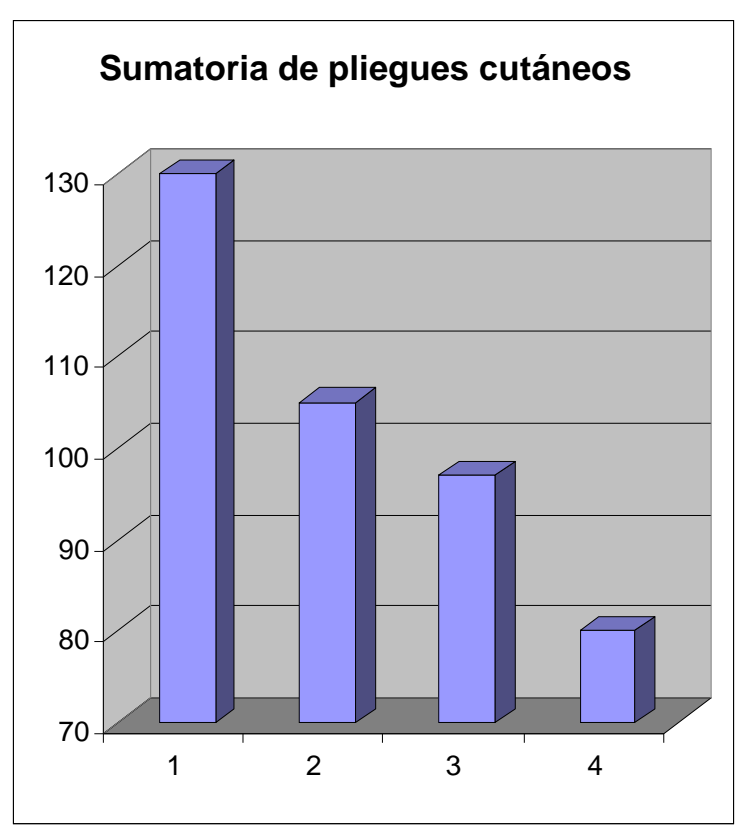

Sumando los 6 pliegues cutáneos de esta persona tenidos en cuenta, y comparando el resultado de la primera prueba y la última, se ve que pasó de $130 \mathrm{~mm}$. a $80 \mathrm{~mm}$; es decir, bajó $50 \mathrm{~mm}$, la misma cantidad que la persona evaluada anteriormente, pero habiendo hecho 12 clases menos. Realizó 55 clases 
10.2.3 Evaluaciones de pliegues cutáneos a la tercera voluntaria

\begin{tabular}{|c|c|c|c|c|c|}
\hline 12 & 15 & 9 & 14 & 27 & 19 \\
\hline Subescapular & Tricipital & Suprailíaco & Abdom inal & Muslo Ant & Pierna In \\
\hline 11 & 15 & 7 & 13 & 28 & 17,5 \\
\hline-1 & 0 & -2 & -1 & 1 & $-1,5$ \\
\hline 9,5 & 15 & 5,5 & 12,5 & 26 & 18,5 \\
\hline$-2,5$ & 0 & $-3,5$ & $-1,5$ & -1 & $-0,5$ \\
\hline 9 & 14,5 & 4,5 & 13 & 23 & 18 \\
\hline-3 & $-0,5$ & $-4,5$ & -1 & -4 & -1 \\
\hline
\end{tabular}

Evaluación A

Evaluación B

Diferencia A-B

Evaluación C

Diferencia A-C

Evaluación D

Diferencia A-D

Estos son los datos de la tercera persona evaluada, mostrando también la diferencia entre las medidas tomadas.

La siguiente es la tabla de datos volcada a una gráfica:

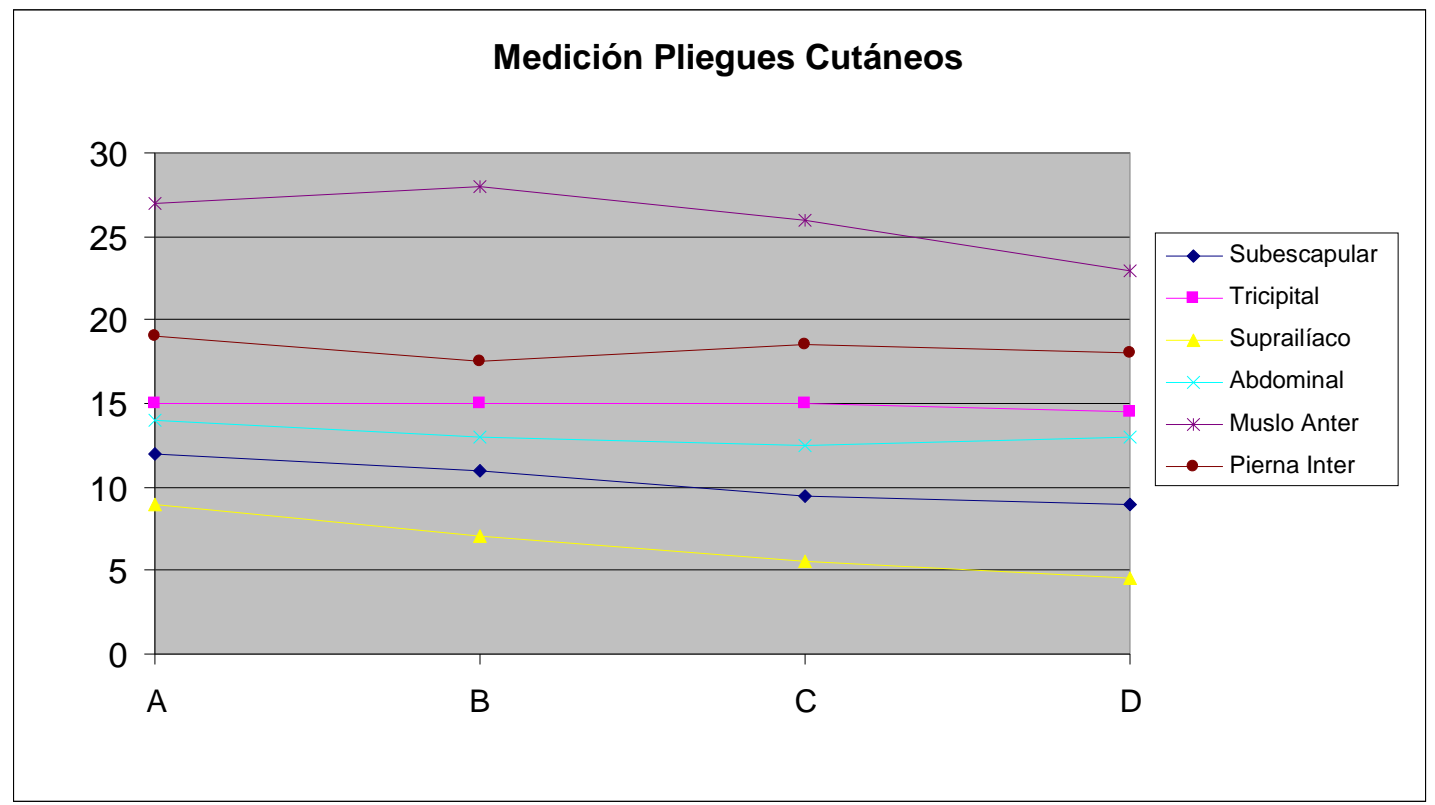

Sumando los pliegues cutáneos, las evaluaciones se manifiestan de la siguiente manera: 


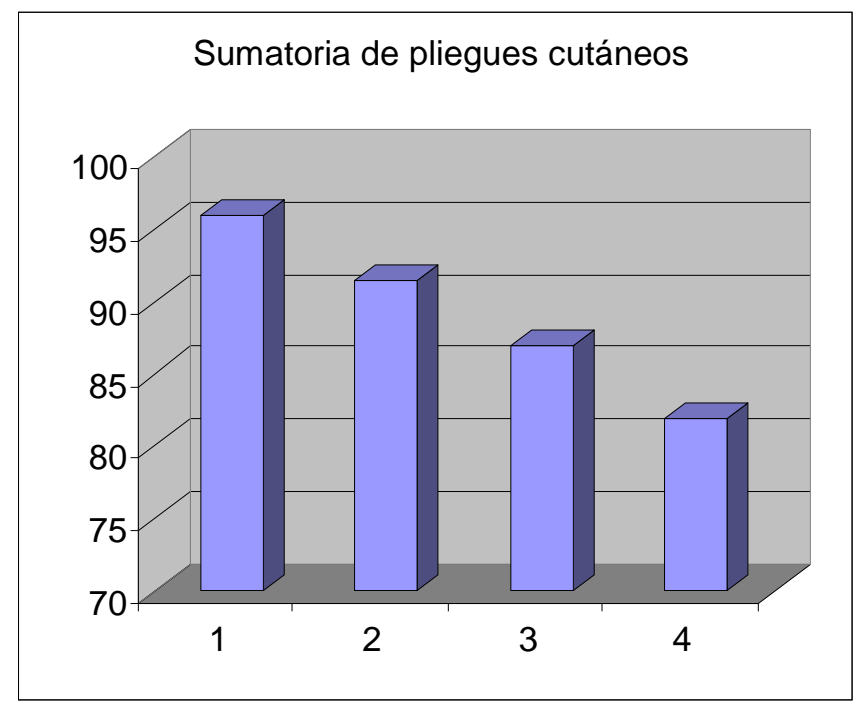

Sumando los 6 pliegues cutáneos de esta persona tenidos en cuenta, y comparando el resultado de la primera prueba y la última, se ve que pasó de $96 \mathrm{~mm}$. a $82 \mathrm{~mm}$; es decir, bajó sólo14 mm. Esta persona realizó 44 clases en total.

\subsection{RESULTADOS DE LAS EVALUACIONES DE FUERZA}

Las evaluaciones de fuerza fueron hechas en horas de la mañana (entre las 10 y 12 hs.), tratando de mantener el mismo tiempo que se dio entre las evaluaciones antropométricas.

Se hicieron 4 evaluaciones a las voluntarias primera y segunda; para la tercera voluntaria se complicó la asistencia a la que sería su última evaluación, así que a ella se le hicieron 3 evaluaciones.

La unidad de medida para las cargas de evaluación está en libras.

Las siguientes tabulaciones presentan la diferencia que se dio entre evaluaciones, partiendo del cálculo que resultó de aplicar la formula de Epley: (Peso levantado $x$ $0,0333 \times$ Repeticiones hasta el fallo) + Peso levantado. También se tuvo en cuenta lo calculado para cada evaluación, el peso que se manejó y la cantidad de repeticiones que la evaluada hizo con ese peso.

Las evaluadas nunca antes habían trabajado con los aparatos multifuncionales. 


\subsubsection{Evaluación de fuerza a la primera voluntaria}

\subsubsection{Evaluación de pectorales a la primera voluntaria}

\begin{tabular}{|l|c|c|c|l|}
\hline & $\mathbf{1 0 0 \%}(\mathbf{1 R M})$ & Peso & Repeticiones & \\
\cline { 2 - 5 } & $\mathbf{1 9 , 5}$ & 15,0 & 9 & Evaluación 1 \\
\hline & $\mathbf{2 4 , 9}$ & 15,0 & 20 & Evaluación 2 \\
\hline Diferencia 1 Vs 2 & $\mathbf{5 , 4}$ & & & \\
\hline & $\mathbf{2 5 , 9}$ & 20,0 & 9 & Evaluación 3 \\
\hline Diferencia 1 Vs 3 & $\mathbf{6 , 5}$ & & & \\
\hline & $\mathbf{2 8 , 6}$ & 20,0 & 13 & Evaluación 4 \\
\hline Diferencia 1 Vs 4 & $\mathbf{9 , 1}$ & & & \\
\hline
\end{tabular}

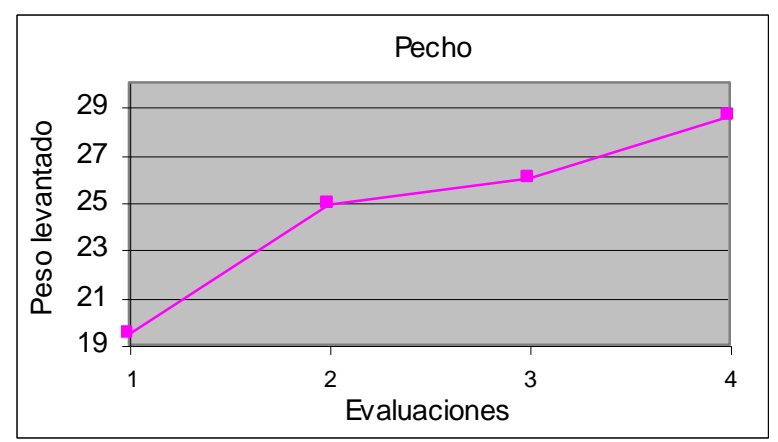

Esta prueba muestra una mejora progresiva que va desde el levantamiento de 5,4 libras hasta el de 9,1 lb., de la primera a la cuarta evaluación.

\subsubsection{Evaluación de extensión de pierna a la primera voluntaria}

\begin{tabular}{|l|c|c|c|c|}
\hline & $\mathbf{1 0 0 \% ( 1 R M )}$ & Ps & Repeticiones & \\
\hline & $\mathbf{5 6 , 1}$ & 32,5 & 22 & Evaluación 1 \\
\hline & $\mathbf{5 6 , 1}$ & 37,5 & 15 & Evaluación 2 \\
\hline Diferencia 1 Vs 2 & $\mathbf{0 , 0}$ & & & \\
\hline & $\mathbf{5 2 , 9}$ & 32,5 & 19 & Evaluación 3 \\
\hline Diferencia 1 Vs 3 & $\mathbf{- 3 , 2}$ & & & \\
\hline & $\mathbf{6 2 , 3}$ & 37,5 & 20 & Evaluación 4 \\
\hline Diferencia 1 Vs 4 & $\mathbf{6 , 2}$ & & & \\
\hline
\end{tabular}

En la evaluación de los cuádriceps se presento el mismo resultado en la primera y segunda prueba, teniendo una desmejora no esperada en la tercera evaluación; en la cuarta prueba mejoró con respecto a la primera, alcanzando las 6,2 libras de peso. 


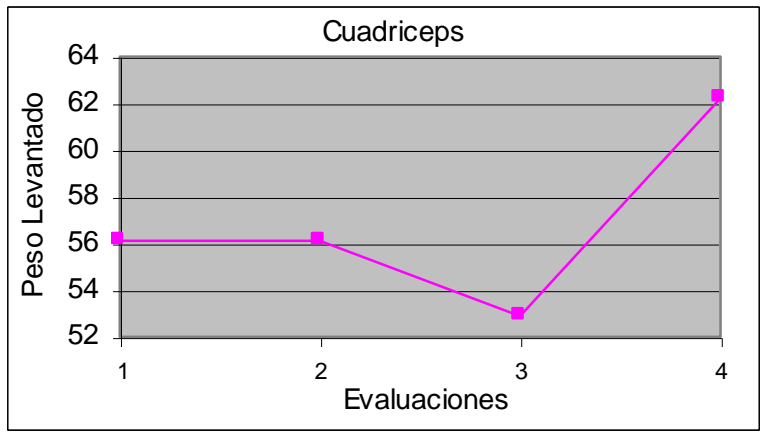

\subsubsection{Evaluación de flexión de brazo a la primera voluntaria}

\begin{tabular}{|l|c|c|c|c|}
\hline & $\mathbf{1 0 0 \% ( 1 \mathbf { R M } )}$ & Ps & Repeticiones & \\
\cline { 2 - 5 } & $\mathbf{1 5 , 8}$ & 12,5 & 8 & Evaluación 1 \\
\hline & $\mathbf{1 6 , 6}$ & 12,5 & 10 & Evaluación 2 \\
\hline Diferencia 1 Vs 2 & $\mathbf{0 , 8}$ & & & \\
\hline & $\mathbf{1 5 , 0}$ & 12,5 & 6 & Evaluación 3 \\
\hline Diferencia 1 Vs 3 & $-\mathbf{0 , 8}$ & & & \\
\hline & $\mathbf{1 5 , 0}$ & 12,5 & 6 & Evaluación 4 \\
\hline Diferencia 1 Vs 4 & $\mathbf{- 0 , 8}$ & & & \\
\hline
\end{tabular}

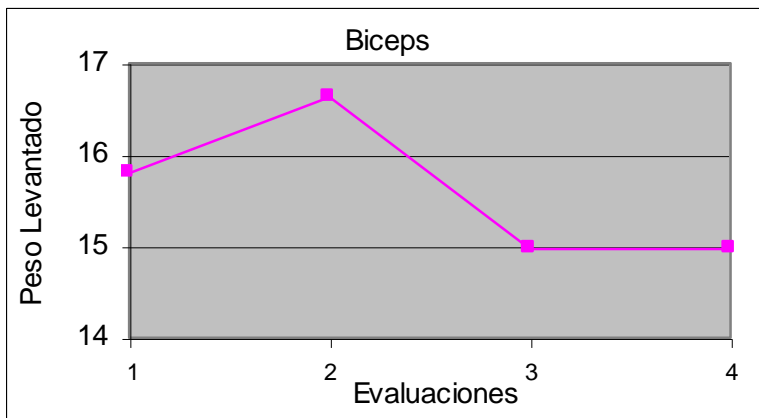

Para la evaluación del bíceps se dio algo inusual, presentando una desmejora de casi una libra.

La causa del resultado podría ser fatiga endógena, o bien falta de motivación para presentar la prueba. 
10.3.1.4 Evaluación de flexión de pierna a la primera voluntaria

\begin{tabular}{|l|c|c|c|c|}
\hline & $\mathbf{1 0 0 \% ( 1 R M )}$ & Ps & Repeticiones & \\
\hline & $\mathbf{4 5 , 6}$ & 25,0 & 25 & Evaluación 1 \\
\hline & $\mathbf{5 6 , 9}$ & 35,0 & 19 & Evaluación 2 \\
\hline Diferencia 1 Vs 2 & $\mathbf{1 1 , 3}$ & & & \\
\hline & $\mathbf{6 6 , 4}$ & 40,0 & 20 & Evaluación 3 \\
\hline Diferencia 1 Vs 3 & $\mathbf{2 0 , 8}$ & & & \\
\hline & $\mathbf{7 4 , 7}$ & 45,0 & 20 & Evaluación 4 \\
\hline Diferencia 1 Vs 4 & $\mathbf{2 9 , 1}$ & & & \\
\hline
\end{tabular}

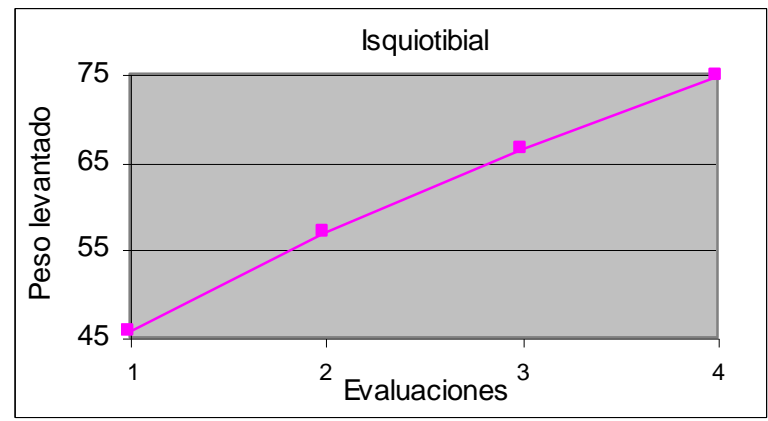

Esta persona tuvo una mejora grandísima de casi el $64 \%$ con respecto a la primera evaluación: en la primera prueba dio un $100 \%$ de 45,6 libras y en la cuarta presentó un $100 \%$ de 74,7 libras.

Sin lugar a dudas, esta persona tiene una forma no muy corriente de hacer fuerza sobre los pedales, dando más trabajo a la flexión de pierna, como se deduce cuando se comparan resultados con los cuádriceps.

\subsubsection{Evaluación de extensión de brazo a la primera voluntaria}

\begin{tabular}{|l|c|c|c|c|}
\hline & $\mathbf{1 0 0}$ (1RM) & Ps & Repeticiones & \\
\hline & $\mathbf{1 8 , 3}$ & 12,5 & 14 & Evaluación 1 \\
\hline & $\mathbf{1 8 , 5}$ & 15,0 & 7 & Evaluación 2 \\
\hline Diferencia 1 Vs 2 & $\mathbf{0 , 2}$ & & & \\
\hline & $\mathbf{1 8 , 0}$ & 15,0 & 6 & Evaluación 3 \\
\hline Diferencia 1 Vs 3 & $\mathbf{- 0 , 3}$ & & & \\
\hline & $\mathbf{2 1 , 9}$ & 15,0 & 14 & Evaluación 4 \\
\hline Diferencia 1 Vs 4 & $\mathbf{3 , 7}$ & & & \\
\hline
\end{tabular}




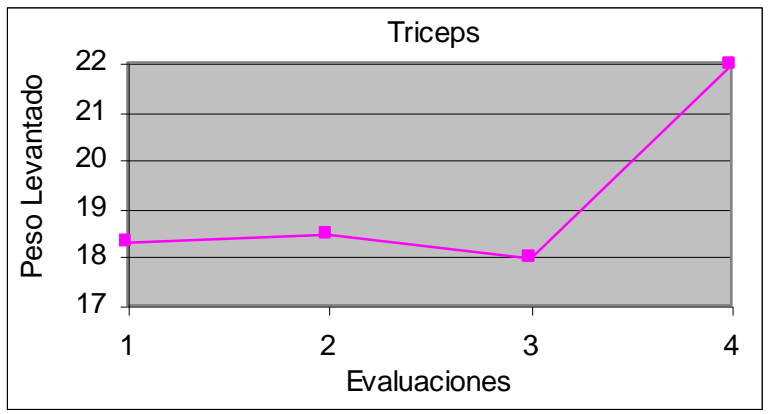

El tríceps presenta una mejora final de 3,7 libras, si bien en la tercera evaluación mostró una desmejora no esperada con respecto a la prueba inicial de 0,3 libras.

\subsubsection{Evaluación de espalda a la primera voluntaria}

\begin{tabular}{|l|c|c|c|c|}
\hline & $\mathbf{1 0 0 \%}(\mathbf{1 R M})$ & Ps & Repeticiones & \\
\hline & $\mathbf{3 7 , 8}$ & 15,0 & 46 & Evaluación 1 \\
\hline & $\mathbf{3 7 , 4}$ & 25,0 & 15 & Evaluación 2 \\
\hline Diferencia 1 Vs 2 & $\mathbf{- 0 , 4}$ & & & \\
\hline & $\mathbf{4 6 , 6}$ & 35,0 & 10 & Evaluación 3 \\
\hline Diferencia 1 Vs 3 & $\mathbf{8 , 8}$ & & & \\
\hline & $\mathbf{5 2 , 3}$ & 35,0 & 15 & Evaluación 4 \\
\hline Diferencia 1 Vs 4 & $\mathbf{1 4 , 6}$ & & & \\
\hline
\end{tabular}

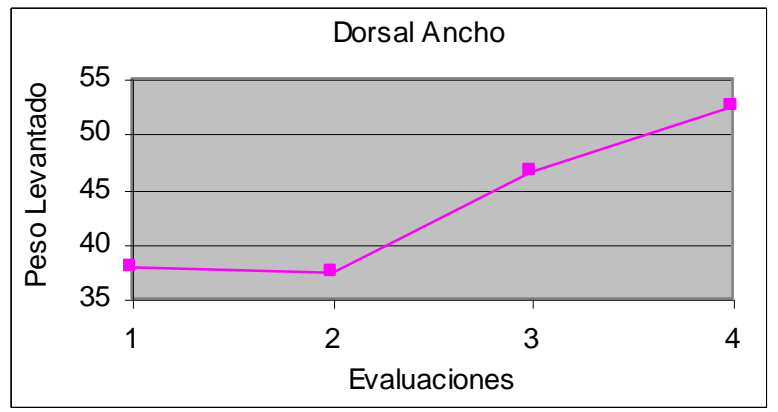

El trabajo del dorsal ancho fue notorio, mejorando casi un $39 \%$ respecto a la primera evaluación.

Se iniciaron las evaluaciones presentando un $100 \%$ de 37,8 libras, en la segunda prueba mostró un pequeño declive de 0,4 libras, y mejoró al final de las pruebas en 14,6 libras. 


\subsubsection{Evaluación de extensión de cadera para pierna derecha a la primera voluntaria}

\begin{tabular}{|l|c|c|c|c|}
\hline & $\mathbf{1 0 0 \% ( 1 \mathbf { R M } )}$ & $\mathbf{P s}$ & Repeticiones & \\
\hline & $\mathbf{1 9 , 9}$ & 10,0 & 30 & Evaluación 1 \\
\hline & $\mathbf{3 3 , 2}$ & 20,0 & 20 & Evaluación 2 \\
\hline Diferencia 1 Vs 2 & $\mathbf{1 3 , 3}$ & & & \\
\hline & $\mathbf{3 2 , 2}$ & 22,5 & 13 & Evaluación 3 \\
\hline Diferencia 1 Vs 3 & $\mathbf{1 2 , 3}$ & & & \\
\hline & $\mathbf{3 3 , 6}$ & 22,5 & 15 & Evaluación 4 \\
\hline Diferencia 1 Vs 4 & $\mathbf{1 3 , 7}$ & & & \\
\hline
\end{tabular}

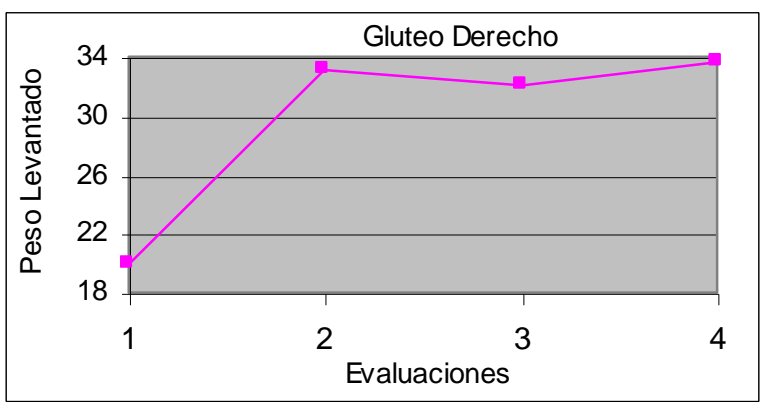

En esta ocasión, una mejora muy marcada se dio en la segunda evaluación, en la que aumentó casi el $67 \%$ de la primera, es decir 13,3 libras. Esto se mantuvo casi hasta la cuarta evaluación, la cual tuvo una mejora de 0,4 libras con respecto a la segunda prueba.

\subsubsection{Evaluación de extensión de cadera para pierna izquierda a la primera voluntaria}

\begin{tabular}{|l|c|c|c|c|}
\hline & $\mathbf{1 0 0} \mathbf{( 1 R M )}$ & Ps & Repeticiones & \\
\hline & $\mathbf{1 9 , 9}$ & 10,0 & 30 & Evaluación 1 \\
\hline & $\mathbf{3 3 , 2}$ & 20,0 & 20 & Evaluación 2 \\
\hline Diferencia 1 Vs 2 & $\mathbf{1 3 , 3}$ & & & \\
\hline & $\mathbf{3 1 , 4}$ & 22,5 & 12 & Evaluación 3 \\
\hline Diferencia 1 Vs 3 & $\mathbf{1 1 , 5}$ & & & \\
\hline & $\mathbf{3 5 , 9}$ & 22,5 & 18 & Evaluación 4 \\
\hline Diferencia 1 Vs 4 & $\mathbf{1 6 , 0}$ & & & \\
\hline
\end{tabular}

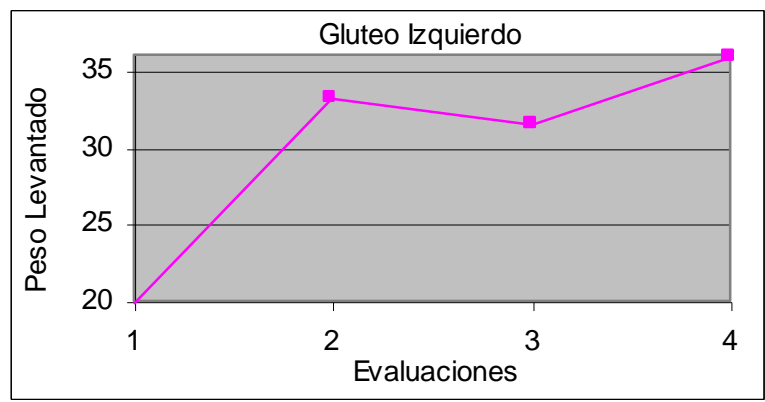


El desempeño en este caso fue similar al del músculo del glúteo derecho, con una mejora un poco mayor: si el del hemisferio derecho ganó hasta 13,7 libras, el izquierdo mejoró 16 libras, 2,7 libras de diferencia.

Con esto se podría llegar a pensar en un trabajo desbalanceado en el que se fuerza un poco más la pierna con la cual se marca la cadencia de pedaleo, o una asimetría en las extremidades inferiores que da más trabajo a la pierna de mayor dimensión.

\subsubsection{Evaluación de extensión de hombros a la primera voluntaria}

\begin{tabular}{|c|c|c|c|c|}
\hline & $100 \%$ (1RM) & Ps & Repeticiones & \\
\hline & 16,9 & 10,0 & 21 & Evaluación 1 \\
\hline & 21,9 & 15,0 & 14 & Evaluación 2 \\
\hline \multirow[t]{2}{*}{ Diferencia 1 Vs 2} & 5,0 & & & \\
\hline & 21,3 & 20,0 & 2 & Evaluación 3 \\
\hline \multirow[t]{2}{*}{ Diferencia $1 \mathrm{Vs} 3$} & 4,4 & & & \\
\hline & 22,0 & 20,0 & 3 & Evaluación 4 \\
\hline \begin{tabular}{|l|} 
Diferencia 1 Vs 4 \\
\end{tabular} & 5,1 & & & \\
\hline
\end{tabular}

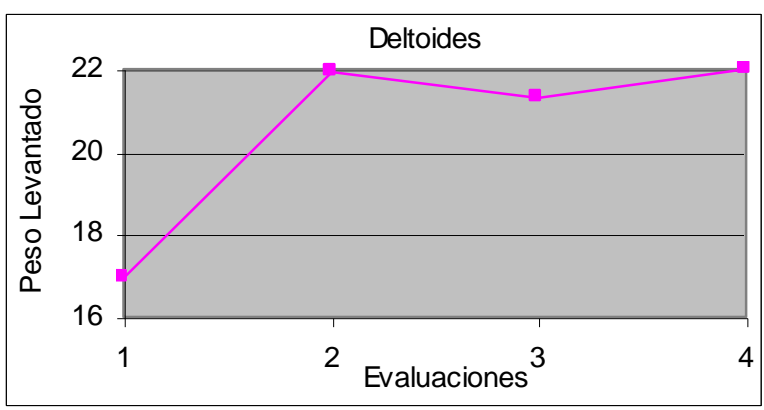

Esta zona muscular tuvo un comportamiento similar al de los glúteos: la gran mejora la presentó entre la primera y segunda evaluación, ganando 5 libras de fuerza y pasando de 16,9 libras a 21,9 libras en el cálculo del levantamiento; esta ganancia se mantuvo hasta el final del seguimiento, que solo dio un 0,1 libras más de mejora. 


\subsubsection{Evaluación de fuerza de la segunda voluntaria}

\subsubsection{Evaluación de pectorales a la segunda voluntaria}

\begin{tabular}{|l|c|c|c|c|}
\hline & $\mathbf{1 0 0 \% ( 1 R M )}$ & Peso & Repeticiones & \\
\cline { 2 - 5 } & $\mathbf{2 5 , 9}$ & 15,0 & 22 & Evaluación 1 \\
\cline { 2 - 5 } & $\mathbf{3 0 , 6}$ & 20,0 & 16 & Evaluación 2 \\
\hline Diferencia 1 Vs 2 & $\mathbf{4 , 7}$ & & & \\
\hline & $\mathbf{3 3 , 3}$ & 25,0 & 10 & Evaluación 3 \\
\hline Diferencia 1 Vs 3 & $\mathbf{7 , 4}$ & & & \\
\hline & $\mathbf{3 8 , 2}$ & 25,0 & 16 & Evaluación 4 \\
\hline Diferencia 1 Vs 4 & $\mathbf{1 2 , 3}$ & & & \\
\hline
\end{tabular}

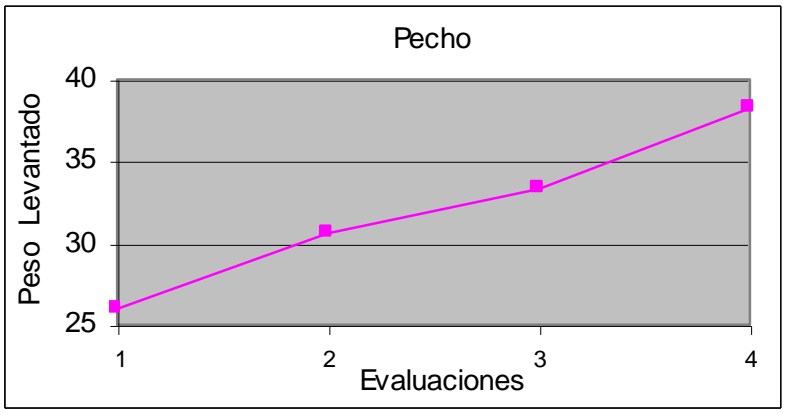

Se considera muy buena la mejoría, esta persona ganó un 47,5\% de fuerza, según las pruebas. La diferencia entre el peso calculado como $100 \%$ en la primer prueba $(25,9$ libras) y en la última (38,2 libras) es de 12,3 libras.

\subsubsection{Evaluación de extensión de pierna a la segunda voluntaria}

\begin{tabular}{|l|c|c|c|c|}
\hline & $\mathbf{1 0 0 \%}(\mathbf{1 R M})$ & Peso & Repeticiones & \\
\cline { 2 - 5 } & $\mathbf{2 9 , 9}$ & 20,0 & 15 & Evaluación 1 \\
\cline { 2 - 5 } & $\mathbf{3 9 , 3}$ & 27,5 & 13 & Evaluación 2 \\
\hline Diferencia 1 Vs 2 & $\mathbf{9 , 4}$ & & & \\
\hline & $\mathbf{4 3 , 2}$ & 32,5 & 10 & Evaluación 3 \\
\hline Diferencia 1 Vs 3 & $\mathbf{1 3 , 3}$ & & & \\
\hline & $\mathbf{4 8 , 6}$ & 32,5 & 15 & Evaluación 4 \\
\hline Diferencia 1 Vs 4 & $\mathbf{1 8 , 7}$ & & & \\
\hline
\end{tabular}




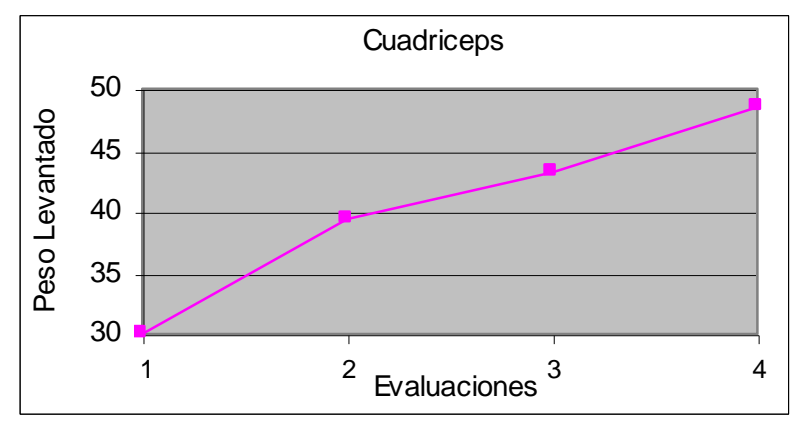

La segunda persona evaluada muestra un comportamiento muy diferente a la evaluada anteriormente.

Esta persona evidencia un desarrollo considerable de la fuerza en los cuádriceps, tuvo una mejora mucho más apreciable: con un pero corporal similar a la primera evaluada, mejoró 3 veces más que esta.

La primera evaluada tuvo una mejora de 6,2 Libras, lo que equivale al $11 \%$ de su primera prueba; la segunda mejoró un $62,5 \%$, dando una ganancia de 18,7 libras de fuerza.

Esto da pie a la muestra del diferente trabajo del tren inferior, viéndose igual la velocidad con que se pedalea, y se puede hacer de diferentes maneras, imponiendo diferentes cargas y manteniendo la misma cadencia de pedaleo dando gasto energético y tener acción muscular de varias maneras.

\subsubsection{Evaluación de flexión de brazo a la segunda voluntaria}

\begin{tabular}{|l|c|c|c|c|}
\hline & $\mathbf{1 0 0 \%}(\mathbf{1 R M})$ & Peso & Repeticiones & \\
\hline & $\mathbf{1 3 , 3}$ & 10,0 & 10 & Evaluación 1 \\
\cline { 2 - 5 } & $\mathbf{1 5 , 4}$ & 12,5 & 7 & Evaluación 2 \\
\hline Diferencia 1 Vs 2 & $\mathbf{2 , 1}$ & & & \\
\hline & $\mathbf{1 4 , 6}$ & 12,5 & 5 & Evaluación 3 \\
\hline Diferencia 1 Vs 3 & $\mathbf{1 , 3}$ & & & \\
\hline & $\mathbf{1 5 , 4}$ & 12,5 & 7 & Evaluación 4 \\
\hline Diferencia 1 Vs 4 & $\mathbf{2 , 1}$ & & & \\
\hline
\end{tabular}

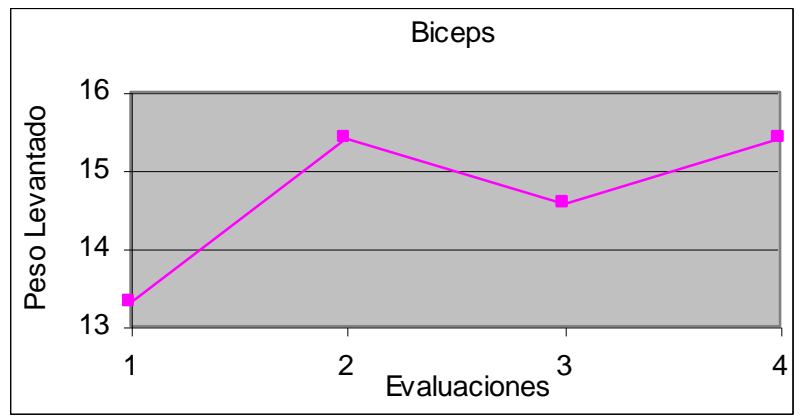


En este caso, no se da una ganancia significativa; por lo visto hasta el momento, no se presenta un aumento considerable de fuerza en las extremidades del tren superior.

\subsubsection{Evaluación de flexión de pierna a la segunda voluntaria}

\begin{tabular}{|l|c|c|c|c|}
\hline \multicolumn{1}{c|}{} & $\mathbf{1 0 0 \% ( \mathbf { R M } )}$ & Peso & Repeticiones & \\
\cline { 2 - 5 } & $\mathbf{5 8 , 1}$ & 35,0 & 20 & Evaluación 1 \\
\hline & $\mathbf{5 3 , 2}$ & 40,0 & 10 & Evaluación 2 \\
\hline Diferencia 1 Vs 2 & $-\mathbf{4 , 9}$ & & & \\
\hline & $\mathbf{5 9 , 8}$ & 40,0 & 15 & Evaluación 3 \\
\hline Diferencia 1 Vs 3 & $\mathbf{1 , 7}$ & & & \\
\hline & $\mathbf{6 2 , 4}$ & 40,0 & 17 & Evaluación 4 \\
\hline Diferencia 1 Vs 4 & $\mathbf{4 , 3}$ & & & \\
\hline
\end{tabular}

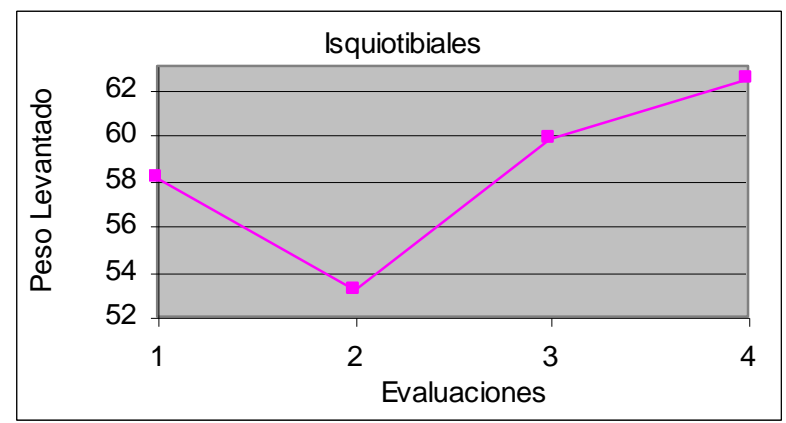

Corroborando una vez más el contraste y la diferente forma en que las personas evaluadas hasta el momento hacían el trabajo con el tren inferior, se da que la persona evaluada en primera posición dio una mejora del $64 \%$ con respecto a la evaluación de flexión de pierna, lo que equivale a 29,1 libras de ganancia de fuerza; esta segunda persona muestra sólo un 7,4 \%. En porcentajes, hay una diferencia del 56,6\%.

No hay duda que ambas personas hacían el trabajo de forma totalmente opuesta, si bien el movimiento cíclico se veía de la misma manera. 
10.3.2.5 Evaluación de extensión de brazo a la segunda voluntaria

\begin{tabular}{|l|c|c|c|c|}
\cline { 2 - 5 } \multicolumn{1}{c|}{} & $\mathbf{1 0 0 \% ( \mathbf { R M } )}$ & Peso & Repeticiones & \\
\hline & $\mathbf{1 8 , 6}$ & 10,0 & 26 & Evaluación 1 \\
\hline & $\mathbf{1 6 , 6}$ & 12,5 & 10 & Evaluación 2 \\
\hline Diferencia 1 Vs 2 & $\mathbf{- 2 , 0}$ & & & \\
\hline & $\mathbf{1 6 , 6}$ & 12,5 & 10 & Evaluación 3 \\
\hline Diferencia 1 Vs 3 & $\mathbf{- 2 , 0}$ & & & \\
\hline & $\mathbf{1 7 , 9}$ & 12,5 & 13 & Evaluación 4 \\
\hline Diferencia 1 Vs 4 & $\mathbf{- 0 , 7}$ & & & \\
\hline
\end{tabular}

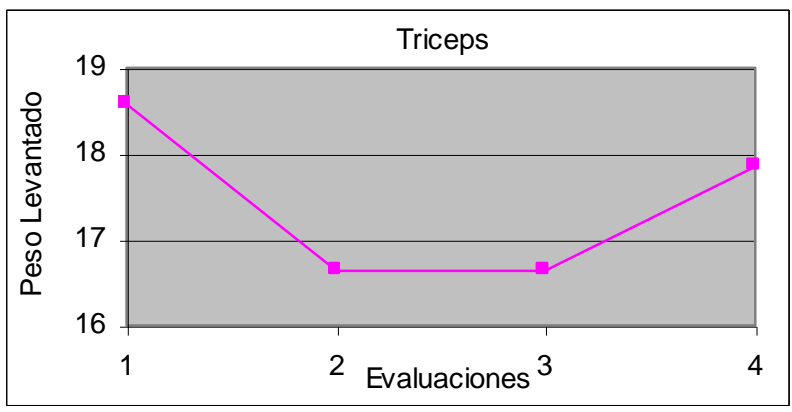

Este caso está dentro de los inusuales; como en todo trabajo físico, se esperan mejorías, pero en este caso, mostró una baja de casi una libra con respecto a la prueba inicial.

Como se menciono anteriormente, el trabajo de brazos para las personas evaluadas hasta el momento no fue lo esperado.

\subsubsection{Evaluación de espalda a segunda voluntaria}

\begin{tabular}{|l|c|c|c|c|}
\hline & $\mathbf{1 0 0 \% ( 1 \mathbf { R M } )}$ & Peso & Repeticiones & \\
\hline & $\mathbf{3 2 , 3}$ & 15,0 & 35 & Evaluación 1 \\
\hline & $\mathbf{3 7 , 8}$ & 20,0 & 27 & Evaluación 2 \\
\hline Diferencia 1 Vs 2 & $\mathbf{5 , 5}$ & & & \\
\hline & $\mathbf{3 7 , 9}$ & 30,0 & 8 & Evaluación 3 \\
\hline Diferencia 1 Vs 3 & $\mathbf{5 , 6}$ & & & \\
\hline & $\mathbf{3 7 , 4}$ & 25,0 & 15 & Evaluación 4 \\
\hline Diferencia 1 Vs 4 & $\mathbf{5 , 1}$ & & & \\
\hline
\end{tabular}




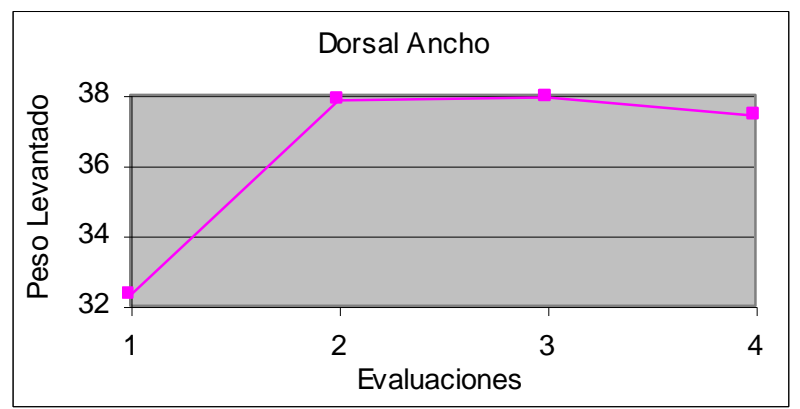

La ganancia significativa apareció en la segunda evaluación, mientras que en las siguientes pruebas mantuvo la fuerza calculada. Se esperaba que la ganancia de fuerza no fuese la misma para la cuarta evaluación, y así ocurrió, bajó con respecto a la primera ganancia 0.4 libras.

\subsubsection{Evaluación de extensión de cadera para pierna derecha a la segunda voluntaria}

\begin{tabular}{|l|c|c|c|c|}
\hline & $\mathbf{1 0 0} \%(\mathbf{1 R M})$ & Peso & Repeticiones & \\
\hline & $\mathbf{1 6 , 9}$ & 10,0 & 21 & Evaluación 1 \\
\hline & $\mathbf{1 8 , 3}$ & 12,5 & 14 & Evaluación 2 \\
\hline Diferencia 1 Vs 2 & $\mathbf{1 , 3}$ & & & \\
\hline & $\mathbf{2 0 , 0}$ & 15,0 & 10 & Evaluación 3 \\
\hline Diferencia 1 Vs 3 & $\mathbf{3 , 0}$ & & & \\
\hline & $\mathbf{2 2 , 4}$ & 15,0 & 15 & Evaluación 4 \\
\hline Diferencia 1 Vs 4 & $\mathbf{5 , 5}$ & & & \\
\hline
\end{tabular}

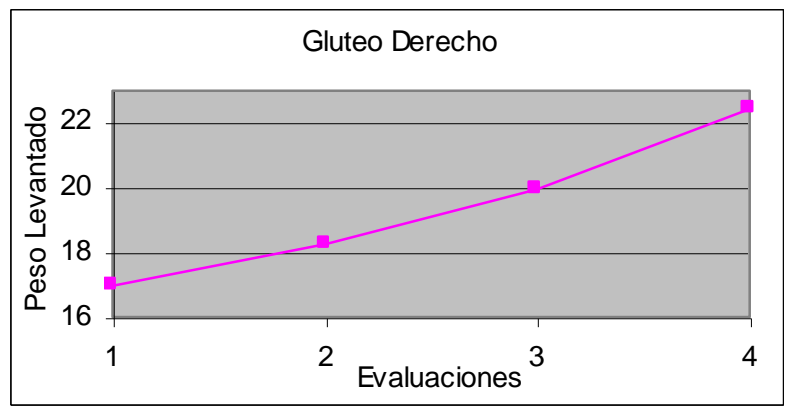

Se dio una mejora en este grupo muscular, que fue progresiva. Si nos apoyamos en la mejora vista en el trabajo de los cuádriceps este cambio no es tan alto; la mejora es de poco más de 5 libras, lo que en porcentaje da un $32,5 \%$ de lo hecho en la primera evaluación. 


\subsubsection{Evaluación de extensión de cadera para pierna izquierda a la segunda evaluada}

\begin{tabular}{|l|c|c|c|c|}
\hline \multicolumn{1}{c|}{} & $\mathbf{1 0 0 \% ( 1 R M )}$ & Peso & Repeticiones & \\
\cline { 2 - 5 } & $\mathbf{1 6 , 6}$ & 10,0 & 20 & Evaluación 1 \\
\hline & $\mathbf{1 8 , 7}$ & 12,5 & 15 & Evaluación 2 \\
\hline Diferencia 1 Vs 2 & $\mathbf{2 , 1}$ & & & \\
\hline & $\mathbf{2 0 , 0}$ & 15,0 & 10 & Evaluación 3 \\
\hline Diferencia 1 Vs 3 & $\mathbf{3 , 4}$ & & & \\
\hline & $\mathbf{2 2 , 4}$ & 15,0 & 15 & Evaluación 4 \\
\hline Diferencia 1 Vs 4 & $\mathbf{5 , 8}$ & & & \\
\hline
\end{tabular}

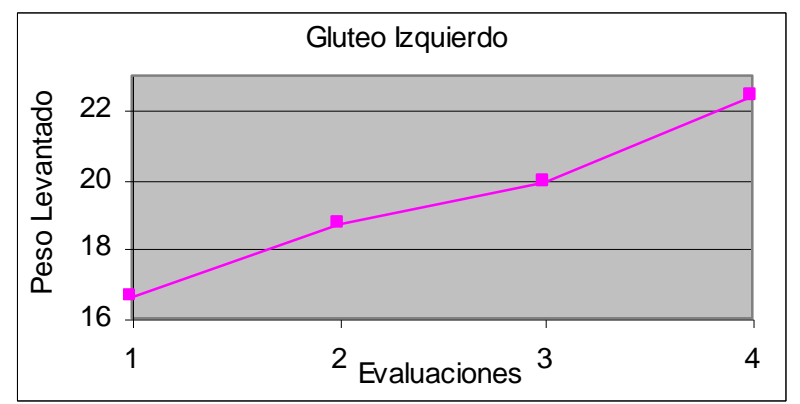

Los resultados de la evaluación del hemisferio izquierdo son muy parecidos a los del hemisferio derecho.

Esta persona realiza un trabajo equilibrado en estos grupos musculares, lo que evita la aparición de lesiones.

\subsubsection{Evaluación de extensión de hombros a la segunda evaluada}

\begin{tabular}{|l|c|c|c|c|}
\hline & $\mathbf{1 0 0 \%}(\mathbf{1 R M})$ & Peso & Repeticiones & \\
\hline & $\mathbf{1 5 , 3}$ & 10,0 & 16 & Evaluación 1 \\
\cline { 2 - 5 } & $\mathbf{2 5 , 3}$ & 20,0 & 8 & Evaluación 2 \\
\hline Diferencia 1 Vs 2 & $\mathbf{1 0 , 0}$ & & & \\
\hline & $\mathbf{1 7 , 5}$ & 15,0 & 5 & Evaluación 3 \\
\hline Diferencia 1 Vs 3 & $\mathbf{2 , 2}$ & & & \\
\hline & $\mathbf{2 1 , 4}$ & 15,0 & 13 & Evaluación 4 \\
\hline Diferencia 1 Vs 4 & $\mathbf{6 , 2}$ & & & \\
\hline
\end{tabular}




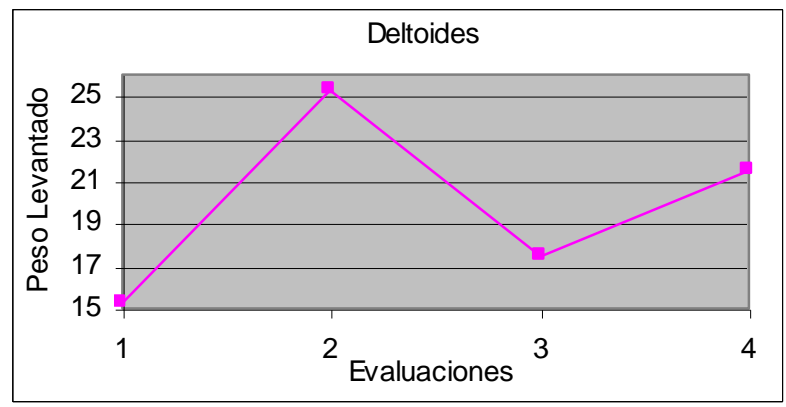

En esta persona se nota un tipo de estancamiento en los resultados de las evaluaciones de fuerza del tren superior: la segunda evaluación es la que da el cambio significativo, y luego se presenta un estancamiento e inclusive una desmejora en los resultados.

La evaluación del hombro no fue la excepción, en la segunda prueba dio una mejora del 60,5\%, para luego bajar, en la evaluación final, un 14,4\%; esto es, 10 y 2,2 libras respectivamente.

Al final, comparando la prueba inicial con la cuarta y última prueba se dio una diferencia favorable de 6,2 libras.

\subsubsection{Evaluación de fuerza de la tercera voluntaria}

Continuando con las evaluaciones hechas a personas que llevan una vida corriente, le damos paso a la tercer y última persona que facilitó la toma de datos, para luego compararlas entre sí.

Por diferentes motivos, a esta persona no se le pudo hacer la cuarta evaluación; sin embargo, los datos obtenidos alcanzan para observar sus reacciones al trabajo que hace sobre la bicicleta estática.

\subsubsection{Evaluación de pectorales a la tercera voluntaria}

\begin{tabular}{|l|c|c|c|c|}
\cline { 2 - 5 } \multicolumn{1}{c|}{} & $\mathbf{1 0 0} \%(\mathbf{1 R M})$ & Peso & Repeticiones & \\
\cline { 2 - 5 } & $\mathbf{1 4 , 0}$ & 10,0 & 12 & Evaluación 1 \\
\hline & $\mathbf{2 0 , 0}$ & 15,0 & 10 & Evaluación 2 \\
\hline Diferencia 1 Vs 2 & $\mathbf{6 , 0}$ & & & \\
\hline & $\mathbf{2 1 , 9}$ & 15,0 & 14 & Evaluación 3 \\
\hline Diferencia 1 Vs 3 & $\mathbf{8 , 0}$ & & & \\
\hline
\end{tabular}

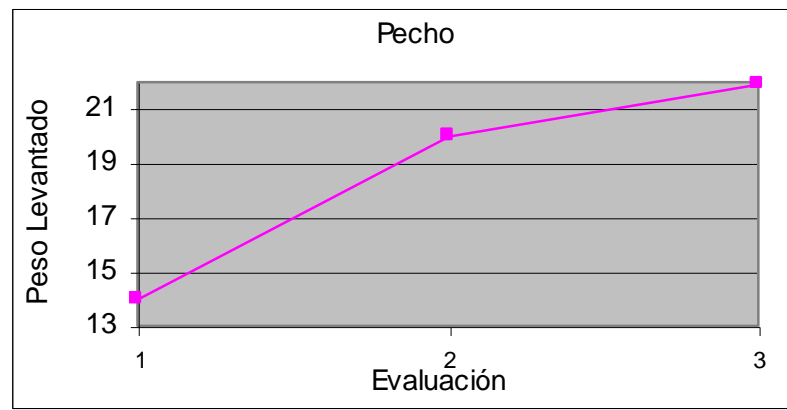


Es de reconocer la mejora progresiva que se presento en esta persona: en libras, pasó de tener un $100 \%$ de 14 libras a un $100 \%$ de 21,9 libras, lo que llevado a porcentajes da un $57,1 \%$ de mejora en la evaluación de fuerza para los pectorales.

\subsubsection{Evaluación de extensión de pierna a la tercera voluntaria}

\begin{tabular}{|l|c|c|c|c|}
\cline { 2 - 5 } & $\mathbf{1 0 0} \%(\mathbf{1 R M})$ & Peso & Repeticiones & \\
\cline { 2 - 5 } & $\mathbf{3 3 , 2}$ & 20,0 & 20 & Evaluación 1 \\
\hline & $\mathbf{3 8 , 4}$ & 27,5 & 12 & Evaluación 2 \\
\hline Diferencia 1 Vs 2 & $\mathbf{5 , 2}$ & & & \\
\hline & $\mathbf{4 6 , 4}$ & 32,5 & 13 & Evaluación 3 \\
\hline Diferencia 1 Vs 3 & $\mathbf{1 3 , 2}$ & & & \\
\hline
\end{tabular}

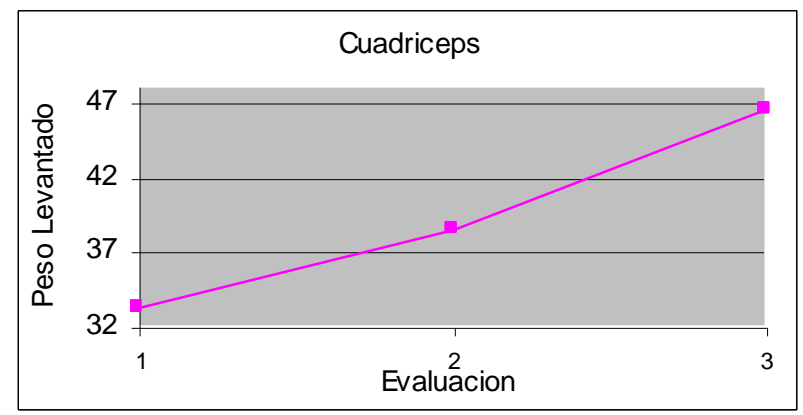

También en los cuádriceps mostró un tipo de mejora simétrica, pasando de levantar 33,2 libras a levantar 46,4 libras; tomado esto en porcentajes, y manejando el resultado de la primera evaluación como un $100 \%$, en la segunda prueba esta persona mejoró un $15,7 \%$, y en la tercera casi un $40 \%$.

\subsubsection{Evaluación de flexión de brazo a la tercera voluntaria}

\begin{tabular}{|l|c|c|c|c|}
\cline { 2 - 5 } \multicolumn{1}{c|}{} & $\mathbf{1 0 0} \%(\mathbf{1 R M})$ & Peso & Repeticiones & \\
\cline { 2 - 5 } & $\mathbf{1 3 , 6}$ & 10,0 & 11 & Evaluación 1 \\
\hline & $\mathbf{1 5 , 8}$ & 12,5 & 8 & Evaluación 2 \\
\hline Diferencia 1 Vs 2 & $\mathbf{2 , 2}$ & & & \\
\hline & $\mathbf{1 6 , 6}$ & 12,5 & 10 & Evaluación 3 \\
\hline Diferencia 1 Vs 3 & $\mathbf{3 , 0}$ & & & \\
\hline
\end{tabular}

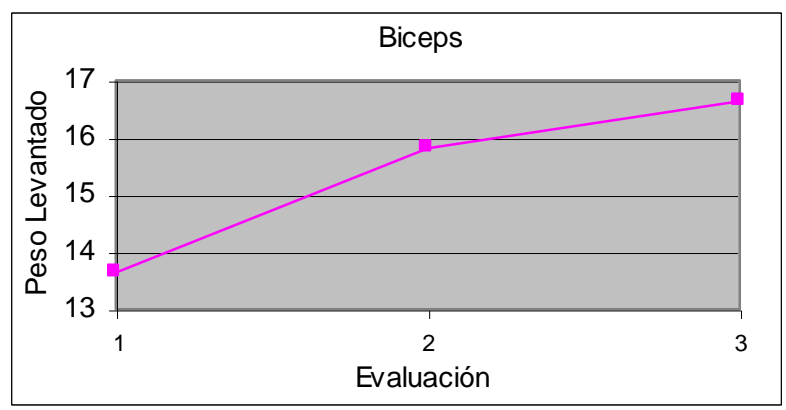


Esta persona sigue mostrando mejoras progresivas, aunque en este grupo muscular no fueron tan significativas.

La primera evaluación dio un cálculo de 13,6 libras como 100\%, y la tercera y última prueba arrojó una mejora de 3,0 libras, es decir, un $22 \%$.

10.3.3.4 Evaluación de flexión de pierna a la tercera voluntaria

\begin{tabular}{|l|c|c|c|c|}
\cline { 2 - 5 } \multicolumn{1}{c|}{} & $\mathbf{1 0 0 \% ( 1 \mathrm { RM } )}$ & Peso & Repeticiones & \\
\cline { 2 - 5 } & $\mathbf{4 4 , 9}$ & 30,0 & 15 & Evaluación 1 \\
\hline & $\mathbf{4 4 , 2}$ & 35,0 & 8 & Evaluación 2 \\
\hline Diferencia 1 Vs 2 & $\mathbf{- 0 , 6}$ & & & \\
\hline & $\mathbf{5 3 , 5}$ & 35,0 & 16 & Evaluación 3 \\
\hline Diferencia 1 Vs 3 & $\mathbf{8 , 6}$ & & & \\
\hline
\end{tabular}

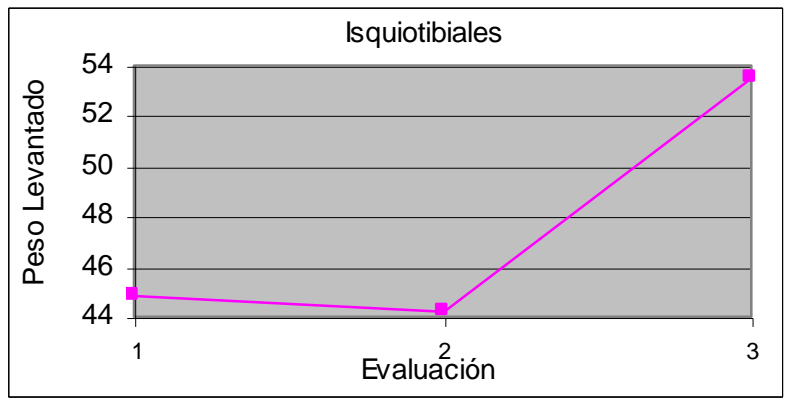

En este caso la segunda prueba no presentó mejora alguna; es más, se da una perdida en el cálculo de la fuerza de 0,6 libras.

Para la tercera prueba parece haber modificado su forma de trabajo (es decir, su forma de pedaleo), ya que mejora su fuerza en un $19,1 \%$, dando mas trabajo a la flexión de la pierna.

\subsubsection{Evaluación de extensión de brazo a la tercera voluntaria}

\begin{tabular}{|l|c|c|c|c|}
\hline \multicolumn{1}{c|}{} & $\mathbf{1 0 0} \%(\mathbf{1 R M})$ & Peso & Repeticiones & \\
\cline { 2 - 5 } & $\mathbf{1 6 , 6}$ & 12,5 & 10 & Evaluación 1 \\
\hline & $\mathbf{2 0 , 3}$ & 12,5 & 19 & Evaluación 2 \\
\hline Diferencia 1 Vs 2 & $\mathbf{3 , 7}$ & & & \\
\hline & $\mathbf{1 9 , 0}$ & 15,0 & 8 & Evaluación 3 \\
\hline Diferencia 1 Vs 3 & $\mathbf{2 , 3}$ & & & \\
\hline
\end{tabular}




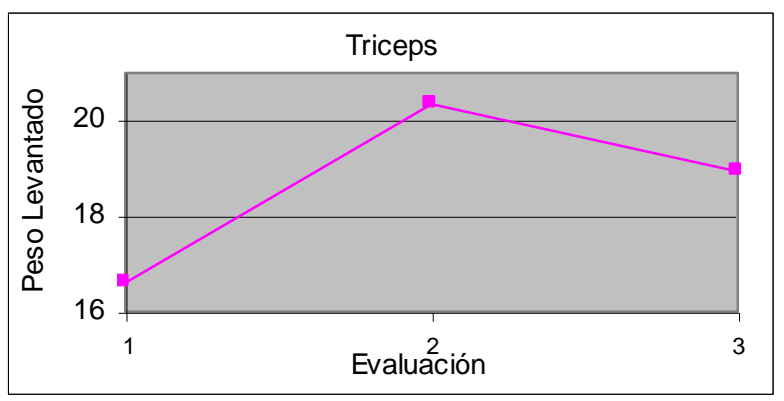

Tal como ocurrió con las personas evaluadas anteriormente, para este grupo muscular el resultado final no es el esperado, ya que no se presentan cambios significativos.

La primera evaluación da una mejora del 22,3\%, y se esperaba que la tercera prueba supere esa marca, o por lo menos la mantenga.

La tercera prueba, sin embargo, da una mejora del $13,8 \%$ con respecto a la inicial, por lo que desmejoró un $8,5 \%$ respecto de la segunda.

\subsubsection{Evaluación de espalda a tercera voluntaria}

\begin{tabular}{|l|c|c|c|c|}
\cline { 2 - 5 } & $\mathbf{1 0 0} \%(\mathbf{1 R M})$ & Peso & Repeticiones & \\
\cline { 2 - 5 } & $\mathbf{1 9 , 9}$ & 10,0 & 30 & Evaluacion 1 \\
\hline & $\mathbf{2 9 , 9}$ & 20,0 & 15 & Evaluacion 2 \\
\hline Diferencia 1 Vs 2 & $\mathbf{1 0 , 0}$ & & & \\
\hline & $\mathbf{3 9 , 9}$ & 25,0 & 18 & Evaluacion 3 \\
\hline Diferencia 1 Vs 3 & $\mathbf{2 0 , 0}$ & & & \\
\hline
\end{tabular}

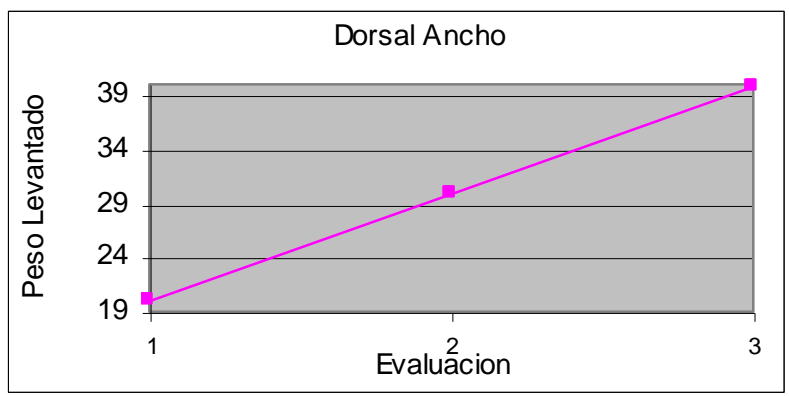

En esta zona muscular es grande el cambio en la forma física que se presenta: esta persona mejoró en un $100 \%$ la fuerza en el dorsal ancho luego de la primera evaluación.

De forma curiosa, las mejoras fueron equidistantes, ya que en la segunda evaluación mejoró en un $50 \%$ de su prueba inicial que fue de 19.9 libras. 
El cálculo de evaluación para la tercera evaluación fue de 39,9 libras, lo que representa el $100 \%$ en la mejora de su fuerza.

\subsubsection{Evaluación de extensión de cadera para pierna derecha a la tercera voluntaria}

\begin{tabular}{|l|c|c|c|c|}
\cline { 2 - 5 } \multicolumn{1}{c|}{} & $\mathbf{1 0 0} \%(\mathbf{1 R M})$ & Peso & Repeticiones & \\
\cline { 2 - 5 } & $\mathbf{1 9 , 9}$ & 10,0 & 30 & Evaluación 1 \\
\hline & $\mathbf{1 9 , 5}$ & 12,5 & 17 & Evaluación 2 \\
\hline Diferencia 1 Vs 2 & $\mathbf{- 0 , 4}$ & & & \\
\hline & $\mathbf{2 1 , 9}$ & 15,0 & 14 & Evaluación 3 \\
\hline Diferencia 1 Vs 3 & $\mathbf{2 , 0}$ & & & \\
\hline
\end{tabular}

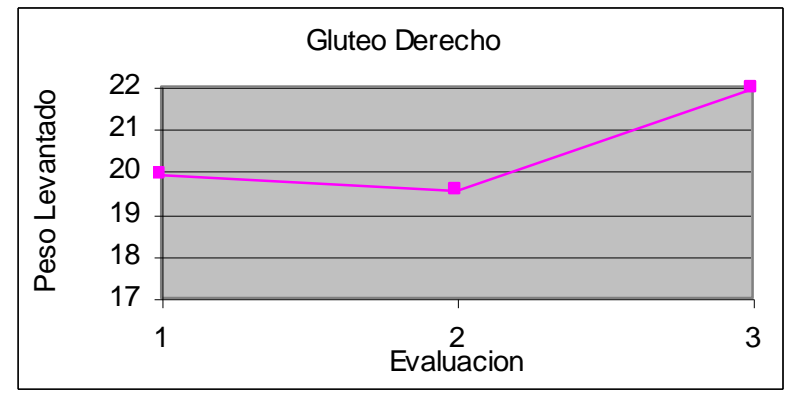

En el ejercicio sobre la bicicleta estática se espera, además de la mejora en el tono muscular, la resistencia, fuerza, velocidad y potencia; sobre todo del tren inferior, por el tipo de acción, y más cuando el trabajo del glúteo da la extensión de cadera.

Las evaluaciones con la tercera persona muestran mínima mejora en esta zona corporal, lo que llama bastante la atención.

Si el cuádriceps muestra en esta persona mejora bastante apreciable, no es tan grande la mejora para los glúteos; esto muestra la forma en que aplica la fuerza durante el pedaleo.

Es claro que esta persona trabaja sobre la bicicleta estática dando más trabajo a los extensores y flexores de la pierna; el músculo de extensión de cadera no muestra una mejora significativa en la evaluación de la fuerza. 
10.3.3.8 Evaluación de extensión de cadera para pierna izquierda a la tercera voluntaria

\begin{tabular}{|l|c|c|c|c|}
\cline { 2 - 5 } \multicolumn{1}{c|}{} & $\mathbf{1 0 0} \%(\mathbf{1 R M})$ & Peso & Repeticiones & \\
\cline { 2 - 5 } & $\mathbf{1 7 , 3}$ & 10,0 & 22 & Evaluación 1 \\
\hline & $\mathbf{1 9 , 5}$ & 12,5 & 17 & Evaluación 2 \\
\hline Diferencia 1 Vs 2 & $\mathbf{2 , 3}$ & & & \\
\hline & $\mathbf{2 1 , 4}$ & 15,0 & 13 & Evaluación 3 \\
\hline Diferencia 1 Vs 3 & $\mathbf{4 , 2}$ & & & \\
\hline
\end{tabular}

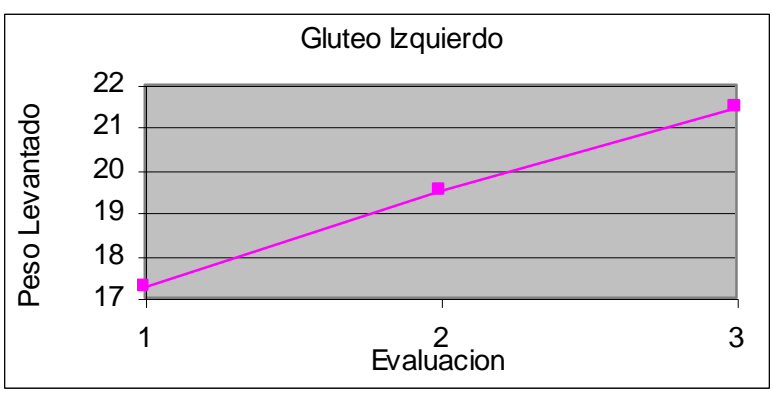

Llaman mucho la atención las evaluaciones de cadera de esta persona, pues, mientras las tomas de fuerza iníciales dan un desbalance de 2,3 libras, al término de las pruebas el resultado de las evaluaciones del glúteo izquierdo da una mejora de 4,2 libras.

La evaluación inicial muestra una mejor condición física del glúteo del hemisferio derecho; al parecer esto se equilibró luego del trabajo, y en la tercera evaluación ambos hemisferios presentaron una fuerza casi idéntica.

\subsubsection{Evaluación de extensión de hombros a la tercera voluntaria}

\begin{tabular}{|l|c|c|c|c|}
\hline & $\mathbf{1 0 0 \% ( \mathbf { R M } )}$ & Peso & Repeticiones & \\
\cline { 2 - 5 } & $\mathbf{1 0 , 7}$ & 10,0 & 2 & Evaluación 1 \\
\hline & $\mathbf{1 3 , 6}$ & 10,0 & 11 & Evaluación 2 \\
\hline Diferencia 1 Vs 2 & $\mathbf{3 , 0}$ & & & \\
\hline & $\mathbf{1 4 , 6}$ & 10,0 & 14 & Evaluación 3 \\
\hline Diferencia 1 Vs 3 & $\mathbf{4 , 0}$ & & & \\
\hline
\end{tabular}

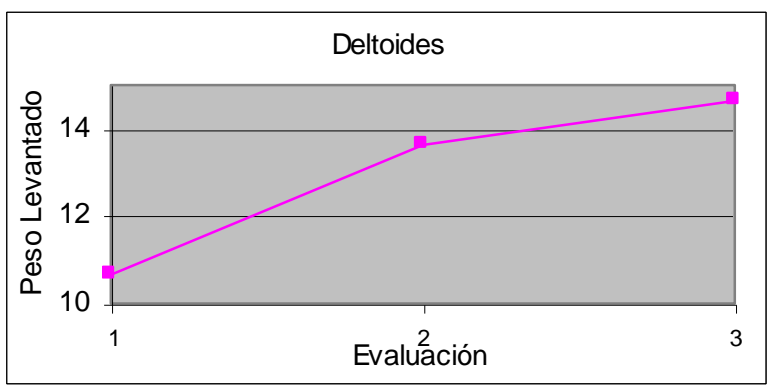


Esta persona uso siempre el mismo peso que fue 10, según la formula usada, la primera vez su $100 \%$ fue 10,7 , realizo 2 repeticiones, en la segunda evaluación fue de 13,6, realizo 11 repeticiones dando una ganancia de $28 \%$ para el peso levantado; en la tercera realizo 14 repeticiones calculando ahora que su $100 \%$ es 14,6, comparando la primera con la tercera evaluación hay una ganancia del 37,4. 


\section{RESULTADOS DE LAS PRUEBAS DE ESFUERZO}

\subsection{TABLA DE RESUMEN DE LOS RESULTADOS DE LA PRIMERA VOLUNTARIA}

Asistencia al salón de trabajo: 3 veces por semana.

\begin{tabular}{|c|c|c|c|c|}
\hline Evaluación & A1 & A2 & A3 & A4 \\
\hline Fecha & $07 / 24 / 06$ & $09 / 06 / 06$ & $12 / 10 / 06$ & $15 / 12 / 06$ \\
\hline Edad (Años) & 30 & 30 & 30 & 30 \\
\hline Peso (Kilogramos) & 58,7 & 58,9 & 58,2 & 57,5 \\
\hline Peso (Libras) & $\underline{129,14}$ & $\underline{129,58}$ & $\underline{128,04}$ & $\underline{126,5}$ \\
\hline Altura (Metros) & 1,65 & 1,65 & 1,65 & 1,65 \\
\hline Índice de masa corporal & 21,6 & 21,6 & 21,4 & 21,1 \\
\hline Frecuencia cardíaca máxima teórica & $\mathbf{1 9 3 , 7}$ & $\mathbf{1 9 3 , 7}$ & $\mathbf{1 9 3 , 7}$ & $\mathbf{1 9 3 , 7}$ \\
\hline Frecuencia cardíaca máxima real & 196 & 198 & 195 & 189 \\
\hline Pulso Basal & 65 & 62 & 62 & 65 \\
\hline Rango Aeróbico & 131,0 & 136,0 & 133,0 & 124,0 \\
\hline Pulsaciones de recuperación al minuto & 171 & 164 & 172 & 160 \\
\hline \% de recuperación al minuto & 19,08 & 25,00 & 17,29 & 23,39 \\
\hline
\end{tabular}

Analizando por separado cada una de las evaluaciones encontramos lo siguiente.

\subsubsection{Evaluaciones de peso corporal de la primera voluntaria}

\begin{tabular}{|c|c|c|c|c|}
\hline Evaluación & A1 & A2 & A3 & A4 \\
\hline Fecha & $07 / 24 / 06$ & $09 / 06 / 06$ & $10 / 12 / 06$ & $12 / 15 / 06$ \\
\hline Peso (Kg.) & 58,7 & 58,9 & 58,2 & 57,5 \\
\hline
\end{tabular}




\section{Peso (Kg)}

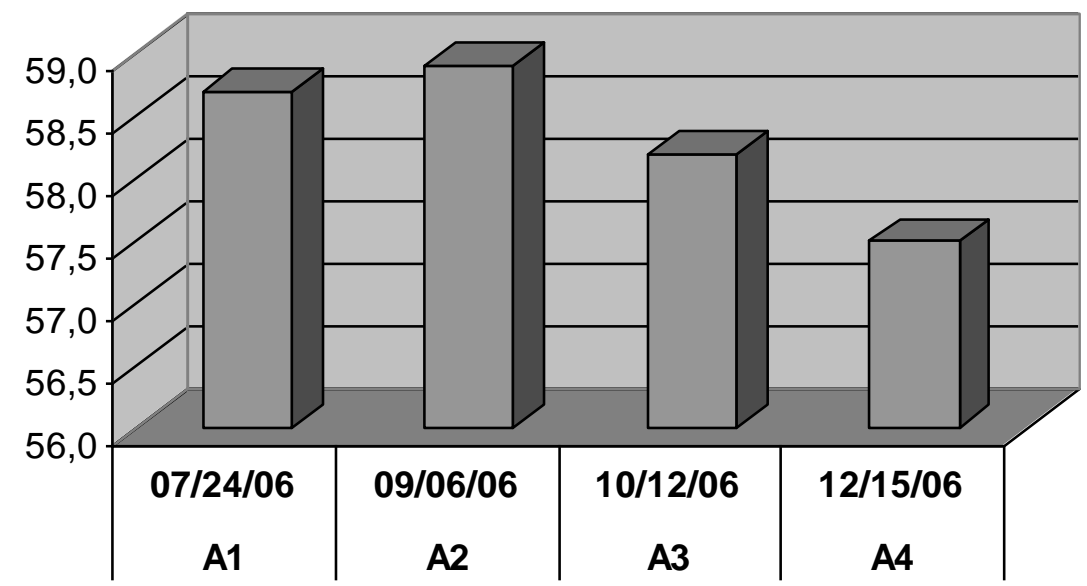

Esta persona perdió 1,2 kilogramos de peso corporal en casi 5 meses de actividad. Esto puede ser tomado por muchos como una baja pérdida de peso, pero si nos remitimos al porcentaje graso, vamos a encontrar que la sumatoria de los pliegues cutáneos tomados en primera instancia daba como resultado $143 \mathrm{~mm}$., y al final la misma toma de pliegues pasó a ser $93 \mathrm{~mm}$.

La diferencia en la sumatoria de pliegues cutáneos fue de $50 \mathrm{~mm}$.; la pérdida de peso corporal no fue mayúscula, pero sí lo fue en cuanto a los pliegues cutáneos.

No hay que olvidar que no se tuvo en cuenta ninguna dieta controlada para estos trabajos, y por lo tanto ella seguía comiendo a voluntad.

Su tono muscular aumentó con el trabajo físico, esto muestra que el tono muscular está directamente relacionado con el trabajo físico y con su peso corporal.

\subsubsection{Evaluaciones de índice de masa corporal de la primera voluntaria}

\begin{tabular}{|c|c|c|c|c|}
\hline Evaluación & A1 & A2 & A3 & A4 \\
\hline Fecha & $07 / 24 / 06$ & $09 / 06 / 06$ & $10 / 12 / 06$ & $12 / 15 / 06$ \\
\hline I.M.C. & 21,6 & 21,6 & 21,4 & 21,1 \\
\hline
\end{tabular}




\section{Índice de masa corporal}

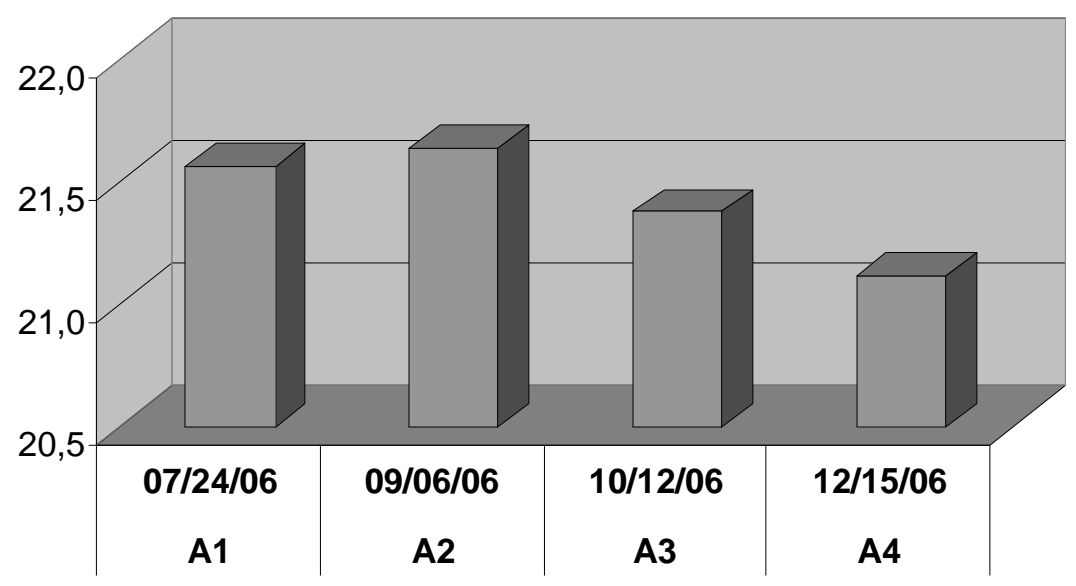

El índice de masa corporal tuvo un mínimo cambio, lo que permite cuestionar la formula de masa corporal: peso $(\mathrm{Kg}) /$ altura $^{2}$ (metros), pues la baja en su porcentaje graso, como se mencionó anteriormente, fue bastante marcada.

11.1.3 Relación entre las pulsaciones máximas reales y las teóricas de la primera voluntaria

\begin{tabular}{|c|c|c|c|c|}
\hline Evaluación & A1 & A2 & A3 & A4 \\
\hline Fecha & $07 / 24 / 06$ & $09 / 06 / 06$ & $10 / 12 / 06$ & $12 / 15 / 06$ \\
\hline Fc.M.T. & 193,7 & 193,7 & 193,7 & 193,7 \\
\hline Fc.M.R. & 196,0 & 198,0 & 195,0 & 189,0 \\
\hline
\end{tabular}

\section{Frecuencia cardíaca máxima teórica Vs frecuencia cardíaca máxima real}

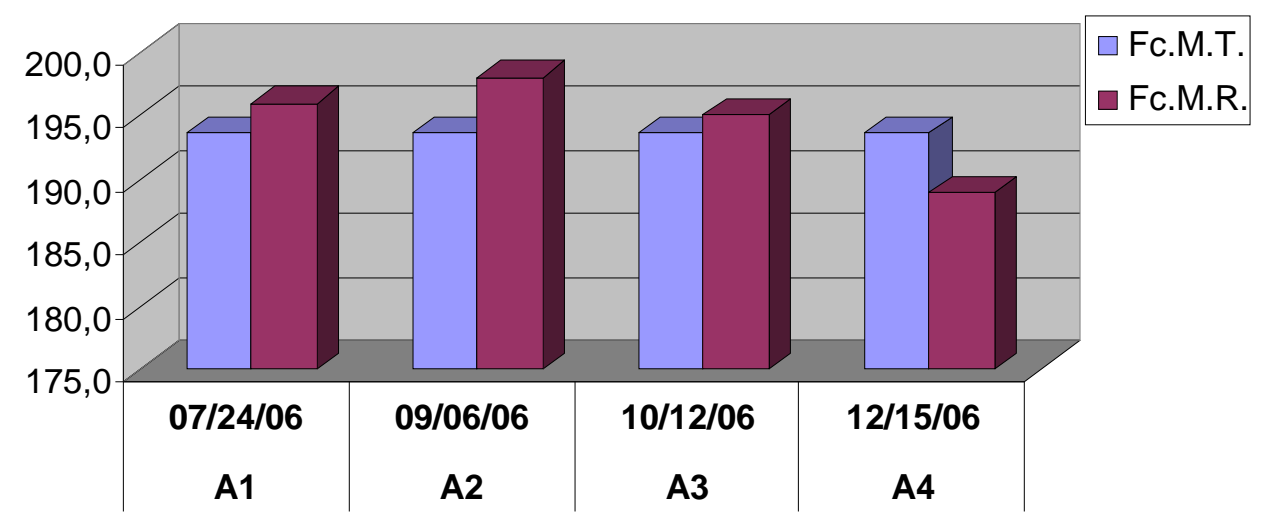


La evaluada estuvo sobre las pulsaciones calculadas teóricamente; si se trabajase con ella apoyándonos en un pulsómetro, estaríamos trabajando por debajo de sus rangos cardíacos reales.

Su $100 \%$ teórico daba como resultado casi 194 pulsaciones por minuto, ella en el seguimiento que se le hizo llegó casi a las 200 pulsaciones por minuto, lo hizo en la segunda evaluación, en la ultima de las evaluaciones estuvo casi 5 pulsaciones por debajo de su máximo teórico.

Lo anterior podría fácilmente atribuirse a fatiga y deshidratación corporal, razones que harían que llegara mucho antes a sus niveles superiores de trabajo: esta última evaluación se hizo en verano Argentino, un 15 de diciembre.

\subsubsection{Pulso basal de la primera voluntaria}

\begin{tabular}{|c|c|c|c|c|}
\hline Evaluación & A1 & A2 & A3 & A4 \\
\hline Fecha & $07 / 24 / 06$ & $09 / 06 / 06$ & $10 / 12 / 06$ & $12 / 15 / 06$ \\
\hline Pulso Basal & 65 & 62 & 62 & 65 \\
\hline
\end{tabular}

\section{Pulso Basal}

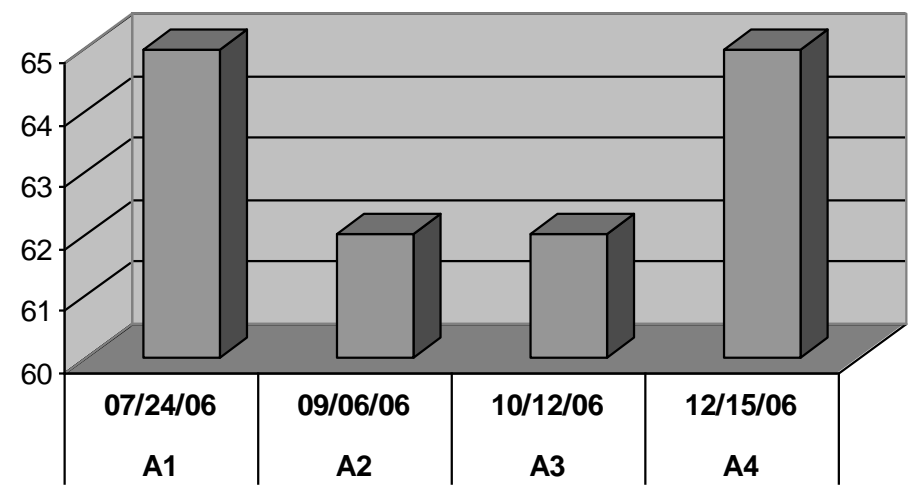

Este campo no tuvo variación alguna entre la primera y la última evaluación: se inicio el plan con 65 pulsaciones por minuto y así se terminó. La fatiga acumulada, el sobre esfuerzo, el mal dormir pueden ser causantes de la elevación en el pulso basal.

El volver al pulso con el que se inició el ciclo de trabajo se atribuye al trabajo en la estación de verano, tal como se mencionó en el punto anterior. 


\subsubsection{Rango de trabajo cardiovascular de la primera voluntaria}

\begin{tabular}{|c|c|c|c|c|}
\hline Evaluación & A1 & A2 & A3 & A4 \\
\hline Fecha & $07 / 24 / 06$ & $09 / 06 / 06$ & $10 / 12 / 06$ & $12 / 15 / 06$ \\
\hline Rango cardiovascular & 131 & 136 & 133 & 124 \\
\hline
\end{tabular}

\section{Rango de trabajo cardiovascular}

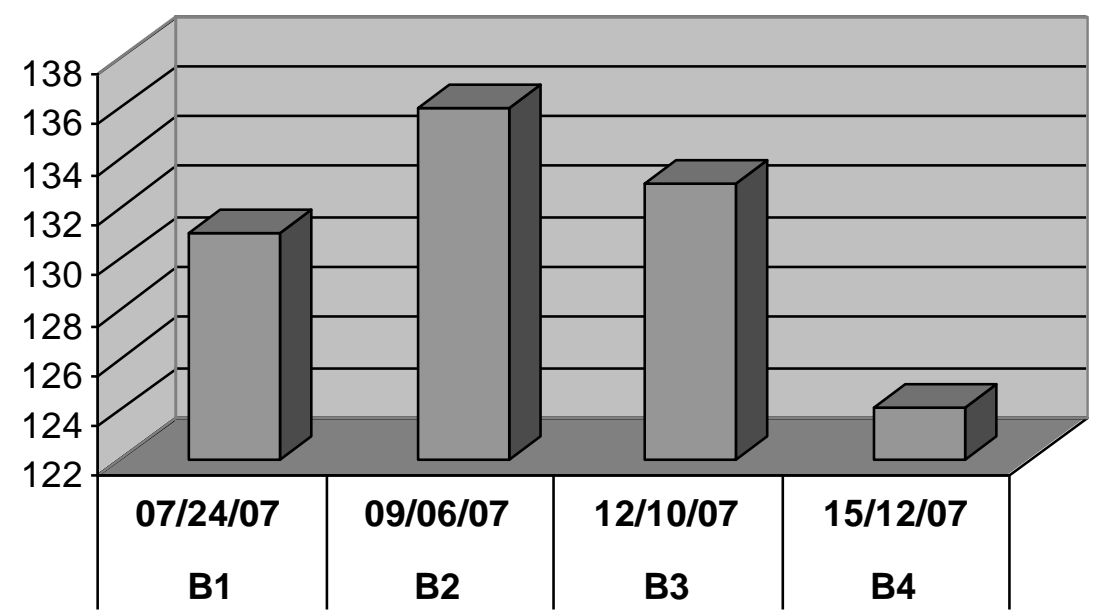

Este es tomado como el campo al cual se aplican los porcentajes al momento de buscar intensidades de trabajo; en esta persona, el rango de trabajo se mostró más amplio en la segunda evaluación.

Se espera que a medida que van avanzando en el trabajo, este rango vaya en progreso hasta llegar a una estabilidad.

Cuando este rango va en desmejora, como en el caso de la primer evaluada, podemos hablar de sobrecargas, desmejoras en la misma calidad de alimentación e incluso justificarlo con la misma temperatura ambiental, como se hizo en el punto anterior.

También aquí puede verse la acumulación de trabajo, o fatiga física: es posible que, poco tiempo después de iniciar la evaluación, la evaluada esté por encima de su rango aeróbico, entrando a lo que es el trabajo anaeróbico y la producción de acido láctico.

\subsubsection{Frecuencia cardíaca luego de recuperarse un minuto de la primera voluntaria}

\begin{tabular}{|c|c|c|c|c|}
\hline Evaluación & A1 & A2 & A3 & A4 \\
\hline Fecha & $07 / 24 / 06$ & $09 / 06 / 06$ & $10 / 12 / 06$ & $12 / 15 / 06$ \\
\hline Pul/Rec. al Min & 171 & 164 & 172 & 160 \\
\hline
\end{tabular}




\section{Frecuencia cardíaca, luego de recuperar un minuto}

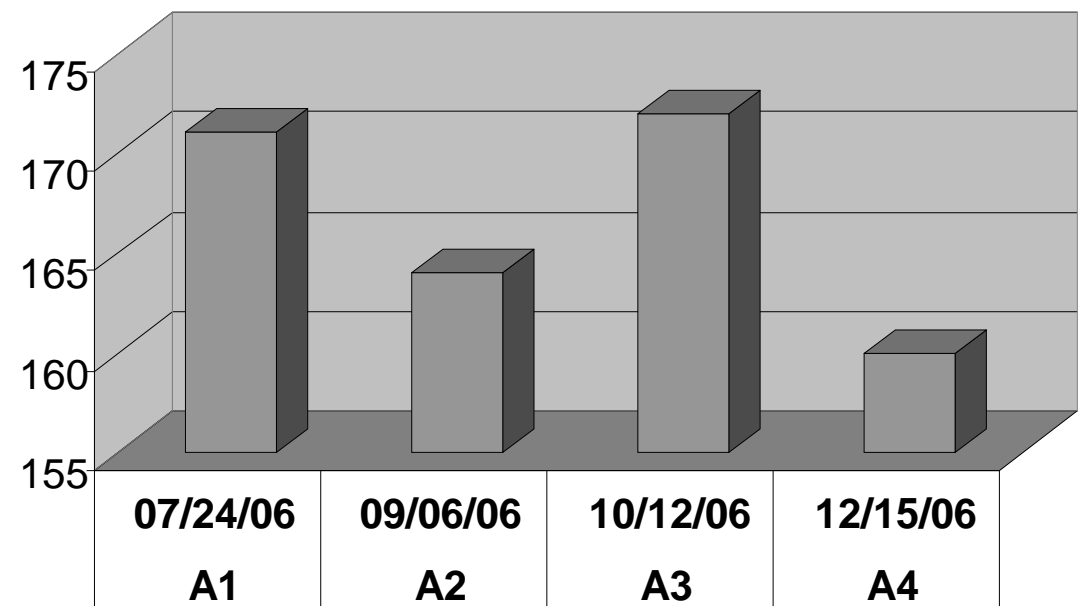

Esta persona muestra un muy buen comportamiento cardíaco a los 3 meses de trabajo: habiendo iniciado el trabajo el 12 de junio de 2006, el 6 de septiembre su corazón se recuperó en un $25 \%$ al minuto de su tope máximo; en la siguiente evaluación su recuperación se presentó muy por debajo, estando solo en un 17,3\%; finalmente, al final del plan de trabajo su corazón respondió un poco mejor a la tarea de recuperación, estando en un $23,4 \%$.

Estos factores certifican de alguna manera la calidad del trabajo, pues la persona muestra progresos cardiovasculares.

\subsubsection{Porcentaje de recuperación al minuto del esfuerzo de la primera voluntaria}

Porcentaje de recuperación al minuto de terminar la prueba, calculado dentro de lo que es el rango aeróbico.

\begin{tabular}{|c|c|c|c|c|}
\hline Evaluación & A1 & A2 & A3 & A4 \\
\hline Fecha & $07 / 24 / 06$ & $09 / 06 / 06$ & $10 / 12 / 06$ & $12 / 15 / 06$ \\
\hline \% De Recuperación al Min & 19,1 & 25,0 & 17,3 & 23,4 \\
\hline
\end{tabular}




\section{Porcentaje de recuperación al minuto de terminar prueba, respecto al rango aeróbico}

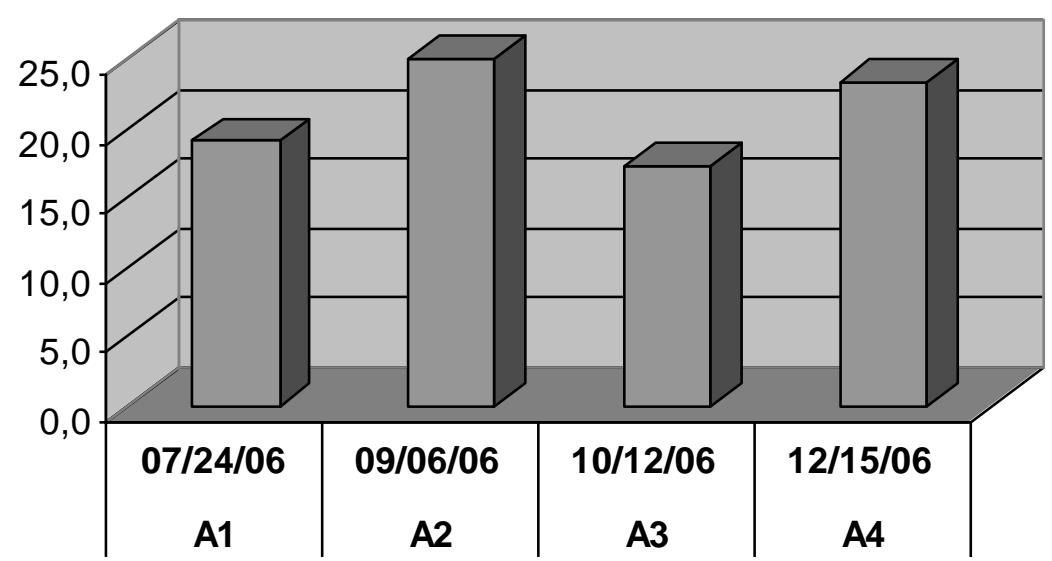

No podemos olvidar que estas evaluaciones fueron hechas sobre personas que no manejaron dietas ni ayudas ergo génicas.

Esta persona, antes de trabajar sobre la bicicleta estática, hizo trabajo aeróbico y taichí por un año.

Los porcentajes de recuperación fueron citados en el punto anterior, aquí se hace la descripción de cada uno de ellos.

\subsection{TABLA RESUMEN DE LOS RESULTADOS DE LAS EVALUACIONES DE LA SEGUNDA VOLUNTARIA}

Asistencia al salón de trabajo: 3 veces por semana.

\begin{tabular}{|c|c|c|c|}
\hline Evaluación & B1 & B2 & B3 \\
\hline Fecha & $07 / 24 / 06$ & $08 / 25 / 06$ & $10 / 12 / 06$ \\
\hline Edad (Años) & 25 & 25 & 25 \\
\hline Peso (Kilogramos) & 63,5 & 61,4 & 61,1 \\
\hline Peso (Libras) & 139,7 & 135,08 & 134,42 \\
\hline Altura (Metros) & 1,58 & 1,58 & 1,58 \\
\hline Índice de masa corporal & 25,4 & 24,6 & 24,5 \\
\hline Frecuencia cardíaca máxima teórica & 196,1 & 196,1 & 196,2 \\
\hline Frecuencia máxima real & 187,0 & 179,0 & 181,0 \\
\hline Pulso Basal & 76 & 76 & 68 \\
\hline Rango Aeróbico & 111,0 & 103,0 & 113,0 \\
\hline Pulso de recuperación al minuto & 149 & 144 & 137 \\
\hline \% de recuperación al minuto & 34,23 & 33,98 & 38,94 \\
\hline
\end{tabular}


Esta persona fue quien tuvo 3 evaluaciones; si bien por razones ajenas no me fue posible hacer la ultima evaluación, de alguna manera se puede analizar lo hecho.

\subsubsection{Evaluaciones de peso corporal de la segunda voluntaria}

\begin{tabular}{|c|c|c|c|}
\hline Evaluación & B1 & B2 & B3 \\
\hline Fecha & $07 / 24 / 06$ & $08 / 25 / 06$ & $10 / 12 / 06$ \\
\hline Peso (Kg.) & 63,5 & 61,4 & 61,1 \\
\hline
\end{tabular}

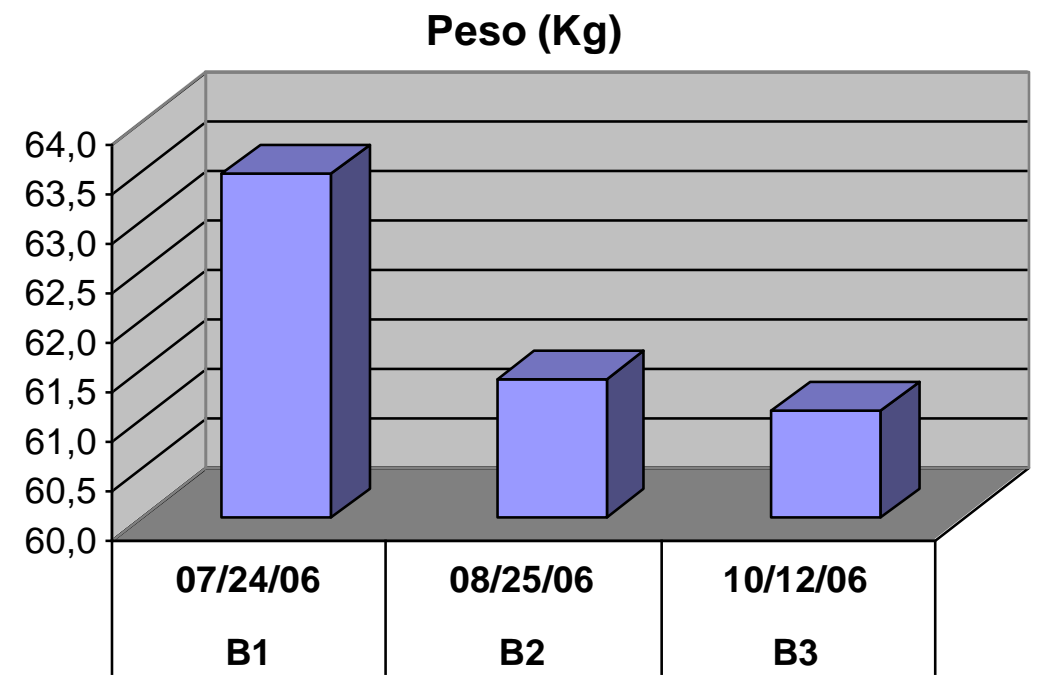

Esta persona, bajó hasta la fecha de su última evaluación 2,4kg.

Esta persona bajó un $25,4 \%$ en la segunda toma, dando como resultado la sumatoria de sus pliegues cutáneos $97 \mathrm{~mm}$.

En la tercera y ultima bajo un $38,5 \%$ de la sumatoria de pliegues cutáneos, ésta evaluación mostró $80 \mathrm{~mm}$ en la suma de pliegues., habiendo empezado en $130 \mathrm{~mm}$.

\subsubsection{Evaluaciones de índice de masa corporal de la segunda voluntaria}

\begin{tabular}{|c|c|c|c|}
\hline Evaluación & B1 & B2 & B3 \\
\hline Fecha & $07 / 24 / 06$ & $08 / 25 / 06$ & $10 / 12 / 06$ \\
\hline I.M.C. & 25,4 & 24,6 & 24,5 \\
\hline
\end{tabular}


Índice de masa corporal

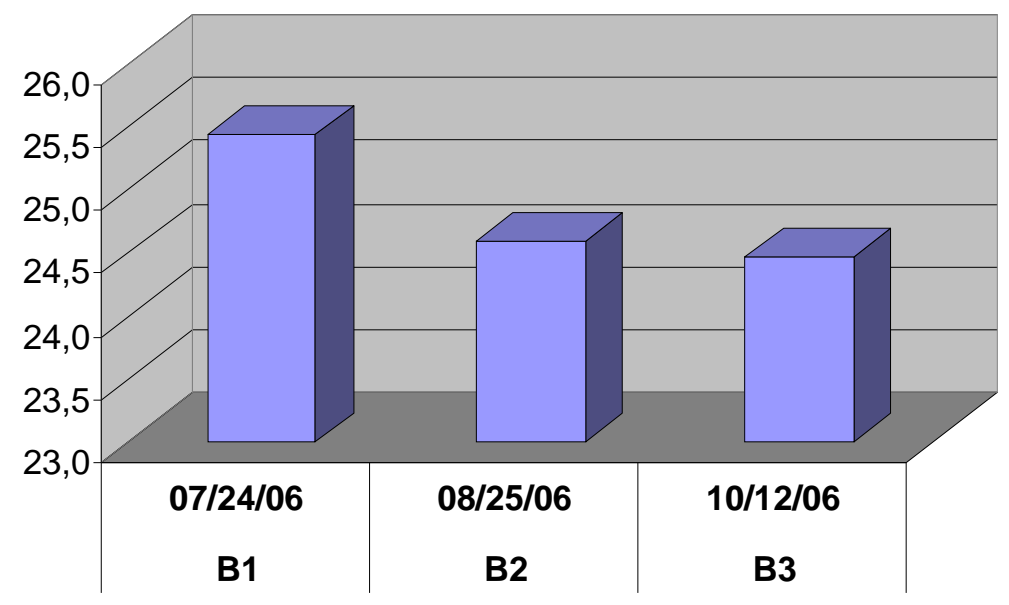

Hay un contraste entre haber perdido mucho según la suma de pliegues y sólo pasar de 25,4 a 24,4 en I.M.C.; de hecho, su trabajo físico le hizo ganar tono muscular, que a la vez hizo ganar peso magro.

11.2.3 Relación entre las pulsaciones máximas reales y las teóricas de la segunda voluntaria

\begin{tabular}{|c|c|c|c|}
\hline Evaluación & B1 & B2 & B3 \\
\hline Fecha & $07 / 24 / 06$ & $08 / 25 / 06$ & $10 / 12 / 06$ \\
\hline Fc.M.T. & 196,1 & 196,1 & 196,1 \\
\hline Fc.M.R. & 187 & 179 & 181 \\
\hline
\end{tabular}

Frecuencia cardíaca máxima teórica Vs

Frecuencia cardíaca máxima real

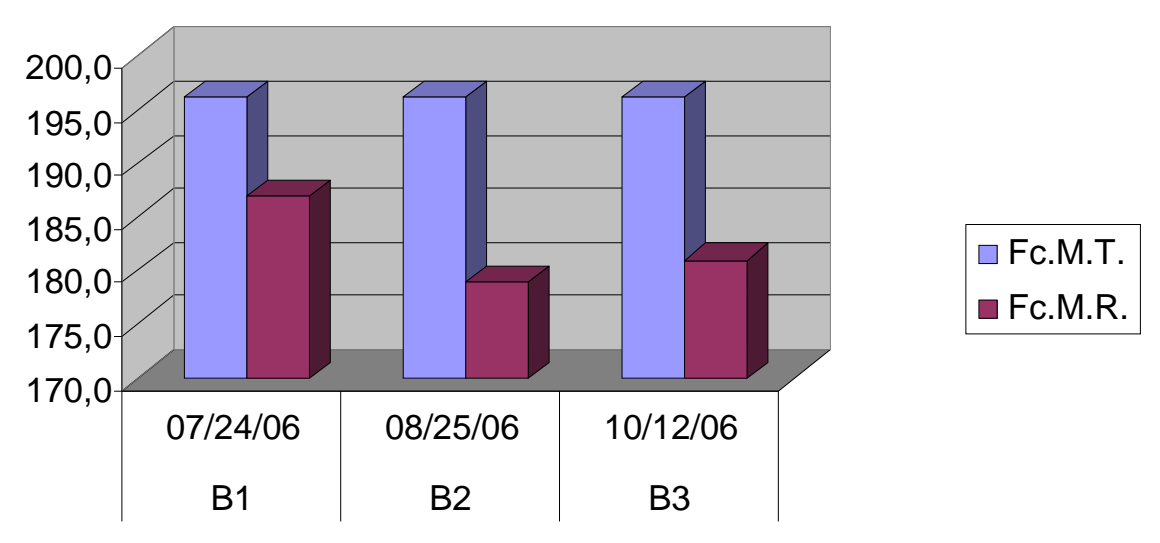


Esta persona, a diferencia de la anterior, estuvo muy por debajo de lo calculado teóricamente, y las pulsaciones más altas las tuvo en la primera evaluación, con casi 190 pulsaciones por minuto, cuando teóricamente se esperaban 196 pulsaciones por minuto.

Sus pulsaciones máximas bajaron con el trabajo.

\subsubsection{Pulso basal de la segunda voluntaria}

\begin{tabular}{|c|c|c|c|}
\hline Evaluación & B1 & B2 & B3 \\
\hline Fecha & $07 / 24 / 06$ & $08 / 25 / 06$ & $10 / 12 / 06$ \\
\hline Pulso Basal & 76 & 76 & 68 \\
\hline
\end{tabular}

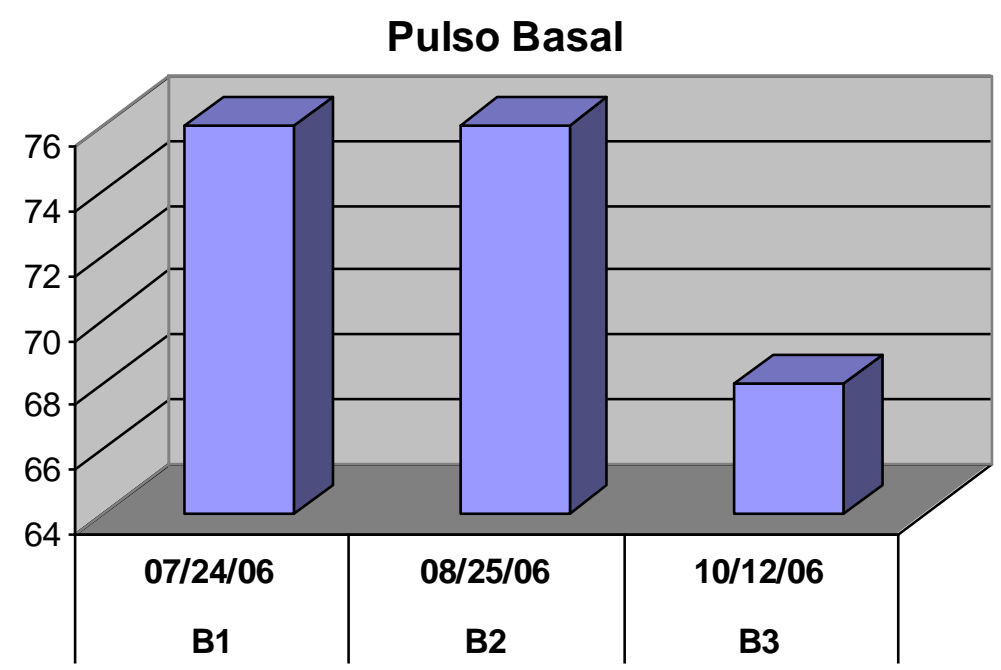

Su pulso basal bajó apreciablemente: siendo una persona que maneja un pulso basal bastante alto, llama mucho la atención cómo su $100 \%$ de pulsaciones cardíacas no es tan alto como se esperaba.

Esta baja en el pulso mínimo manifiesta una mejora en el comportamiento del cuerpo ante la exigencia física.

\subsubsection{Rango de trabajo cardiovascular de la segunda voluntaria}

\begin{tabular}{|c|c|c|c|}
\hline Evaluación & B1 & B2 & B3 \\
\hline Fecha & $07 / 24 / 06$ & $08 / 25 / 06$ & $10 / 12 / 06$ \\
\hline Rango cardiovascular & 111,0 & 103,0 & 113,0 \\
\hline
\end{tabular}




\section{Rango de trabajo cardiovascular}

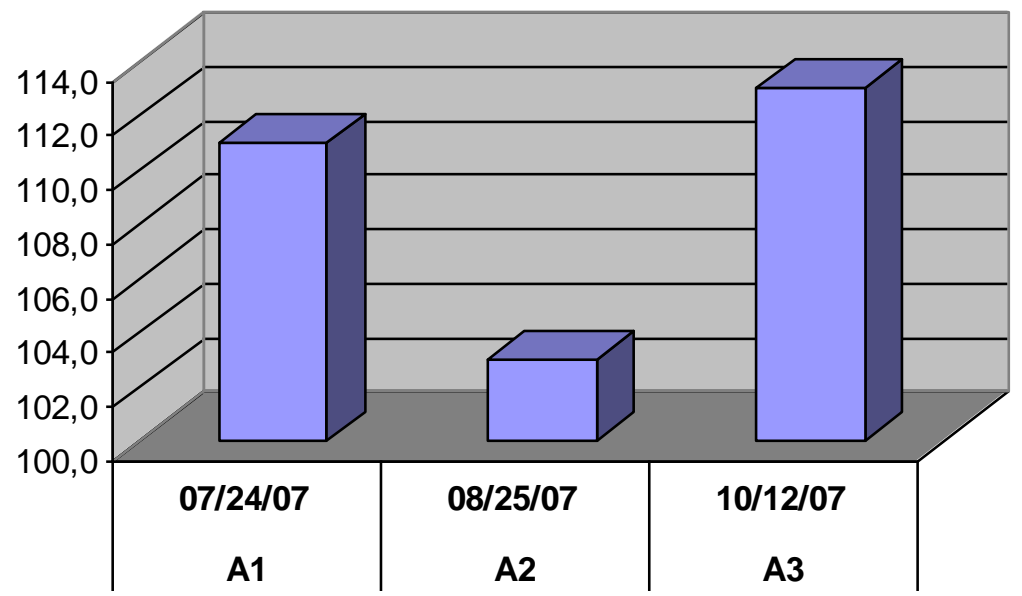

El mayor de los rangos de trabajo se tuvo en la tercera evaluación, aunque con un registro parecido a la primera.

La baja significativa en el pulso basal de la última evaluación facilitó este concepto de que el $100 \%$ del trabajo cardiovascular de 220 - edad esta un poco distante a lo real.

Se puede deducir a partir de acá que la exigencia cardiovascular de esta persona no era la mayor; manejando sí una baja apreciable en su grasa corporal, la mejora en la fuerza tampoco fue la mejor de todas.

Con todo lo anterior se puede deducir que su alimentación dio cambios de rendimiento físico y aspecto corporal.

11.2.6 Frecuencia cardíaca luego de recuperarse un minuto de la segunda voluntaria

\begin{tabular}{|c|c|c|c|}
\hline Evaluación & B1 & B2 & B3 \\
\hline Fecha & $07 / 24 / 06$ & $08 / 25 / 06$ & $10 / 12 / 06$ \\
\hline Pul/Rec. al Min & 149,00 & 144,00 & 137,00 \\
\hline
\end{tabular}


Frecuencia cardíaca, luego de recuperar un minuto

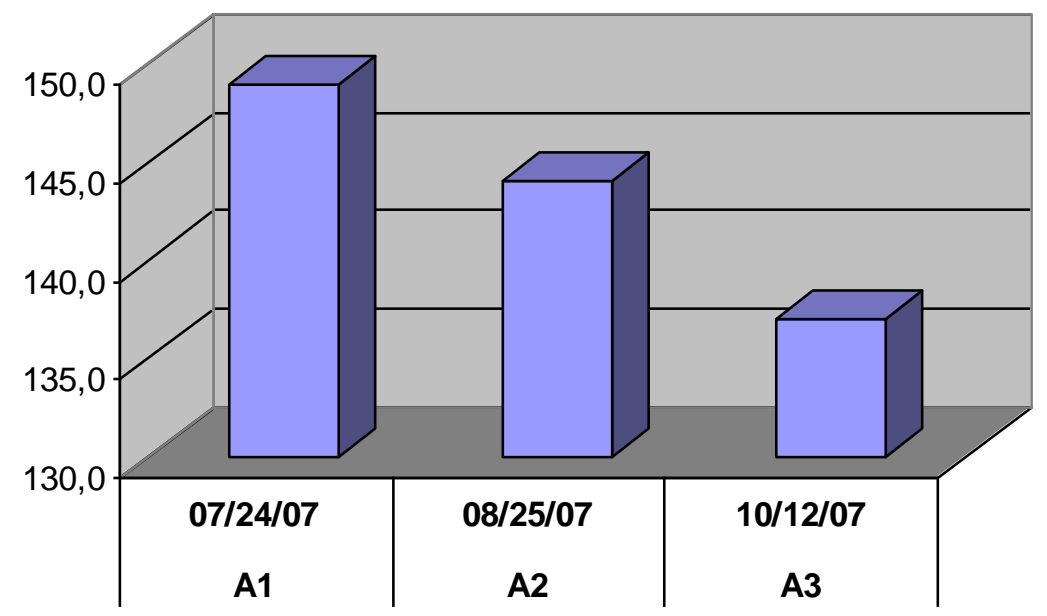

En el pasado punto, que describe el rango de trabajo cardiovascular, no se nota el trabajo tanto como se nota aquí, en la velocidad de recuperación; en la primera evaluación, hubo 38 pulsaciones de diferencia entra la máxima y las pulsaciones que tenia al minuto de recuperación.

En la tercera prueba tenia 44 de diferencia.

11.2.7 Porcentaje de recuperación al minuto del esfuerzo de la segunda voluntaria

Porcentaje de recuperación al minuto de terminar la prueba, calculado dentro de lo que es el rango aeróbico.

\begin{tabular}{|c|c|c|c|}
\hline Evaluación & A1 & A2 & A3 \\
\hline Fecha & $07 / 24 / 07$ & $08 / 25 / 07$ & $10 / 12 / 07$ \\
\hline \% De Recuperación al Min & 34,2 & 34,0 & 38,9 \\
\hline
\end{tabular}




\section{Porcentaje de recuperación al Minuto de terminar la prueba, respecto al rango aeróbico}

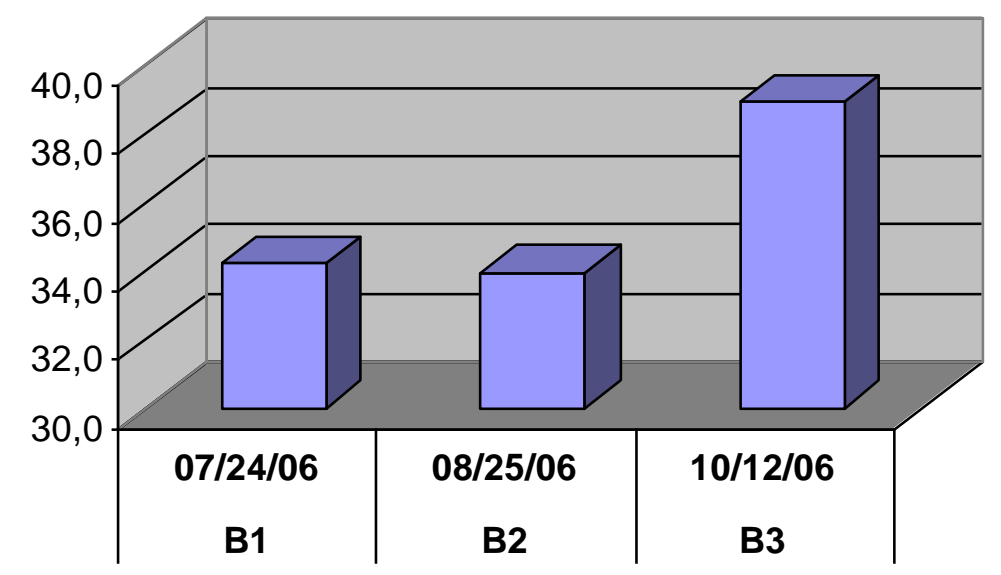

Aquí se transcriben los porcentajes de recuperación al minuto, de 34,2\% a 38,9\%, mostrando las mejoras en los resultados cardíacos.

\subsection{TABLA RESUMEN DE LOS RESULTADOS DE LAS EVALUACIONES DE LA TERCERA VOLUNTARIA}

Asistencia al salón de trabajo: 2 veces por semana

\begin{tabular}{|c|c|c|c|c|}
\hline Evaluación & C1 & C2 & C3 & C4 \\
\hline Fecha & $07 / 24 / 06$ & $08 / 24 / 06$ & $10 / 05 / 06$ & $12 / 13 / 06$ \\
\hline Edad (Años) & 31 & 31 & 31 & 31 \\
\hline Peso (Kilogramos) & 60 & 59,2 & 59,6 & 58,7 \\
\hline Peso (Libras) & $\underline{132}$ & $\underline{130,24}$ & $\underline{131,12}$ & $\underline{129,14}$ \\
\hline Altura (Metros) & 1,74 & 1,74 & 1,74 & 1,74 \\
\hline Índice de masa corporal & 19,8 & 19,6 & 19,7 & 19,4 \\
\hline Frecuencia cardíaca máxima teórica & 193,2 & 193,2 & 193,2 & 193,2 \\
\hline Frecuencia cardíaca máxima real & 180 & 190 & 185 & 191 \\
\hline Pulso Basal & 55 & 56 & 53 & 52 \\
\hline Rango Aeróbico & 125 & 134 & 132 & 139 \\
\hline Pulso de recuperación al minuto & 150 & 166 & 134 & 149 \\
\hline \% de recuperación al minuto & 24,00 & 17,91 & 38,64 & 30,22 \\
\hline
\end{tabular}




\subsubsection{Evaluaciones de peso corporal de la tercera voluntaria}

\begin{tabular}{|c|c|c|c|c|}
\hline Evaluación & C1 & C2 & C3 & C4 \\
\hline Fecha & $07 / 24 / 06$ & $08 / 24 / 06$ & $10 / 05 / 06$ & $12 / 13 / 06$ \\
\hline Peso (Kg.) & 60 & 59,2 & 59,6 & 58,7 \\
\hline
\end{tabular}

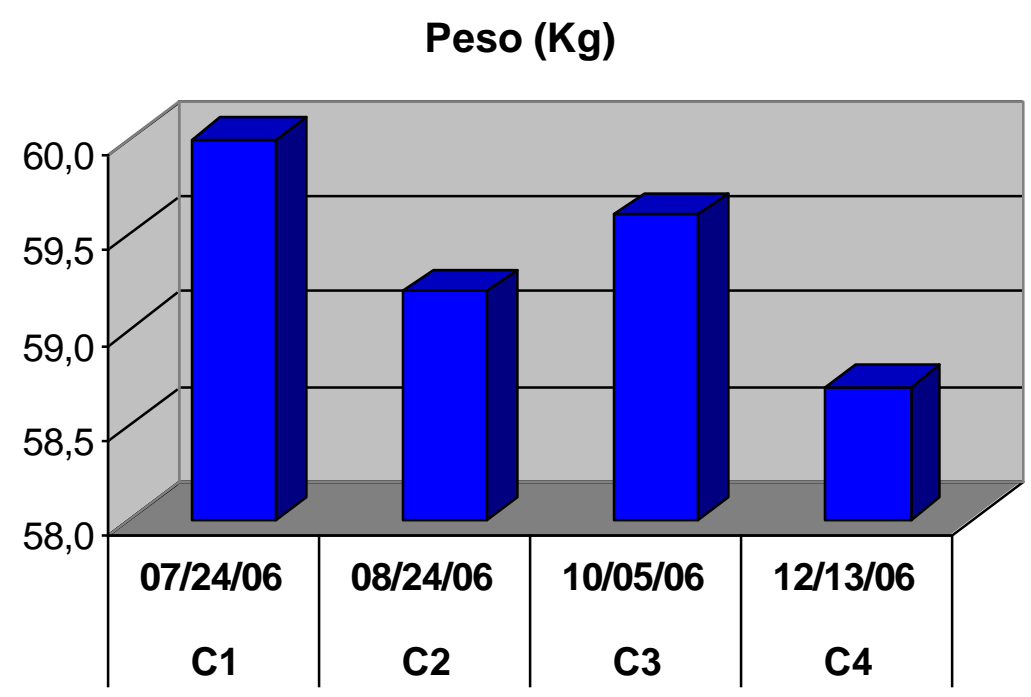

Esta persona perdió1,3 kg. de peso corporal en el tiempo de trabajo; de las tres evaluadas, ésta fue la que menos peso graso perdió.

Para ella, la suma de los pliegues cutáneos en primera instancia dio $96 \mathrm{~mm}$., y en la última terminó con 82 mm.: esto, expresado en porcentajes, es el 14,6\%.

Las características corporales de esta tercera evaluada son las de una persona longilínea, a diferencia de las dos primeras.

\subsubsection{Evaluaciones de índice de masa corporal de la tercera voluntaria}

\begin{tabular}{|c|c|c|c|c|}
\hline Evaluación & C1 & C2 & C3 & C4 \\
\hline Fecha & $07 / 24 / 06$ & $08 / 24 / 06$ & $10 / 05 / 06$ & $12 / 13 / 06$ \\
\hline I.M.C. & 19,8 & 19,6 & 19,7 & 19,4 \\
\hline
\end{tabular}




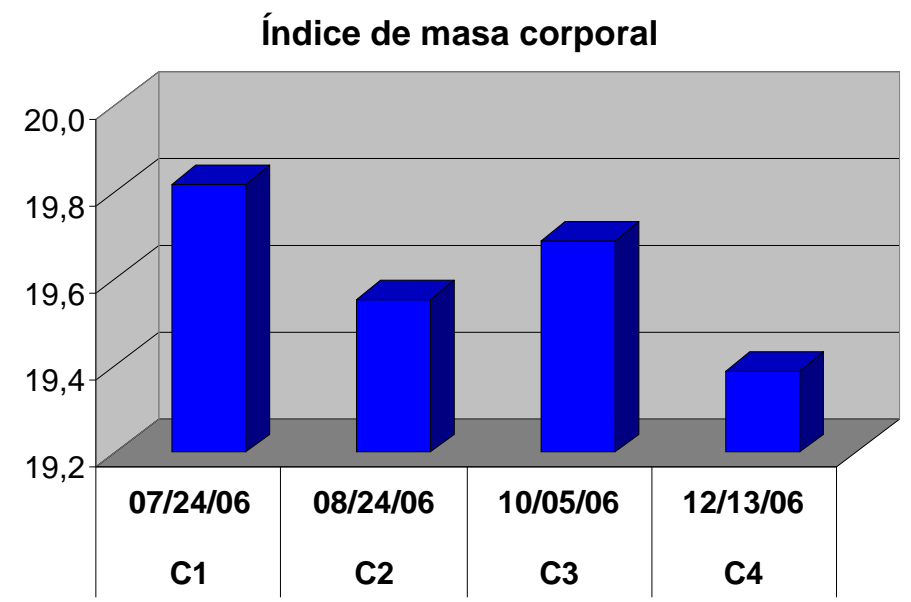

La variación en el índice de masa corporal y en el porcentaje graso fue mínima.

11.3.3 Relación entre las pulsaciones máximas reales y las teóricas de la tercera voluntaria

\begin{tabular}{|c|c|c|c|c|}
\hline Evaluación & C1 & C2 & C3 & C4 \\
\hline Fecha & $07 / 24 / 06$ & $08 / 24 / 06$ & $10 / 05 / 06$ & $12 / 13 / 06$ \\
\hline Fc.M.T. & 193,2 & 193,2 & 193,2 & 193,2 \\
\hline Fc.M.R. & 180,0 & 190,0 & 185,0 & 191,0 \\
\hline
\end{tabular}

Frecuencia cardíaca máxima teórica Vs frecuencia cardíaca máxima real

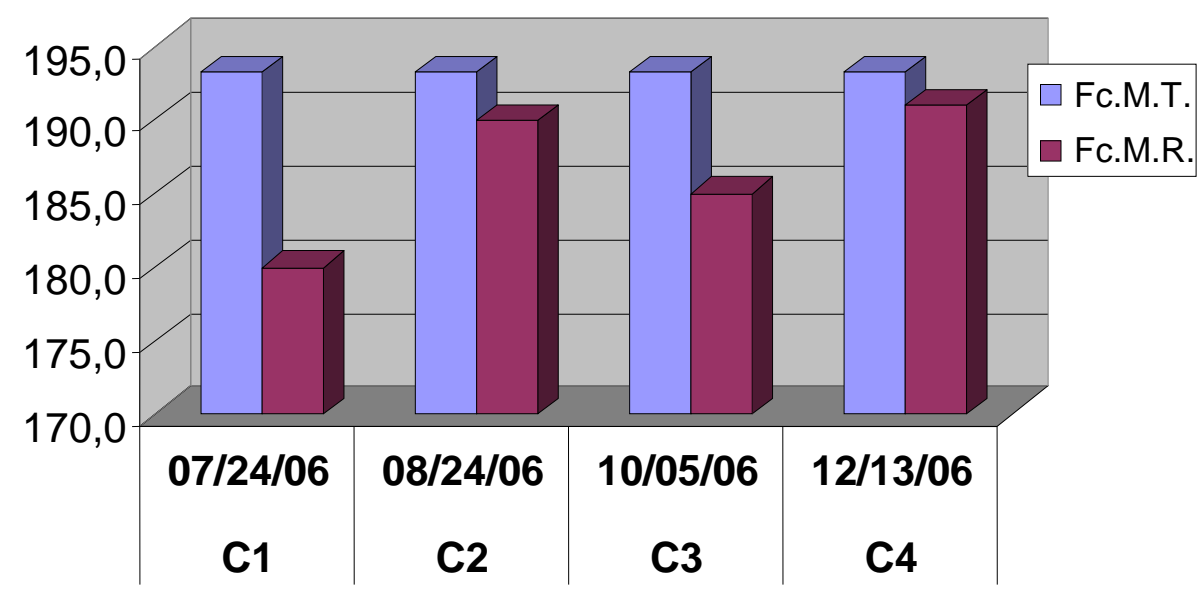

Esta persona muestra un desarrollo esperado, yendo de menos a más. 
De acuerdo a su respuesta cardiaca en la exigencia física, se nota la respuesta al ejercicio y su desarrollo del músculo cardíaco.

De cualquier manera no se puede olvidar el cambio en las temperaturas, me refiero a que se iniciaron las evaluaciones en invierno y se terminaron en el verano del país de Argentina en la ciudad de La Plata.

\subsubsection{Pulso basal de la tercera voluntaria}

\begin{tabular}{|c|c|c|c|c|}
\hline Evaluación & C1 & C2 & C3 & C4 \\
\hline Fecha & $07 / 24 / 06$ & $08 / 24 / 06$ & $10 / 05 / 06$ & $12 / 13 / 06$ \\
\hline Pulso Basal & 55 & 56 & 53 & 52 \\
\hline
\end{tabular}

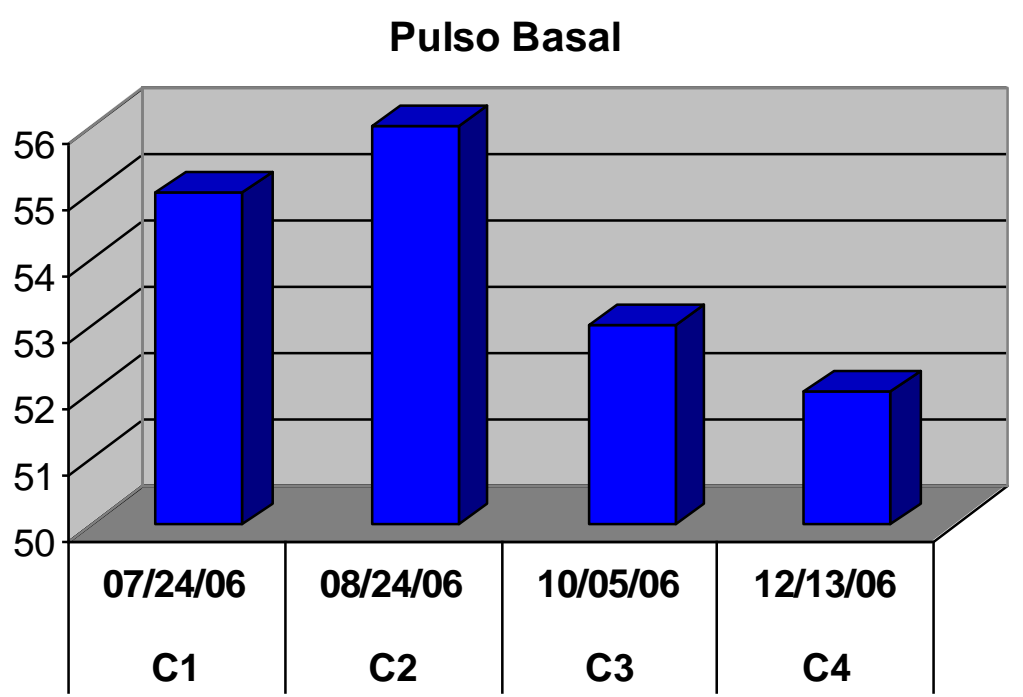

Lo visto hasta aquí es lo esperado en el ejercicio cardiovascular.

El desarrollo cardiovascular de esta persona es bueno.

\subsubsection{Rango de trabajo cardiovascular de la tercera voluntaria}

\begin{tabular}{|c|c|c|c|c|}
\hline Evaluación & C1 & C2 & C3 & C4 \\
\hline Fecha & $07 / 24 / 06$ & $08 / 24 / 06$ & $10 / 05 / 06$ & $12 / 13 / 06$ \\
\hline Rango Aeróbico & 125 & 134 & 132 & 139 \\
\hline
\end{tabular}




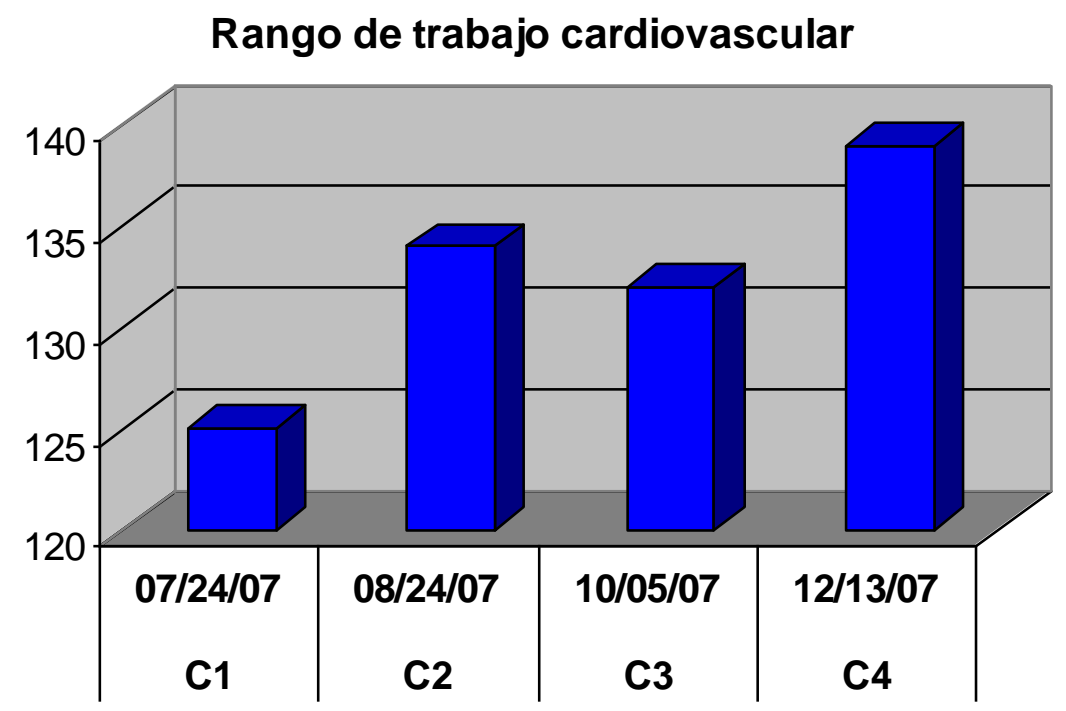

Continuando con la buena respuesta al trabajo se ve el aumento en la franja de trabajo cardiovascular; haciendo la operación de las pulsaciones máximas y la del pulso basal, la última evaluación es la que muestra más espacio de trabajo.

\subsubsection{Frecuencia cardíaca luego de recuperarse un minuto de la tercera voluntaria}

\begin{tabular}{|c|c|c|c|c|}
\hline Evaluación & C1 & C2 & C3 & C4 \\
\hline Fecha & $07 / 24 / 06$ & $08 / 24 / 06$ & $10 / 05 / 06$ & $12 / 13 / 06$ \\
\hline Pul/Rec. al Min & 150 & 166 & 134 & 149 \\
\hline
\end{tabular}

Frecuencia cardíaca, luego de recuperar un minuto

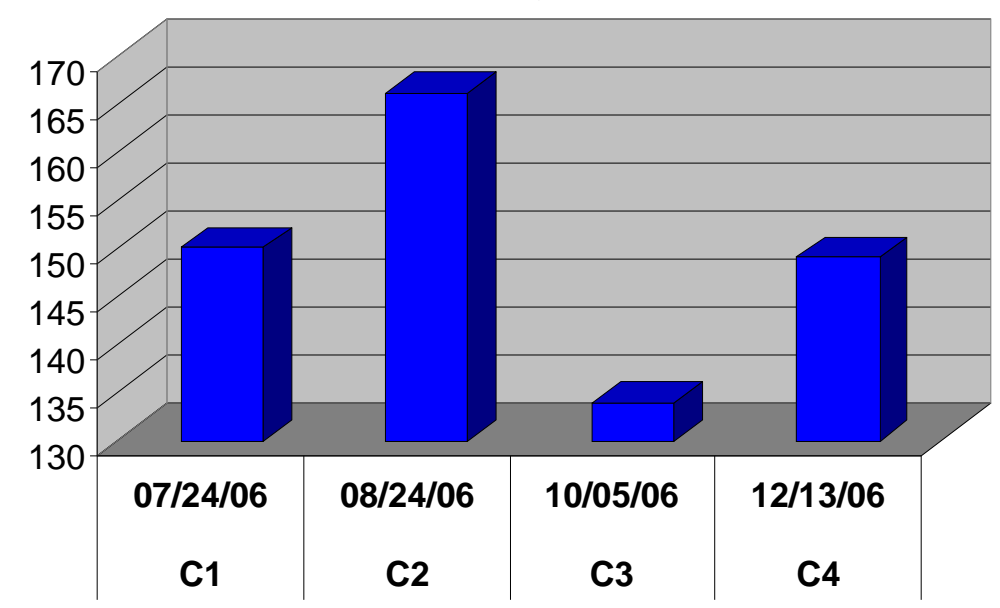


La tercera evaluación muestra la mejor y más amplia de las recuperaciones, bajando de 185 a 134 pulsaciones por minuto. Luego, tomando el rango de trabajo cardiovascular como un $100 \%$, se nota que la recuperación de la penúltima evaluación fue del $38 \%$, mientras que la de la última fue de $30,2 \%$, que no es mala considerando las temperaturas de la estación de verano.

\subsubsection{Porcentaje de recuperación al minuto del esfuerzo de la tercera voluntaria}

Porcentaje de recuperación al minuto de terminar la prueba, respecto al rango aeróbico.

\begin{tabular}{|c|c|c|c|c|}
\hline Evaluación & C1 & C2 & C3 & C4 \\
\hline Fecha & $07 / 24 / 06$ & $08 / 24 / 06$ & $10 / 05 / 06$ & $12 / 13 / 06$ \\
\hline \% De Recuperación al Min & 24,0 & 17,9 & 38,6 & 30,2 \\
\hline
\end{tabular}

\section{Porcentaje de recuperación al minuto de terminar} prueba, respecto al rango aeróbico

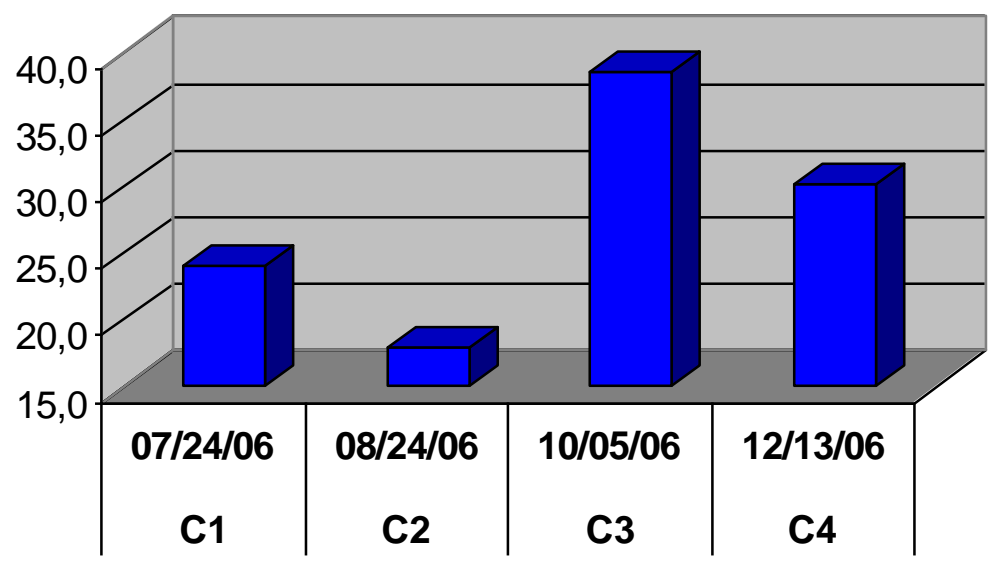

Esta es una continuación del comentario anterior, el cual resalta las velocidades de recuperación y la buena respuesta cardiaca al trabajo propuesto. 


\section{CONCLUSIONES}

El rango de edad de los practicantes "E.S.B.E." es de 21 a 60 años.

La mayoría de los practicantes de "E.S.B.E." son mujeres, estudiantes o empleadas, que se encuentran en el rango de edad entre los 21 y 30 años.

Cerca de la mitad de la población analizada se ejercita en forma regular desde hace menos de un año, pero es importante resaltar que hay un porcentaje importante de usuarios que se ejercitan regularmente desde hace más de 5 años.

La mayoría de los usuarios asistía a las clases dos veces por semana y llevaba trabajando entre 3 y 6 meses con el sistema "E.S.B.E."; así lo manifestaron cuando fueron encuestadas. Las encuestas fueron realizadas en el segundo semestre de 2006.

La mayoría de las personas nunca realizó entrenamiento similar con otro instructor, pero los que sí lo hicieron postularon como principales diferencias la técnica, la buena música y el marcar el ritmo de pedaleo con la música. Es interesante que la mayoría de los usuarios empezó a practicar "E.S.B.E." por recomendación, lo que puede indicar la gran aceptación que esta actividad física tiene en el público en general.

Casi la mitad de los usuarios realizan otra actividad física aparte del "E.S.B.E", la mayoría 2 veces por semana: las más comunes son el pádel y pesas-aparatosmáquinas.

Casi la totalidad de los usuarios han realizado al menos una actividad física que luego abandonaron: la más citada es la de pesas-aparatos-máquinas, seguida por gimnasia localizada o modeladora y natación. Estas actividades fueron practicadas durante más de un año por la mayoría de los usuarios que las abandonaron.

La razón por la que eligieron el "E.S.B.E." es por ser considerada una actividad completa; las respuestas fueron muy variadas, con un abanico de 31 razones diferentes. Del mismo modo se encontró una gran variedad de respuestas a la pregunta por qué es lo que más les gusta del "E.S.B.E.": la mayoría de los usuarios dicen que es dinámico, divertido y entretenido, y mencionan en segundo lugar la música.

La gran mayoría de los encuestados consideran que con la práctica del "E.S.B.E." han mejorado la forma física y la salud, liberado stress, tonificado y reafirmado, además de fortalecer. La respuesta con menor porcentaje fue la de que con el "E.S.B.E." han bajado de peso.

Dentro de los 10 aspectos de posible mejoría en los que fueron consultados, el mayor porcentaje de encuestados consideró que estaba mejorando de 4 a 7 aspectos. En una pregunta relacionada, en la que se les consultó si habían notado cambios físicos y corporales, la gran mayoría de los usuarios respondió que tanto ellos como otras personas habían notado sus propios cambios, principalmente en la tonificación muscular. 
Es importante resaltar que las dos terceras partes de los usuarios tienen un índice de masa corporal normal de acuerdo a la OMS (organización mundial de la salud), y tan solo la sexta parte de los usuarios tiene bajo peso, la misma proporción con la que se encuentran los que tienen sobrepeso. Ninguno de los usuarios encuestados está catalogado como obeso, pero a pesar de esto la mayoría desea pesar menos, aunque en general tienen como meta bajar menos de un $10 \%$ de su peso corporal. En algún momento de sus vidas, la tercera parte de los usuarios ha tenido un I.M.C. que los cataloga como obesos, y más de la mitad han tenido I.M.C. correspondientes a la categoría de bajo peso.

El método para perder peso más popular entre los usuarios es el de las dietas y la alimentación sana: en general comen entre 3 y 4 veces por día, invierten más de 40 minutos en sus comidas, comen mientras realizan otra actividad y consumen raciones moderadas, aunque la mayoría menciona el hecho de que algunas veces repiten los platos.

En general se encontró dentro de los hábitos alimenticios que hay bajo consumo de dulces y repostería, frutos secos, alimentos fritos y café; se encontró en cambio un alto consumo de lácteos, carnes rojas, pollo, frutas, mate, sal, y un consumo moderado de queso, embutidos, bebidas con gas, helado y postres.

De acuerdo a las encuestas se puede concluir que los usuarios están interesados en recibir información referente a la salud y el ejercicio físico, dado que la mayoría de las personas leen siempre o casi siempre los correos electrónicos semanales que Marco Ríos envía con este tipo de información. Además, la totalidad de los encuestados considera que se le ha suministrado buena información sobre la técnica de esta actividad, lo que se podría confirmar por el hecho de que solo 2 de los 58 encuestados han tenido alguna lesión relacionada con el "E.S.B.E." (ninguna de ellas de rodilla). Estos resultados contradicen lo dicho por algunos médicos y público en general de que esta actividad genera gran cantidad de lesiones, especialmente de rodilla. Podría por lo tanto decirse que, si el entrenamiento sobre bicicletas estáticas es realizado con la técnica adecuada, no tiene porque generar lesiones.

Pocos respondieron que habían cambiado los patrones de sueño. En cuanto al temperamento y la sociabilidad, dicen no haber notado ningún cambio. Sin embargo, esto contrasta con el hecho de que la gran mayoría de los usuarios manifiesta haber tenido cambios en la sensación de bienestar general desde que practica el "E.S.B.E.".

En cuanto al estudio de los hábitos, se encontró en estas encuestas que la mayoría de los usuarios ha fumado alguna vez y cerca de la mitad lo continúa haciendo. De los que fumaban al momento de la encuesta, la gran mayoría consumía entre 6 y 20 cigarrillos por día, y la edad de inicio de consumo de cigarrillo más común es entre los 16 y los 20 años. La mayoría de los que dejaron de fumar lo hicieron más de 3 años antes de la encuesta.

En cuanto al consumo de alcohol, se encontró que la mayoría tomaba entre 1 y 5 días por mes, pero en general no más de 5 vasos por ocasión.

Es importante destacar que, a pesar del interés por la salud, la mayoría de los usuarios dijo no conocer su presión arterial ni su colesterol total. Sin embargo, dentro de los que 
sí conocían estos datos se encontró que la mayoría tenía tanto presión arterial como colesterol total normal.

Con respecto a las pruebas de trabajo físico se encontró:

La velocidad de recuperación no es la misma en el transcurso del seguimiento, mejorando progresivamente, si bien la estación del verano no es la mejor. En Argentina (como caso especial) es en esta época cuando los gimnasios tienen más trabajo por la preparación social que tiene la gente, así que se hace ejercicio cuando al cuerpo más le cuesta recuperarse.

No pierden peso corporal de forma considerable, bajando sí su porcentaje graso.

Los trabajos de fuerza isométrica para el tren inferior no son hechos con las exigencias físicas esperadas.

La aceptación del ejercicio no es la misma, dependiendo mucho de su nutrición, así que no importa la intensidad del mismo si no va acompañada de una debida alimentación, horas de consumo y cantidad.

Los resultados de la actividad no son indiferentes a la forma del pedaleo; debido al marcado se tiende a realizar más fuerza con la pierna que demarca la cadencia de pedaleo, y si no se hace énfasis en la igualdad de la exigencia de la extremidades inferiores puede una pierna desarrollarse más que la otra, arriesgando a una lesión en la que más trabaja en inicio y a la que menos se exige con el tiempo, llevando la más débil a sobrecargas por su no acondicionamiento.

La forma del pedaleo no es la misma para todo el mundo, acá encontramos 3 formas diferentes de trabajo: mover los pedales con el trabajo de extensión de pierna, con la flexión de pierna o (la más usada) con la extensión de cadera. 


\section{BIBLIOGRAFÍA}

- Duque Naranjo, Rafael (1984). Los escarabajos de la vuelta a Colombia. Bogotá: Editorial Oveja Negra.

- Gordis, Kent - Greg Lemond, (1989). Ciclismo completo. Barcelona: Editorial Hispano Europea.

- Heyward, Vivian H. (2006). Evaluación y prescripción del ejercicio. Badalona: Editorial Paidotribo.

- Pérez, Juan Carlos (1978). Ciclismo en Pista. España: Editorial Pila Teleña.

- Pérez, Juan Carlos (1981). Nuevo ciclismo agonístico. España: Editorial Pila Teleña.

- Pérez, Juan Carlos (1990). La construcción del ciclista, Técnica, Táctica, Entrenamiento. La Bicicleta. Madrid: Editorial La Librería.

- Rabasa Singla, Simeón (1986). Manual práctico del ciclista. Barcelona: Editorial Juventud.

- Van der Plass, Rob (1988) Correr y competir en ciclismo. Equipo, técnica, táctica y entrenamiento para cada modalidad. Barcelona: Editorial Hispano Europea. 


\section{CYBERGRAFÍA (SITIOS WEB)}

http://www.spinning.com/es/spinner_bikes http://www.elsalvador.com/noticias/EDICIONESANTERIORES/noviembre17/VIDA/ http://www.hispagimnasios.com/a_culturismo/ses_spinning.php http://www.lindisima.com/enforma2/spinning.htm http://ciclismo.8m.net/ruta.html http://es.wikipedia.org/wiki/Ciclismo\#Ciclismo_en_pista http://alinome.net/bici/reclinada/prohibido.php http://ciclismo.8m.net/pista.html http://www.monografias.com/trabajos/eduvialbici/eduvialbici.shtml http://www.mundocaracol.com/bicicletos/historia.asp http://www.ccactur.com/historiabici.htm http://es.wikipedia.org/wiki/Bicicleta http://www.atikoestudio.com/disenador/industrial/bicicletas/historia\%20bicicleta.htm http://www.arrakis.es/ palarra/bicicleta.htm http://www.taringa.net/posts/info/1058555/Historia-de-la-bicicleta.html http://www.efitnessdirect.com/product-86.html?term=spinning 